UNIVERSIDADE DE SÃO PAULO

INSTITUTO DE ASTRONOMIA, GEOFISICA E CIÊNCIAS ATMOSFÉRICAS DEPARTAMENTO DE CIÊNCIAS ATMOSFÉRICAS

EXTREMOS INTRA-SAZONAIS DE TEMPERATURA NA PENÍNSULA ANTÁRTICA E MECANISMOS ATMOSFÉRICOS ASSOCIADOS

NATHALIE TISSOT BOIASKI

DISSERTAÇÃO DE MESTRADO

ORIENTADORA: PROF ${ }^{a}$.DR ${ }^{a}$. LEILA MARIA VÉSPOLI DE CARVALHO

SÃO PAULO 
NATHALIE TISSOT BOIASKI

\section{EXTREMOS INTRA-SAZONAIS DE TEMPERATURA NA PENÍNSULA ANTÁRTICA E MECANISMOS ATMOSFÉRICOS ASSOCIADOS}

Dissertação apresentada ao Instituto de Astronomia, Geofísica e Ciências Atmosféricas da Universidade de São Paulo para obtenção do título de Mestre em Ciências.

Área de concentração: Meteorologia.

Orientadora: Prof ${ }^{a}$. Dr ${ }^{\mathrm{a}}$. Leila Maria Véspoli de Carvalho.

SÃO PAULO 
Aos meus pais, Arnaldo e Marion, com admiração, amor e gratidão. 


\section{AGRADECIMENTOS}

\section{À Deus.}

Meu especial agradecimento à $\operatorname{Prof}^{\mathrm{a}} \operatorname{Dr}^{\mathrm{a}}$. Leila M. V. de Carvalho, por esta oportunidade. Seus ensinamentos, dedicação são exemplos a serem seguidos. Sobretudo, lembrarei sempre da sua amizade e carinho.

Aos meus pais pela formação moral, incentivo e pelo exemplo de vida, e as minhas irmãs, Morgana e Vanessa, por estarem sempre ao meu lado me apoiando.

Com muito amor agradeço ao Jônatan D. Tatsch, por seu carinho, companheirismo, apoio e incentivo que foram fundamentais nesta etapa da minha vida.

À minha avó Ruth e tia Marisa, pelo apoio e pelas palavras carinhosas que me ajudaram a suportar a saudade.

À minha sobrinha amada, Luiza Boiaski Brignol, que mesmo tão pequenina, fez parte do meu incentivo para a realização da pesquisa.

À minha cunhada e amiga "Dada", por seu carinho, amizade e companheirismo.

Aos amigos do laboratório GEM: Ana Elizabethe, Fábio, Flávio, Michel, Rodrigo e Sebastian, pela amizade, auxílio e discussões que foram fundamentais no desenvolvimento da pesquisa.

Aos amigos Candida, Marta e Ricardo Acosta, pelo carinho, companheirismo e pela ajuda em diversas etapas da pesquisa.

Aos colegas de mestrado e professores do IAG, pelo conhecimento compartilhado.

Ao Departamento de Ciências Atmosféricas, pela oportunidade de realização do curso de mestrado.

À FAPESP pelo suporte financeiro desta pesquisa através do auxílio 05/52389-2.

Ao pessoal do suporte técnico, secretárias e biblioteca, em especial ao Samuel, Sebastião, Luciana, Rose, Bete e Rosa M. S. Santos.

Ao Prof. Dr. Edmilson Dias de Freitas, pela sua amizade e companheirismo.

A todos os amigos que de alguma forma ajudaram direta ou indiretamente no desenvolvimento desta dissertação. 
"Suba o primeiro degrau com fé. Não é necessário que você veja toda a escada. Apenas dê o primeiro passo". 


\section{RESUMO}

O clima na Antártica tem um papel fundamental no balanço de energia global. Estudos sugerem que a atividade convectiva tropical e a circulação estratosférica exercem um papel importante sobre a circulação atmosférica nos extratrópicos. A temperatura do ar é uma variável sensível às mudanças na circulação, no entanto, ainda não foi investigada a importância da escala intra-sazonal na sua variabilidade sobre a Antártica. Neste trabalho estudou-se a variabilidade intra-sazonal da temperatura do ar a superfície na região da Península Antártica enfocando as interações trópicos-extratrópicos e troposfera-estratosfera na modulação de eventos extremos de temperatura naquela região. Foram utilizados dados diários de estações localizadas nos setores leste e oeste da Península Antártica no período de 1986-2002. A análise espectral dos dados ressaltou a importância da escala intra-sazonal na variabilidade da temperatura na Península Antártica, principalmente no período de inverno, primavera e verão. Baseado nestes resultados, os dados foram filtrados na escala intra-sazonal (banda de 20-100 dias) e posteriormente, obteve-se os extremos intra-sazonais frios e quentes para as três estações do ano, através dos quartis da distribuição dos dados. Os eventos extremos intra-sazonais de temperatura (EIT) foram mais intensos no inverno e mais fracos no verão. As características da circulação atmosférica intra-sazonal associada aos EIT foram obtidas através de composições defasadas das anomalias intra-sazonais da altura geopotencial em $200 \mathrm{hPa}$, vento zonal em $200 \mathrm{hPa}$ e vento meridional em $850 \mathrm{hPa}$. Nas três estações do ano, observou-se nos eventos extremos intra-sazonais frios (EIF) a persistência de anomalias ciclônicas em altos níveis, a diminuição da intensidade do jato polar e uma advecção de ar frio em baixos níveis sobre a região de estudo. Uma situação oposta foi verificada nos eventos extremos intra-sazonais quentes (EIQ). De forma geral, observou-se um trem de ondas entre latitudes médias e altas no Hemisfério Sul (HS) durante os EIT, particularmente no inverno e primavera. Esta configuração mostrou-se semelhante a tele-conexão conhecida como Pacífico-Sul Americano (PSA). O papel do modo anular do HS sobre os EIT foi analisado através do cálculo de Funções Ortogonais Empíricas das anomalias intra-sazonais da altura geopotencial em $700 \mathrm{hPa}$ ao sul de $20^{\circ} \mathrm{S}$. Sua estrutura foi mais intensa (mais fraca) nos EIF (EIQ) de inverno sobre a região de estudo. A interação troposfera-estratosfera no controle dos EIT foi investigada através do Fluxo Eliassen-Palm. Nas composições das anomalias intrasazonais deste fluxo (EP $\mathrm{ES}_{\mathrm{IS}}$ ), observou-se durante os EIF (EIQ) de inverno, um aumento da atividade de onda da baixa estratosfera (alta troposfera) para a alta troposfera (baixa estratosfera) sobre a região de estudo, associado à diminuição (aumento) da intensidade do jato polar. Na primavera, a atividade de onda foi mais intensa e verificou-se uma mudança na direção do fluxo $\mathrm{EP}_{\mathrm{IS}}$ quando comparado com os EIT de inverno. $\mathrm{O}$ fluxo $\mathrm{EP}_{\mathrm{IS}}$ e as anomalias intra-sazonais do vento zonal foram mais fracos no verão. As anomalias intra-sazonais da circulação atmosférica e da atividade de onda na troposfera e estratosfera foram observadas por cerca de 10 dias antes da observação dos EIT de inverno. Portanto, a atividade intrasazonal nos extratrópicos e as interações troposfera-estratosfera são fatores relevantes para um melhor entendimento da variabilidade da temperatura sobre a Península Antártica. 


\begin{abstract}
The Antarctic climate plays a significant role for the global energy budget. Previous studies suggest that interactions tropics-extratropics and the dynamics of the stratosphere are important factors to understand climate variations in the extratropics. The air temperature near surface responds to changes in circulation in low and upper levels. However, no previous studies have objectively investigated the importance of intraseasonal variations in modulating temperature around the Antarctica Peninsula. The present study examines intraseasonal extreme anomalies of near surface air temperature in the Antarctica Peninsula, and investigates interactions tropics-extratropics and troposphere-stratosphere. Daily temperature data from stations located east and west of the Antarctica Peninsula during 1986-2002 are investigated. Spectral analyses indicate that intraseasonal anomalies in temperature records are statistically significant during summer, winter and spring in all stations. Based on these results, temperatures are band-filtered on intraseasonal timescales (20-100 days) and extreme anomalies are investigated in each season (spring, summer and winter) based on the quartiles of the distributions. Intraseasonal extreme temperature (IET) anomalies are more intense during winter than during summer. Variations in the atmospheric circulation during IET are investigated by performing composites of intraseasonal anomalies of the geopotential height in $200 \mathrm{hPa}$, zonal wind in $200 \mathrm{hPa}$ and meridional wind in $850 \mathrm{hPa}$. During the three seasons, cold IET are associated with persistent upper level cyclonic anomalies, easterly anomalies of the polar jet and cold advection in low levels over the Peninsula. Opposite features are observed during warm IET. An extratropical wave-train is observed during all IET with stronger intensity during winter and spring. This feature resembles the Pacific South American (PSA) teleconnection pattern. The Southern Hemisphere Annular mode during the IET, identified as the first Empirical Orthogonal Function (EOF) of the intraseasonal $700 \mathrm{hPa}$ geopotential height anomalies poleward of $20^{\circ} \mathrm{S}$, is more intense (weak) during cold (warm) IET events during winter. The stratosphere-troposphere interaction during IET events was examined with composites of the Eliassen-Palm Flux intraseasonal anomalies (EPIS). During spring, the wave activity is more intense and the $\mathrm{EP}_{\mathrm{IS}}$ direction is opposite to winter. During summer, $\mathrm{EP}_{\mathrm{IS}}$ are weak. Intraseasonal anomalies in the circulation and the wave activity in the troposphere and stratosphere lead the IET during winter in about 10 days. Therefore, the intraseasonal activity in the extratropics and the interactions stratosphere-troposphere are important factors for a complete understanding of the temperature variability over the Antarctica Peninsula.
\end{abstract}




\section{SUMÁRIO}

LISTA DE FIGURAS iii

LISTA DE TABELAS $\quad \mathrm{x}$

LISTA DE ABREVIATURAS $\quad$ xi

Capítulo 1: Introdução 1

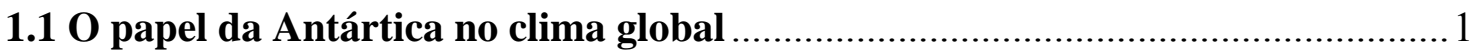

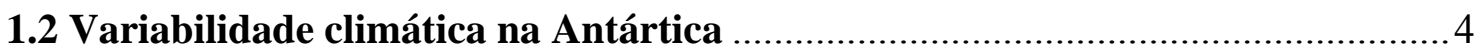

1.2.1 Oscilação intra-sazonal tropical: Oscilação Madden-Julian (OMJ) ................

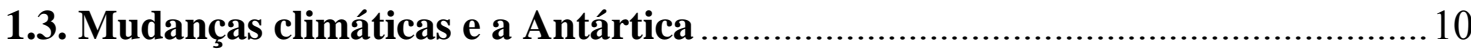

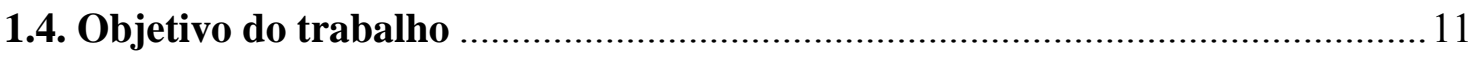

Capítulo 2: Variabilidade da temperatura do ar na Península Antártica 13

2.1. Caracterização do clima na Península Antártica ........................................... 13

2.2. Descrição dos dados e das estações meteorológicas utilizadas ........................ 16

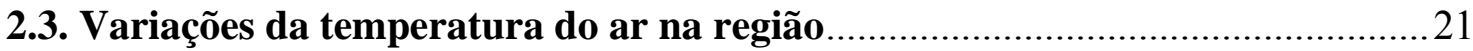

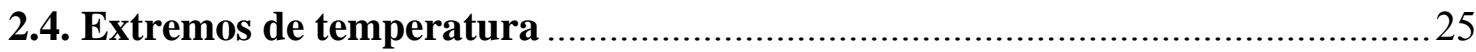

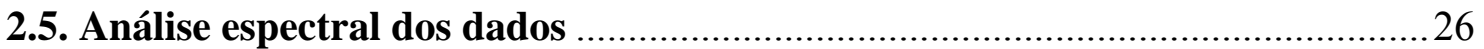

Capítulo 3: Extremos intra-sazonais de temperatura na Península Antártica 33

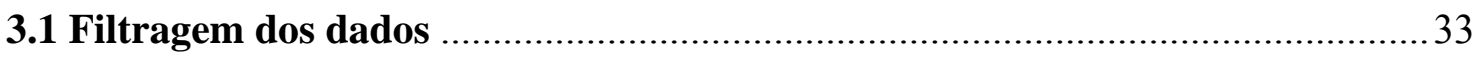

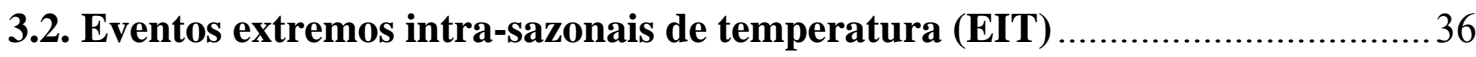

3.2.1. Variabilidade interanual dos EIT: relação com o El Niño-Oscilação Sul ..... 45

3.3. Variações intra-sazonais da circulação atmosférica associada aos EIT ...........51

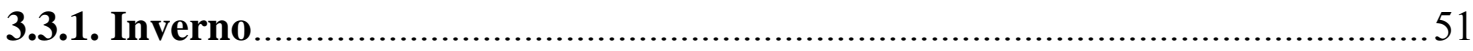

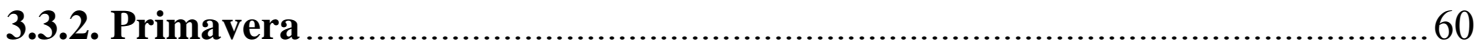

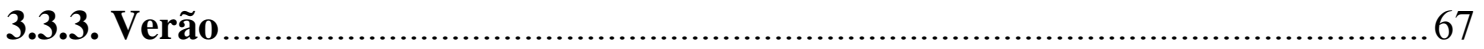


3.3.4. Comparação entre os casos com intensidades e persistências extremas e próximas da mediana

3.4. Variações intra-sazonais da atividade convectiva nos trópicos e os EIT .........79

3.5. Variações intra-sazonais na estrutura da $A A O$ : relação com os EIT .83

Capítulo 4: Interação troposfera-estratosfera e os EIT na Península Antártica

4.1. A atividade de onda e a interação com o fluxo zonal médio 89

4.1.1. O Fluxo Eliassen-Palm (EP) 89

4.1.2. Comparação entre a climatologia da temperatura, circulação e da atividade de onda entre troposfera - estratosfera .90

4.2. Anomalias intra-sazonais do Fluxo EP e os EIT .94

4.2.1. Inverno 95

4.2.2. Primavera .98

4.2.3. Verão. 101

4.3. Considerações gerais 104

Capítulo 5: Conclusões e sugestões para trabalhos futuros

Apêndice A: Diferença entre duas proporções

Apêndice B: Funções Ortogonais Empíricas (EOF) 


\section{LISTA DE FIGURAS}

Figura 1. 1. Mapa orográfico da Antártica. O intervalo dos contornos é de 500m (Turner e Pendlebury 2004).

Figura 1. 2. (a) Modelo conceitual da circulação troposférica sobre a Antártica. Ventos catabáticos em superfície estão em equilíbrio com a convergência em altitude e a subsidência sobre o continente, que sustenta uma circulação ciclônica em níveis médios (King e Turner, 1997, p.163). (b) Divergência em superfície resulta em ventos catabáticos que adquirem forte componente de leste próximo à costa (King e Turner, 1997, p.94).

Figura 1. 3. Esquema representando a circulação atmosférica na região da Antártica, destacando a alta pressão sobre o continente e a região de baixa pressão circumpolar próxima à latitude de $66^{\circ} \mathrm{S}$ (Adaptada de Australian Antarctic Division). 3

Figura 1. 4. Concentração média do gelo marinho antártico baseado na climatologia do período de 1978-2002, para os meses de (a) fevereiro, período de concentração mínima de gelo e (b) setembro, período de máxima concentração de gelo (Adaptada de National Snow and Ice Data Center - NSIDC, 2004).

Figura 1. 5. Padrões de tele-conexão obtidos pelas anomalias do vento zonal em $200 \mathrm{hPa}$ (U200) durante os eventos negativos (acima), positivos (centro) da $A A O$ e a diferença entre os dois campos (abaixo). Figura extraída de Carvalho et al. 2005. .8

Figura 2. 1. Mapa da Península Antártica localizando as estações de pesquisas utilizadas neste estudo (pontos em laranja). Imagem obtida pelo google earth. 14

Figura 2. 2. Desenvolvimento dos ventos de barreira (adaptado de King e Turner, 1997, p.282)

Figura 2. 3. Trajetórias dos fluxos inerciais originários dos ventos de barreira, ao ultrapassar o extremo norte da Península Antártica. Velocidade inicial estimada em $20 \mathrm{~m} \mathrm{~s}^{-1}$. A trajetória a representa o fluxo de ar sem atrito; b e c representam trajetórias com atrito fraco e forte, respectivamente (adaptado de Schwerdtfeger, 1984, p.108). 15

Figura 2. 4. Mapa da Ilha Rei George, localizando algumas estações utilizadas neste estudo (adaptada de Turner e Pendlebury 2004) 
Figura 2. 5. Dendrograma gerado a partir das distâncias euclidianas (DE) das séries diárias da temperatura do ar entre as estações da Península Antártica.

Figura 2. 6. Distribuição de freqüência da temperatura média diária em cada mês para: (a) Arturo e (b) Marambio. A caixa (box) em verde representa o intervalo inter-quartílico (25\%-75\%) e os pontos conectados dentro do box, a mediana. A barra em azul representa os valores mínimos e máximos. 22

Figura 2. 7. Anemograma climatológico para as estações (a) Arturo e (b) Marambio. Os dados de vento foram obtidos no NSIDC. 23

Figura 2. 8. Temperaturas médias anuais para Arturo (linha sólida) e Marambio (linha tracejada) e suas respectivas tendências em ${ }^{\circ} \mathrm{C} / \mathrm{ano}$, obtidas por regressão linear das séries de dados.

Figura 2. 9. Variação da temperatura média anual em ${ }^{\circ} \mathrm{C}$ da estação Marambio (linha preta) e

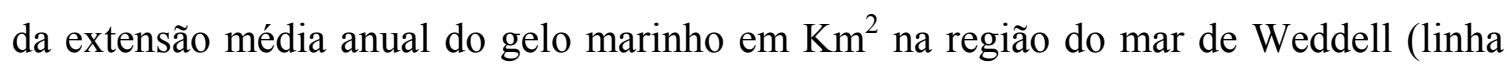
azul), no período de 1991 a 2002. Também são mostrados os valores das tendências de cada variável, que em ambos os casos foram significativos ao nível de 99\%. Os dados de gelo marinho foram obtidos no NSIDC.

Figura 2. 10. Função taper - split-cosine-bell aplicada em $10 \%$ nas extremidades das séries de temperatura para evitar descontinuidades no final das mesmas (como exemplo, o trimestre de inverno - JJA).

Figura 2. 11. Demonstração da aplicação dos pesos da função "taper" nas anomalias de temperatura (como exemplo, o inverno de 1986 da estação Arturo)...... 30

Figura 2. 12. Densidade espectral média (linha azul) da temperatura do ar, calculada para a estação Arturo durante: (a) inverno, (b) primavera, (c) verão e (d) outono. As linhas vermelhas e verdes (verdes tracejadas) correspondem ao ruído vermelho e o nível de significância de $95 \%$ (90\%), respectivamente. 31

Figura 2. 13. Idem a Fig. 2.12, mas para a estação Marambio. 32

Figura 3. 1. Comparação entre as séries das anomalias intra-sazonais (vermelho) e totais (azul) de temperatura das estações Arturo (a) e Marambio (b) no período de 1986-2002.

Figura 3. 2. Correlação entre as anomalias intra-sazonais de temperatura em Arturo (ordenada) e Marambio (abscissa). 36

Figura 3. 5. Distribuição de freqüência da persistência dos eventos intra-sazonais frios (EIF) e quentes (EIQ) em Arturo para o período de inverno (a), primavera (b) e verão (c). A 
caixa (box) em verde representa o intervalo inter-quartílico (25\%-75\%) e o ponto verde, a mediana (median). Os pontos discrepantes (outliers) são valores $\geq$ a 1,5 vezes a altura do box e os extremos (extremes) são pontos onde os valores são $\geq$ a 3,0 vezes a altura do box.

Figura 3. 6. Idem a Figura 3.5, mas para a estação Marambio 45

Figura 3. 7. Variabilidade interanual da frequência dos eventos extremos intra-sazonais frios (EIF) e quentes (EIQ) durante o inverno (a), primavera (b) e verão (c) para Arturo. Os pontos em azul (vermelho) representam os anos de episódios La Niña (El Niño) do ENOS obtidos pelo CPC/NCEP.

Figura 3. 8. Idem a Figura 3.7, mas para a estação Marambio. 48

Figura 3. 11. Composições defasadas de anomalias intrasazonais do geopotencial (mgp) em $200 \mathrm{hPa}$ durante os eventos extremos intrasazonais: (a) frios (EIF) e (b) quentes (EIQ) no inverno em Arturo (Península oeste). As linhas contínuas (tracejadas) indicam valores positivos (negativos). As áreas destacadas em vermelho (azul) são para os valores positivos (negativos) estatisticamente significativos ao nível de 95\%, baseado no teste tStudent. O intervalo dos contornos é de $10 \mathrm{mgp}$. 53

Figura 3. 12. Idem a Fig. 3.11, mas para Marambio (Península leste). 54

Figura 3. 13. (a) EOF1 e (b) EOF2 da função corrente turbulenta em $200 \mathrm{hPa}$ durante o inverno austral. (c) Correlações defasadas entre a PC1 e PC2 das anomalias totais (círculo em branco) e da série temporal filtrada na banda intra-sazonal (10-90 dias) (círculo em preto). Figura extraída de Mo e Higgins (1998). 55

Figura 3. 14. Composições defasadas de anomalias intrasazonais do vento zonal $(\mathrm{m} / \mathrm{s})$ em $200 \mathrm{hPa}$ durante os eventos extremos intrasazonais: (a) frios (EIF) e (b) quentes (EIQ) no inverno em Arturo (Península oeste). As linhas contínuas (tracejadas) indicam valores positivos (negativos). As áreas destacadas em vermelho (azul) são para os valores positivos (negativos) estatisticamente significativos ao nível de $95 \%$, baseado no teste t-

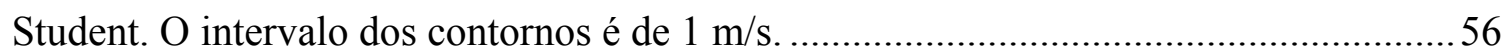

Figura 3. 15. Idem a Fig. 3.14, mas para Marambio (Península leste)................................... 57

Figura 3. 16. Composições defasadas de anomalias intrasazonais do vento meridional $(\mathrm{m} / \mathrm{s})$ em $850 \mathrm{hPa}$ durante os eventos extremos intrasazonais: (a) frios (EIF) e (b) quentes (EIQ) no inverno em Arturo (Península oeste). As linhas contínuas (tracejadas) indicam valores positivos (negativos). As áreas destacadas em vermelho (azul) são para os valores positivos (negativos) estatisticamente significativos ao nível de 95\%, baseado no teste t-Student. O intervalo dos contornos é de $1 \mathrm{~m} / \mathrm{s}$. 58 
Figura 3. 17. Idem a Fig. 3.16, mas para Marambio (Península leste). 59

Figura 3. 18. Composições defasadas de anomalias intrasazonais do geopotencial (mgp) em $200 \mathrm{hPa}$ durante os eventos extremos intrasazonais: (a) frios (EIF) e (b) quentes (EIQ) na primavera em Arturo (Península oeste). As linhas contínuas (tracejadas) indicam valores positivos (negativos). As áreas destacadas em vermelho (azul) são para os valores positivos (negativos) estatisticamente significativos ao nível de $95 \%$, baseado no teste $\mathrm{t}$ Student. O intervalo dos contornos é de $10 \mathrm{mgp}$.

Figura 3. 19. Idem a Fig. 3.18, mas para Marambio (Península leste). 62

Figura 3. 20. Composições defasadas de anomalias intrasazonais do vento zonal $(\mathrm{m} / \mathrm{s})$ em $200 \mathrm{hPa}$ durante os eventos extremos intrasazonais: (a) frios (EIF) e (b) quentes (EIQ) na primavera em Arturo (Península oeste). As linhas contínuas (tracejadas) indicam valores positivos (negativos). As áreas destacadas em vermelho (azul) são para os valores positivos (negativos) estatisticamente significativos ao nível de $95 \%$, baseado no teste tStudent. O intervalo dos contornos é de $1 \mathrm{~m} / \mathrm{s}$. 63

Figura 3. 21. Idem a Fig. 3.20, mas para Marambio (Península leste). 64

Figura 3. 22. Composições defasadas de anomalias intrasazonais do vento meridional $(\mathrm{m} / \mathrm{s})$ em $850 \mathrm{hPa}$ durante os eventos extremos intrasazonais: (a) frios (EIF) e (b) quentes (EIQ) na primavera em Arturo (Península oeste). As linhas contínuas (tracejadas) indicam valores positivos (negativos). As áreas destacadas em vermelho (azul) são para os valores positivos (negativos) estatisticamente significativos ao nível de 95\%, baseado no teste t-Student. O intervalo dos contornos é de $1 \mathrm{~m} / \mathrm{s}$. 65

Figura 3. 23. Idem a Fig. 3.22, mas para Marambio (Península leste). .66

Figura 3. 24. Composições defasadas de anomalias intrasazonais do geopotencial (mgp) em $200 \mathrm{hPa}$ durante os eventos extremos intrasazonais: (a) frios (EIF) e (b) quentes (EIQ) no verão em Arturo (Península oeste). As linhas contínuas (tracejadas) indicam valores positivos (negativos). As áreas destacadas em vermelho (azul) são para os valores positivos (negativos) estatisticamente significativos ao nível de $95 \%$, baseado no teste tStudent. O intervalo dos contornos é de $10 \mathrm{mgp}$. 68

Figura 3. 25. Idem a Fig. 3.24, mas para Marambio (Península leste). 69

Figura 3. 26. Composições defasadas de anomalias intrasazonais do vento zonal $(\mathrm{m} / \mathrm{s})$ em $200 \mathrm{hPa}$ durante os eventos extremos intrasazonais: (a) frios (EIF) e (b) quentes (EIQ) no verão em Arturo (Península oeste). As linhas contínuas (tracejadas) indicam valores positivos (negativos). As áreas destacadas em vermelho (azul) são para os valores 
positivos (negativos) estatisticamente significativos ao nível de $95 \%$, baseado no teste $\mathrm{t}$ Student. O intervalo dos contornos é de $1 \mathrm{~m} / \mathrm{s}$.

Figura 3. 27. Idem a Fig. 3.26, mas para Marambio (Península leste).

Figura 3. 28. Composições defasadas de anomalias intrasazonais do vento meridional $(\mathrm{m} / \mathrm{s})$ em $850 \mathrm{hPa}$ durante os eventos extremos intrasazonais: (a) frios (EIF) e (b) quentes (EIQ) no verão em Arturo (Península oeste). As linhas contínuas (tracejadas) indicam valores positivos (negativos). As áreas destacadas em vermelho (azul) são para os valores positivos (negativos) estatisticamente significativos ao nível de 95\%, baseado no teste t-Student. O intervalo dos contornos é de $1 \mathrm{~m} / \mathrm{s}$.

Figura 3. 29. Idem a Fig. 3.28, mas para Marambio (Península leste). 73

Figura 3. 30. Composições das anomalias intrasazonais do vento zonal (m/s) em $200 \mathrm{hPa}$ para os casos: (a) abaixo do percentil de 10\% e (b) acima do percentil de $90 \%$ das anomalias intra-sazonais de temperatura no inverno em Arturo. As figuras (c-e) representam os EIQ em Arturo com persistência abaixo do percentil 25\%, igual ao percentil de $50 \%$ e acima do percentil de $75 \%$, respectivamente. As linhas contínuas (tracejadas) indicam valores positivos (negativos). As áreas destacadas em vermelho (azul) são para os valores positivos (negativos) estatisticamente significativos ao nível de $95 \%$, baseado no teste t-Student. O intervalo dos contornos é de $1 \mathrm{~m} / \mathrm{s}$. 75

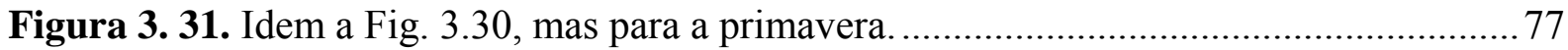

Figura 3. 32. Idem a Fig. 3.30, mas para o verão. 78

Figura 3. 33. Composições defasadas de anomalias intrasazonais de radiação de onda longa $\left(\mathrm{W} / \mathrm{m}^{2}\right)$ durante os eventos extremos intrasazonais: (a) frios (EIF) e (b) quentes (EIQ) no inverno em Arturo (Península oeste). As linhas contínuas (tracejadas) indicam valores positivos (negativos). As áreas destacadas em vermelho (azul) são para os valores positivos (negativos) estatisticamente significativos ao nível de $95 \%$, baseado no teste $\mathrm{t}$ Student. O intervalo dos contornos é de $2 \mathrm{~W} / \mathrm{m}^{2}$. 80

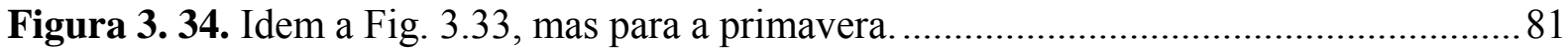

Figura 3. 35. Idem a Fig. 3.33, mas para o verão. 82

Figura 3. 36. Coeficiente de regressão das anomalias diárias da altura geopotencial em 700 hPa na EOF-1. Este modo explica cerca de $26 \%$ da variância total dos dados (Figura obtida em Carvalho et al. 2005).

Figura 3. 37. Correlação entre as anomalias de H700 IS e a EOF-1 obtida para os EIF (a) e os EIQ (b), no inverno em Arturo. A variância explicada pela EOF-1 está indicada no topo de cada figura. 
Figura 3. 38. Idem a Fig. 3.37, mas para Marambio.

Figura 3. 39. Correlação entre as anomalias de H700 IS e a EOF-1 obtida para os EIF (a) e os EIQ (b), na primavera em Arturo. A variância explicada pela EOF-1 está indicada no topo de cada figura. 86

Figura 3. 40. Idem a Fig. 3.39, mas para Marambio. 86

Figura 3. 41. Correlação entre as anomalias de H700 IS e a EOF-1 obtida para os EIF (a) e os EIQ (b), no verão em Arturo. A variância explicada pela EOF-1 está indicada no topo de cada figura. 87

Figura 3. 42. Idem a Figura 3.41, mas para Marambio. 87

Figura 4. 1. Climatologia do vetor EP $\left(10^{11} \mathrm{~kg} \mathrm{~m} \mathrm{~s}^{-2}\right)$ e do vento zonal $(\mathrm{m} / \mathrm{s})$ na alta troposfera e baixa estratosfera para o inverno (a), primavera (b), verão (c) e outono (d), no período de 1979-2005. O vetor EP em $150 \mathrm{hPa}$ foi multiplicado por $10^{-1}$ devido as diferenças de magnitude entre a troposfera e estratosfera. Os vetores EP foram escalados tal que $F \mapsto\left(c F_{y}, F_{z}\right)$, onde $\mathrm{c}=0,0091$, como descrito em Palmer (1981)

Figura 4. 2. Climatologia da temperatura do ar $\left({ }^{\circ} \mathrm{C}\right)$ na baixa estratosfera (em $\left.50 \mathrm{hPa}\right)$, durante o inverno (a), primavera (b), verão (c) e outono (d), obtida por reanálises do NCEP-NCAR no período de 1979-2005.

Figura 4. 3. Idem a Fig. 4.2, mas para alta troposfera (em $200 \mathrm{hPa})$. 94

Figura 4. 4. Composições defasadas das anomalias intra-sazonais do vetor EP $\left(10^{11} \mathrm{~kg} \mathrm{~m} \mathrm{~s}^{-2}\right)$ e do vento zonal $(\mathrm{m} / \mathrm{s})$ na alta troposfera e baixa estratosfera para os EIF (a) e EIQ (b), durante o inverno em Arturo. O vetor EP em $150 \mathrm{hPa}$ foi multiplicado por $10^{-2}$ devido as diferenças de magnitude entre a troposfera e estratosfera. Os vetores EP foram escalados como na Fig 4.1. 96

Figura 4. 5. Idem a Fig. 4.4, mas para a estação Marambio. 97

Figura 4. 6. Composições defasadas das anomalias intra-sazonais do vetor EP $\left(10^{11} \mathrm{~kg} \mathrm{~m} \mathrm{~s}^{-2}\right)$ e do vento zonal (m/s) na alta troposfera e baixa estratosfera para os EIF (a) e EIQ (b), durante a primavera em Arturo. O vetor EP em $150 \mathrm{hPa}$ foi multiplicado por $10^{-2}$ devido as diferenças de magnitude entre a troposfera e estratosfera. Os vetores EP foram escalados como na Fig 4.1.

Figura 4. 7. Idem a Fig. 4.6, mas para Marambio. 100

Figura 4. 8. Composições defasadas das anomalias intra-sazonais do vetor EP $\left(10^{11} \mathrm{~kg} \mathrm{~m} \mathrm{~s}^{-2}\right)$ e do vento zonal $(\mathrm{m} / \mathrm{s})$ na alta troposfera e baixa estratosfera para os EIF (a) e EIQ (b), 
durante o verão em Arturo. $\mathrm{O}$ vetor $\mathrm{EP}$ em $150 \mathrm{hPa}$ foi multiplicado por $10^{-2}$ devido as diferenças de magnitude entre a troposfera e estratosfera. Os vetores EP foram escalados

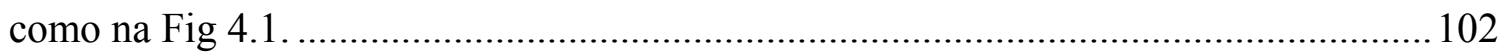

Figura 4. 9. Idem a Fig. 4.8, mas para Marambio.......................................................... 103 


\section{LISTA DE TABELAS}

Tabela 2. 1. Estações utilizadas neste estudo com suas respectivas elevações, latitude, longitude, período de dados disponíveis e porcentagem de dados faltantes no período 1986-2002.

Tabela 2. 2. Análise do coeficiente linear de correlação de Pearson entre as séries temporais das estações da Península Antártica.

Tabela 2. 3. Média, desvio padrão e tendência da temperatura média anual nas estações Arturo e Marambio. Valor em negrito: significativo ao nível de 95\%.

Tabela 2. 4. Análise sazonal da tendência na temperatura média anual nas estações Arturo e Marambio. Valores em negrito: significativos ao nível de $90 \%$.

Tabela 2. 5. Análise sazonal dos extremos frios (q25) e quentes (q75) nas estações Arturo e Marambio.

Tabela 3. 1. Data do primeiro dia de cada evento intra-sazonal frio (EIF) e quente (EIQ) e suas respectivas persistências, em ordem de ocorrência $(\mathrm{N})$, para as estações Arturo e Marambio, durante o inverno austral.

Tabela 3. 2. Idem a tabela 3.1, mas para a primavera austral. 42

Tabela 3. 3. Idem a tabela 3.1, mas para o verão austral. 43

Tabela 3. 4. Número de eventos El Niño, La Niña e neutros do ENOS, observados em cada estação do ano durante 1986-2002. 


\section{LISTA DE ABREVIATURAS}

HS Hemisfério Sul

AAO Antarctic Oscillation

EOF Empirical Orthogonal Function

HN Hemisfério Norte

AO Artic Oscillation

ENOS El Niño- Oscilação Sul

EN El Niño

OS Oscilação Sul

TSM Temperatura da superfície do mar

PSA Pacific-South American

PNA Pacific-North American

OI Oscilação Intra-sazonal

OMJ Oscilação Madden-Julian

EIT Eventos extremos intra-sazonais de temperatura

EIF Eventos intra-sazonais frios

EIQ Eventos intra-sazonais quentes

NSIDC National Snow and Ice Data Center

DE Distância Euclidiana

q75 quartil superior

q25 quartil inferior

FFT Fast Fourier Transform

CPC Climate Prediction Center

NCEP National Centers for Environmental Prediction

NCAR National Center for Atmospheric Research 


\section{Capítulo 1: Introdução}

\subsection{O papel da Antártica no clima global}

A atmosfera terrestre é uma grande máquina de calor, impulsionada pela diferença no balanço de energia, positivo no equador e negativo nos pólos. A circulação geral da atmosfera organiza-se de forma a distribuir esta energia por todo o globo.

O continente antártico é o grande "sumidouro" de calor do Hemisfério Sul (HS), devido seu balanço de radiação deficitário, exercendo controle sobre a circulação atmosférica em médias e altas latitudes. A imensa massa de gelo permanente, com temperaturas que variam entre $-30^{\circ} \mathrm{C}$ e $-70^{\circ} \mathrm{C}$ no seu interior, induz a formação de um centro de alta pressão sobre o continente. Em função da altitude do domo de gelo, superando $4000 \mathrm{~m}$ no platô Antártico (Figura 1.1), esta circulação gera fortes e persistentes ventos catabáticos, que conduzem ar frio do interior do continente em direção à costa (Figura 1.2a). O efeito catabático, aliado ao gradiente negativo de pressão da escala global, devido à Coriolis, resulta em ventos de leste praticamente constantes próximo à costa (Figura 1.2b) (King e Turner, 1997).

Em altitude, a orografia assimétrica do continente com relação ao pólo geográfico dá origem às ondas de Rossby, que afetam a circulação de latitudes médias ao propagarem-se para o norte. Esta ondulação é modulada pela corrente de jato polar, que marca o posicionamento da Frente Polar e serve de condutora para os sistemas meteorológicos transientes, promovendo a troca de massas de ar subtropicais e polares. Estes sistemas são ciclones e anticiclones extratropicais migratórios, que evoluem ao redor do continente antártico. Esta região, em latitude média de aproxidamente $66^{\circ} \mathrm{S}$, configura a Baixa Pressão Circumpolar (Figura 1.3). Caracteriza-se pela convergência do ar frio vindo do continente 
com o ar quente vindo de latitudes mais baixas, sendo a região do planeta com maior quantidade de nuvens (cobertura média de 6/8 a 8/8) (King e Turner, 1997).

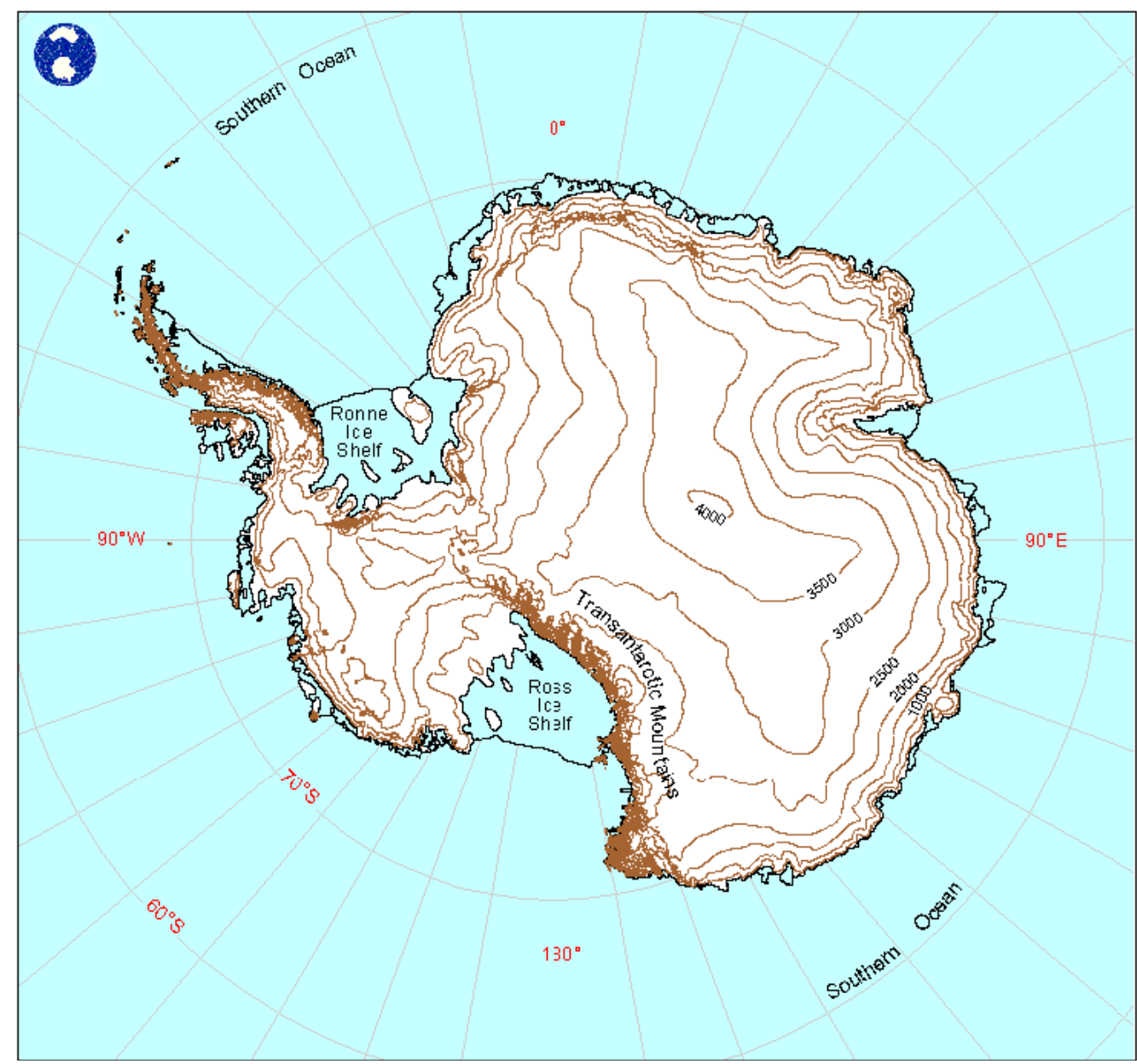

Figura 1. 1. Mapa orográfico da Antártica. O intervalo dos contornos é de 500m (Turner e Pendlebury 2004).

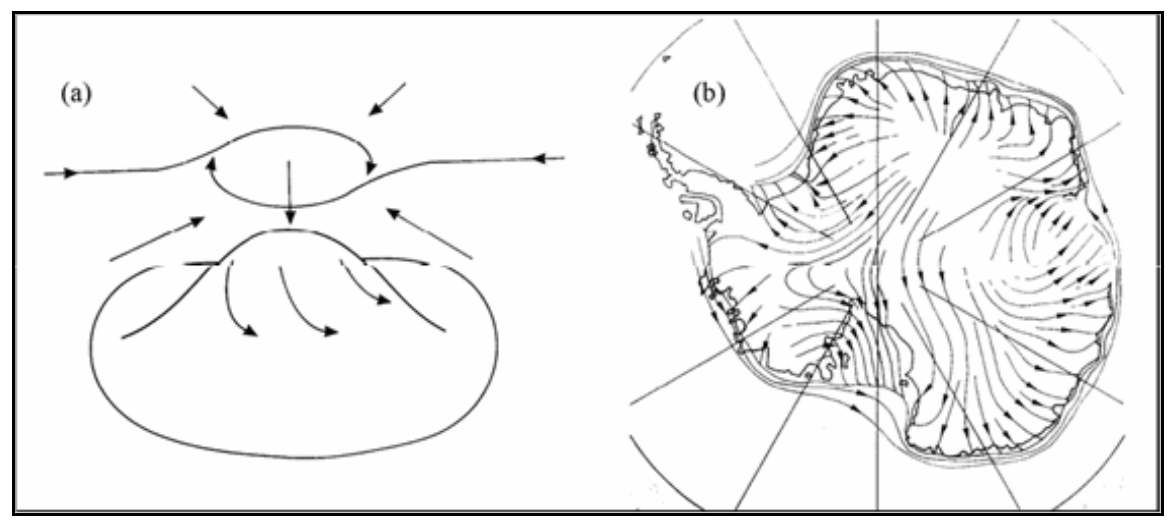

Figura 1. 2. (a) Modelo conceitual da circulação troposférica sobre a Antártica. Ventos catabáticos em superfície estão em equilíbrio com a convergência em altitude e a subsidência sobre o continente, que sustenta uma circulação ciclônica em níveis médios (King e Turner, 1997, p.163). (b) Divergência em superfície resulta em ventos catabáticos que adquirem forte componente de leste próximo à costa (King e Turner, 1997, p.94). 


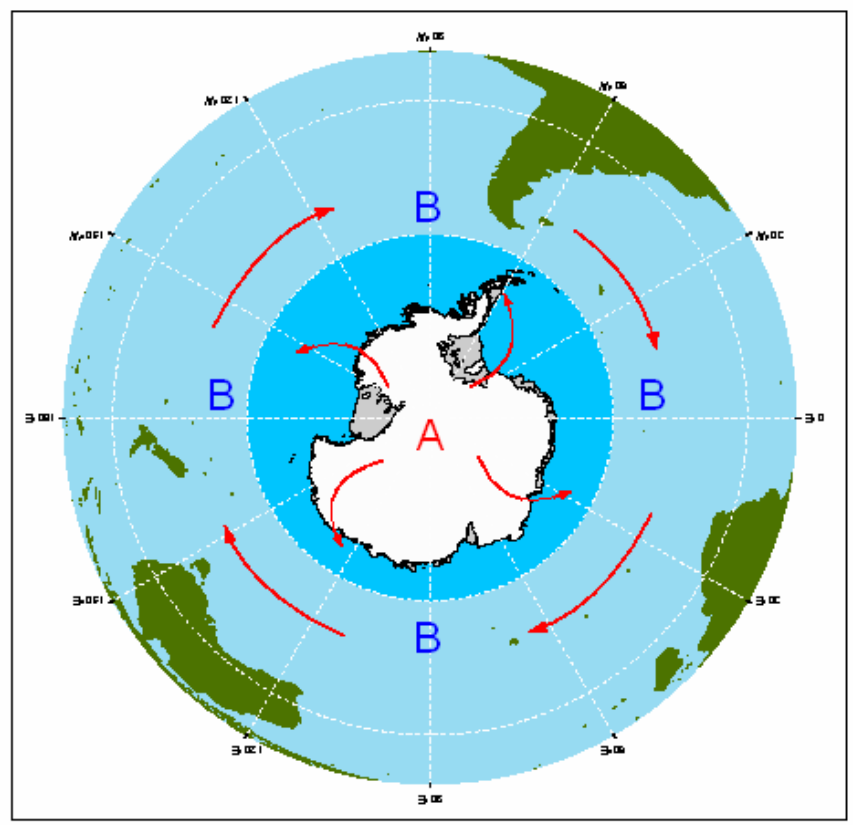

Figura 1. 3. Esquema representando a circulação atmosférica na região da Antártica, destacando a alta pressão sobre o continente e a região de baixa pressão circumpolar próxima à latitude de $66^{\circ} \mathrm{S}$ (Adaptada de Australian Antarctic Division).

O estado médio da atmosfera, chamado de clima, é determinado pela emissão da radiação solar, rotação da Terra e características orbitais, composição da atmosfera, e interações entre a atmosfera e os outros componentes do sistema terrestre que determinam os fluxos de massa, energia e momentum na superfície da Terra, como os oceanos e a criosfera. Estes componentes contribuem para a inércia térmica do sistema climático. Se não fosse pelo grande armazenamento de calor no oceano e criosfera durante o verão, e a liberação deste calor no inverno seguinte, as variações sazonais na temperatura sobre continentes em média e altas latitudes seriam maiores que o observado.

Os oceanos - por conta das correntes geradas pelos ventos e da circulação termohalina gerada pelas diferenças de densidade - transportam águas relativamente frias para o equador e calor para os pólos. No Oceano Sul, a circulação oceânica governada pelos ventos de oeste em superfície, chamada de Corrente Circumpolar Antártica (localizada ao longo de $55^{\circ} \mathrm{S}$, latitude da passagem de Drake que separa a Antártica e a América do Sul), modera as temperaturas nas regiões costeiras em altas latitudes do HS.

A criosfera contribui para a refletividade ou albedo da Terra, influencia a circulação termohalina e armazena quantidade significativa de água influenciando o nível do mar global. A área continental da Antártica representa cerca de 2,7\% área da superfície da Terra (contra 0,35 \% da Groenlândia) (Wallace e Hobbs 2006). Sua superfície é coberta de gelo e contém 
cerca de $90 \%$ da água doce do mundo. A presença de gelo marinho ao redor da Antártica tem efeito significativo na interação oceano-atmosfera, seja na troca de calor, transferência de vapor d'água para a atmosfera ou no balanço de radiação solar recebida e refletida (Ferron, 1999). A extensão do gelo varia sazonalmente (Figura 1.4), atingindo a máxima em setembro $\left(18,8\right.$ milhões de $\left.\mathrm{km}^{2}\right)$ e a mínima em fevereiro $\left(3,6\right.$ milhões de $\left.\mathrm{km}^{2}\right)$, o que resulta numa variação $\left(15,2\right.$ milhões de $\left.\mathrm{km}^{2}\right)$ que supera a própria área do continente (14 milhões de $\left.\mathrm{km}^{2}\right)$ (Ferron, 1999).

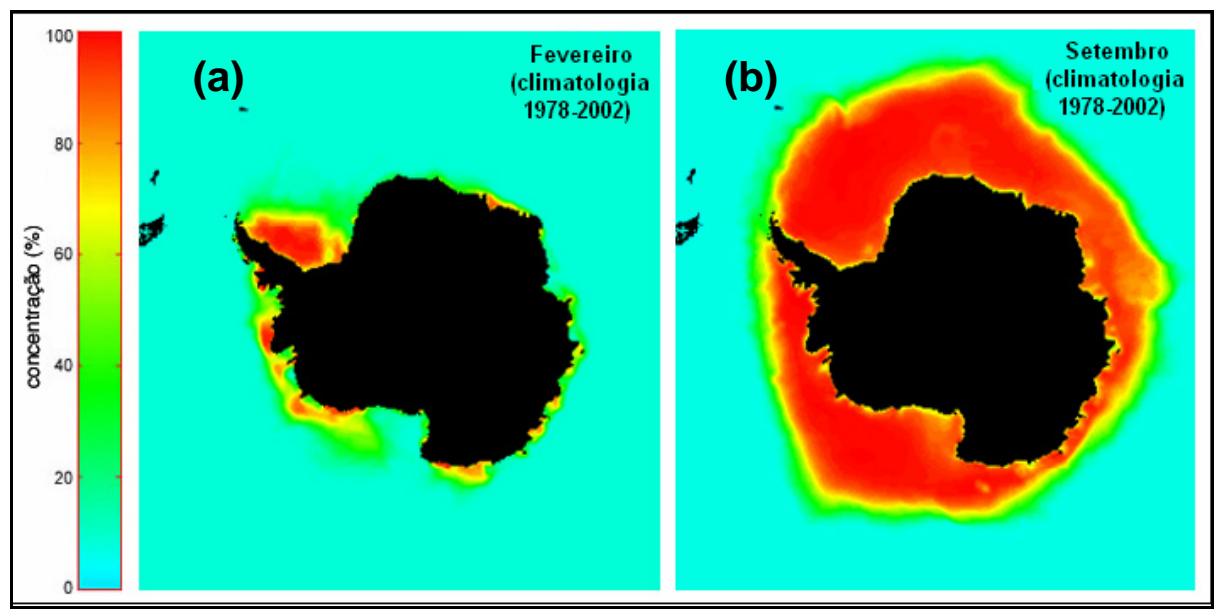

Figura 1. 4. Concentração média do gelo marinho antártico baseado na climatologia do período de 1978-2002, para os meses de (a) fevereiro, período de concentração mínima de gelo e (b) setembro, período de máxima concentração de gelo (Adaptada de National Snow and Ice Data Center - NSIDC, 2004).

\subsection{Variabilidade climática na Antártica}

As variações de longo prazo ou mudanças no estado médio da atmosfera, dentro de um mesmo intervalo de tempo, são referidas como variabilidade climática. Estas variações podem ser geradas por processos internos na atmosfera, processos acoplados com outros componentes do sistema terrestre (como os oceanos e a criosfera) e por forçantes externas (como a variabilidade solar, erupções vulcânicas ou mudanças na composição atmosférica induzida pela atividade humana) (Wallace e Hobbs 2006).

Muitos padrões de variabilidade climática (algumas vezes referidos como "modos") identificados no HS apresentam sinais robustos no continente Antártico. A Oscilação Antártica (Antarctic Oscillation - AAO), também conhecida como modo anular de altas latitudes do Hemisfério Sul, é um dos mais importantes modos de variabilidade nas médias e altas latitudes do HS. A $A A O$ foi originalmente identificada por Walker (1928) como as 
mudanças de pressão observadas num cinturão de pressão que atravessa o Chile e Argentina, com sinais opostos sobre os mares de Weddell e Bellingshausen. Muitos estudos subseqüentes determinaram que a $A A O$ é uma flutuação zonal de pressão e geopotencial entre latitudes médias e altas do HS (Gong e Wang 1999; Thompson e Wallace, 2000; Carvalho et al. 2005).

A $A A O$ pode ser objetivamente caracterizada através da análise de funções ortogonais empíricas (Empirical Orthogonal Function - EOF) na anomalia da altura geopotencial em $700 \mathrm{hPa}$. A fase positiva da primeira componente principal (ou índice da $A A O$ ) consiste em anomalias negativas na altura geopotencial sobre a Antártica e próximo aos oceanos austrais em altas latitudes e anomalias positivas da altura geopotencial ao norte de $50^{\circ} \mathrm{S}$. Gong e Wang (1999) descobriram que a $A A O$ existe durante todo o ano na troposfera, mas se amplifica com a altura em direção à estratosfera em certas épocas do ano ou estações ativas (Thompson e Wallace 2000). Estes autores mostram ainda que a estação ativa no HS é no final da primavera austral e que a $A A O$ parece modular a intensidade da circulação média na baixa estratosfera, a altura da coluna de ozônio e a altura da tropopausa sobre latitudes médias e altas. Além disso, a tendência da $A A O$ em décadas recentes para a fase positiva da oscilação (e.g., Thompson et al. 2000) está associada ao aumento dos ventos de oeste em latitudes médias e às condições frias sobre a maior parte da Antártica, exceto sobre a Península, onde torna-se mais quente devido a advecção de ar dos mares a oeste. As razões para estas mudanças estão sob discussão, mas já se sabe que o aumento na concentração dos gases estufa e a diminuição do ozônio estratosférico são fatores importantes que afetam a $A A O$ (Turner, 2004). Esta oscilação tem uma contraparte no Hemisfério Norte (HN) chamada de Artic Oscillation (AO). A variabilidade sazonal dos modos anulares e a conexão troposfera - baixa estratosfera tem algumas implicações. Thompson et al. (2002) mostraram evidências que anomalias de baixas (altas) temperaturas do ar em superfície durante o inverno e o aumento na freqüência de ocorrência de extremos frios (quentes) sobre algumas regiões continentais no HN estariam relacionadas ao enfraquecimento (intensificação) do vórtice polar estratosférico durante o inverno no HN. No entanto, ainda não foram investigadas as conseqüências da relação entre a $A A O$ e a estratosfera para o clima e tempo de médias e altas latitudes do HS.

A variabilidade acoplada mais proeminente envolvendo atmosfera-oceano é como conhecido como ENOS, o qual se refere ao fenômeno El Niño (indicado por um padrão de anomalias positivas da temperatura da superfície do mar no Pacífico equatorial) e a Oscilação Sul (indicado por um padrão de anomalias da pressão ao nível do mar em Darwin na Austrália e no Taiti). Ambas as séries temporais de El Niño (EN) e Oscilação Sul (OS) (não mostradas) 
revelam um forte acoplamento entre a atmosfera e oceano na escala interanual. As fases do ENOS têm impactos na circulação global, em particular na posição e intensidade dos jatos subtropicais em altos níveis em ambos os hemisférios (e.g., Karoly 1989; Chen et al. 1996; Kiladis e Mo, 1998).

A relação entre ENOS e Antártica foi discutida por Turner (2004), ao analisar as anomalias de altura geopotencial em $500 \mathrm{hPa}$ durante o inverno do $\mathrm{HS}$. O autor verificou que em anos de El Niño (La Niña) anomalias positivas (negativas) de geopotencial são observadas no Pacífico Sul, próximo ao continente Antártico, causando um aumento (diminuição) da temperatura média da camada sobre esta região. Chen et al. (1996) mostraram que o jato subtropical é mais intenso durante eventos quentes do ENOS, com o jato polar mais intenso durante eventos frios ou neutros.

A $A A O$ proporciona uma forma de acoplamento entre o clima antártico com o clima de latitudes mais baixas. Portanto, variações no ENOS podem também afetá-la (Carvalho et al. 2005). A fase negativa (positiva) da $A A O$ durante o verão austral está associada com padrões de temperatura da superfície do mar (TSM), convecção e anomalias de circulação que se assemelham à fase El Niño (La Niña) do ENOS (Carvalho et al. 2005).

Muitos trabalhos mostram tele-conexões (i.e., correlações estatisticamente significativas entre parâmetros meteorológicos em regiões remotas) entre as condições atmosféricas no Pacífico tropical e latitudes extratropicais. Hoskins e Karoly (1981), por meio de uma investigação teórica, mostraram que regiões de convecção profunda próxima ao equador podem gerar ondas de Rossby, através da vorticidade gerada por aquecimento diabático. Estas ondas movem-se em direção aos pólos em ambos os hemisférios, e proporcionam uma forma de tele-conexão entre ENOS e o clima de médias latitudes. Karoly (1989) relatou que um trem de ondas é observado durante o inverno austral em anos de El Niño. Este trem de ondas afeta as condições sinóticas sobre a região sul da América do Sul, bem como a Península Antártica (Harangozo, 2000). Os padrões de tele-conexão em anomalias mensais da pressão ao nível do mar e altura geopotencial em $500 \mathrm{hPa}$ no HS foram investigados por Mo e White (1985). Carvalho et al. (2005), examinaram os padrões de teleconexão nas anomalias do vento zonal em $200 \mathrm{hPa}$ (U200) relacionados com as fases opostas da $A A O$. Os autores escolheram U200, pois os jatos de oeste podem atuar como guias de ondas de Rossby (Hoskins e Ambrizzi 1993), direcionando a propagação das ondas para regiões geográficas preferenciais (Ambrizzi et al. 1995) e, assim, fornecendo uma melhor interpretação dos padrões de tele-conexão entre trópicos-extratrópicos. De acordo com a 
Figura 1.5. obtida em Carvalho et al. (2005), observa-se que o padrão de tele-conexão simétrico zonalmente nos subtrópicos (altas latitudes), com máximo negativo em aprox. $45^{\circ} \mathrm{S}$ $\left(60^{\circ} \mathrm{S}\right)$, está relacionado ao jato subtropical (polar) no HS. Para as fases negativas da $A A O$ (Figura. 1.5, acima), as características subtropicais estão mais deslocadas para o equador do que durante as fases positivas, visto que as características em altas latitudes estão mais fracas (exceto nas regiões centradas em $180^{\circ}$ e $100^{\circ} \mathrm{W}$ ). Outra notável diferença é observada próxima à costa sudeste da América do Sul (Fig. 1.5, abaixo), que juntamente com estas duas regiões de máxima mencionadas anteriormente, sugerem a trajetória preferencial de propagação dos trens de onda em latitudes médias observados no verão austral (Carvalho et al. 2004). As fases positivas da $A A O$ (Fig. 1.5, centro) estão associadas com um deslocamento para o pólo das características subtropicais e uma intensificação das características em altas latitudes. Em suma, o padrão de tele-conexão observado na Fig. 1.5 sugere modificações na posição e intensidade do jato subtropical e assim as ondas de Rossby podem propagar para o pólo seguindo os guias de onda e tomando trajetos descritos em Hoskins e Ambrizzi (1993).

Mo e Ghil (1987), investigando a circulação de inverno no HS, detectaram através da terceira EOF das anomalias da altura geopotencial em $500 \mathrm{hPa}$, um padrão de anomalias anticiclônicas sobre o Pacífico Central associado a anomalias ciclônicas no Pacífico Sul e anomalias anti-ciclônicas centradas na Península Antártica. Este padrão foi denominado Pacífico/Sul Americano (PSA) por ser análogo aos três centros do padrão de tele-conexão Pacífico/Norte Americano observado na América do Norte por Wallace e Gutzler (1981). Posteriormente, Ghil e Mo (1991b), Mo e Higgins (1998) entre outros, encontraram dois modos de baixa freqüência, no qual são conhecidos como os modos do padrão do PSA (PSA1 e PSA2) e são caracterizados por dois padrões de números de onda três em quadratura entre si (i.e., defasados 90 graus entre si) e por trens de ondas bem definidos estendendo do Pacífico central ao continente sul Americano. Os modos foram obtidos por EOFs das anomalias de altura geopotencial em $500 \mathrm{hPa}$ ou função corrente em $200 \mathrm{hPa}$ e são observados nas bandas interanual (Kidson 1988; Mo e Paegle 2001) e intra-sazonal (Kidson 1991; Ghil e Mo 1991; Mo e Higgins 1998; Mo e Paegle 2001). Ambos os modos do PSA são padrões de teleconexão no HS (Mo e White 1985). Além disso, Grimm e Silva-Dias (1995) encontraram que a reposta das ondas de Rossby à fontes de onda no Pacífico exibe padrões horizontais similares aos modos do PSA. 


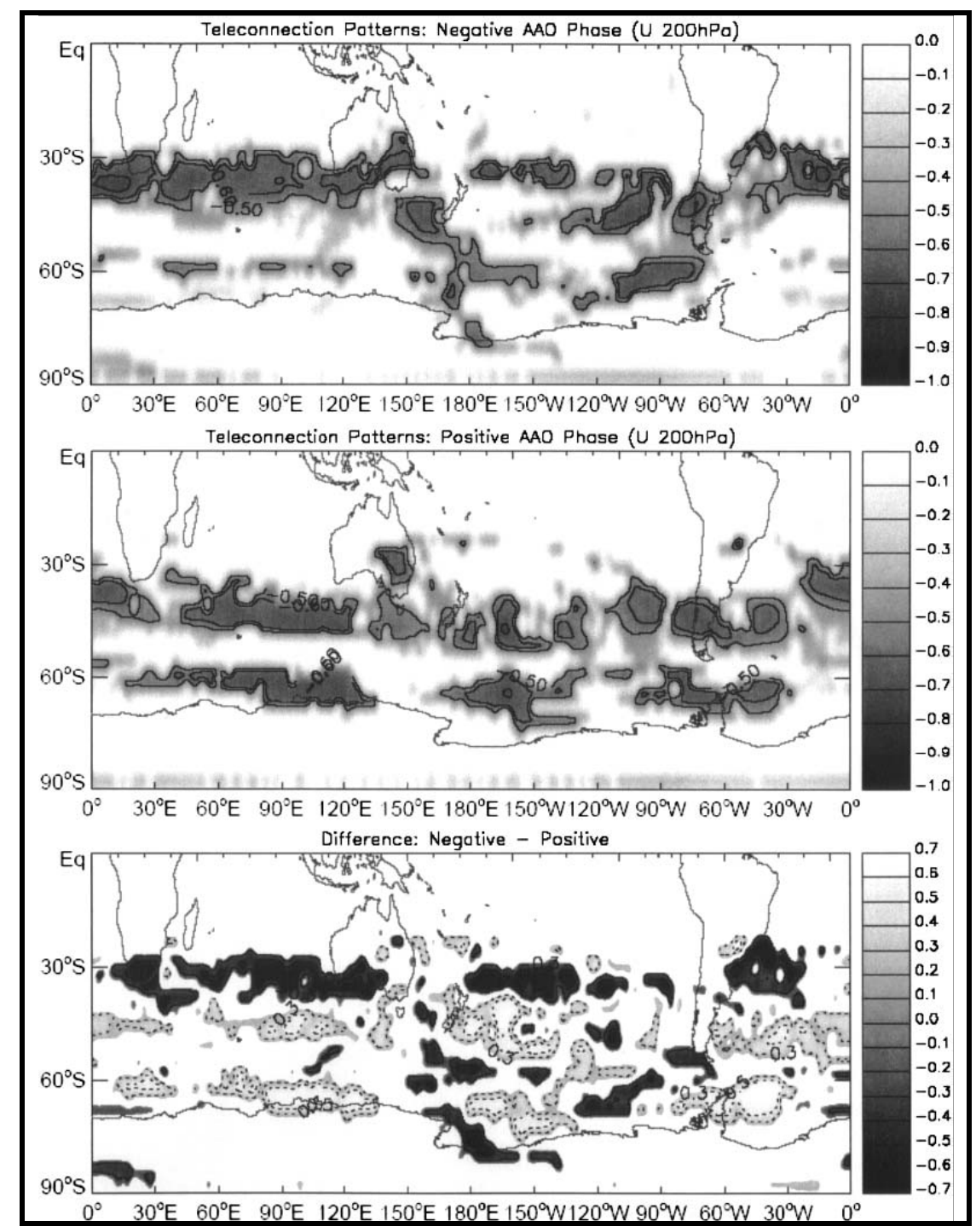

Figura 1. 5. Padrões de tele-conexão obtidos pelas anomalias do vento zonal em $200 \mathrm{hPa}$ (U200) durante os eventos negativos (acima), positivos (centro) da $A A O$ e a diferença entre os dois campos (abaixo). Figura extraída de Carvalho et al. 2005.

Na escala interanual, o PSA1 aparece como resposta ao ENSO no HS (Karoly 1989; Mo e Paegle 2001) e o PSA2 é associado com a componente quase-bienal do ENOS, com um período de 22-28 meses (Mo e Paegle 2001). Na banda intra-sazonal, os modos do PSA são modulados pela convecção tropical no verão e inverno (Mo e Paegle 2001). Durante a fase positiva do PSA1, observa-se um aumento da convecção no Pacífico central e supressão da convecção no Pacífico oeste, o qual é a assinatura da Oscilação intra-sazonal (OI) tropical (Mo e Higgins 1998, Mo e Paegle 2001). O padrão de convecção associado ao PSA2 é o oposto ao observado no PSA1.

No Hemisfério Norte (HN), Higgins e Mo (1997) demonstraram que o desenvolvimento de anomalias persistentes no Pacífico Norte está freqüentemente relacionado 
com a oscilação intra-sazonal (OI) tropical. Segundo Mo e Higgins (1998), a relação entre a OI tropical e os modos do PSA são muito similares às anomalias persistentes no Pacífico Norte. A forçante tropical cria uma situação favorável para o desenvolvimento de um dos modos do PSA (Mo e Higgins, 1998).

\subsubsection{Oscilação intra-sazonal tropical: Oscilação Madden-Julian (OMJ)}

Assim como o fenômeno ENOS, a Oscilação Madden-Julian (OMJ) é um dos principais modos de variabilidade de baixa freqüência na atmosfera tropical, no qual é a componente dominante da variabilidade intra-sazonal (aprox. 10-90 dias) (Madden e Julian 1994). A OMJ consiste de padrões acoplados entre a circulação atmosférica de grande-escala e a convecção, manifestando-se com uma lenta propagação para leste (velocidade de fase na ordem de 5-10 $\mathrm{m} / \mathrm{s}$ ) dos distúrbios atmosféricos sobre os oceanos Índico equatorial e Pacífico oeste/central (onde a instabilidade convectiva pode ser sustentada pela superfície do mar quente, conhecida como a "piscina quente"). Sua estrutura horizontal é dominada por número de onda um e dois na direção zonal, e sua estrutura vertical é baroclínica. As estruturas das ondas de Kelvin e Rossby foram consideradas dinamicamente essenciais para a OMJ (e.g., Madden, 1986).

Uma importante característica da OMJ é o alto grau de variabilidade caso a caso bem como sua variação sazonal a interanual (e.g., Madden e Julian 1994; Jones et al. 2004b). A existência da variabilidade sazonal das anomalias intra-sazonais nos trópicos está bem documentada. Um exemplo é o aumento na freqüência e intensidade das anomalias intrasazonais tropicais durante o verão austral (e.g., Jones et al. 2004b). Em latitudes médias, a máxima atividade intra-sazonal é observada durante o período de inverno em ambos os hemisférios (Ghil e Mo 1991). A variabilidade sazonal da OMJ influencia o clima em diversas regiões do globo, como as monções na Austrália (Hendon e Liebmann, 1990), Ásia (Lau e Chan, 1986), e nas Américas (Mo e Higgins 1998; Jones 2000; Jones e Carvalho 2002; Liebmann et al. 2004). Esta oscilação afeta a precipitação e eventos extremos em diversas localidades ao redor do mundo (Jones 2000; Jones et al. 2004c; Carvalho et al. 2004).

Desde sua descoberta por Madden e Julian (1971), a OMJ tem sido um tópico de grande interesse devido à diversidade de fenômenos que interagem com esta oscilação. A OMJ no Pacífico parece ser robusta antes de um evento quente do ENOS e fraca depois e durante um evento frio (Zhang e Gottschalck, 2002). Jones et al. (2004) verificaram que, para o período de 1979-2002, mais eventos OMJ ocorreram durante eventos El Niño e neutros do que durante La Niña no verão austral; entretanto, estas diferenças não são estatisticamente 
significativas. A relação entre a OMJ e $A A O$ foi investigada por Carvalho et al. (2005) durante o verão austral (DJF). Os autores detectaram um aumento (diminuição) da atividade intra-sazonal dos trópicos para os extratrópicos do HS associado com as fases negativas (positivas) da $A A O$. Além disso, encontraram indicações que o início da fase negativa da $A A O$ esteja relacionado com a propagação da OMJ. Na fase positiva da $A A O$ foi observada supressão da atividade convectiva intra-sazonal sobre a Indonésia.

Estes resultados sugerem que a convecção profunda no Pacífico central tropical, o qual está relacionada com o El Niño e (ou) com a propagação para leste da MJO, modula a circulação no HS e favorece a fase negativa da $A A O$ durante o verão austral (Carvalho et al. 2005). Além disso, a OMJ parece estar relacionada com o trem de onda que se estende sobre o Pacífico Sul a América do Sul (Mo e Higgins 1998), que consequentemente pode afetar as condições de tempo e clima na Península Antártica.

\subsection{Mudanças climáticas e a Antártica}

As mudanças climáticas observadas no último século são caracterizadas principalmente por mudanças na temperatura média global, especialmente desde a metade da década de 1970, assim como mudanças na circulação atmosférica. No Hemisfério Sul (HS), as maiores tendências significativas na temperatura foram observadas sobre a Antártica, com destaque no aquecimento registrado na região da Península Antártica (IPCC 2001; King 1994; Vaughan et al. 2001; Marshall et al. 2002; Turner et al. 2005; Trenberth et al. 2007). De acordo com Turner et al. $(2002 ; 2005 ; 2007)$, altas tendências anuais de aquecimento foram encontradas nesta região, as quais atingiram valores de até $+0,56{ }^{\circ} \mathrm{C}$ por década no setor oeste da Península, na estação Faraday/Vernadsky. O maior aquecimento observado ocorreu no inverno para a maioria das estações da Península Antártica, chegando a $+1,09{ }^{\circ} \mathrm{C}$ por década na estação Faraday/Vernadsky. Concomitantemente, foi observado um resfriamento no continente Antártico de aprox. $-0,2{ }^{\circ} \mathrm{C}$ por década no Pólo Sul (Thompson e Solomon 2002; Turner et al. 2005; Turner et al. 2007; Chapman e Walsh 2007).

Turner et al. (2006) relataram um aquecimento significativo na média troposfera em décadas recentes utilizando observações de radiossondagem na Península e continente Antártico, mas os resultados em superfície não foram tão evidentes. No entanto, ao longo da Península Antártica, o progressivo derretimento (colapso) de plataformas de gelo tem ocorrido desde o final da década de 1980 (Vaughan 1993), culminando com o colapso da plataforma Larsen-B (no leste da Península Antártica) em 2002 (Trenberth et al. 2007). 
O impacto que essas mudanças podem trazer para o clima global e a razão para o aquecimento observado sobre a Península Antártica não são bem compreendidos. Por essa razão, é crucial que se entenda em profundidade os principais mecanismos que influenciam o clima da Antártica, os quais ocorrem em diversas escalas espaciais e temporais. Estes, por sua vez, estão associados com variações na circulação atmosférica e as mudanças nas concentrações de ozônio estratosférico, que podem produzir flutuações de baixa freqüência na temperatura do ar na Península Antártica (Thompson e Solomon 2002; Turner et al. 2007; Trenberth et al. 2007).

\subsection{Objetivo do trabalho}

Este trabalho tem como objetivo avaliar a natureza e as causas da variabilidade intrasazonal da temperatura do ar, utilizando dados medidos em estações de pesquisas situadas na região da Península Antártica. A variabilidade da temperatura será investigada para cada estação do ano separadamente: inverno (maio-setembro), primavera (agosto-dezembro), verão (novembro-março) e outono (fevereiro-junho). Confirmada a existência da variabilidade intrasazonal na temperatura, serão investigadas a ocorrência de eventos extremos intra-sazonais de temperatura (EIT) e suas propriedades estatísticas (freqüência, persistência e intensidade), com o objetivo de responder as seguintes questões:

1) Existe uma dependência sazonal das propriedades (freqüência, persistência e intensidade) dos EIT?

2) Quanto à variabilidade interanual, há alguma relação com as fases do ENOS?

3) Qual é a característica da circulação atmosférica relacionada com a ocorrência de EIT na Península Antártica?

4) Há alguma relação dos EIT com as fases do modo anular do HS $(A A O)$ ?

5) Pode a interação troposfera-estratosfera desempenhar um papel na modulação dos EIT?

O trabalho foi desenvolvido em quatro etapas principais. No Capítulo 2, é caracterizados o clima da região da Península Antártica, a seleção das estações de pesquisa utilizadas neste estudo e uma discussão sobre a variabilidade da temperatura do ar na região. No Capítulo 3, são apresentados os resultados da variabilidade extrema intra-sazonal da temperatura na Península Antártica, discutindo a variabilidade sazonal e interanual dos 
eventos intra-sazonais quentes (EIQ) e frios (EIF), juntamente com a circulação atmosférica observada durante a ocorrência desses eventos. O papel da interação troposfera-estratosfera na modulação de EIT é apresentado no Capítulo 4. Por fim, as conclusões do trabalho são apresentadas no Capítulo 5. 


\section{Capítulo 2: Variabilidade da temperatura do ar na Península Antártica}

\subsection{Caracterização do clima na Península Antártica}

A península Antártica, posicionada quase-longitudinalmente entre as latitudes $63^{\circ} \mathrm{e}$ $75^{\circ} \mathrm{S}$ (aproximadamente), é uma faixa de terra montanhosa com largura média de $70 \mathrm{~km}$, composta por um platô interno com elevação média de 1500 m (Ferron, 1999) e representa cerca de $3,7 \%$ da área do continente antártico (Figura 2.1). Funciona como uma barreira à circulação atmosférica regional, provocando marcada distinção climática de um lado e de outro.

No lado leste está o mar de Weddell, região climaticamente mais fria devido à drenagem constante do ar frio do interior continental antártico. O ar nos primeiros 500-1000 m é bastante estável em função do resfriamento provocado pela superfície da cobertura de gelo. Acima dele encontra-se uma camada de ar relativamente mais quente (cerca de $5-10{ }^{\circ} \mathrm{C}$ a mais no verão; $10-20{ }^{\circ} \mathrm{C}$ a mais no inverno). Os ventos persistentes de leste na região costeira empurram este ar frio contra a barreira montanhosa da península, que fica ali comprimido devido à forte inversão térmica (Schwerdtfeger 1975, 1984; Schwerdtfeger e Amaturo, 1979). A massa de ar frio não consegue ascender e, portanto deflete para norte/nordeste, paralelo à cordilheira, acompanhando o gradiente de pressão. Estes ventos, chamados ventos de barreira, promovem o transporte de grandes porções da banquisa para nordeste, abrindo canais que logo congelarão novamente (daí a grande produção de gelo marinho no mar de Weddell, um dos únicos setores da Antártica a preservar gelo plurianual). Mais ao norte, próximo à latitude $64^{\circ} \mathrm{S}$, a deriva do gelo sofre desvio para leste, pois não há mais a proteção das montanhas ante os ventos de oeste (Schwerdtfeger, 1975). 


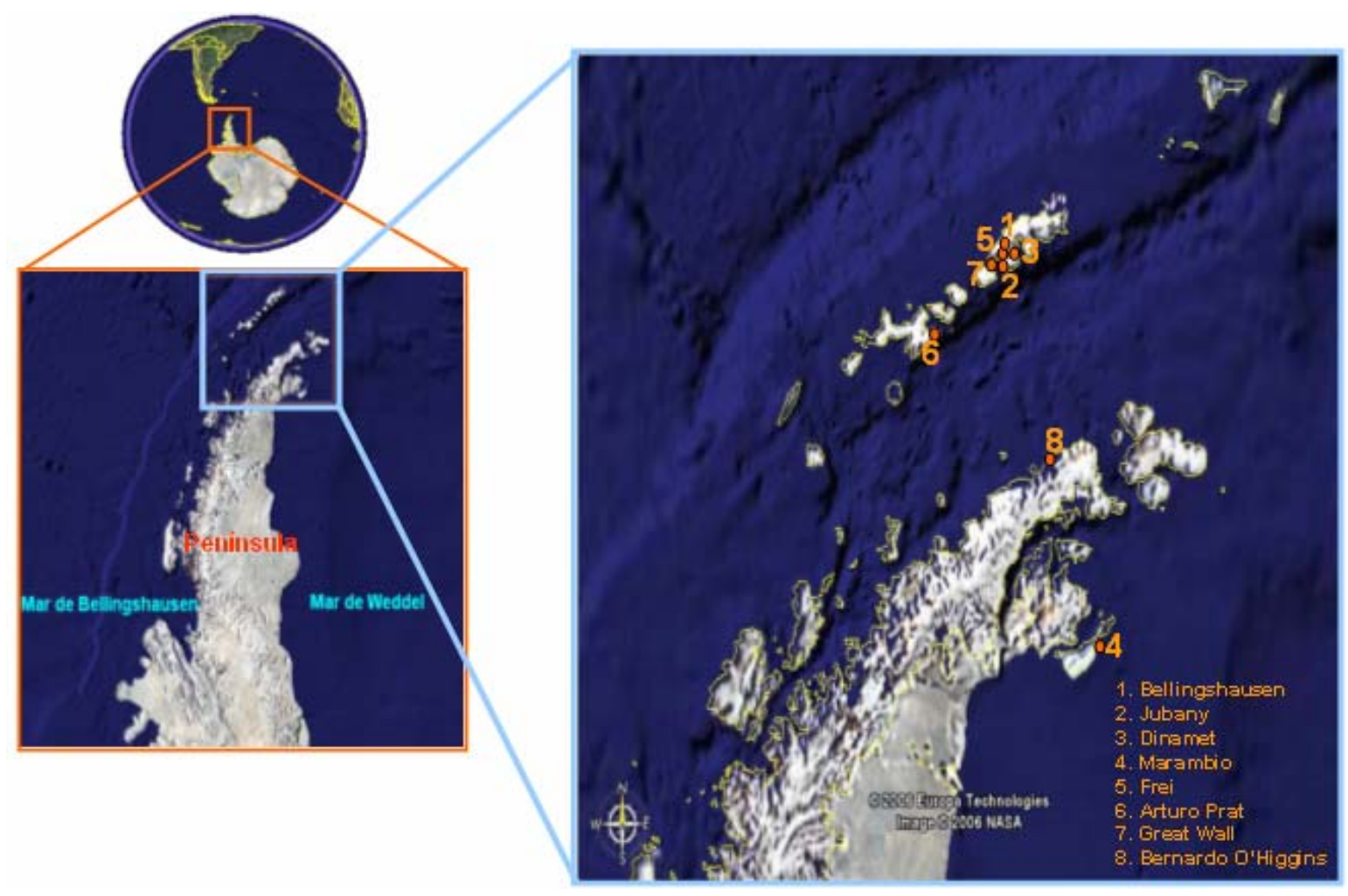

Figura 2. 1. Mapa da Península Antártica localizando as estações de pesquisas utilizadas neste estudo (pontos em laranja). Imagem obtida pelo google earth.

O constante aporte de ar frio do continente e a conseqüente cobertura de gelo no mar de Weddell fazem com que a costa leste da Península Antártica apresente um clima pseudocontinental (Aquino, 1999). O ar frio acumulado contra a montanha força a ascensão do ar mais aquecido que está sobre ele, até que este ultrapasse a altura da barreira montanhosa. A alta pressão que ali se forma faz com que o ar aquecido flua para além da crista e desça a vertente oeste, originando ventos catabáticos do tipo föhn (Figura 2.2) (King e Turner, 1997). Nestas condições, as temperaturas na face leste podem ser até $10^{\circ} \mathrm{C}$ inferiores e a pressão atmosférica $5 \mathrm{mb}$ superiores em relação à face oeste na mesma latitude (Schwerdtfeger, 1984).

Fluxos inerciais de ar frio são comuns no estreito de Bransfield. No extremo norte da Península Antártica, quando termina a barreira montanhosa, o ar transportado nos ventos de barreira depara-se com um novo ambiente onde o gradiente de pressão horizontal não lhe exerce nenhuma oposição, sendo muitas vezes inexistente. A parcela de ar pode então manter a sua identidade por mais algum tempo, sofrendo apenas um ajuste inercial do efeito Coriolis, que força a sua deflexão no sentido anti-horário (Figura 2.3) (Schwerdtfeger, 1984). 


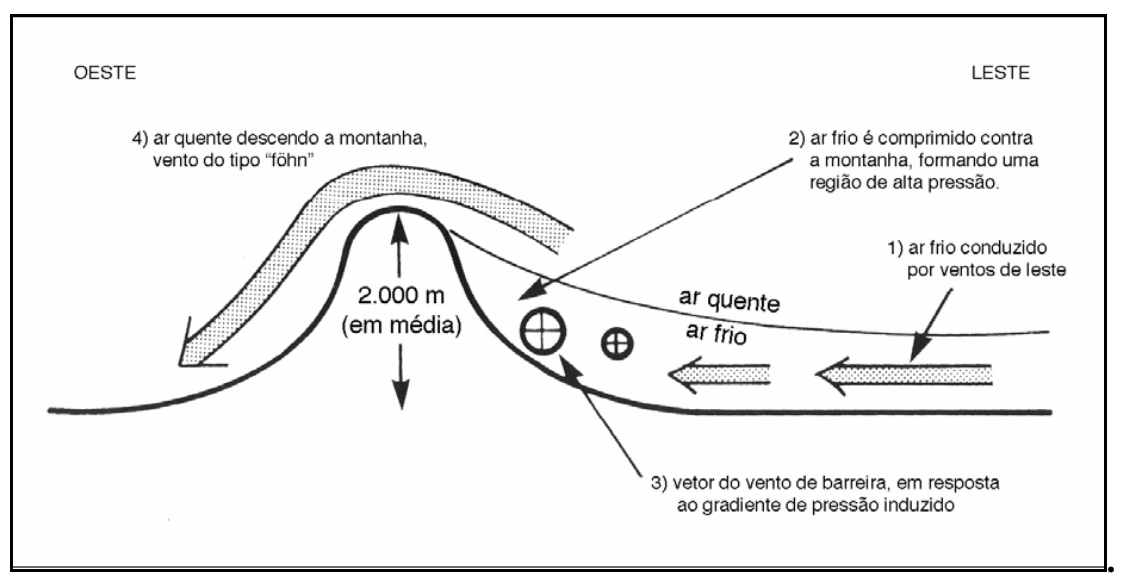

Figura 2. 2. Desenvolvimento dos ventos de barreira (adaptado de King e Turner, 1997, p.282).

$\mathrm{Na}$ costa oeste os ventos são predominantemente de norte e nordeste, sendo a região mais temperada e úmida de toda a Antártica (Ferron et al., 2004), pois tais ventos trazem o ar relativamente quente e úmido do oceano Pacífico para o mar de Bellingshausen.

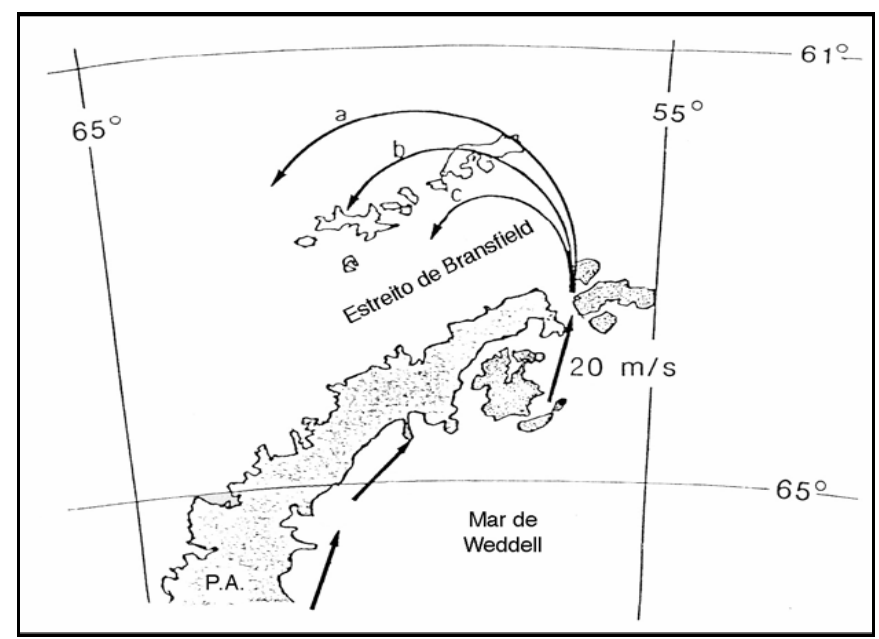

Figura 2. 3. Trajetórias dos fluxos inerciais originários dos ventos de barreira, ao ultrapassar o extremo norte da Península Antártica. Velocidade inicial estimada em $20 \mathrm{~m} \mathrm{~s}^{-1}$. A trajetória a representa o fluxo de ar sem atrito; b e c representam trajetórias com atrito fraco e forte, respectivamente (adaptado de Schwerdtfeger, 1984, p.108).

O estudo de Carrasco et al. (1997) avaliou a atividade de vórtices ciclônicos de mesoescala no entorno da Península Antártica, no ano de 1991. Eles se formam e se desenvolvem sobre o setor sul do mar de Bellingshausen próximos à área costeira ou no limite da extensão do gelo marinho (King e Turner 1997), devido a insurgências de ar frio associadas a ciclones de escala sinótica. Este ar frio migra do interior do continente antártico em direção ao equador, cruzando sobre um ambiente mais quente e úmido que é o setor sudeste do oceano Pacífico. Fluxos de calor sensível e latente do oceano para a camada inferior da atmosfera podem induzir convecção na massa de ar frio, desenvolvendo ou fortalecendo perturbações 
ciclônicas. Acompanhando as correntes oceânicas, estes sistemas avançam para nordeste em direção à passagem de Drake, levando condições de tempo severas ao extremo norte da Península Antártica.

O clima da Península Antártica é influenciado pela variação nas extensões médias de gelo marinho nos mares de Weddell e Bellingshausen (Figura 1.4). O gelo, por sua vez, tem sua formação influenciada diretamente pela ação dos ventos dominantes na região, ventos estes que têm padrões de circulação impostos pela presença da Península (Setzer e Hungria, 1994). Se no lado leste a advecção de sul/sudoeste (ventos de barreira - ar frio) contribui para a contínua formação de gelo marinho, no lado oeste vem ocorrendo justamente o contrário. Um incremento na advecção de norte/noroeste, trazendo ar mais aquecido durante o inverno, está sendo interpretado como um dos possíveis agentes responsáveis pela retração do gelo marinho no leste do mar de Bellingshausen (Schwerdtfeger, 1976; Jacobs e Comiso, 1993, 1997; King e Harangozo, 1998; Smith e Stammerjohn, 2001). Todos estes trabalhos afirmam que a extensão do gelo marinho a oeste da península Antártica possui forte correlação negativa com a temperatura do ar (i.e., extensão do gelo marinho aumenta enquanto a temperatura do ar diminui, e vice-versa), todavia os processos estariam acoplados e não se sabe qual agente seja indutor do outro. King (1994) atribui maior variabilidade interanual e tendência de aumento na temperatura média do ar para os meses de inverno, o que implica numa diminuição da amplitude térmica anual. Seu estudo reporta também uma tendência de retardo das anomalias de gelo marinho com relação a anomalias de temperatura do ar, o que sugere uma dependência da primeira variável com relação a segunda e não o contrário. Smith e Stammerjohn (2001) atestam que o gradiente norte-sul ao longo da Península, tanto do gelo marinho quanto da temperatura, é resultado de um balanço entre influências climáticas marítimas (norte) e continentais (sul). Uma maior variabilidade nos meses de inverno seria conseqüência disto, pois ela é atribuída à alta variabilidade interanual da cobertura de gelo marinho e o correspondente aumento na influência continental quando esta cobertura existe. Quando ela não existe (i.e., no verão), predomina a influência marítima e, portanto a variabilidade da temperatura é menor.

\subsection{Descrição dos dados e das estações meteorológicas utilizadas}

Os dados de temperatura do ar da península Antártica foram obtidos no Centro Nacional de Dados de Neve e Gelo (National Snow and Ice Data Center - NSIDC) da 
Universidade do Colorado. As estações de pesquisa foram selecionadas em função da melhor cobertura temporal de dados, totalizando oito estações de pesquisa situadas na península Antártica (Figura 2.1; Tabela 2.1). Os dados estão disponibilizados na escala horária, em geral, a cada 3 horas. Posteriormente, estes dados foram analisados, excluindo valores espúrios, e convertidos em médias diárias de temperatura do ar para cada estação. O período de dados é heterogêneo entre as estações; no entanto, foi escolhido o período entre 19862002, que compreende o período em comum entre as estações da península Antártica (Tabela 2.1). Das oito estações selecionadas, seis estão localizadas no arquipélago das Shetland do Sul: a estação chilena Arturo Prat, localizada na Ilha Greenwich (Figura 2.1); e cinco estações localizadas na Ilha Rei George (Bellingshausen, Jubany, Dinamet, Presidente Frei e Great Wall) (Figura 2.4). A estação uruguaia Dinamet fica nas proximidades da estação Artigas (Figura 2.4). A estação chilena Bernardo O’Higgins está localizada na península Trinity, costa oeste do extremo norte da península Antártica. Também na península Trinity, mas no setor leste da península Antártica, localiza-se na Ilha Seymour a estação argentina Marambio (Figura 2.1).

Tabela 2. 1. Estações utilizadas neste estudo com suas respectivas elevações, latitude, longitude, período de dados disponíveis e porcentagem de dados faltantes no período 1986-2002.

\begin{tabular}{cccccccc}
\hline $\begin{array}{c}\mathbf{N}^{\circ} \text { da } \\
\text { estação } \\
(\mathbf{O} . \mathbf{M} \mathbf{M})\end{array}$ & $\begin{array}{c}\text { Nome da } \\
\text { estação }\end{array}$ & $\begin{array}{c}\text { País } \\
\text { responsável }\end{array}$ & $\begin{array}{c}\text { Altitude } \\
\mathbf{( m )}\end{array}$ & Latitude & Longitude & $\begin{array}{c}\text { Período de } \\
\text { dados } \\
\text { (anos) }\end{array}$ & $\begin{array}{c}\text { Dados Faltantes } \\
\text { (\%) entre 1986- } \\
\text { 2002 }\end{array}$ \\
\hline 89050 & Bellingshausen & Rússia & 16 & $62^{\circ} 12^{\prime} \mathrm{S}$ & $58^{\circ} 56^{\prime} \mathrm{W}$ & $1973-2002$ & 5,3 \\
89053 & Jubany & Argentina & 11 & $62^{\circ} 14^{\prime} \mathrm{S}$ & $58^{\circ} 38^{\prime} \mathrm{W}$ & $1985-2002$ & 3,0 \\
89054 & Dinamet & Uruguai & 10 & $62^{\circ} 10^{\prime} \mathrm{S}$ & $58^{\circ} 50^{\prime} \mathrm{W}$ & $1986-2002$ & 3,4 \\
89055 & Marambio & Argentina & 198 & $64^{\circ} 14^{\prime} \mathrm{S}$ & $56^{\circ} 43^{\prime} \mathrm{W}$ & $1973-2002$ & 2,8 \\
89056 & Pres. Frei & Chile & 10 & $62^{\circ} 25^{\prime} \mathrm{S}$ & $58^{\circ} 53^{\prime} \mathrm{W}$ & $1985-2002$ & 2,0 \\
89057 & Arturo Prat & Chile & 5 & $62^{\circ} 30^{\prime} \mathrm{S}$ & $59^{\circ} 41^{\prime} \mathrm{W}$ & $1986-2002$ & 1,9 \\
89058 & Great Wall & China & 10 & $62^{\circ} 13^{\prime} \mathrm{S}$ & $58^{\circ} 58^{\prime} \mathrm{W}$ & $1986-2002$ & 3,7 \\
89059 & O'Higgins & Chile & 10 & $63^{\circ} 19^{\prime} \mathrm{S}$ & $57^{\circ} 54^{\prime} \mathrm{W}$ & $1985-2002$ & 2,0 \\
\hline
\end{tabular}




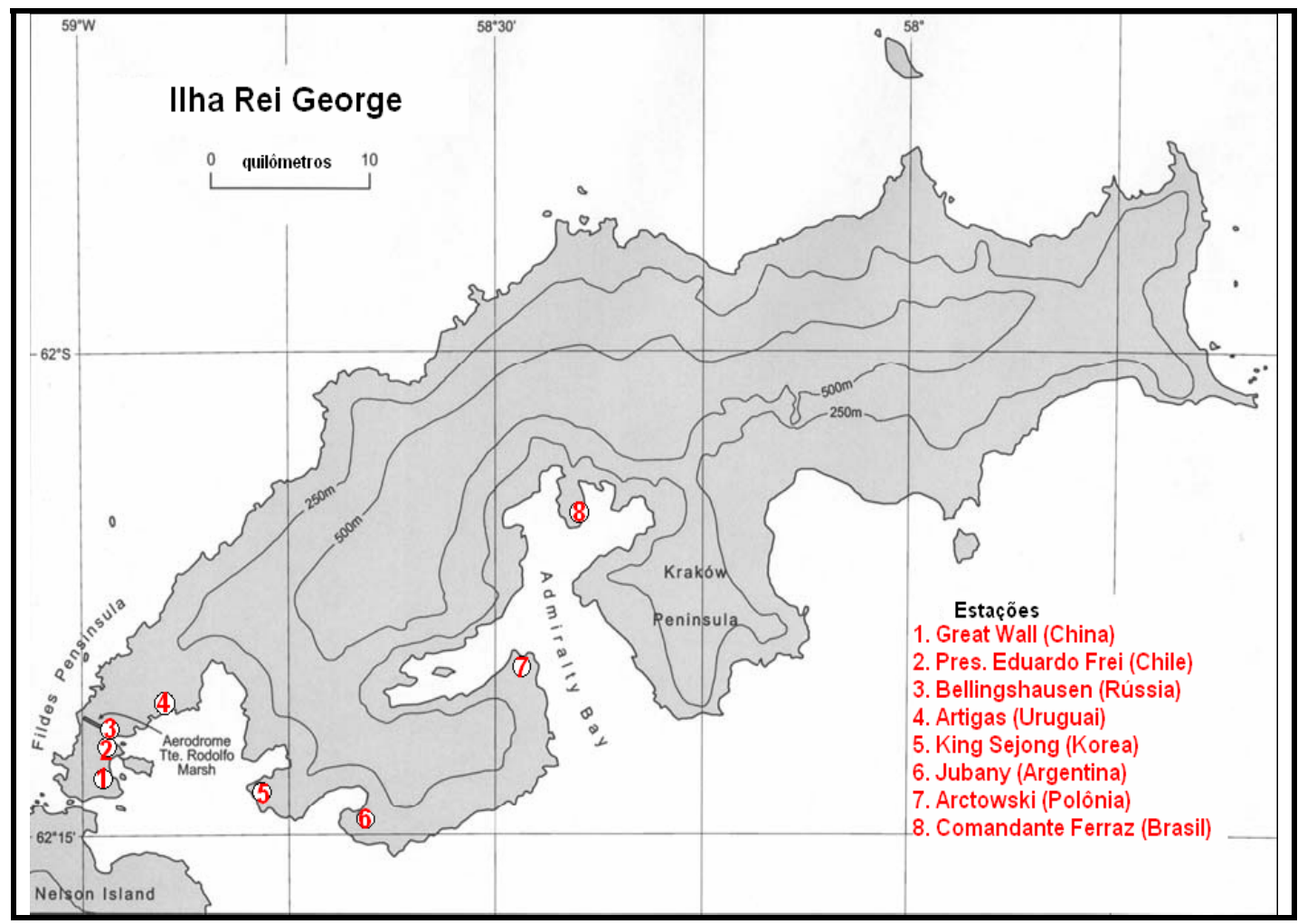

Figura 2. 4. Mapa da Ilha Rei George, localizando algumas estações utilizadas neste estudo (adaptada de Turner e Pendlebury 2004).

Através da análise de agrupamentos (cluster analysis), é possível obter informações de quais estações possuem comportamentos semelhantes, visto que algumas estão localizadas em regiões climáticas diferentes (como descrito anteriormente). A análise de agrupamentos baseia-se nas distâncias euclidianas (DE), calculadas a cada par de conjuntos de dados (x,y), verificando o nível de similaridade entre eles (equação 2.1). Portanto, quanto menor o valor de DE, maior a semelhança entre dois conjuntos de dados.

$$
D E(x, y)=\left[\sum_{i=1}^{n}(x i-y i)^{2}\right]^{1 / 2}
$$

Uma representação gráfica da análise de agrupamento é dada pelo dendrograma (gráfico em forma de árvore). Na escala vertical está indicado o nível de similaridade entre as temperaturas diárias das estações da península Antártica (Figura 2.5), obtido pelo cálculo de DE. No eixo horizontal estão marcadas as estações, onde as linhas verticais partindo das estações têm altura correspondente ao nível em que as estações são consideradas semelhantes. É importante ressaltar que não há um critério comparativo para afirmar se a semelhança é 
muita ou pouca. O conhecimento do processo e a familiaridade com as grandezas envolvidas é que irão contribuir para uma boa análise (Bassab et al. 1990). Observando a Figura 2.5, notase que a série temporal de Marambio tem um comportamento diferenciado em relação às séries das demais estações. As estações mais similares em termos de temperatura são as localizadas no arquipélago das Shetland Sul. Em ordem decrescente de semelhanças: 1) Great Wall e Bellingshausen; 2) Pres. Frei e Jubany; 3) Dinamet, Pres. Frei e Jubany; 4) Dinamet, Pres. Frei, Jubany, Great Wall e Bellingshausen; 5) Arturo, Dinamet, Pres. Frei, Jubany, Great Wall e Bellingshausen. A estação Bernardo O'Higgins apresenta o comportamento da temperatura um pouco diferenciado em relação às temperaturas das estações localizadas nas Ilhas Shetland Sul; porém, não tanto quanto o comportamento da estação Marambio. Em suma, a análise de cluster identificou duas principais regiões homogêneas em função da temperatura do ar: uma contendo as estações localizadas no setor oeste da península Antártica, representada pelas estações das Ilhas Shetland Sul; e a outra localizada no leste da península Antártica, representada pela estação Marambio.

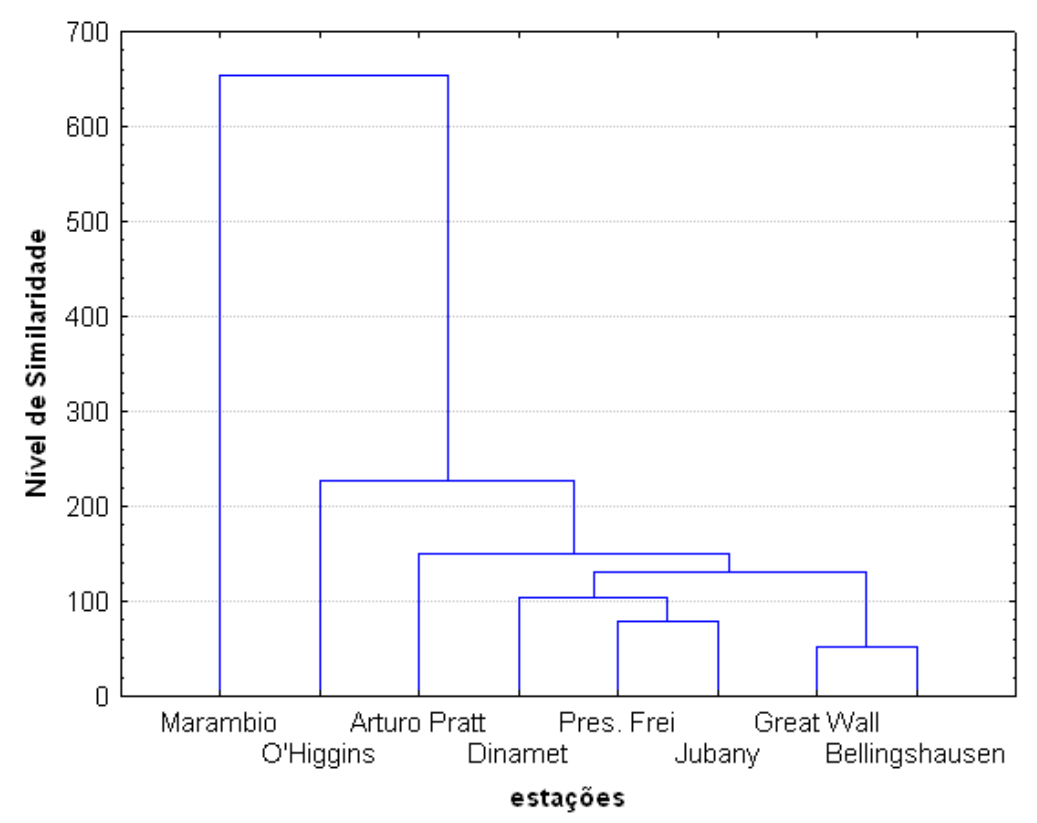

Figura 2. 5. Dendrograma gerado a partir das distâncias euclidianas (DE) das séries diárias da temperatura do ar entre as estações da Península Antártica.

Para selecionar a estação representativa do setor oeste da península, foi calculado o coeficiente linear de correlação de Pearson entre as séries temporais das estações (equação 2.2). 


$$
r=\frac{\sum_{i=1}^{n}\left(x_{i}-\bar{x}\right)\left(y_{i}-\bar{y}\right)}{\sqrt{\sum_{i=1}^{n}\left(x_{i}-\bar{x}\right)^{2} \sqrt{\sum_{i=1}^{n}\left(y_{i}-\bar{y}\right)^{2}}}}
$$

onde xi, yi representam dois conjuntos de dados e $\bar{x}, \bar{y}$ as médias de cada conjunto de dados, respectivamente.

O comportamento diferenciado da série temporal de Marambio apresentado pela análise de agrupamentos, é confirmado pelos valores mais baixos do coeficiente de correlação desta estação com as demais (Tabela 2.2). A estação de Bellingshausen mostrou maior correlação entre as estações da península oeste (Tabela 2.2); entretanto ela apresentou maior quantidade de dados faltantes, cerca de 5\% (Tabela 2.1). Por isso, alternativamente, optou-se pela estação Arturo Prat como representativa da península oeste, por ter menor quantidade de dados faltantes $(1,9 \%$, Tabela 2.1) e boa correlação (acima de 0,9) com as estações localizadas na Ilha Rei George (Tabela 2.2).

Tabela 2. 2. Análise do coeficiente linear de correlação de Pearson entre as séries temporais das estações da Península Antártica.

\begin{tabular}{|c|c|c|c|c|c|c|c|c|}
\hline & Belling & Jubany & Dinamet & Marambio & Frei & Arturo & Great & O'Higgins \\
\hline Belling & & 0,93 & 0,92 & 0,78 & 0,95 & 0,90 & 0,99 & 0,93 \\
\hline Jubany & & & 0,96 & 0,81 & 0,98 & 0,92 & 0,94 & 0,89 \\
\hline Dinamet & & & & 0,77 & 0,96 & 0,92 & 0,92 & 0,87 \\
\hline Marambio & & & & & 0,79 & 0,78 & 0,80 & 0,86 \\
\hline Frei & & & & & & 0,92 & 0,95 & 0,90 \\
\hline Arturo & & & & & & & 0,90 & 0,86 \\
\hline Great & & & & & & & & 0,93 \\
\hline O'Higgins & & & & & & & & \\
\hline
\end{tabular}

Estas análises também serviram para o preenchimento de falhas nos dados, utilizando os dados das estações que apresentaram melhor similaridade e alta correlação com a estação Arturo. Os procedimentos para preencher as falhas nos dados foram: (i) interpolação linear: na ausência de apenas um dado (um dia), foi realizada a interpolação do valor correspondente ao dia anterior e posterior; (ii) regressão linear: na ausência de dados por dois ou mais dias, utilizou-se a equação da reta de regressão entre duas estações para o preenchimento, sendo estas bem correlacionadas; (iii) climatologia: utilizou-se o ciclo anual quando nenhum dos 
métodos anteriores foi satisfeito. Na estação Marambio, somente as condições (i) e (iii) foram utilizadas no preenchimento de falhas, devido a pouca similaridade e baixa correlação com as demais estações (Figura 2.4 e Tabela 2.2). É importante ressaltar ainda, que ao utilizar a climatologia no preenchimento de falhas, qualquer sinal de alta ou baixa freqüência perde a continuidade.

\subsection{Variações da temperatura do ar na Península Antártica}

A estação Marambio destaca-se pela menor temperatura média anual $\left(-8,2{ }^{\circ} \mathrm{C}\right)$ e maior desvio padrão interanual $\left(8,2{ }^{\circ} \mathrm{C}\right)$, enquanto que Arturo apresenta $-1,7^{\circ} \mathrm{C}$ de média anual e menor variabilidade, com desvio padrão de $3,6^{\circ} \mathrm{C}$ (Tabela 2.3).

Tabela 2. 3. Média, desvio padrão e tendência da temperatura média anual nas estações Arturo e Marambio. Valor em negrito: significativo ao nível de $95 \%$.

\begin{tabular}{cccc}
\hline & Média $\left({ }^{\circ} \mathrm{C}\right)$ & Desvio padrão $\left({ }^{\circ} \mathrm{C}\right)$ & Tendência ( $\left.{ }^{\circ} \mathrm{C} / \mathrm{ano}\right)$ \\
\hline Marambio & $-8,2$ & 8,2 & $\mathbf{+ 0 , 1 2}$ \\
Arturo Prat & $-1,7$ & 3,6 & $+0,04$ \\
\hline
\end{tabular}

A Figura 2.6 mostra a variabilidade sazonal da temperatura média diária nas duas estações selecionadas. Ambas exibem valores mínimos em junho-julho e máximos entre dezembro-janeiro, mas a estação Marambio apresenta um ciclo mais pronunciado na curva de medianas do que a estação Arturo, sendo as amplitudes anuais de aprox. $15^{\circ} \mathrm{C}$ e $3,5^{\circ} \mathrm{C}$, respectivamente. Observa-se que as distribuições de freqüência de temperatura em Arturo são assimétricas, com um pronunciado alongamento para as temperaturas frias principalmente nos meses de outono até a primavera (Fig. 2.6a). Por outro lado, Marambio apresenta uma maior simetria mesmo durante o inverno (Figura 2.6b). Uma discussão mais detalhada sobre a variabilidade dos quartis de temperatura nas estações Arturo e Marambio será abordada no item 2.4. 
(a) Arturo

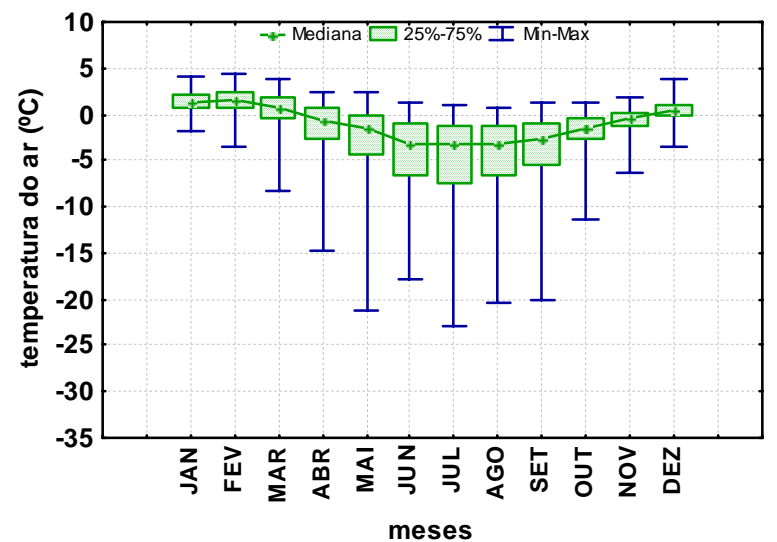

(b) Marambio

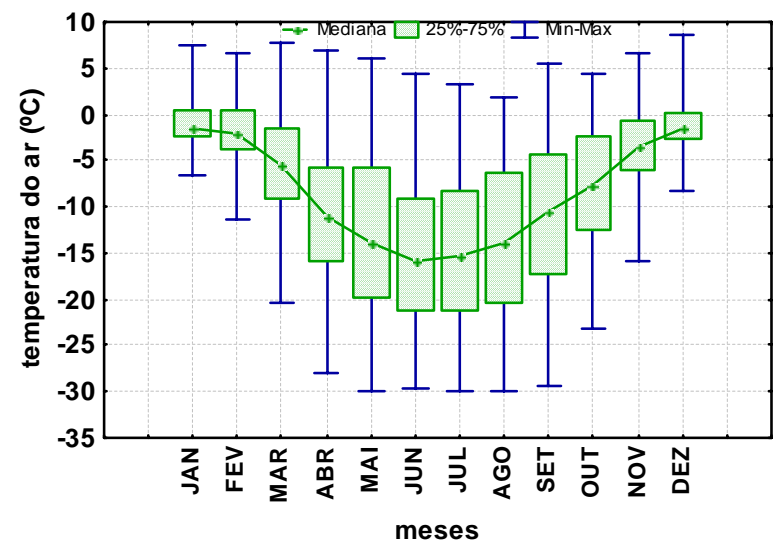

Figura 2. 6. Distribuição de freqüência da temperatura média diária em cada mês para: (a) Arturo e (b) Marambio. A caixa (box) em verde representa o intervalo inter-quartílico (25\%-75\%) e os pontos conectados dentro do box, a mediana. A barra em azul representa os valores mínimos e máximos.

O vento predominante na estação Marambio é de sudoeste (Figura 2.7b), devido ao ar frio que escoa do interior do continente antártico seguindo a configuração topográfica da Península Antártica. Adicionalmente, a cobertura de gelo predomina na maior parte do ano (Figura 1.4) sobre o mar de Weddell, caracterizando um clima "pseudo-continental" nesta região (Aquino, 1999). Na costa oeste, onde se localiza a estação Arturo os ventos são predominantemente de leste e sudoeste (Figura 2.7a). Esta região é influenciada, além dos ventos catabáticos (Figura 1.2b), pela passagem freqüente de sistemas ciclônicos que tem origem na porção sul do mar de Bellingshausen e que acompanham as correntes oceânicas avançando para nordeste, advectando ar relativamente quente e úmido do Oceano Pacífico. Estas características de cada estação explicam as diferenças entre as magnitudes das temperaturas médias (Tabela 2.3). Adicionalmente, a estação Arturo é 193 metros mais baixa que a estação Marambio (Tabela 2.1) e a presença de gelo marinho dura no máximo dois meses (Smith et al. 1996), predominando a influência marítima, o que explica a menor amplitude anual da temperatura (Figura 2.6a). 
(a) Arturo

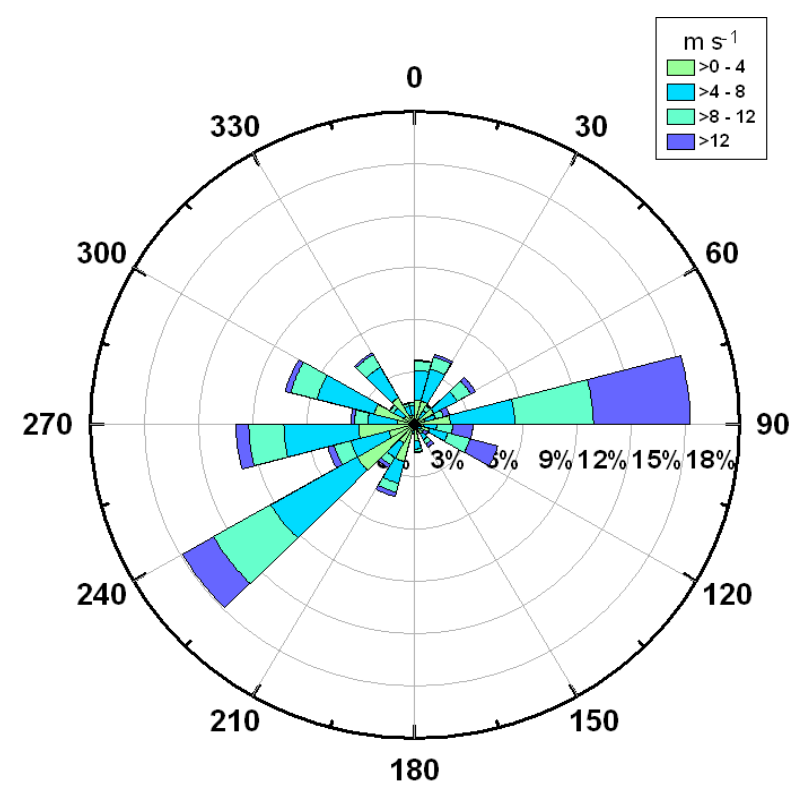

(b) Marambio

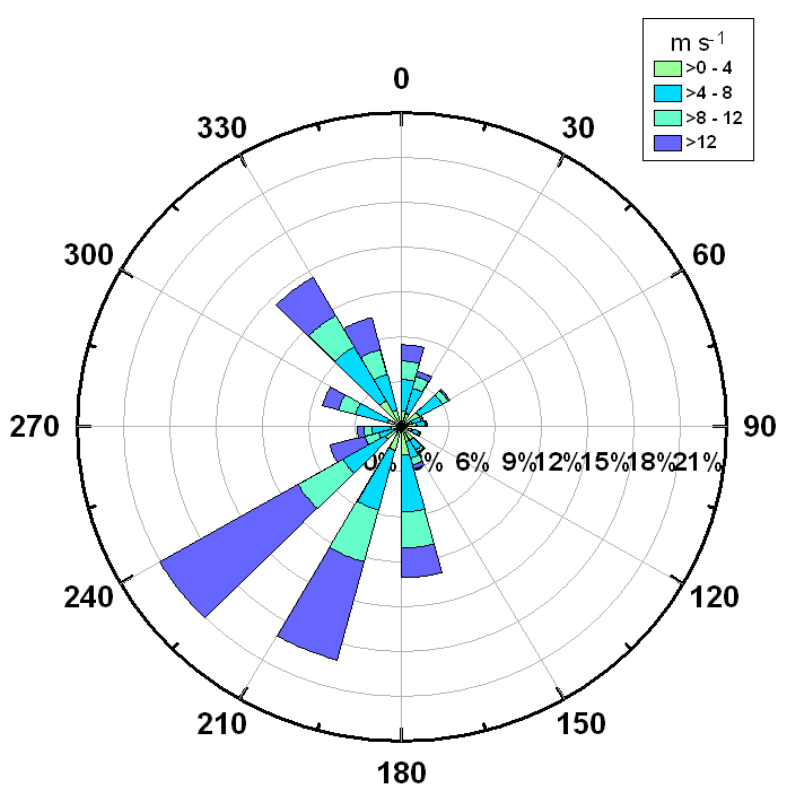

Figura 2. 7. Anemograma climatológico para as estações (a) Arturo e (b) Marambio. Os dados de vento foram obtidos no NSIDC.

Com respeito às tendências (Figura 2.8 e Tabela 2.3), as estações mostraram um aumento na temperatura ao longo dos anos, assim como observado em estudos prévios para algumas estações da Península Antártica (p.ex. Turner et al. 2005; 2007). A estação Arturo apresentou menor tendência na temperatura $\left(+0,68{ }^{\circ} \mathrm{C}\right.$ em 17 anos), enquanto Marambio apresentou maior aquecimento ao longo dos anos (aproximadamente $+2{ }^{\circ} \mathrm{C} \mathrm{em} 17$ anos, com significância estatística de 95\%). Isto também pode ser observado na análise sazonal das tendências na temperatura média anual para as estações Arturo e Marambio (Tabela 2.4.). Nesta análise é possível verificar que as estações apresentaram aquecimento durante todas as estações do ano, sendo que as maiores tendências na temperatura são observadas no verão (dezembro-fevereiro) e outono (março-maio) em ambas as estações. Neste período, as tendências de $+0,024$ no verão e $+0,118{ }^{\circ} \mathrm{C}_{\text {ano }}{ }^{-1}$ no outono foram observadas em Arturo, enquanto que as tendências na temperatura em Marambio foram de $+0,09 \mathrm{e}+0,3{ }^{\circ} \mathrm{C}$ ano ${ }^{-1}$, respectivamente. Estes valores são estatisticamente significativos ao nível de $90 \%$, baseados no teste-t. Valores de $+0,068 \mathrm{e}+0,038{ }^{\circ} \mathrm{C}$ ano ${ }^{-1}$ são observados em Marambio no inverno e na primavera, respectivamente. Em Arturo, valores ainda menores são observados nesta época: $+0,005^{\circ} \mathrm{C}_{\text {ano }}{ }^{-1}$ no inverno e $+0,006^{\circ} \mathrm{C}_{\text {ano }}{ }^{-1}$ na primavera. Porém, essas tendências não são significativas. Estes resultados divergem de alguns estudos prévios que observaram um maior aquecimento durante o inverno em algumas estações da Península Antártica (p.ex. Turner et al. 2005; 2007). No entanto, estes trabalhos avaliaram tendências em séries mais 
longas de temperatura (nos últimos 50 anos), o que pode explicar as tendências diferentes, dependendo do período de dados que está sendo computada a regressão linear.

A variação dos valores médios anuais de temperatura para Marambio e da extensão de gelo marinho para o Mar de Weddell mostrou que nos últimos 10 anos (Figura 2.9), há uma tendência de aumento da temperatura $\left(+1,9{ }^{\circ} \mathrm{C}\right.$ por década) e concorrente tendência de redução na extensão de gelo marinho $\left(-3,5 \times 10^{5} \mathrm{Km}^{2}\right.$ por década), ambas significativas ao nível de 99\% (baseadas no teste-t). As duas variáveis mostraram uma alta correlação negativa $(\mathrm{r}=-0,86)$, indicando a presença de um forte mecanismo de feedback entre a temperatura do ar e o gelo marinho no lado leste da Península Antártica. Para o setor oeste da Península Antártica (não mostrado), não foi encontrada significância estatística entre as tendências da temperatura do ar em Arturo e a extensão do gelo marinho na região do mar de Bellingshausen.

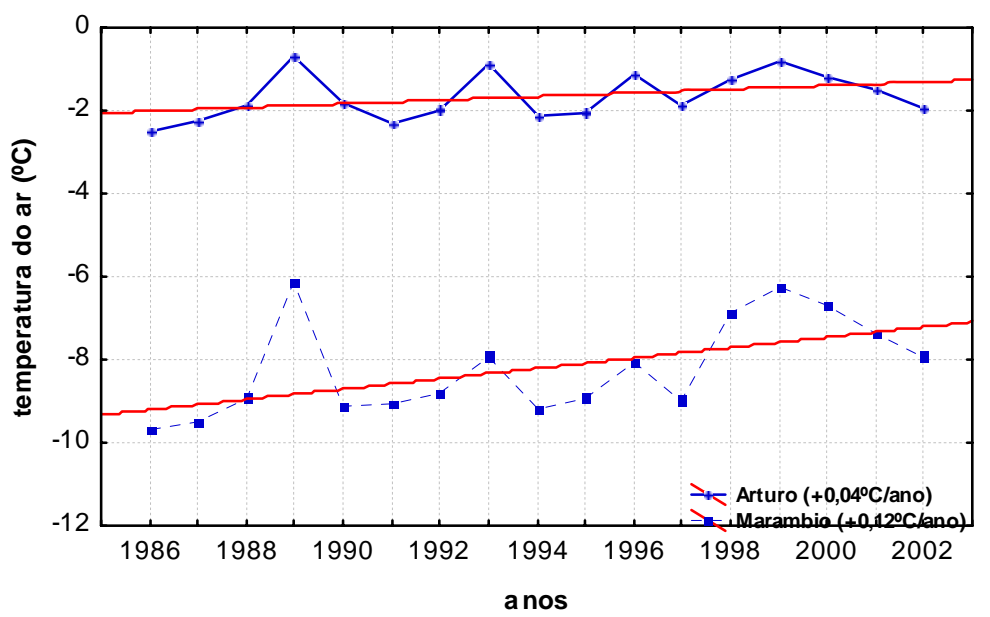

Figura 2. 8. Temperaturas médias anuais para Arturo (linha sólida) e Marambio (linha tracejada) e suas respectivas tendências em ${ }^{\circ} \mathrm{C} / \mathrm{ano}$, obtidas por regressão linear das séries de dados.

Tabela 2. 4. Análise sazonal da tendência na temperatura média anual nas estações Arturo e Marambio. Valores em negrito: significativos ao nível de $90 \%$.

\begin{tabular}{ccccc}
\hline Tendência ('Clano) & Inverno (JJA) & Primavera (SON) & Verão (DJF) & Outono (MAM) \\
\hline Arturo & $+0,005$ & $+0,006$ & $\mathbf{+ 0 , 0 2 4}$ & $\mathbf{+ 0 , 1 1 8}$ \\
Marambio & $+0,068$ & $+0,038$ & $+\mathbf{0 , 0 9 0}$ & $\mathbf{+ 0 , 3 0 0}$ \\
\hline
\end{tabular}




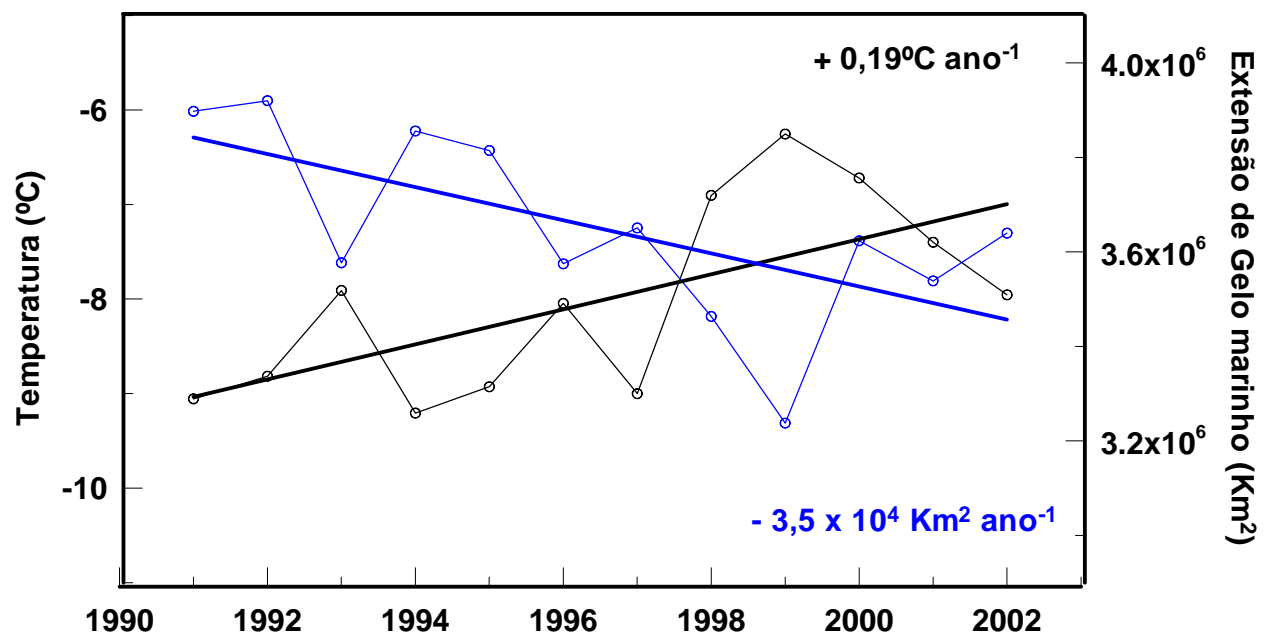

Figura 2. 9. Variação da temperatura média anual em ${ }^{\circ} \mathrm{C}$ da estação Marambio (linha preta) e da extensão média anual do gelo marinho em $\mathrm{Km}^{2}$ na região do mar de Weddell (linha azul), no período de 1991 a 2002. Também são mostrados os valores das tendências de cada variável, que em ambos os casos foram significativos ao nível de $99 \%$. Os dados de gelo marinho foram obtidos no NSIDC.

\subsection{Extremos de temperatura na Península Antártica}

Os extremos foram definidos utilizando como critério o quartil inferior (q25) e superior (q75) da distribuição da temperatura do ar para Arturo e Marambio. Abaixo do quartil inferior são considerados os extremos frios e acima do quartil superior, os extremos quentes. Os limiares q25 e q75 foram obtidos para cada estação do ano separadamente: inverno (junho, julho, agosto), primavera (setembro, outubro, novembro), verão (dezembro, janeiro, fevereiro) e outono (março, abril, maio). Na tabela 2.5 são apresentados os valores dos limiares para cada estação do ano. Os extremos frios são mais intensos no inverno (abaixo de $-21,0{ }^{\circ} \mathrm{C}$ ), seguido pelo outono (abaixo de $-15,4{ }^{\circ} \mathrm{C}$ ), primavera (abaixo de $-11,6{ }^{\circ} \mathrm{C}$ ) e verão (abaixo de $-2,8^{\circ} \mathrm{C}$ ) na estação Marambio; enquanto que em Arturo os valores mais baixos de temperatura são observados no inverno (abaixo de $-6,7^{\circ} \mathrm{C}$ ), seguido pela primavera (abaixo de $-3,1{ }^{\circ} \mathrm{C}$ ), outono (abaixo de $-2,3{ }^{\circ} \mathrm{C}$ ) e verão (abaixo de $0,3{ }^{\circ} \mathrm{C}$ ). Esta situação é observada nos extremos quentes, onde Arturo apresenta valores maiores de temperatura no verão (acima de $1,9^{\circ} \mathrm{C}$ ) e outono (acima de $0,9^{\circ} \mathrm{C}$ ), enquanto que Marambio os extremos quentes são mais intensos no verão (acima de $0,3{ }^{\circ} \mathrm{C}$ ) e primavera (acima de $-2,0{ }^{\circ} \mathrm{C}$ ). Em suma, Arturo e Marambio apresentam algumas diferenças na intensidade dos extremos nas estações de transição: Arturo mais frio na primavera do que no outono, enquanto em Marambio ocorre o contrário. Uma explicação para tal acontecimento é dada pela influência do gelo marinho nos mares ao redor das estações Arturo e Marambio. Entre agosto-setembro 
(aproximadamente) observa-se a presença do gelo marinho no Mar de Bellingshausen (Smith et al. 1996), enquanto que o Mar de Weddell concentra gelo marinho quase todo ano (Figura 1.4), fazendo com que as temperaturas em Marambio sejam mais baixas e o clima caracterizado como pseudocontinental (Aquino 1999). Em Arturo, o regime climático marítimo predomina na maior parte do ano, fazendo com que as temperaturas sejam mais elevadas, exceto no inverno-primavera onde a presença do gelo marinho na região, faz com que as temperaturas apresentem valores mais baixos e maior variabilidade do que as demais estações do ano (Figura 2.6.).

Tabela 2. 5. Análise sazonal dos extremos frios (q25) e quentes (q75) nas estações Arturo e Marambio.

\begin{tabular}{cccccccccc} 
& \multicolumn{4}{c}{ Arturo } & \multicolumn{4}{c}{ Marambio } \\
\cline { 2 - 9 } & Inverno & Primavera & Verão & Outono & Inverno & Primavera & Verão & Outono \\
\hline $\mathrm{q} 25\left({ }^{\circ} \mathrm{C}\right)$ & $-6,7$ & $-3,1$ & 0,3 & $-2,3$ & $-21,0$ & $-11,6$ & $-2,8$ & $-15,4$ \\
$\mathrm{q} 75\left({ }^{\circ} \mathrm{C}\right)$ & $-1,1$ & $-0,2$ & 1,9 & 0,9 & $-7,9$ & $-2,0$ & 0,3 & $-3,7$ \\
\hline
\end{tabular}

\subsection{Análise espectral da temperatura na Península Antártica}

Para detectar a influência sistemática de fenômenos atmosféricos em determinadas bandas de freqüência nas séries diárias de temperatura foi estimada a densidade espectral média para cada estação do ano nas estações Arturo e Marambio. Primeiramente, a tendência linear e o ciclo anual das médias diárias de temperatura foram removidos, obtendo-se assim uma série de anomalias. A seguir, aplicou-se uma função taper do tipo split-cosine-bell (w(t), eq. 2.3) em uma porção p igual a $10 \%$ das extremidades das séries ( $5 \%$ em cada extremidade) para evitar descontinuidades no final das mesmas (Bloomfield, 1976). Uma descontinuidade na série poderia acrescentar um co-seno que na realidade não existe.

$$
\begin{cases}w(t)=0,5\{1-\cos [\pi(t-0,5) / m]\} & 1 \leq t \leq m \\ w(t)=1 & m+1 \leq t \leq N-m \\ w(t)=0,5\{1-\cos [\pi(N-t+0,5) / m]\} & N-m+1 \leq t \leq N\end{cases}
$$

onde $\mathrm{m}$ é calculado tal que $\mathrm{p}=2 \mathrm{~m} / \mathrm{N}$. Neste caso, $\mathrm{p}=10 \%, \mathrm{~N}=$ tamanho da série (92 dias no inverno, 91 na primavera, 90 no verão e 92 dias no verão) e, portanto, m 5.

Uma ilustração da função taper aplicada para o período de inverno (como exemplo) é dada na Figura 2.10, onde se observa os pesos tendendo a zero do quinto ao primeiro dia, 
assim como nos cinco últimos dias. A demonstração da aplicação da função taper splitcosine-bell nas anomalias de temperatura no inverno de 1986 na estação Arturo Prat (como exemplo), é mostrada na Figura 2.11.

Após a aplicação do taper, completou-se a série com zeros até a potência de base dois mais próxima. Este procedimento reduz o tempo computacional para o cálculo da transformada de Fourier, onde, posteriormente, foram obtidas as estimativas "brutas" das amplitudes espectrais $C^{2}{ }_{k}(\mathrm{k}=1, \mathrm{n} / 2)$. A obtenção das transformadas de Fourier discretas consiste do cálculo dos coeficientes $A_{k}$ e $B_{k}$ através das equações (2.4) e (2.5), respectivamente. Isso é feito para as $\mathrm{n} / 2$ funções harmônicas, sendo $n$ o tamanho da série. Através desses coeficientes obtém-se a amplitude $C_{k}$ (eq. 2.6).

A mais alta ou a maior freqüência relativa à resolução dos dados é correspondente a uma oscilação da função co-seno executando um ciclo inteiro em apenas dois intervalos de dados igualmente espaçados no tempo, equivalente a chamada freqüência de Nyquist. Por outro lado, a mais baixa ou menor freqüência é dada por $\mathrm{n} / 2$ ciclos sobre o comprimento inteiro dos dados.

$$
\begin{gathered}
A_{k}=\frac{2}{n} \sum_{t=1}^{n} y_{t} \cos \left[\frac{2 \pi k t}{n}\right] \\
B_{k}=\frac{2}{n} \sum_{t=1}^{n} y_{t} \operatorname{sen}\left[\frac{2 \pi k t}{n}\right] \\
C_{k}=\sqrt{A_{k}^{2}+B_{k}^{2}}
\end{gathered}
$$

O método de simples cálculo das transformadas de Fourier discretas é computacionalmente ineficiente e muitos dos cálculos de $A_{k}$ e $B_{k}$ são redundantes de maneira que estes problemas podem ser evitados com a transformada rápida de Fourier (Fast Fourier Transform - FFT). Para tanto, a FFT é usualmente descrita em termos de notação exponencial complexa de Euler:

$$
e^{i w t}=\cos (w t)+i \operatorname{sen}(w t)
$$

onde $i$ é um número imaginário $\left(i^{2}=-1\right)$ e $\mathrm{w}=2 \pi \mathrm{k} / \mathrm{n}$, a freqüência angular. Desta forma, as exponenciais complexas são utilizadas como uma conveniência notacional que tornam algumas manipulações menos trabalhosas. 
Posteriormente, as estimativas espectrais (periodogramas) foram suavizadas, com a finalidade de eliminar ruídos nos espectros, utilizando-se o método da média móvel de comprimento $L$, com peso igual para cada ponto (janela Daniell). Outras janelas espectrais podem ser utilizadas para este fim (Tukey, Parzen, Hamming), mas a janela Daniell (média móvel) é um dos métodos mais comuns. Este procedimento resulta na chamada densidade espectral. Portanto, para cada ano foi obtida uma densidade espectral (totalizando 17 densidades espectrais) e em seguida calculou-se a média das densidades espectrais, semelhante à metodologia utilizada por Jones et al. (1998). Fazendo a média das densidades espectrais, boa parte do ruído é eliminado e assim, optou-se por um valor pequeno de $\mathrm{L}(\mathrm{L}=3)$.

A seguir, estimou-se o número de graus de liberdade $v$ (eq. 2.8), considerando-se $\mathrm{p}=10 \%$ do taper. Se $\mathrm{p}$ for um valor diferente deste, a equação 2.8 deve ser recalculada (Madden e Julian, 1971).

$$
v \cong 2 \cdot L \cdot 0,873 \cdot N S
$$

onde, neste caso, L=3 é o tamanho da média móvel e NS =17 (16), correspondente ao número de espectros utilizados para o cálculo do espectro médio, ou seja, o total de invernos, outonos e primaveras (verões).

Por fim, é necessário detectar o espectro de fundo e determinar se o espectro calculado difere do espectro de fundo por uma quantia estatisticamente significativa. O espectro de fundo é um espectro teórico que pode ser considerado como ruído branco, quando todas as freqüências (ou bandas de freqüência) têm a mesma importância, ou seja, um processo físico livre de persistência; ou caso contrário será um ruído vermelho. Matematicamente, o espectro de fundo pode ser determinado através da análise de auto-correlação $(R)$ com lag (defasada no tempo) (eq. 2.9). Em geral, se a auto-correlação de lag 1 ( $\left.\mathrm{R}_{1}\right)$ não difere de zero, o espectro de fundo é dado por um ruído branco. Em contrapartida, se $\mathrm{R}_{1}$ difere de zero e as auto-correlações seguintes seguem uma aproximação exponencial: $\mathrm{R}_{2} \cong R_{1}^{2}$, $\mathrm{R}_{3} \cong R_{1}^{3}$ e etc, então o espectro de fundo é denominado de ruído vermelho (eq. 2.10).

$$
r_{m}=\frac{\sum_{t=1}^{n-p}\left(x_{t}-\bar{x}\right)\left(x_{t=p}-\bar{x}\right)}{\sum_{t=1}^{n}\left(x_{t}-\bar{x}\right)^{2}}
$$




$$
\theta(k)=\bar{S}\left[\frac{1-R_{1}^{2}}{1+R_{1}^{2}-2 R_{1} \cos (k \pi / N F)}\right]
$$

onde $\bar{S}$ é a média das amplitudes espectrais e NF é o número de freqüências

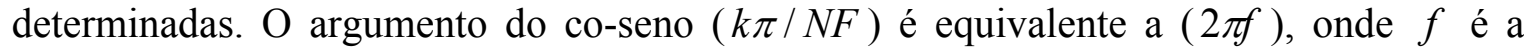
freqüência. Neste caso, o espectro $\theta(k)$ passa a ser $\theta(f)$.

Após, determinou-se se as amplitudes espectrais calculadas $\mathrm{C}^{2}(\mathrm{k})$ diferem das amplitudes do espectro de fundo $\theta(\mathrm{k})$ por uma quantia estatisticamente significativa $\alpha$, seguindo uma distribuição qui-quadrado $\left(\chi^{2}\right)$ :

$$
\mu_{\alpha}=\frac{\chi_{\alpha}^{2} \theta(k)}{v}
$$

onde $\alpha$ é o nível de significância desejado. Neste trabalho, utilizou-se $\alpha=5 \%$ e $\alpha=10 \%$ e, assim obteve-se a curva de significância estatística $\mu$, onde somente os picos espectrais acima desta curva devem ser interpretados.

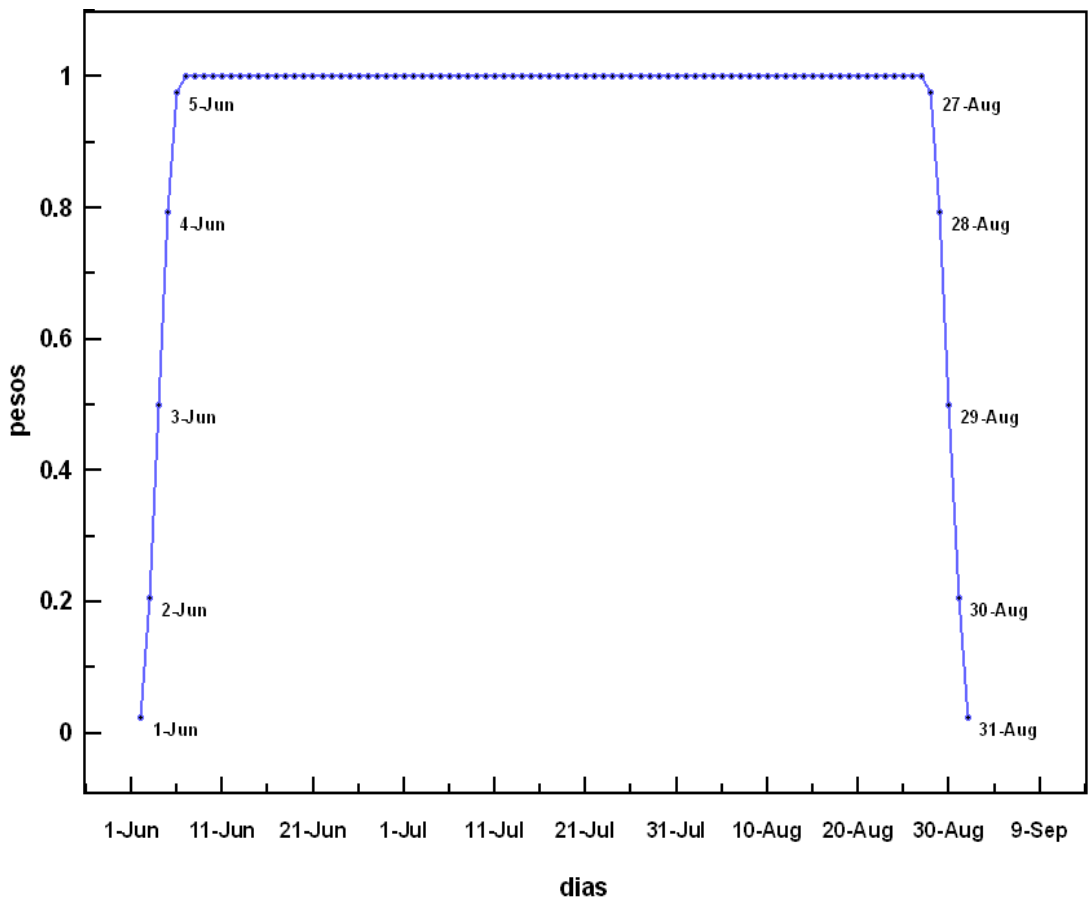

Figura 2. 10. Função taper - split-cosine-bell aplicada em $10 \%$ nas extremidades das séries de temperatura para evitar descontinuidades no final das mesmas (como exemplo, o trimestre de inverno - JJA). 


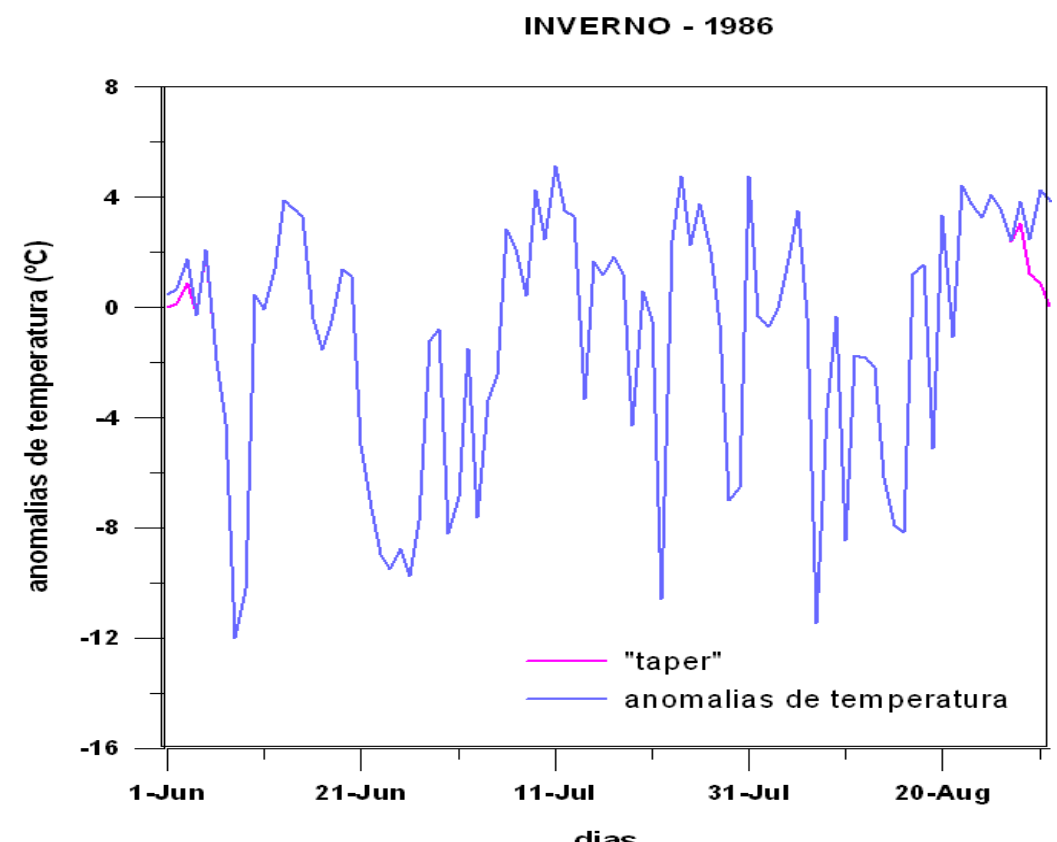

Figura 2. 11. Demonstração da aplicação dos pesos da função "taper" nas anomalias de temperatura (como exemplo, o inverno de 1986 da estação Arturo).

A densidade espectral média da temperatura do ar, calculada para os períodos de inverno, primavera, verão e outono (1986-2002), mostra um pico significativo em torno de 42,67 dias na estação Arturo durante o inverno e primavera (Figuras 2.12a e 2.12b). Observase ainda, um pico significativo (ao nível de 90\%) em torno de 21,33 dias durante o verão (Figura 2.12c) e outros dois picos em alta freqüência, aproximadamente 8 dias no inverno (Figura 2.12a) e 5 dias no outono (Figura 2.12d) na estação Arturo. A estação Marambio apresenta picos espectrais significativos somente em alta freqüência (escala sinótica): um pico entre 8-10 dias durante o inverno, primavera e outono (Figuras 2.13a, 2.13b e 2.13d, respectivamente), outro entre 12-14 dias no inverno (Figura 2.13a) e um pico em torno de 4 dias no outono (Figura 2.13d). Destaca-se ainda na estação Marambio, um pico espectral em torno de 42,67 dias no inverno e primavera (Figuras 2.13a e 2.13b) e outro em aproximadamente 21,33 dias no verão (Figura 2.13c), embora ambos não sejam estatisticamente significativos.

Apesar da estação Marambio (Península leste) não tenha apresentado significância estatística nos picos espectrais na escala intra-sazonal (Figura 2.13), esta escala parece ser de grande importância na variabilidade da temperatura do ar na região da Península Antártica, devido aos maiores valores de densidade espectral observados nesta escala de variabilidade nas estações Arturo e Marambio, principalmente no inverno, primavera e verão (Figuras 2.12 e 2.13). 
Assim, dada a importância dos picos entre 20-50 dias no espectro de temperatura das estações da Península, particularmente para as estações a oeste da mesma, o foco deste estudo será a investigação dos mecanismos atmosféricos relacionados com a variabilidade intrasazonal da temperatura em Arturo e Marambio no período de inverno, primavera e verão. Estes resultados serão discutidos no Capítulo 3.

\section{Arturo}

(a)

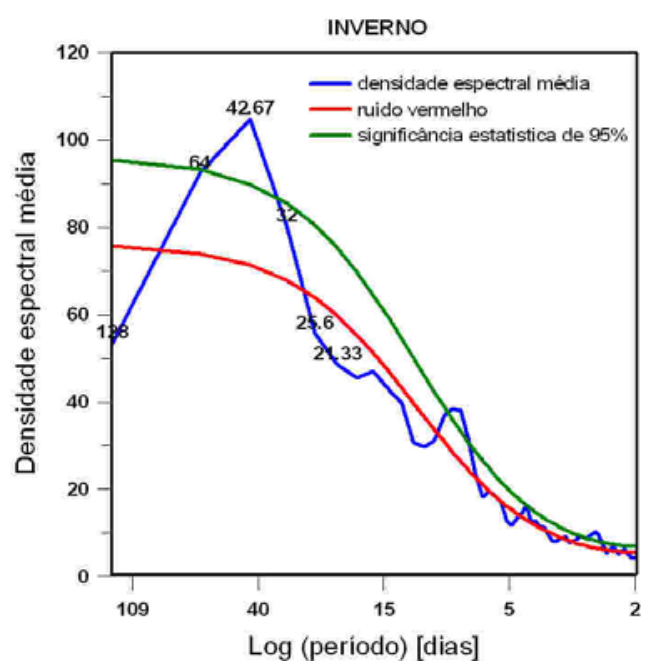

(c)

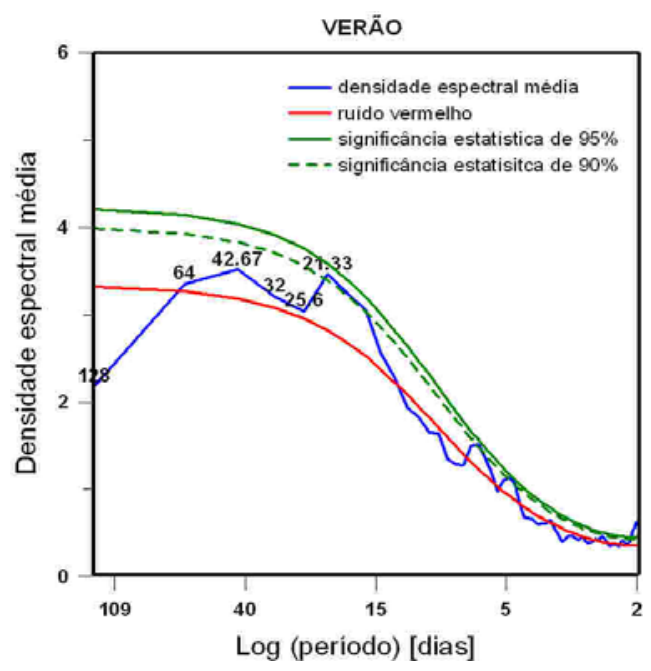

(b)

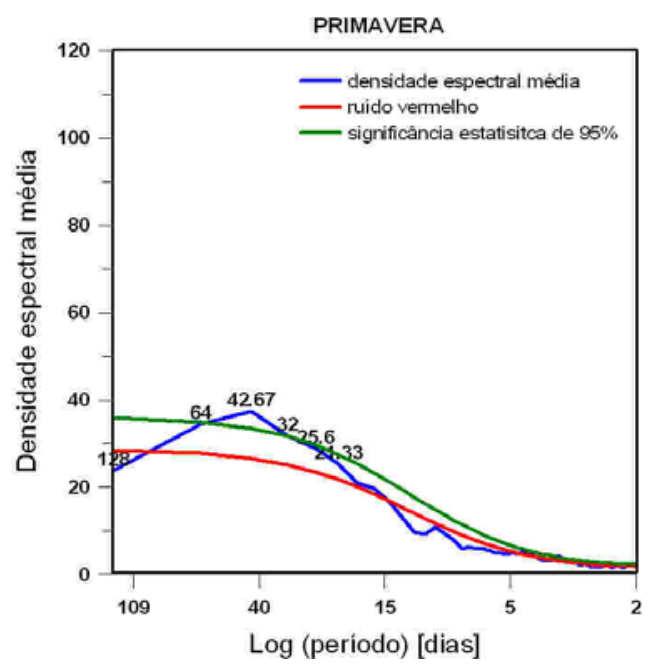

(d)

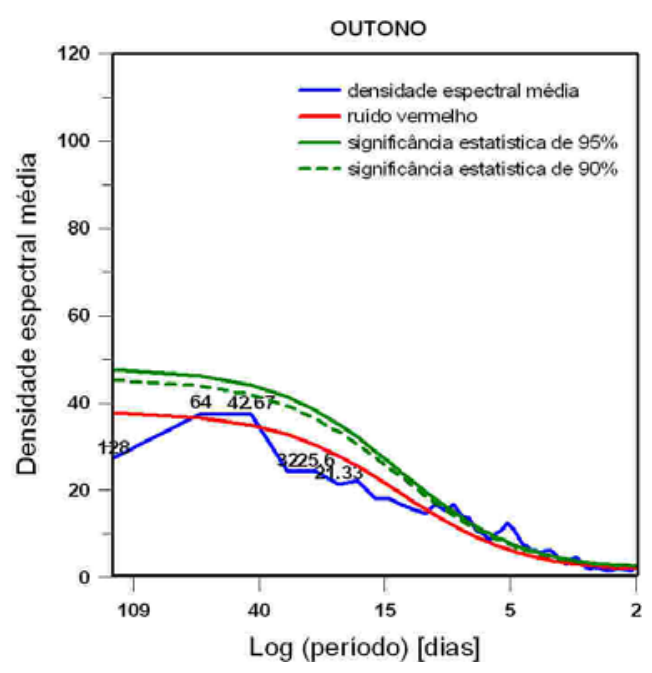

Figura 2. 12. Densidade espectral média (linha azul) da temperatura do ar, calculada para a estação Arturo durante: (a) inverno, (b) primavera, (c) verão e (d) outono. As linhas vermelhas e verdes (verdes tracejadas) correspondem ao ruído vermelho e o nível de significância de $95 \%$ (90\%), respectivamente. 


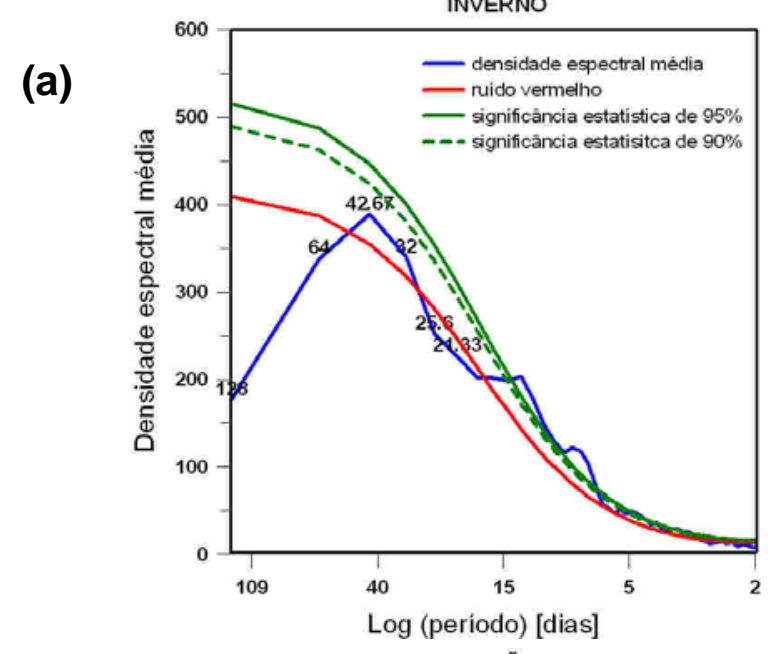

\section{Marambio}

(c)

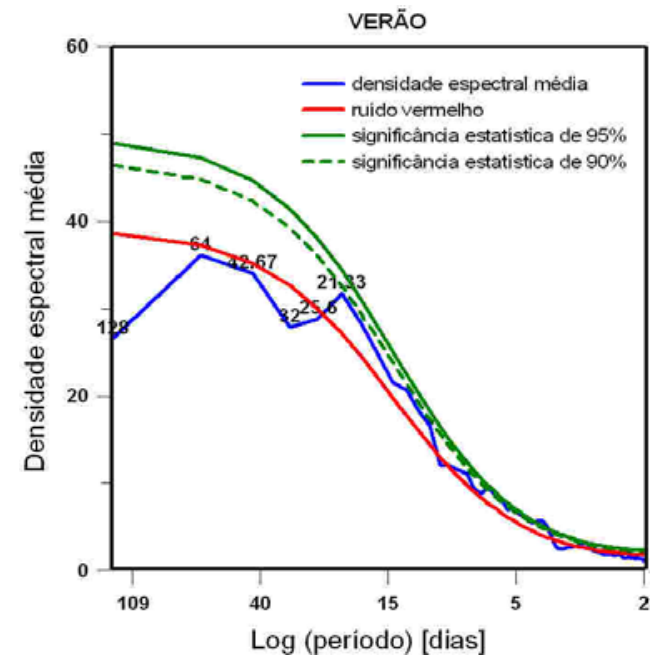

(b)
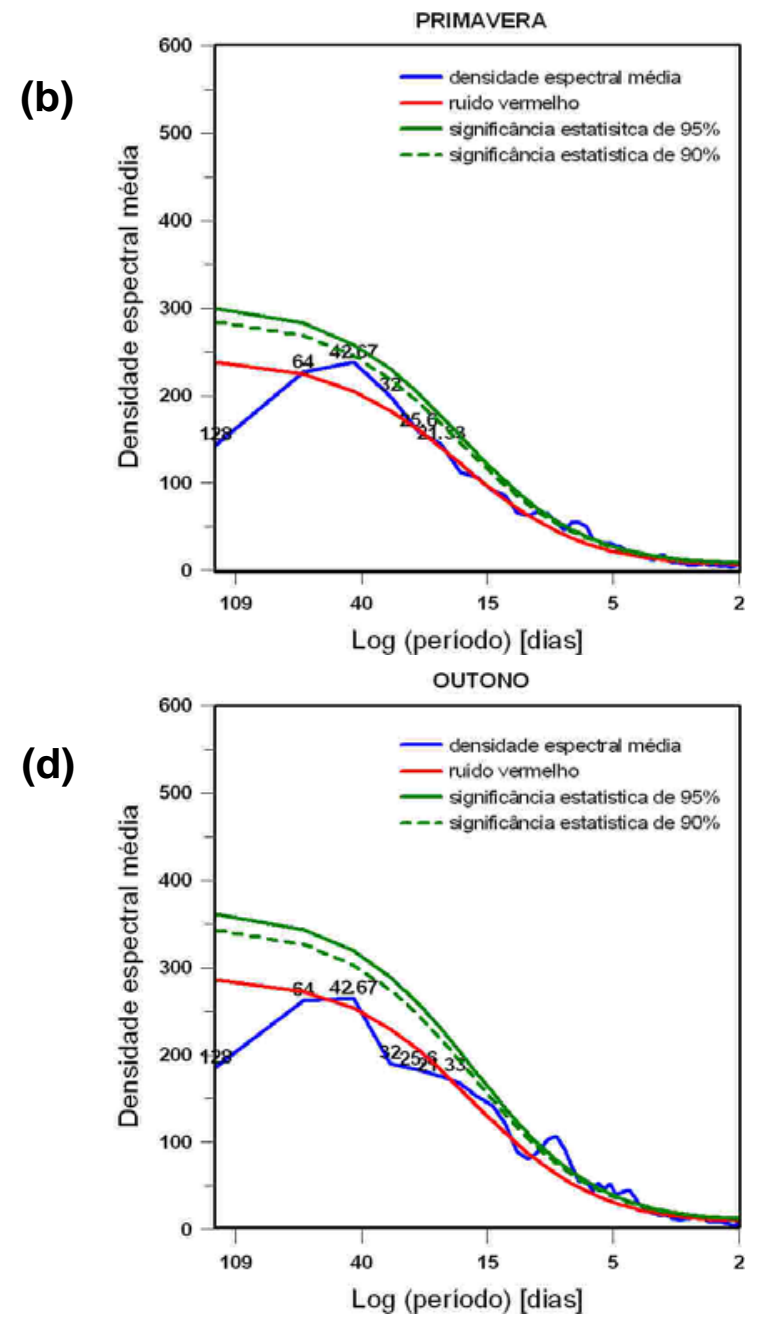

Figura 2. 13. Idem a Fig. 2.12, mas para a estação Marambio. 


\section{Capítulo 3: Extremos intra-sazonais de temperatura na Península Antártica}

Neste capítulo serão apresentados os resultados referentes à variabilidade intra-sazonal de temperatura nas estações da Península Antártica, Arturo e Marambio, a fim de investigar a ocorrência de eventos extremos intra-sazonais de temperatura (EIT) e suas propriedades estatísticas (freqüência, persistência e intensidade) no período de inverno, primavera e verão. Adicionalmente, uma avaliação da variabilidade interanual é abordada, buscando a relação entre ENOS e EIT. Posteriormente é apresentado uma caracterização da circulação atmosférica associada aos EIT e o controle do modo anular do HS sobre estes eventos.

\subsection{Filtragem dos dados}

Para investigar a variabilidade intra-sazonal de temperatura, as séries temporais de Arturo e Marambio foram filtradas utilizando a transformada rápida de Fourier (FFT). O objetivo do filtro em uma série de dados é melhor observar um intervalo de freqüências, através da atribuição de pesos que permitem uma resposta da banda de interesse. No caso da FFT, a separação da banda é dada por uma função retangular a qual atribui valor igual a um para as freqüências a que se deseja separar e zero para as demais. Primeiramente, a tendência linear e o ciclo anual dos dados de temperatura de cada estação foram removidos, obtendo-se uma série diária de anomalias $X(t)$, denominada aqui como anomalias totais. Assim, calculouse a $F F T$ em $X(t)$ (eq. 3.1) e a seguir determinou-se a função retangular na série transformada $H(f)$, ambas no domínio da freqüência. Para tanto, determinou-se a convolução (eq. 3.2) entre a resposta de freqüência $R(\omega)$ (eq. 3.3) e $H(f)$, de tal forma que $R(\omega)$ é construída a fim de reter as freqüências desejadas. No presente caso, o filtro construído foi um "passa-banda". As freqüências de interesse, neste caso, correspondem à escala intra-sazonal (20-100 dias). Desta forma, obteve-se uma nova função $H^{\prime}(f)$, cujas amplitudes correspondem às freqüências de 
interesse. Por fim, para retornar ao domínio do tempo, calculou-se a inversa da $F F T$ em $H^{\prime}(f)$ (eq. 3.4). Uma discussão mais detalhada sobre estes procedimentos pode ser encontrada em Chatfield (1996).

$$
\begin{gathered}
H(f)=\int_{-\infty}^{\infty} X(t) \exp (2 \pi i f t) d t \\
G^{*} X=\int_{-\infty}^{\infty} g(\tau) X(t-\tau) d \tau \\
R\left(\omega_{k}\right)=\frac{C^{\prime}\left(\omega_{k}\right)}{C\left(\omega_{k}\right)}
\end{gathered}
$$

onde $C^{\prime}\left(\omega_{k}\right)$ e $C\left(\omega_{k}\right)$ são as amplitudes das séries temporais filtradas e não filtradas, respectivamente, ambas em função da freqüência $\omega_{k}$.

$$
X(t)=\int_{-\infty}^{\infty} H^{\prime}(f) \exp (-2 \pi i f t) d f
$$

Os dados de temperatura filtrados na escala intra-sazonal (20-100 dias), são aqui chamados de anomalias intra-sazonais de temperatura. Na Figura 3.1 são apresentadas as séries das anomalias totais e intra-sazonais da temperatura nas estações de Arturo e Marambio. Nas duas estações observa-se claramente que a amplitude de variação entre as séries é diferente. O desvio padrão das anomalias intra-sazonais é 50\% do desvio padrão das anomalias totais $\left(3{ }^{\circ} \mathrm{C}\right.$ em Arturo e $6{ }^{\circ} \mathrm{C}$ em Marambio). Destaca-se também uma assimetria nas anomalias totais em Arturo, com uma distribuição alongada para os valores mais baixos de temperatura (Figura 3.1a) enquanto que na estação Marambio, a distribuição é mais simétrica, tanto nas anomalias totais quanto nas anomalias intra-sazonais (Figura 3.1b). Comparando-se as séries das anomalias intra-sazonais de temperatura em Arturo e Marambio (Fig. 3.2), observa-se uma boa correlação entre as duas séries $\left(r^{2}=0,56\right.$ e $\left.r=0,8\right)$. 


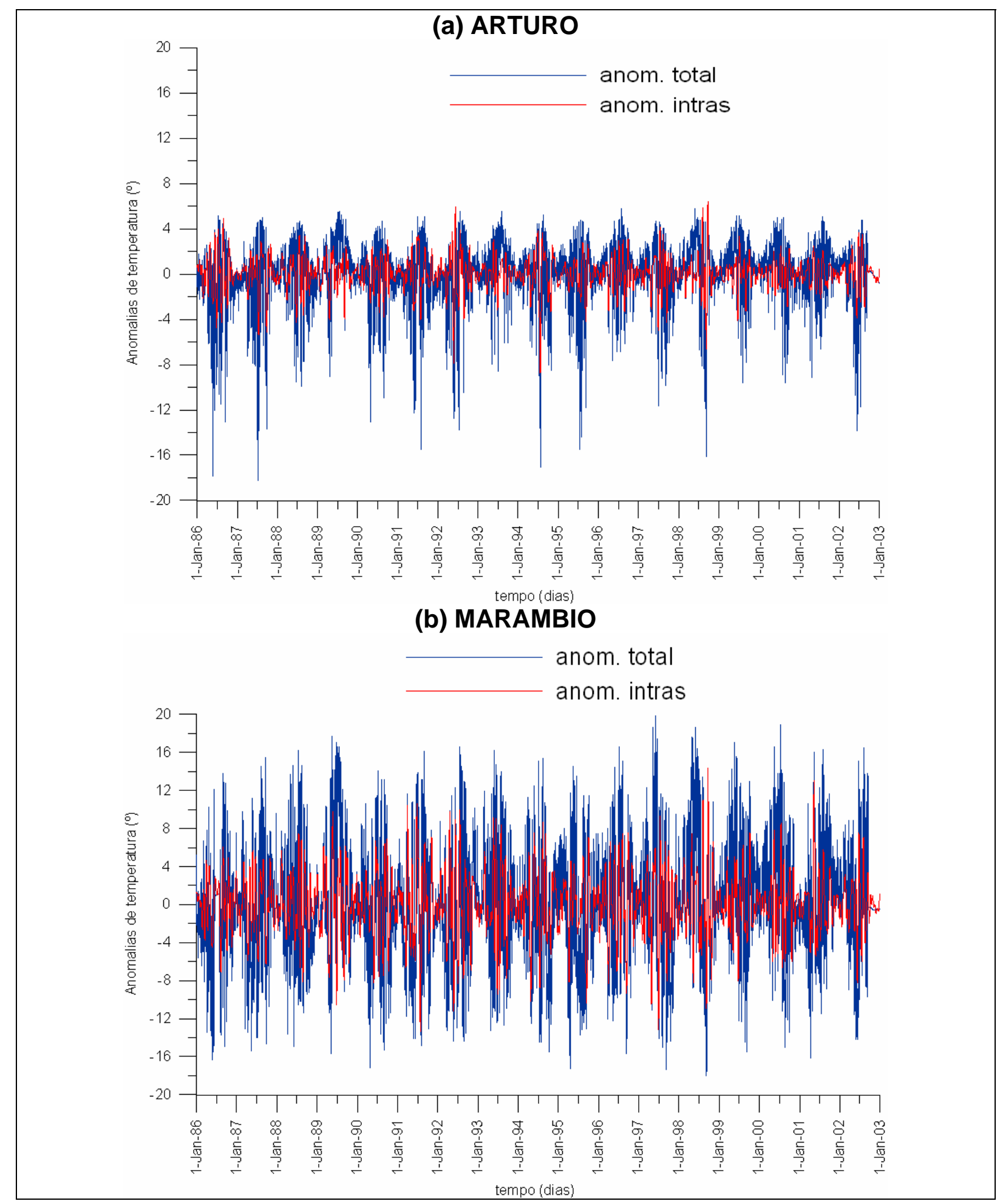

Figura 3. 1. Comparação entre as séries das anomalias intra-sazonais (vermelho) e totais (azul) de temperatura das estações Arturo (a) e Marambio (b) no período de 1986-2002. 


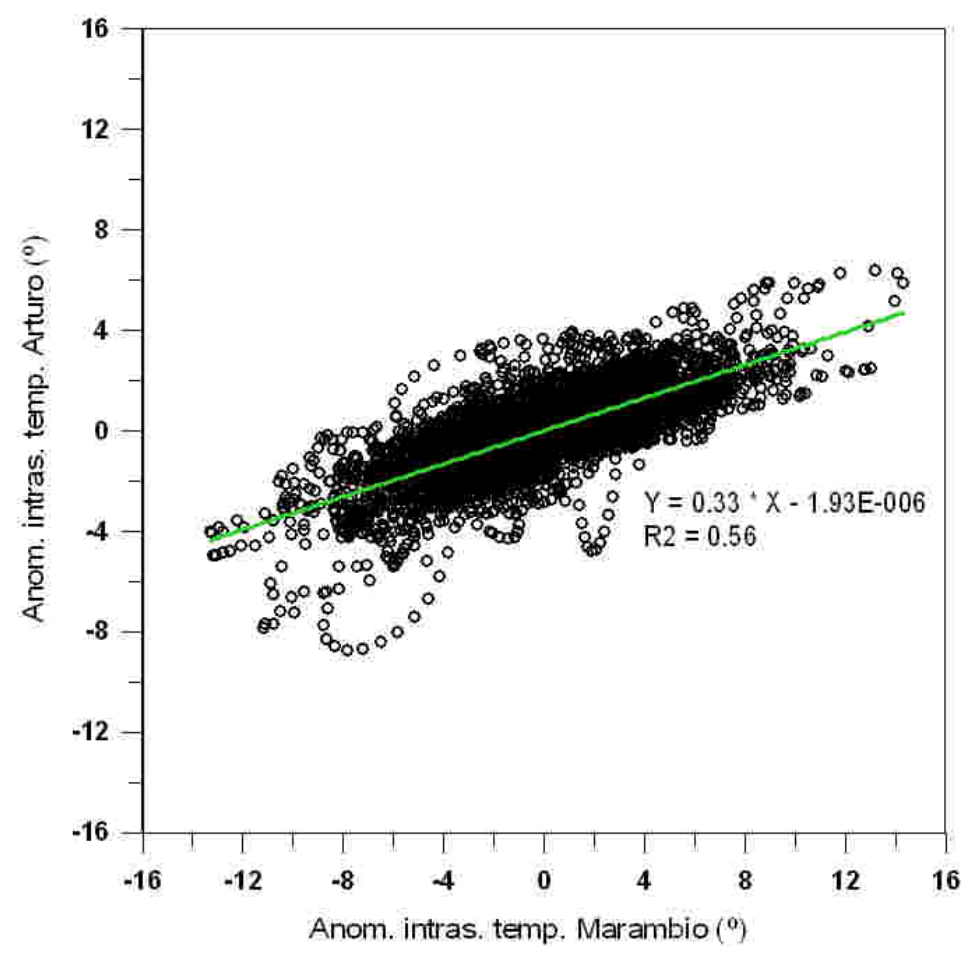

Figura 3. 2. Correlação entre as anomalias intra-sazonais de temperatura em Arturo (ordenada) e Marambio (abscissa).

\subsection{Eventos extremos intra-sazonais de temperatura (EIT) na Península Antártica}

Os extremos das anomalias intra-sazonais de temperatura foram obtidos como descrito no capítulo 2 (seção 2.4). Porém, neste caso, os limiares foram calculados somente para o período de inverno, primavera e verão, pois de acordo com análise espectral da temperatura (seção 2.5), não foram observados picos espectrais estatisticamente significativos na escala intra-sazonal (20-100 dias) durante o outono nas estações da Península Antártica. As propriedades estatísticas, persistência, freqüência e intensidade dos extremos intra-sazonais de temperatura das estações Arturo e Marambio, foram obtidas para as três estações do ano. A persistência dos extremos foi definida como a ocorrência consecutiva de dias que satisfazem as condições de extremos frios (q25) ou quentes (q75), semelhante à metodologia empregada por Carvalho et al (2004) e Muza (2005). A persistência dos eventos será uma informação importante para as análises de significância estatística, a qual requer o número de graus de liberdade relacionado à ocorrência de eventos independentes. Todas as ocorrências de extremos que foram separadas por dois ou mais dias foram consideradas como eventos independentes. A intensidade foi definida como a média dos extremos intra-sazonais de temperatura calculada em cada evento intra-sazonal frio (EIF) ou quente (EIQ). 
Os extremos intra-sazonais frios e quentes em Arturo são mais intensos no inverno ($1,3{ }^{\circ} \mathrm{C}$ e $+1,4{ }^{\circ} \mathrm{C}$, respectivamente), seguido pela primavera $\left(-0,8{ }^{\circ} \mathrm{C} \quad \mathrm{e} \quad+0,8{ }^{\circ} \mathrm{C}\right.$, respectivamente) e com menor intensidade no verão $\left(-0,4{ }^{\circ} \mathrm{C}\right.$ e $+0,4{ }^{\circ} \mathrm{C}$, respectivamente) (Figura 3.3). Da mesma forma ocorre em Marambio, porém a magnitude dos extremos intrasazonais frios e quentes é maior quando comparada com Arturo: $-3,1^{\circ} \mathrm{C}$ e $+2,9{ }^{\circ} \mathrm{C}$ no inverno, $-2,0{ }^{\circ} \mathrm{C}$ e $+2,3{ }^{\circ} \mathrm{C}$ na primavera e $-1,1^{\circ} \mathrm{C}$ e $+1,0{ }^{\circ} \mathrm{C}$ no verão (Figura 3.4). 


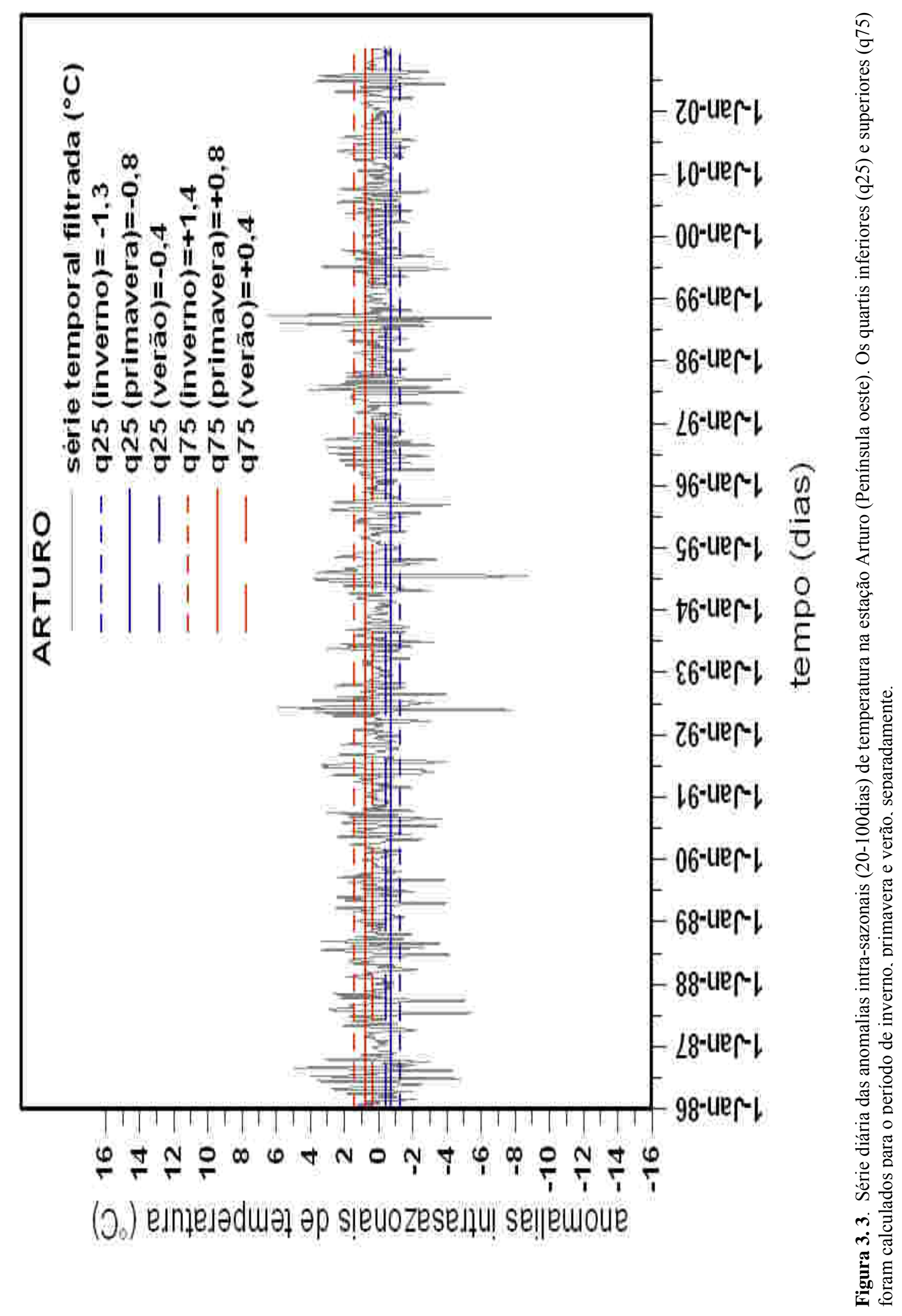




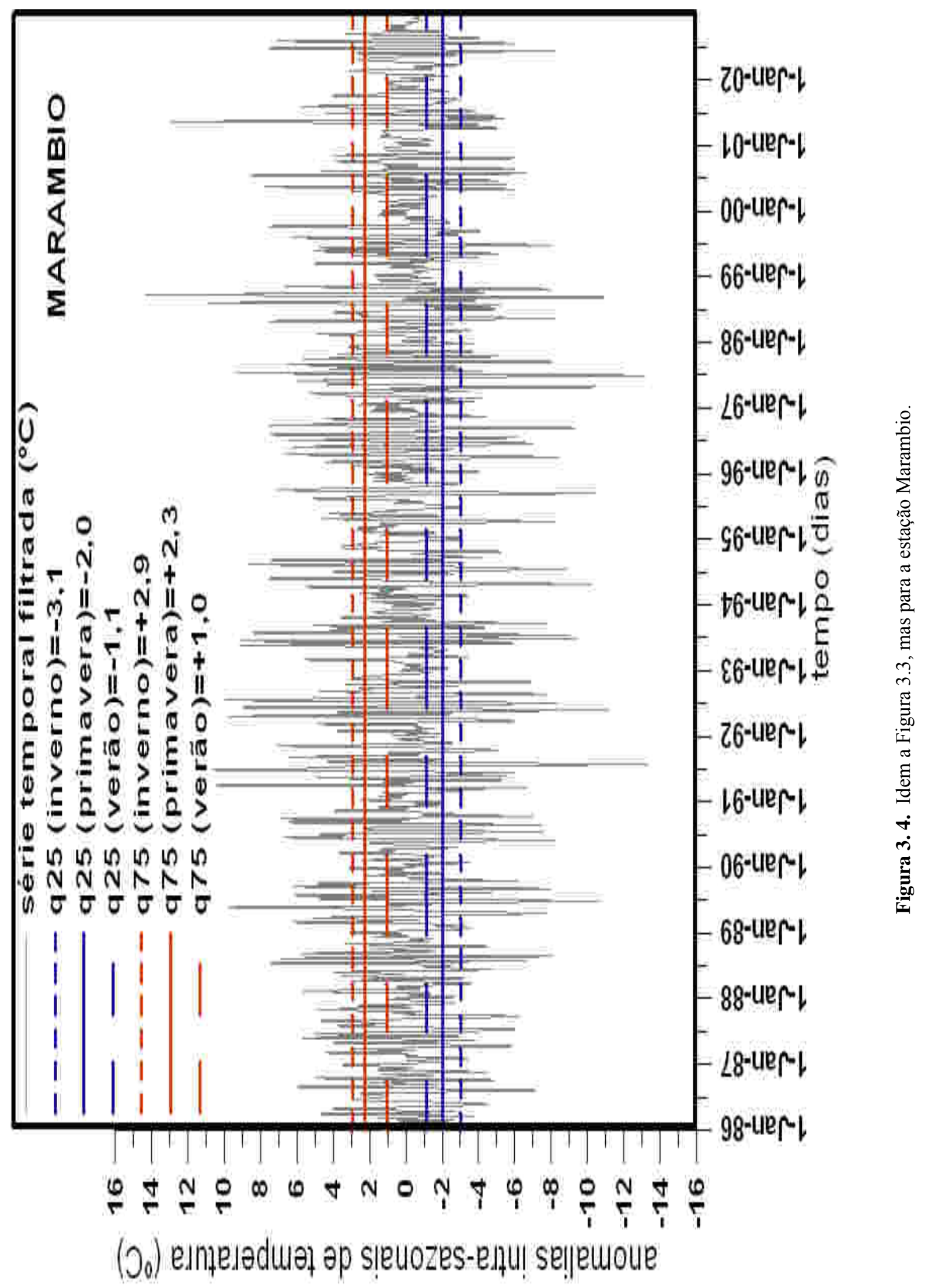


A data do primeiro dia de cada evento intra-sazonal frio (EIF) e quente (EIQ) e suas respectivas persistências, juntamente com a ordem de ocorrência dos eventos independentes (N) nas estações Arturo e Marambio no período de inverno, primavera e verão austral, é apresentada nas Tabelas 3.1. 3.2 e 3.3, respectivamente. Em Arturo, ocorreram 38 EIF e 33 EIQ no inverno, enquanto que em Marambio ocorreram três eventos a mais: 41 EIF e 36 EIQ (Tabela 3.1), no mesmo período. Na primavera em Arturo, ocorreram 42 EIF e 38 EIQ, sendo que em Marambio ocorreram menos EIF (31) e a mesma quantidade de EIQ que em Arturo (38). Durante o verão, a ocorrência entre EIF e EIQ foi bem distribuída tanto em Arturo (41 e 40, respectivamente) quanto em Marambio (43 e 44, respectivamente). É importante ressaltar que grande parte dos EIF e EIQ ocorridos na estação Arturo, também ocorreram na estação Marambio (cerca de 80\% dos casos EIF e 70\% dos EIQ, independente da estação do ano); porém, com a defasagem de alguns dias, geralmente entre 1-6 dias. Além disso, uma relação alternada entre a ocorrência de EIF e EIQ (i.e., a ocorrência de EIF na seqüência de EIQ, e vice-versa) foi observada em $70 \%$ dos casos das estações Arturo e Marambio na maioria das estações do ano aqui pesquisadas.

As características estatísticas da distribuição da persistência dos EIF e EIQ em Arturo e Marambio podem ser observadas nas Figuras 3.5 e 3.6, respectivamente. Em Arturo, houve pouca variabilidade sazonal na mediana da persistência dos EIF: cerca de 12 dias no inverno (Fig. 3.5a), 11 dias na primavera (Fig. 3.5b) e 10 dias no verão (Fig. 3.5c). Para os e EIQ, a mediana da persistência foi por volta de 12 dias para as três estações do ano (Figura 3.5a, b, c). O quartil superior da persistência em Arturo também indicou pouca variabilidade dos EIF (EIQ): cerca de 15 (15) dias no inverno (Fig. 3.5a), 14 (15) dias na primavera (Fig. 3.5b) e 12 (15) dias no verão (Fig. 3.5c). Pela característica da distribuição de freqüência da persistência dos eventos em Arturo, observou-se pouca variabilidade sazonal dos EIF e EIQ. Porém, os EIQ apresentaram mais valores discrepantes e extremos na persistência do que os EIF no inverno e primavera (Figura 3.5a e 3.5b, respectivamente). Já em Marambio, a mediana de persistência dos EIF (EIQ) foi cerca de 11 (11) dias no inverno (Fig. 3.6a), 14 (12) dias na primavera (Fig. 3.6b) e 9 (9) dias no verão (Fig. 3.6c). O quartil superior da persistência em Marambio indicou que os EIF (EIQ) ocorreram cerca de 13 (14) dias no inverno (Fig. 3.6a), 16 (14) dias na primavera (Fig. 3.6b) e 12 (15) dias no verão (Fig. 3.6c). A distribuição de freqüência da persistência dos eventos em Marambio mostrou de forma geral, que os EIF persistiram mais que os EIQ no inverno e na primavera (Figuras 3.6a e 3.6b, respectivamente), enquanto que no verão os EIQ persistiram mais que os EIF (Fig. 3.6c). 
Tabela 3. 1. Data do primeiro dia de cada evento intra-sazonal frio (EIF) e quente (EIQ) e suas respectivas persistências, em ordem de ocorrência $(\mathrm{N})$, para as estações Arturo e Marambio, durante o inverno austral.

\begin{tabular}{|c|c|c|c|c|c|c|c|c|c|c|c|}
\hline \multicolumn{6}{|c|}{ Arturo } & \multicolumn{6}{|c|}{ Marambio } \\
\hline Tipo & $\mathrm{N}$ & Ano & Mês & Dia & Persistência & Tipo & $\mathrm{N}$ & Ano & Mês & Dia & Persistência \\
\hline EIF & 1 & 1986 & 5 & 16 & 17 & EIF & 1 & 1986 & 5 & 18 & 15 \\
\hline EIF & 2 & 1986 & 6 & 21 & 12 & EIF & 2 & 1986 & 8 & 3 & 16 \\
\hline EIF & 3 & 1986 & 8 & 6 & 14 & EIF & 3 & 1987 & 7 & 4 & 20 \\
\hline EIF & 4 & 1987 & 7 & 7 & 18 & EIF & 4 & 1988 & 6 & 8 & 11 \\
\hline EIF & 5 & 1988 & 6 & 14 & 16 & EIF & 5 & 1988 & 7 & 27 & 8 \\
\hline EIF & 6 & 1988 & 7 & 30 & 8 & EIF & 6 & 1988 & 8 & 20 & 11 \\
\hline EIF & 7 & 1988 & 8 & 21 & 11 & EIF & 7 & 1989 & 6 & 20 & 14 \\
\hline EIF & 8 & 1989 & 6 & 6 & 2 & EIF & 8 & 1989 & 8 & 9 & 7 \\
\hline EIF & 9 & 1989 & 6 & 25 & 8 & EIF & 9 & 1989 & 8 & 29 & 11 \\
\hline EIF & 10 & 1989 & 8 & 29 & 12 & EIF & 10 & 1990 & 5 & 26 & 12 \\
\hline EIF & 11 & 1990 & 5 & 25 & 8 & EIF & 11 & 1990 & 7 & 12 & 12 \\
\hline EIF & 12 & 1990 & 7 & 12 & 12 & EIF & 12 & 1990 & 8 & 20 & 11 \\
\hline EIF & 13 & 1990 & 8 & 22 & 12 & EIF & 13 & 1991 & 6 & 7 & 10 \\
\hline EIF & 14 & 1991 & 5 & 20 & 26 & EIF & 14 & 1991 & 7 & 21 & 16 \\
\hline EIF & 15 & 1991 & 7 & 21 & 17 & EIF & 15 & 1992 & 5 & 20 & 13 \\
\hline EIF & 16 & 1992 & 5 & 19 & 14 & EIF & 16 & 1992 & 6 & 25 & 16 \\
\hline EIF & 17 & 1992 & 6 & 21 & 23 & EIF & 17 & 1992 & 8 & 15 & 14 \\
\hline EIF & 18 & 1992 & 8 & 20 & 13 & EIF & 18 & 1993 & 5 & 31 & 7 \\
\hline EIF & 19 & 1993 & 6 & 1 & 6 & EIF & 19 & 1993 & 6 & 22 & 11 \\
\hline EIF & 20 & 1993 & 6 & 23 & 12 & EIF & 20 & 1993 & 7 & 12 & 11 \\
\hline EIF & 21 & 1993 & 8 & 24 & 5 & EIF & 21 & 1993 & 8 & 25 & 6 \\
\hline EIF & 22 & 1994 & 7 & 12 & 20 & EIF & 22 & 1994 & 7 & 12 & 20 \\
\hline EIF & 23 & 1995 & 6 & 28 & 5 & EIF & 23 & 1994 & 8 & 27 & 1 \\
\hline EIF & 24 & 1995 & 7 & 19 & 11 & EIF & 24 & 1995 & 6 & 26 & 1 \\
\hline EIF & 25 & 1996 & 6 & 14 & 14 & EIF & 25 & 1996 & 6 & 9 & 16 \\
\hline EIF & 26 & 1996 & 8 & 21 & 11 & EIF & 26 & 1996 & 7 & 15 & 11 \\
\hline EIF & 27 & 1997 & 6 & 21 & 17 & EIF & 27 & 1997 & 6 & 21 & 16 \\
\hline EIF & 28 & 1997 & 7 & 26 & 9 & EIF & 28 & 1997 & 7 & 25 & 5 \\
\hline EIF & 29 & 1998 & 7 & 21 & 9 & EIF & 29 & 1998 & 7 & 1 & 10 \\
\hline EIF & 30 & 1998 & 8 & 17 & 8 & EIF & 30 & 1998 & 7 & 21 & 8 \\
\hline EIF & 31 & 1999 & 6 & 16 & 13 & EIF & 31 & 1998 & 8 & 19 & 4 \\
\hline EIF & 32 & 1999 & 8 & 30 & 12 & EIF & 32 & 1999 & 6 & 19 & 12 \\
\hline EIF & 33 & 2000 & 6 & 21 & 4 & EIF & 33 & 2000 & 6 & 15 & 8 \\
\hline EIF & 34 & 2001 & 6 & 2 & 10 & EIF & 34 & 2000 & 7 & 27 & 8 \\
\hline EIF & 35 & 2001 & 7 & 11 & 11 & EIF & 35 & 2000 & 8 & 19 & 10 \\
\hline EIF & 36 & 2002 & 6 & 3 & 15 & EIF & 36 & 2001 & 5 & 24 & 10 \\
\hline EIF & 37 & 2002 & 7 & 9 & 9 & EIF & 37 & 2001 & 6 & 9 & 9 \\
\hline EIF & 38 & 2002 & 8 & 14 & 18 & EIF & 38 & 2001 & 7 & 7 & 6 \\
\hline EIQ & 1 & 1986 & 6 & 7 & 11 & EIF & 39 & 2002 & 6 & 5 & 12 \\
\hline EIQ & 2 & 1986 & 7 & 6 & 13 & EIF & 40 & 2002 & 7 & 16 & 11 \\
\hline EIQ & 3 & 1986 & 8 & 23 & 13 & EIF & 41 & 2002 & 8 & 17 & 11 \\
\hline EIQ & 4 & 1987 & 6 & 25 & 6 & EIQ & 1 & 1986 & 8 & 25 & 12 \\
\hline EIQ & 5 & 1987 & 7 & 30 & 34 & EIQ & 2 & 1987 & 6 & 17 & 9 \\
\hline EIQ & 6 & 1988 & 7 & 8 & 18 & EIQ & 3 & 1987 & 8 & 1 & 8 \\
\hline EIQ & 7 & 1988 & 8 & 12 & 4 & EIQ & 4 & 1987 & 8 & 24 & 14 \\
\hline EIQ & 8 & 1989 & 8 & 18 & 6 & EIQ & 5 & 1988 & 7 & 12 & 11 \\
\hline EIQ & 9 & 1990 & 6 & 12 & 4 & EIQ & 6 & 1988 & 8 & 8 & 9 \\
\hline EIQ & 10 & 1990 & 7 & 29 & 17 & EIQ & 7 & 1989 & 7 & 8 & 8 \\
\hline EIQ & 11 & 1991 & 6 & 20 & 27 & EIQ & 8 & 1989 & 7 & 25 & 10 \\
\hline EIQ & 12 & 1992 & 6 & 4 & 13 & EIQ & 9 & 1990 & 6 & 11 & 26 \\
\hline EIQ & 13 & 1992 & 7 & 17 & 12 & EIQ & 10 & 1991 & 6 & 21 & 26 \\
\hline EIQ & 14 & 1992 & 8 & 9 & 7 & EIQ & 11 & 1991 & 8 & 10 & 7 \\
\hline EIQ & 15 & 1993 & 6 & 12 & 6 & EIQ & 12 & 1992 & 6 & 4 & 14 \\
\hline EIQ & 16 & 1994 & 6 & 15 & 23 & EIQ & 13 & 1992 & 7 & 14 & 15 \\
\hline EIQ & 17 & 1994 & 8 & 4 & 16 & EIQ & 14 & 1993 & 6 & 10 & 10 \\
\hline EIQ & 18 & 1994 & 8 & 26 & 15 & EIQ & 15 & 1993 & 7 & 26 & 24 \\
\hline EIQ & 19 & 1995 & 8 & 5 & 20 & EIQ & 16 & 1994 & 5 & 21 & 15 \\
\hline EIQ & 20 & 1996 & 7 & 2 & 10 & EIQ & 17 & 1994 & 7 & 2 & 5 \\
\hline EIQ & 21 & 1996 & 8 & 6 & 11 & EIQ & 18 & 1994 & 8 & 9 & 12 \\
\hline EIQ & 22 & 1997 & 5 & 24 & 21 & EIQ & 19 & 1995 & 8 & 10 & 14 \\
\hline EIQ & 23 & 1997 & 7 & 11 & 11 & EIQ & 20 & 1996 & 5 & 23 & 11 \\
\hline EIQ & 24 & 1997 & 8 & 7 & 10 & EIQ & 21 & 1996 & 6 & 30 & 10 \\
\hline EIQ & 25 & 1997 & 8 & 31 & 5 & EIQ & 22 & 1996 & 7 & 31 & 15 \\
\hline EIQ & 26 & 1998 & 6 & 22 & 8 & EIQ & 23 & 1997 & 5 & 22 & 17 \\
\hline EIQ & 27 & 1998 & 8 & 2 & 13 & EIQ & 24 & 1997 & 7 & 9 & 11 \\
\hline EIQ & 28 & 1999 & 6 & 7 & 3 & EIQ & 25 & 1997 & 8 & 5 & 6 \\
\hline EIQ & 29 & 1999 & 7 & 3 & 11 & EIQ & 26 & 1997 & 8 & 26 & 9 \\
\hline EIQ & 30 & 2000 & 7 & 15 & 9 & EIQ & 27 & 1998 & 6 & 11 & 11 \\
\hline EIQ & 31 & 2001 & 7 & 30 & 12 & EIQ & 28 & 1998 & 8 & 2 & 13 \\
\hline EIQ & 32 & 2002 & 6 & 22 & 13 & EIQ & 29 & 1999 & 6 & 6 & 8 \\
\hline EIQ & 33 & 2002 & 7 & 23 & 15 & EIQ & 30 & 1999 & 8 & 1 & 13 \\
\hline & & & & & & EIQ & 31 & 2000 & 7 & 12 & 12 \\
\hline & & & & & & EIQ & 32 & 2000 & 8 & 8 & 7 \\
\hline & & & & & & EIQ & 33 & 2001 & 6 & 24 & 6 \\
\hline & & & & & & EIQ & 34 & 2001 & 7 & 31 & 13 \\
\hline & & & & & & EIQ & 35 & 2002 & 6 & 20 & 13 \\
\hline & & & & & & EIQ & 36 & 2002 & 7 & 31 & 11 \\
\hline
\end{tabular}


Tabela 3. 2. Idem a tabela 3.1, mas para a primavera austral.

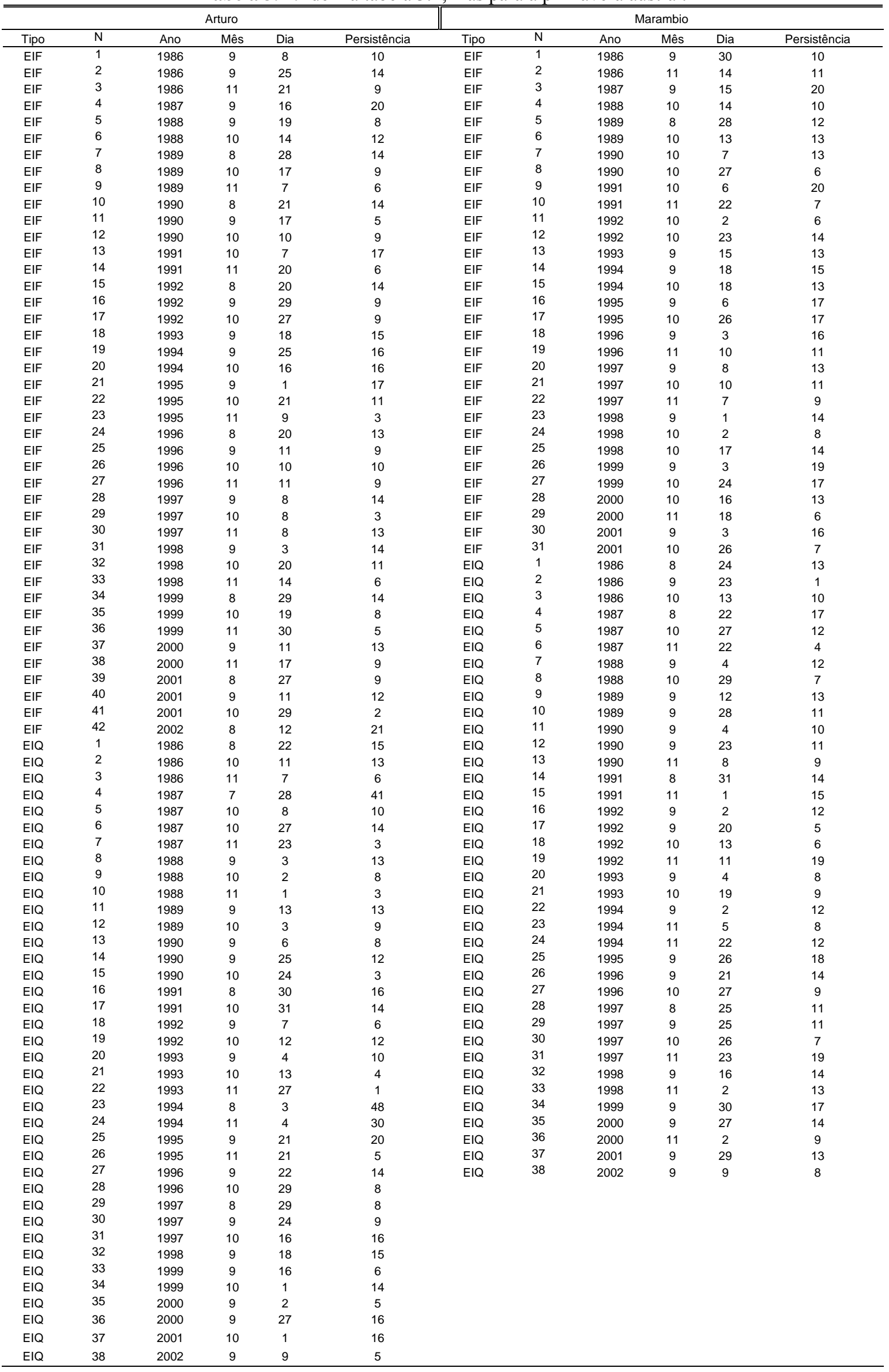


Tabela 3. 3. Idem a tabela 3.1, mas para o verão austral.

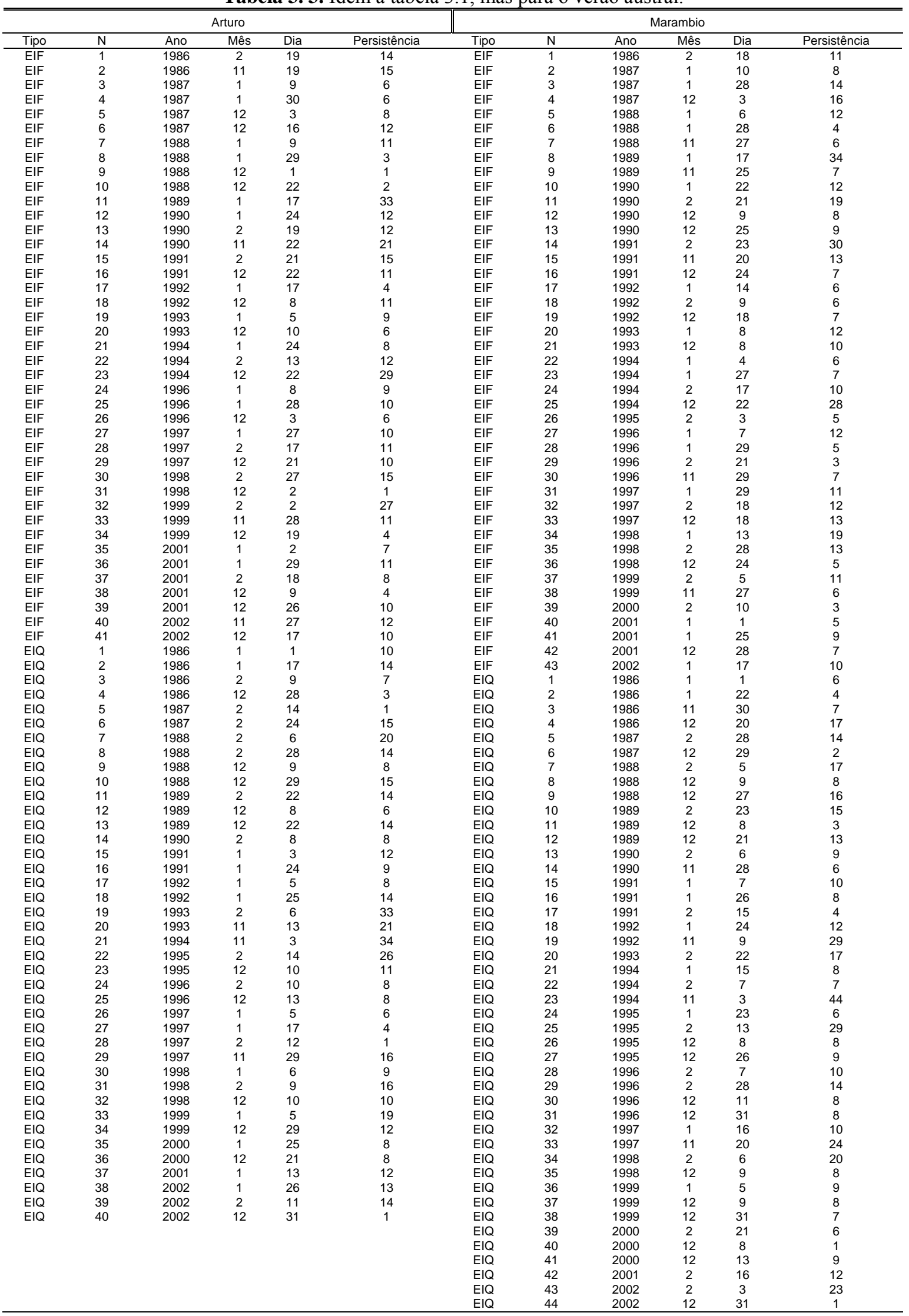


(a)

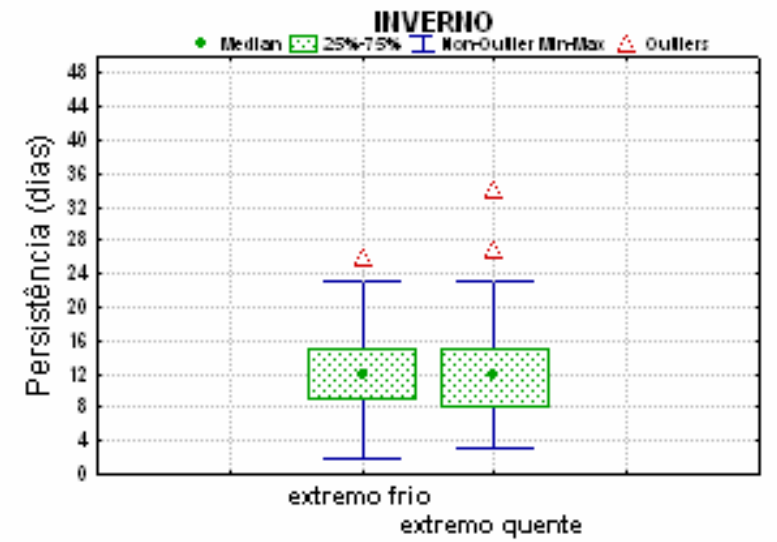

(c)

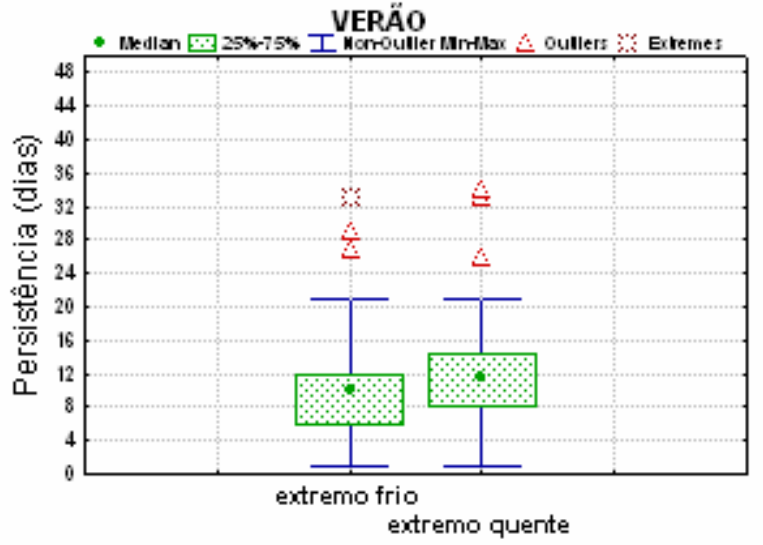

(b)

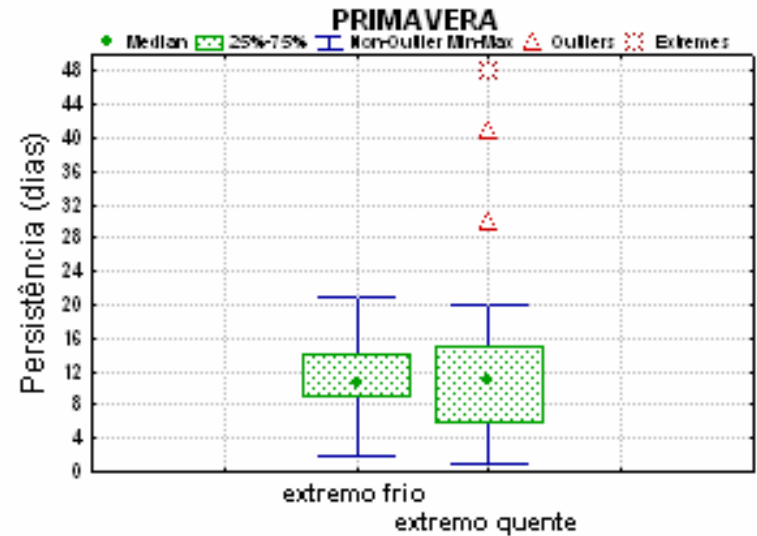

Figura 3. 5. Distribuição de freqüência da persistência dos eventos intra-sazonais frios (EIF) e quentes (EIQ) em Arturo para o período de inverno (a), primavera (b) e verão (c). A caixa (box) em verde representa o intervalo inter-quartílico (25\%-75\%) e o ponto verde, a mediana (median). Os pontos discrepantes (outliers) são valores $\geq$ a 1,5 vezes a altura do box e os extremos (extremes) são pontos onde os valores são $\geq$ a 3,0 vezes a altura do box. 
(a)

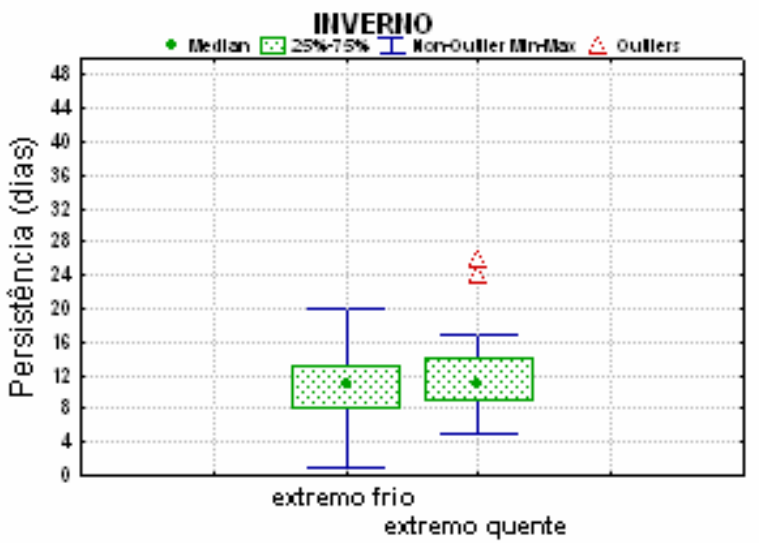

(c)

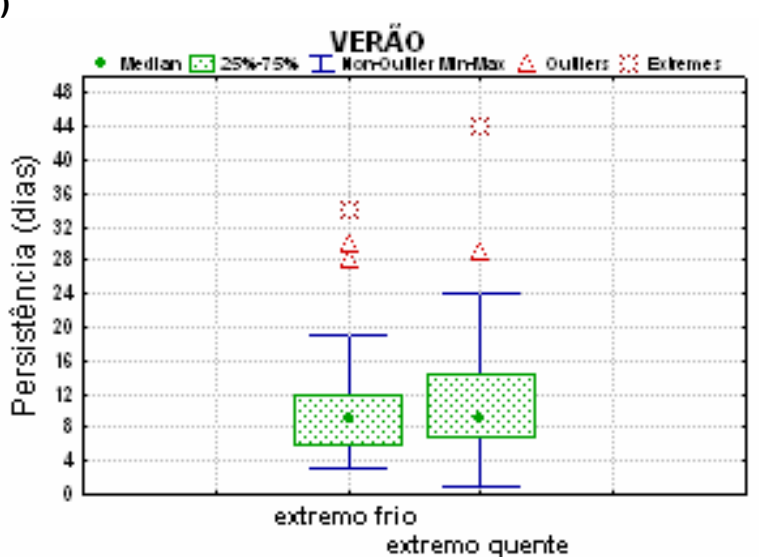

MARAMBIO

(b)

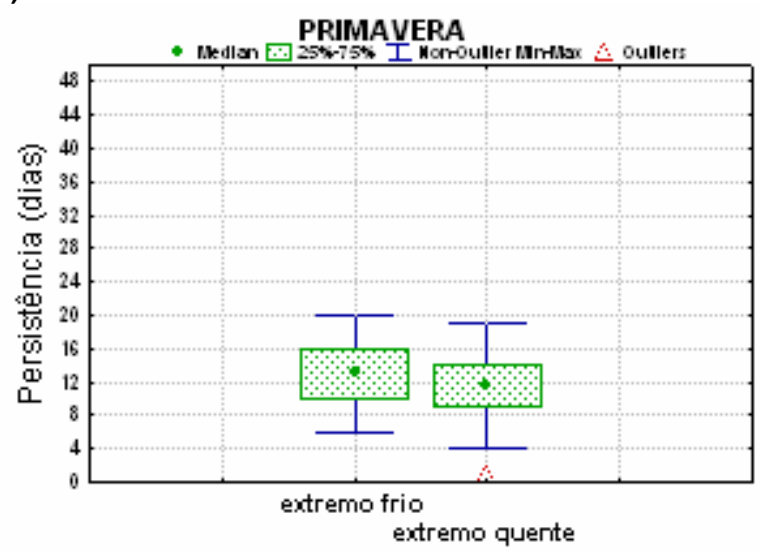

Figura 3. 6. Idem a Figura 3.5, mas para a estação Marambio.

\subsubsection{Variabilidade interanual dos EIT: relação com o El Niño/Oscilação Sul}

Para ilustrar a variabilidade interanual do número de eventos EIF e EIQ nas estações Arturo e Marambio, são apresentadas as Figuras 3.7 e 3.8, respectivamente. Observa-se que nos 17 invernos, somente em três ocorreram mais EIQ do que EIF em Arturo: em 1987, 1994 e 1997 (Figura 3.7a). Estes foram anos de episódios El Niño do ENOS, classificados como moderados a fortes pelo Climate Prediction Center - National Centers for Environmental Prediction - CPC/NCEP (baseado na TSM da região do Niño 3.4: $5^{\circ} \mathrm{N}-5^{\circ} \mathrm{S}, 120^{\circ}-170^{\circ} \mathrm{W}$ ). Em Marambio, além desses três anos, observa-se que em 1996 e 1999 o número de EIQ superou o número de EIF, porém não estão associados com eventos quentes do ENOS, e sim, com eventos neutros e frios, respectivamente (Figura 3.8a). 
Na primavera de 1987, 1988 e 1993 em Arturo, o número de EIQ superou o número de EIF (Figura 3.7b). No entanto, a freqüência de EIQ nestes anos não parece estar relacionada com apenas uma fase do ENOS, visto que em 1987 foi um episódio El Niño, em 1988 La Niña, e em 1993 foram observadas condições de neutralidade do ENOS na primavera. Já em Marambio, nos anos de 1995, 1998, 1999 e 2001 observa-se que os EIF foram mais freqüentes que os EIQ (Figura 3.8b). Exceto em 2001, que foi um episódio neutro do ENOS na primavera, nos demais anos foram episódios La Niña.

No verão ocorreram tanto EIF quanto EIQ nas duas estações (Tabela 3.3). Os anos que apresentam maior número de EIF do que EIQ no verão em Arturo foram: 1987, 1990, 1994, 1996, 1999 e 2001 (Figura 3.7c). Destes anos, apenas em 1999 foi um episódio La Niña do ENOS e dois foram episódios El Niño: 1987 e 1994; os demais foram episódios neutros do ENOS. Os anos de 1986, 1989, 1995, 1997, 1998, 2000 e 2002 apresentaram maior número de EIQ do que EIF no verão em Arturo (Figura 3.7c). Destes sete anos, três foram anos de episódios La Niña do ENOS (1995, 1998 e 2000) e três foram eventos El Niño: 1986, 1997 e 2002. Em Marambio, os anos de 1987, 1990, 1992, 1993, 1994, 1997, 1998, 2001 apresentaram maior número de EIF do que EIQ no verão (Figura 3.8c). Destes anos, três foram eventos El Niño do ENOS (1987, 1994 e 1997) e apenas o ano de 1998 foi um episódio La Niña; os demais foram anos de condições neutras. Já os anos que apresentaram maior número de EIQ do que EIF em Marambio durante o verão foram: 1986, 1989, 1995, 1999, 2000 e 2002 (Figura 3.8c). Nestes anos, os episódios La Niña do ENOS predominaram (1995, 1999 e 2000), seguido por episódios quentes (1986 e 2002).

Em suma, em anos de El Niño no inverno, observou-se o predomínio de EIQ nas estações Arturo e Marambio. Na primavera em Arturo não foi observada uma relação entre as fases do ENOS e o número de EIF e EIQ. Em Marambio, observou-se que os EIF predominaram em anos de La Niña na primavera. No verão não foi observada uma relação entre o número de EIF e EIQ e as fases do ENOS.

No entanto, observa-se que durante o período analisado (1986 a 2002), houve o predomínio de eventos El Niño e neutros do ENOS, principalmente no inverno e na primavera (Tabela 3.4). Para verificar a influência do El Niño e La Niña na freqüência dos EIF e EIQ nas estações Arturo e Marambio, foi realizado o teste estatístico da diferença entre proporções (Apêndice A). Estes resultados são discutidos e apresentados a seguir (Figuras 3.9 e 3.10, respectivamente). 
(a)

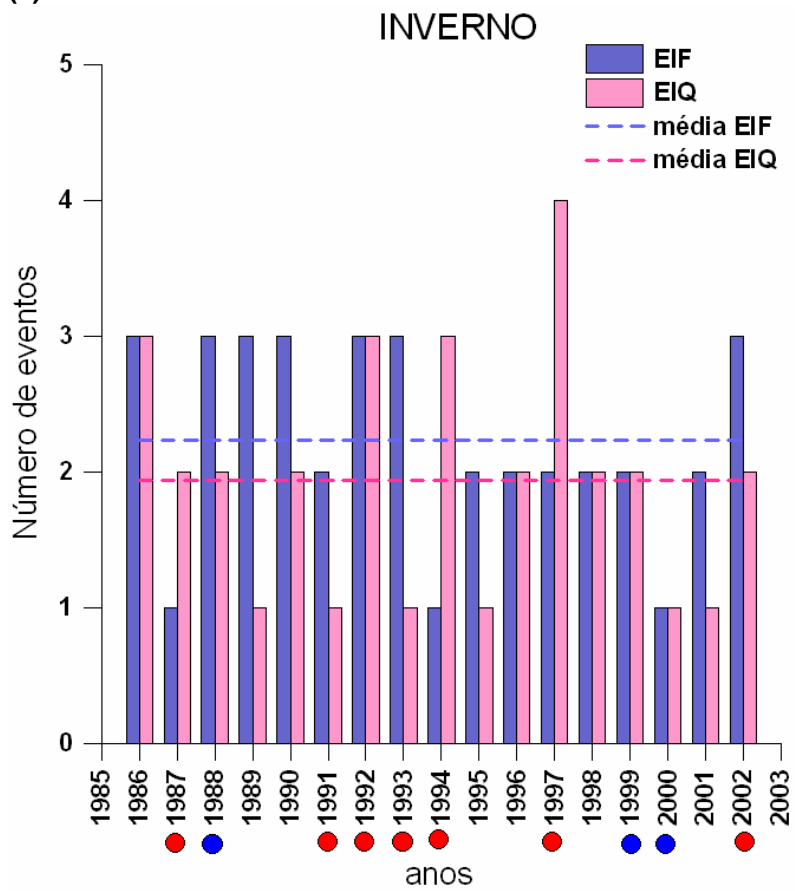

(c)

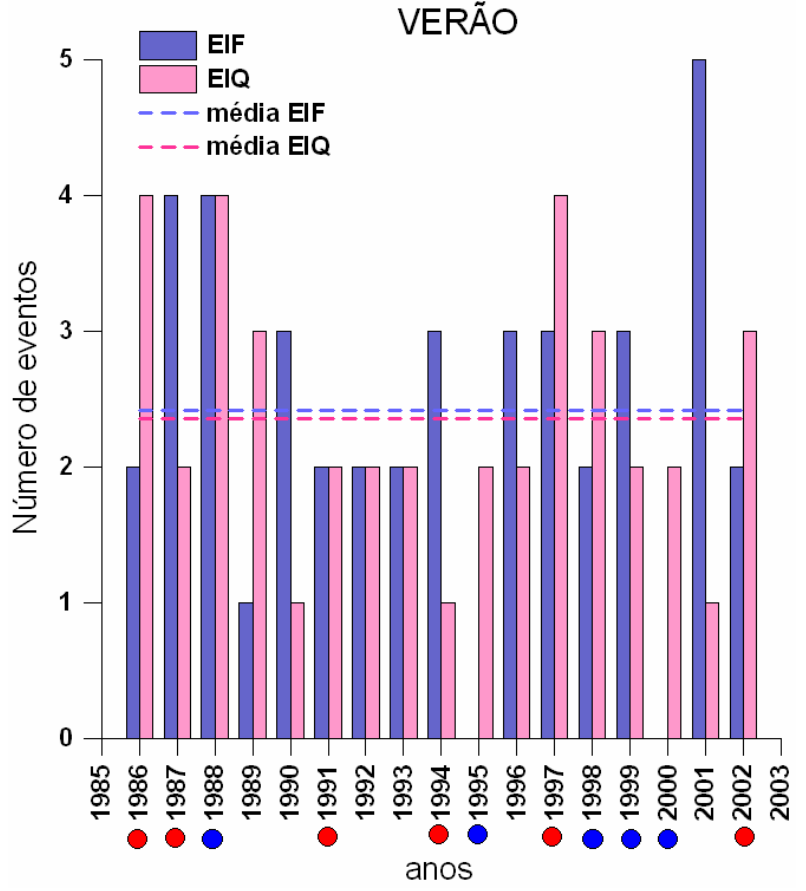

(b)

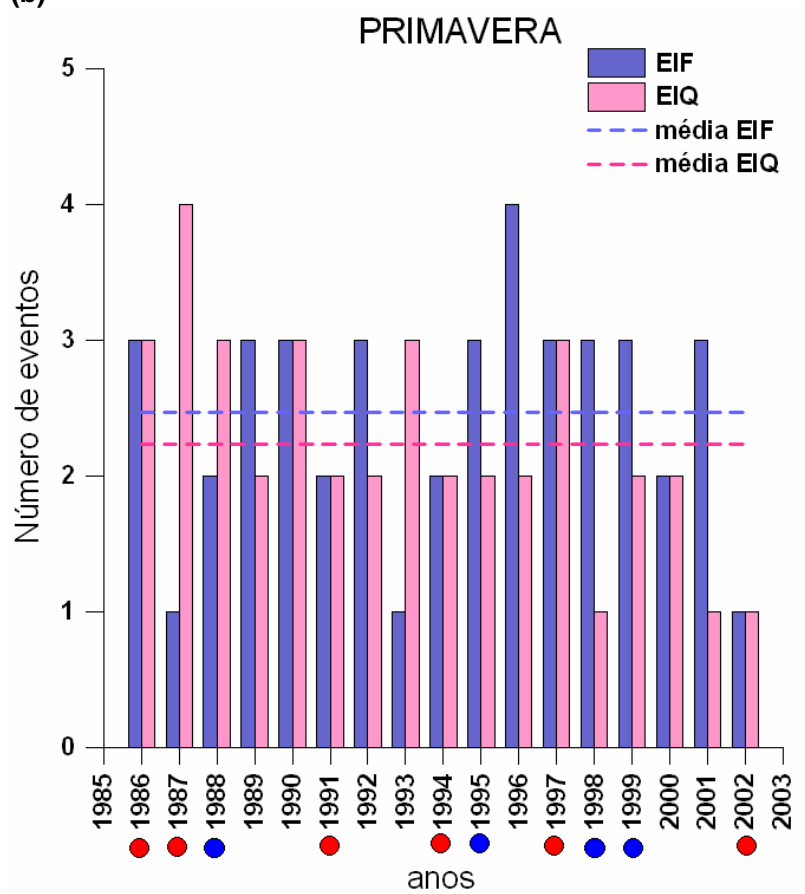

Figura 3. 7. Variabilidade interanual da frequência dos eventos extremos intra-sazonais frios (EIF) e quentes (EIQ) durante o inverno (a), primavera (b) e verão (c) para Arturo. Os pontos em azul (vermelho) representam os anos de episódios La Niña (El Niño) do ENOS obtidos pelo CPC/NCEP. 
(a)

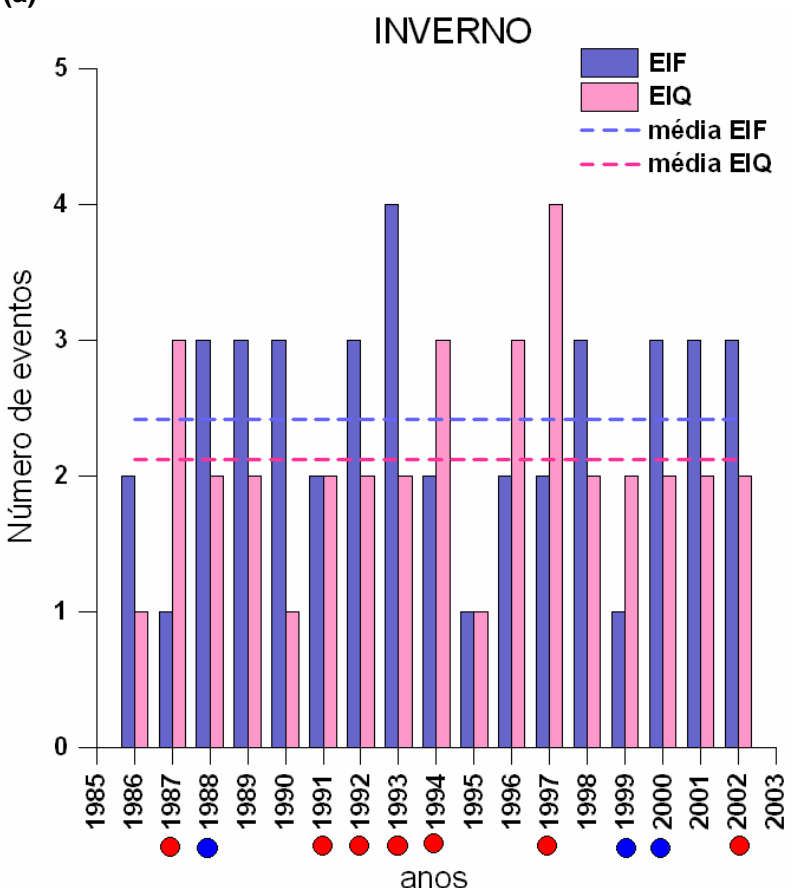

(c)

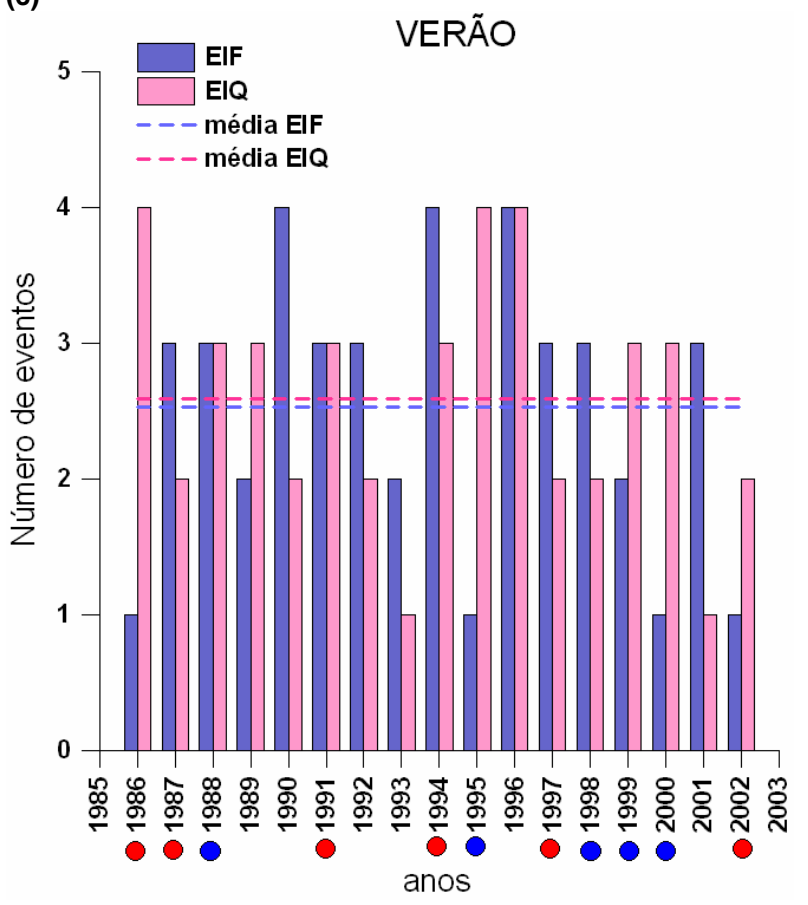

(b)

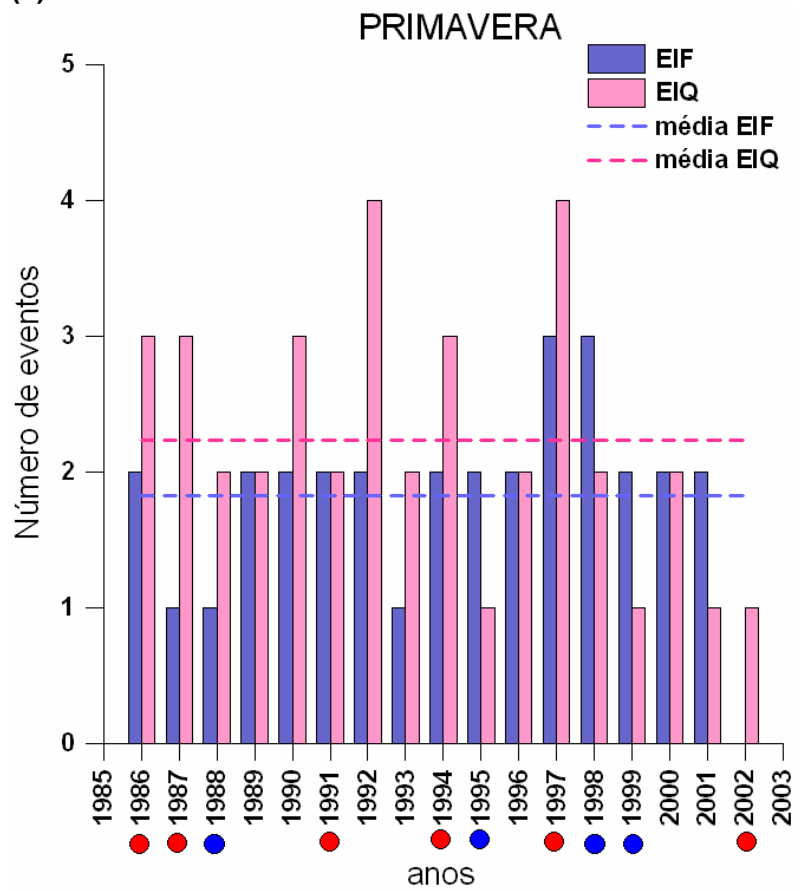

Figura 3. 8. Idem a Figura 3.7, mas para a estação Marambio. 
Tabela 3. 4. Número de eventos El Niño, La Niña e neutros do ENOS, observados em cada estação do ano durante 1986-2002.

\begin{tabular}{cccc}
\hline $\begin{array}{c}\text { Número de eventos ENOS } \\
\text { durante 1986-2002 }\end{array}$ & Inverno & Primavera & Verão \\
\hline EL Niño & 7 & 6 & 6 \\
La Niña & 3 & 4 & 5 \\
Neutros & 7 & 7 & 6 \\
\hline
\end{tabular}

Durante o inverno, o número de dias com EIQ e EIF é maior durante episódios quentes do ENOS nas estações Arturo e Marambio (Figuras 3.9a e 3.10a, respectivamente). No entanto, esta proporção não foi estatisticamente significativa quando comparada com anos neutros (baseado no teste das proporções, Apêndice A).

$\mathrm{Na}$ primavera em Arturo, durante os eventos El Niño é observado quase o triplo (o dobro) de dias com EIQ do que em eventos La Niña (neutros) (Fig. 3.9b), porém estes resultados também não foram significativos segundo o teste estatístico das proporções. Em Marambio, a diferença entre dias com EIQ nos eventos El Niño e neutros é muito pequena (apenas 1\%, Fig. 3.10b). Os EIF são mais freqüentes durante anos neutros na primavera em ambas as estações (Figuras 3.9b e 3.10b). Durante o verão nas estações Arturo e Marambio (Figuras 3.9c e 3.10c, respectivamente), observa-se que o número de dias com EIF é maior durante os episódios quentes do ENSO; no entanto, é pouca diferença quando comparado com anos neutros (apenas 3\% e 4\%, respectivamente). O número de dias com EIQ é maior em anos de La Niña no verão em Arturo, mas a diferença é pequena quando se compara com as demais fases do ENOS (Fig. 3.9c). No verão em Marambio, os EIQ são mais freqüentes durante anos neutros (Fig. 3.10c).

Em suma, estas figuras mostraram que nem toda a variabilidade dos eventos é modulada pelas fases do ENOS, em vista disso, outros mecanismos podem estar envolvidos nas variações dos EIT. Além disso, o fato do teste das proporções não ter indicado diferenças estatisticamente significativas entre as proporções dos EIT observados nas diferentes fases do ENOS, possivelmente esteja relacionado à baixa amostragem de eventos El Niño e La Niña observados no período de estudo (Tabela 3.4). 

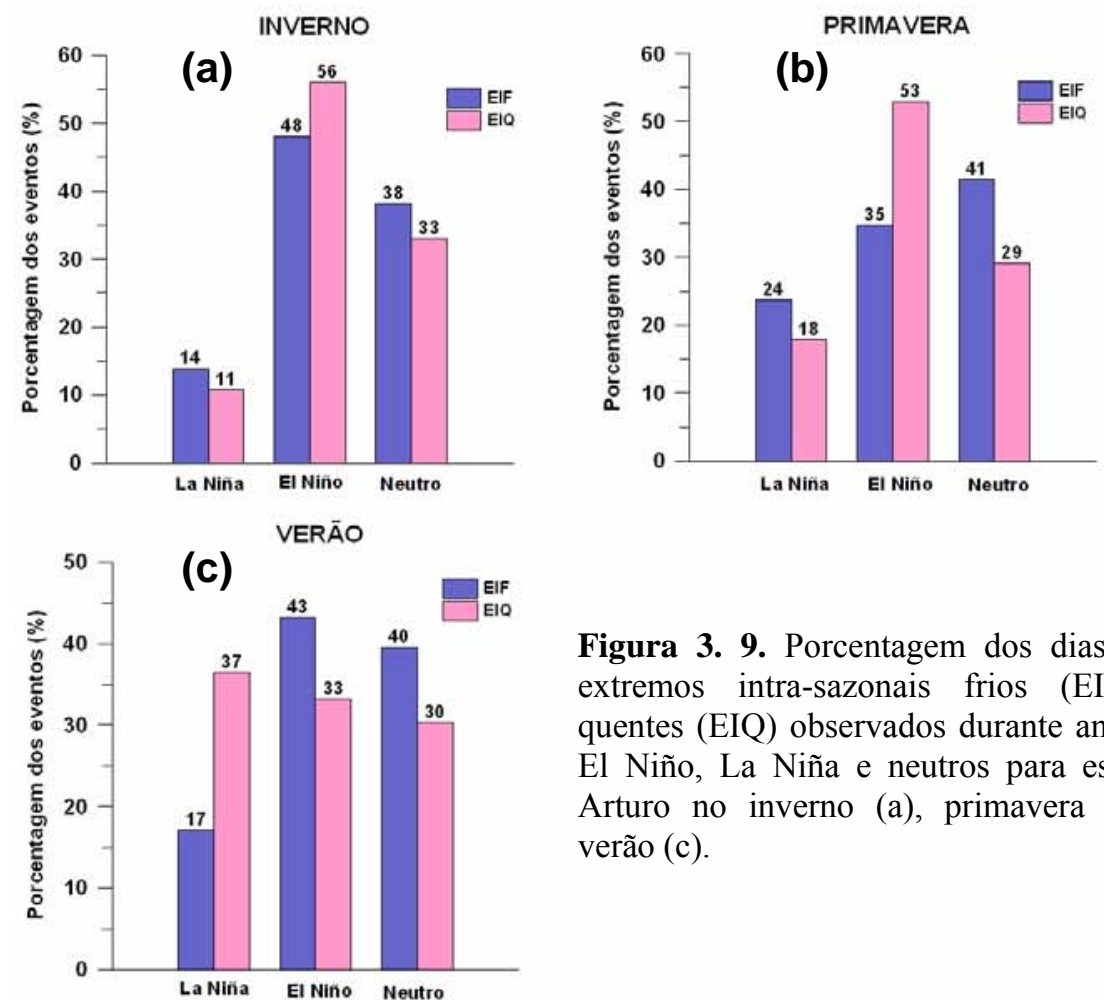

Figura 3. 9. Porcentagem dos dias com extremos intra-sazonais frios (EIF) e quentes (EIQ) observados durante anos de El Niño, La Niña e neutros para estação Arturo no inverno (a), primavera (b) e verão (c).
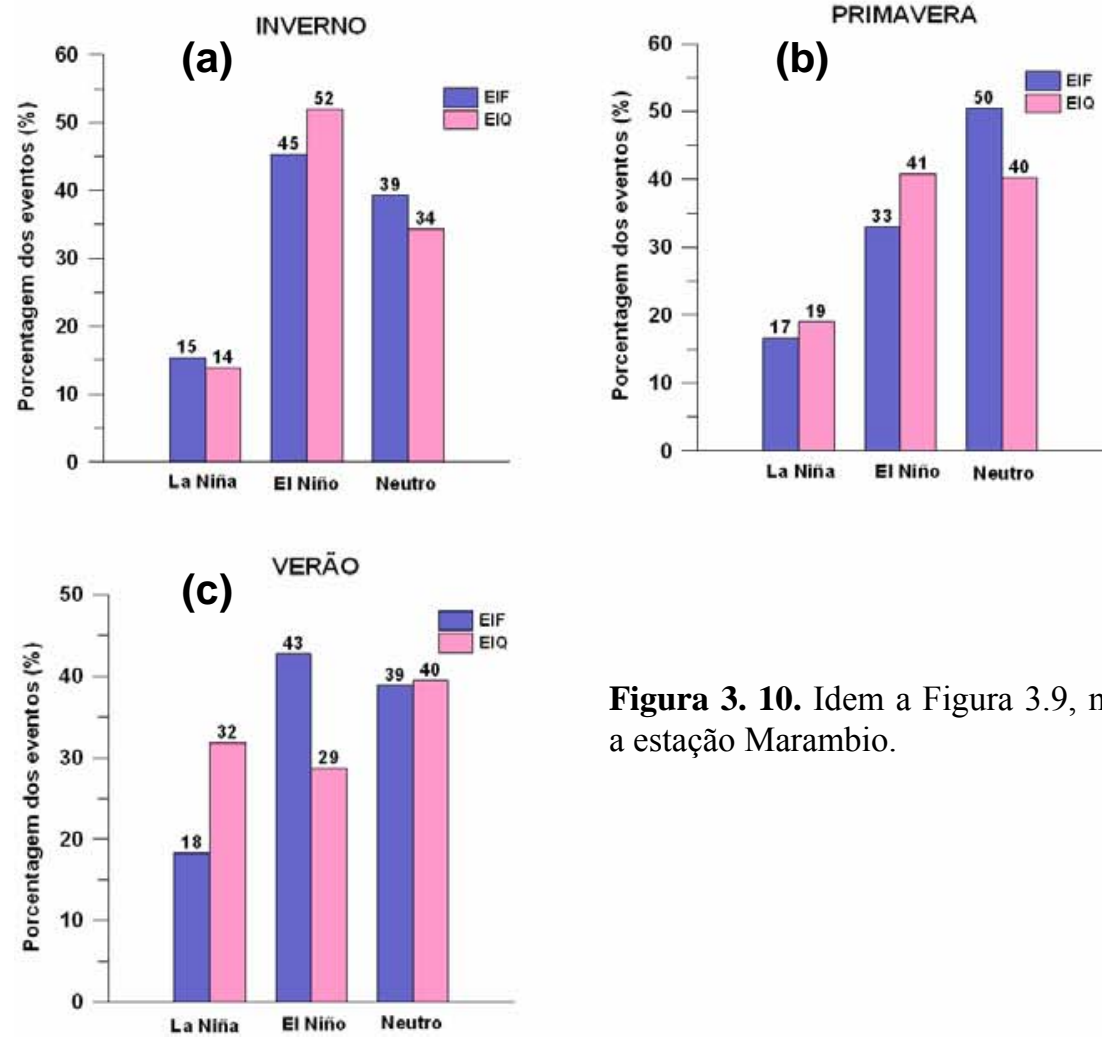

Figura 3. 10. Idem a Figura 3.9, mas para a estação Marambio. 


\subsection{Variações intra-sazonais da circulação atmosférica associada aos EIT}

Nesta etapa do trabalho são investigados os padrões de anomalias intra-sazonais da circulação atmosférica no período que antecede, durante e após a ocorrência dos EIT observados na estações representativas do setor oeste e leste da Península Antártica, Arturo e Marambio, respectivamente. Para tanto, filtrou-se na escala intra-sazonal, na banda de 20-100 dias (semelhante ao procedimento descrito no item 3.1), os dados diários de altura geopotencial em $200 \mathrm{hPa}\left(\mathrm{H}_{200}\right.$ IS $)$, vento zonal em $200 \mathrm{hPa}\left(\mathrm{U} 200_{\mathrm{IS}}\right)$ e vento meridional em $850 \mathrm{hPa}\left(\mathrm{V} 850_{\mathrm{IS}}\right)$, obtidos por reanálises do National Centers for Environmental PredictionNational Center for Atmospheric Research-NCEP/NCAR (Kalnay et al, 1996). Os dados estão distribuídos em uma resolução horizontal de $2,5^{\circ}$ x $2,5^{\circ}$.

Para investigar a evolução temporal das anomalias intra-sazonais de cada variável citada acima, foram realizadas composições defasadas (com lag) considerando 25 dias antecedentes aos EIT (lag=-25) até 25 dias posteriores ao seu início (lag=25). Dentro deste intervalo, foi selecionado o período em que o trem de ondas pôde ser bem identificado (lag= 10 a $l a g=5)$ e com valores de anomalias estatisticamente significativos ao nível de 95\%, baseado no teste t-Student.

\subsubsection{Inverno}

Observa-se, por meio de H200 IS (Figuras 3.11 e 3.12), um trem de ondas entre latitudes médias e altas do HS, semelhante ao padrão observado por diversos estudos (p.ex., Mo e Ghil 1987; Ghil e Mo 1991; Ambrizzi et al. 1995; Mo e Higgins 1998), conhecido como PSA. Os modos do PSA (PSA1 e PSA2), obtido por Mo e Higgins (1998) para o inverno austral através de EOFs da função corrente turbulenta em $200 \mathrm{hPa}$, são apresentados na Figura 3.13. O modo PSA1 (Fig. 3.13a) indica uma defasagem em relação ao modo PSA2 (Fig. 3.13b) e ambos exibem um número de onda 3 em latitudes médias, com maiores amplitudes no setor do Pacífico - América do Sul. No Pacífico, as anomalias nos subtrópicos estão fora de fase com as anomalias em latitudes médias. A Fig. 3.13c mostra a correlação defasada entre as componentes principais (PC1 e PC2), obtidas através da projeção das anomalias da função corrente em 200 hPa nos dois modos do PSA. As duas PCs tem máxima correlação entre 4-5 dias, sendo que as maiores correlações são encontradas na banda intra-sazonal (10-90 dias). 
Estes resultados sugerem que estes dois modos representam a oscilação intra-sazonal no HS (Mo e Higgins 1998). Outros trabalhos envolvendo o padrão de teleconexão PSA foram mencionados no Capítulo 1 (seção 1.2).

Durante os EIT na Península Antártica, observa-se que este padrão ao propagar-se para leste afeta a circulação na região da Península Antártica. A presença de anomalias negativas (ciclônicas) de $\mathrm{H} 200_{\text {IS }}$ sobre a Península Antártica foi observada durante os EIF (Figuras 3.11a e 3.12a). Além disso, observa-se que o deslocamento meridional das anomalias ciclônicas afeta o sul da América do Sul, enquanto que na região sudeste do continente observa-se a presença de anomalias anti-ciclônicas durante os EIF nas estações Arturo e Marambio (Figuras 3.11a e 3.12a). Comparando-se os EIQ (Figuras 3.11b e 3.12b) e os EIF (Figuras 3.11a e 3.12a) nas estações da Península Antártica, observa-se que estes estiveram associados a fases opostas do trem de ondas observado por meio de H200Is. As composições de H200 IS para a Península leste (Fig. 3.12) apresentaram um comportamento similar ao da Península oeste (Fig. 3.11).

A característica da circulação atmosférica em altos níveis, através de U200Is, associada aos EIF e EIQ na Península oeste e leste, é apresentada nas Figuras 3.14 e 3.15, respectivamente. Observa-se durante os EIF, a presença de anomalias negativas (de leste) de U200Is sobre a Península Antártica (Figuras 3.14a e 3.15a). De modo geral, para os EIQ, aspectos opostos aos EIF foram observados na Península Antártica, ou seja, a presença de anomalias positivas (de oeste) de U200Is sobre a região durante o inverno (Figuras 3.14b e 3.15b). As características da circulação nos EIF e EIQ na Península leste (Fig. 3.15) são semelhantes as observadas na Península oeste (Fig. 3.14). Estes resultados estão de acordo com a propagação do trem de ondas associado ao padrão de teleconexão PSA observado no inverno austral em estudos prévios (p. ex., Mo e Higgins 1998; Fig. 3.13). Além disso, observa-se um fraco trem de ondas estendendo-se do Pacífico para a América do Norte durante o período que antecede os EIF (lag=-10) e um par de anomalias de oeste (a norte) e leste (a sul) no Pacífico norte, próximo à costa oeste da América do Norte durante os EIQ $($ lag $=-5$ a $\operatorname{lag}=0)$.

Os EIF (EIQ) no inverno estiveram associados a anomalias positivas (negativas) de V850Is, ou seja, anomalias de sul (de norte), persistentes até o dia do evento (lag=0) entre a Península oeste e o Mar de Bellingshausen (Figuras 3.16 e 3.17). Além disso, anomalias de norte (de sul) são observadas no sudeste da América do Sul no período que antecede os EIF (EIQ) na Península Antártica, propagando-se para o norte do continente 5 dias depois. 


\section{PENÍNSULA OESTE}

(a) EIF
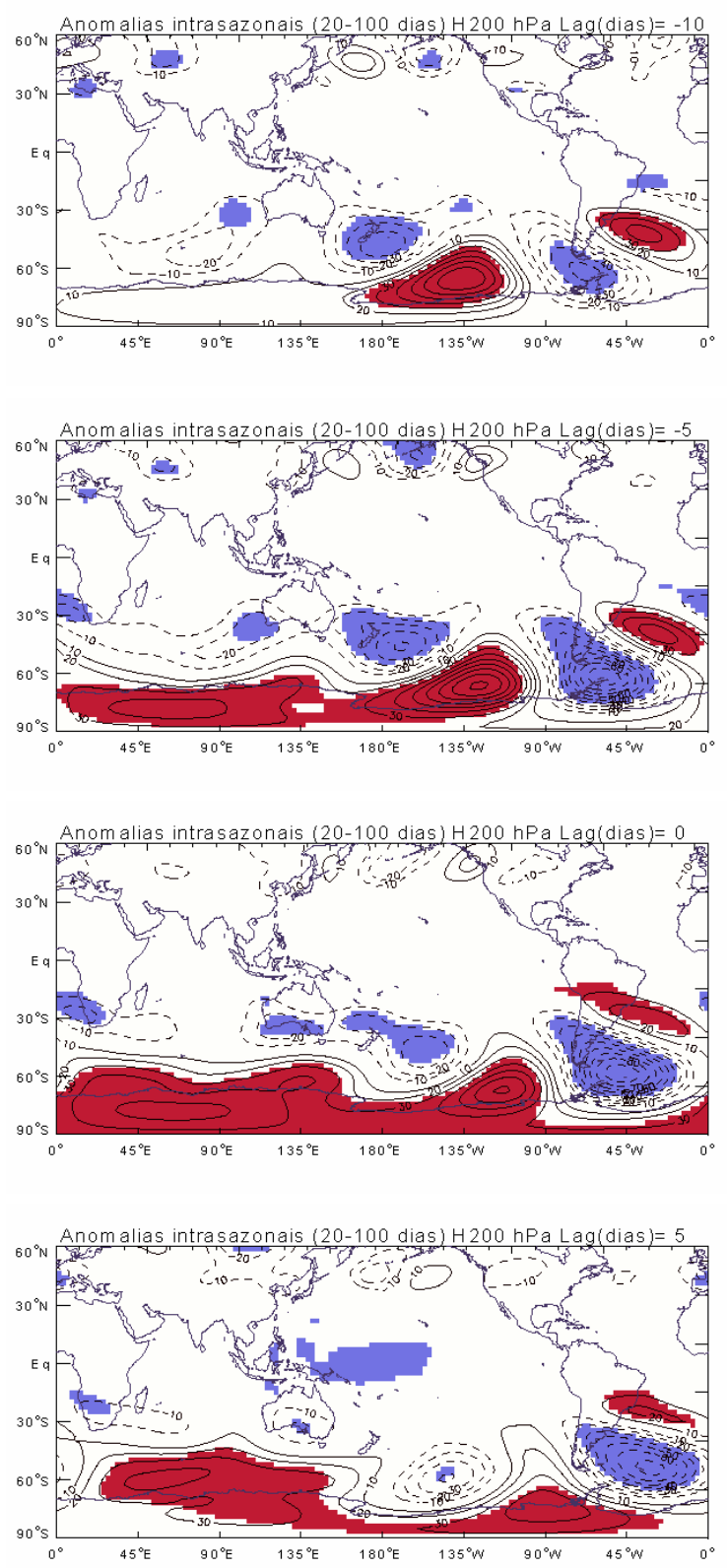

(b) EIQ
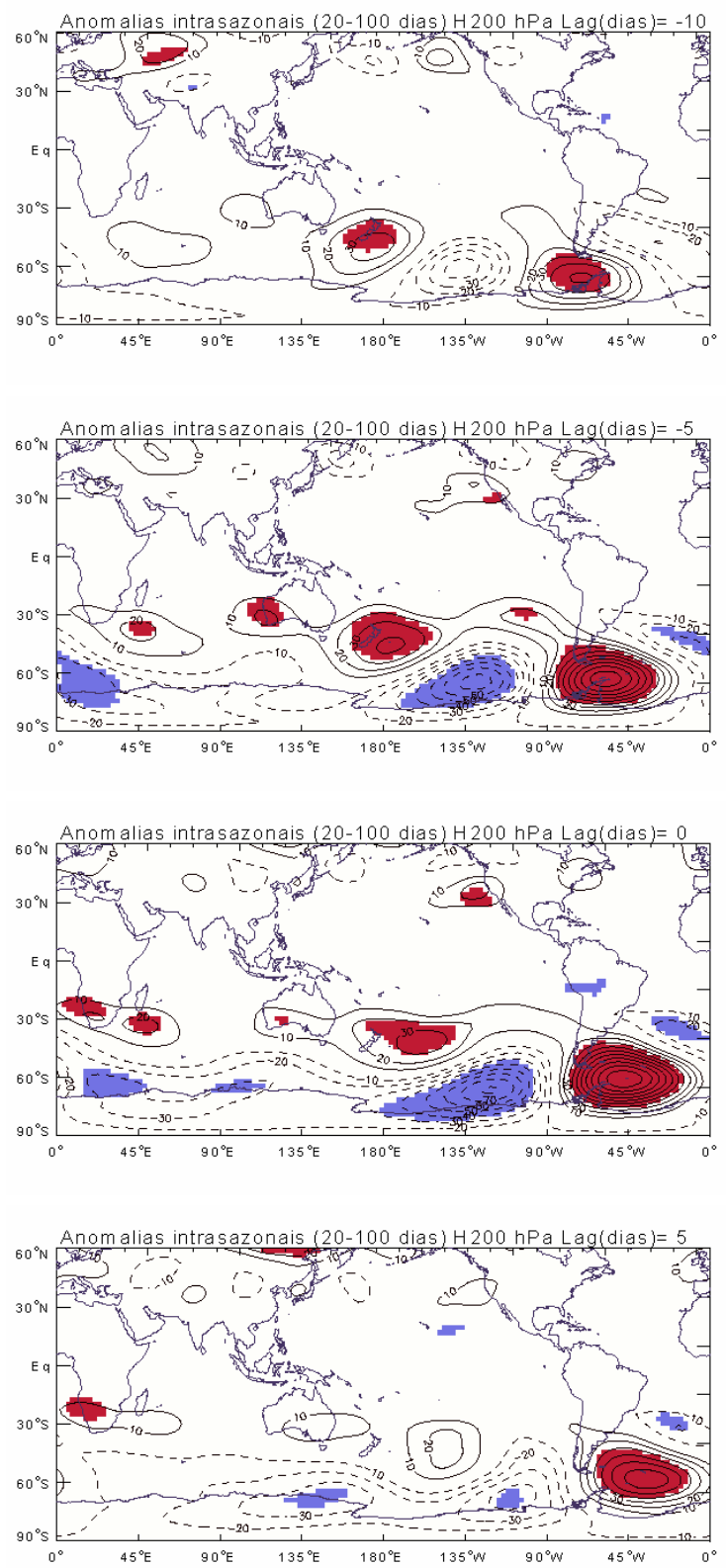

Figura 3. 11. Composições defasadas de anomalias intrasazonais do geopotencial (mgp) em $200 \mathrm{hPa}$ durante os eventos extremos intrasazonais: (a) frios (EIF) e (b) quentes (EIQ) no inverno em Arturo (Península oeste). As linhas contínuas (tracejadas) indicam valores positivos (negativos). As áreas destacadas em vermelho (azul) são para os valores positivos (negativos) estatisticamente significativos ao nível de $95 \%$, baseado no teste t-Student. O intervalo dos contornos é de 10 mgp. 


\section{PENÍNSULA LESTE}

(a) EIF
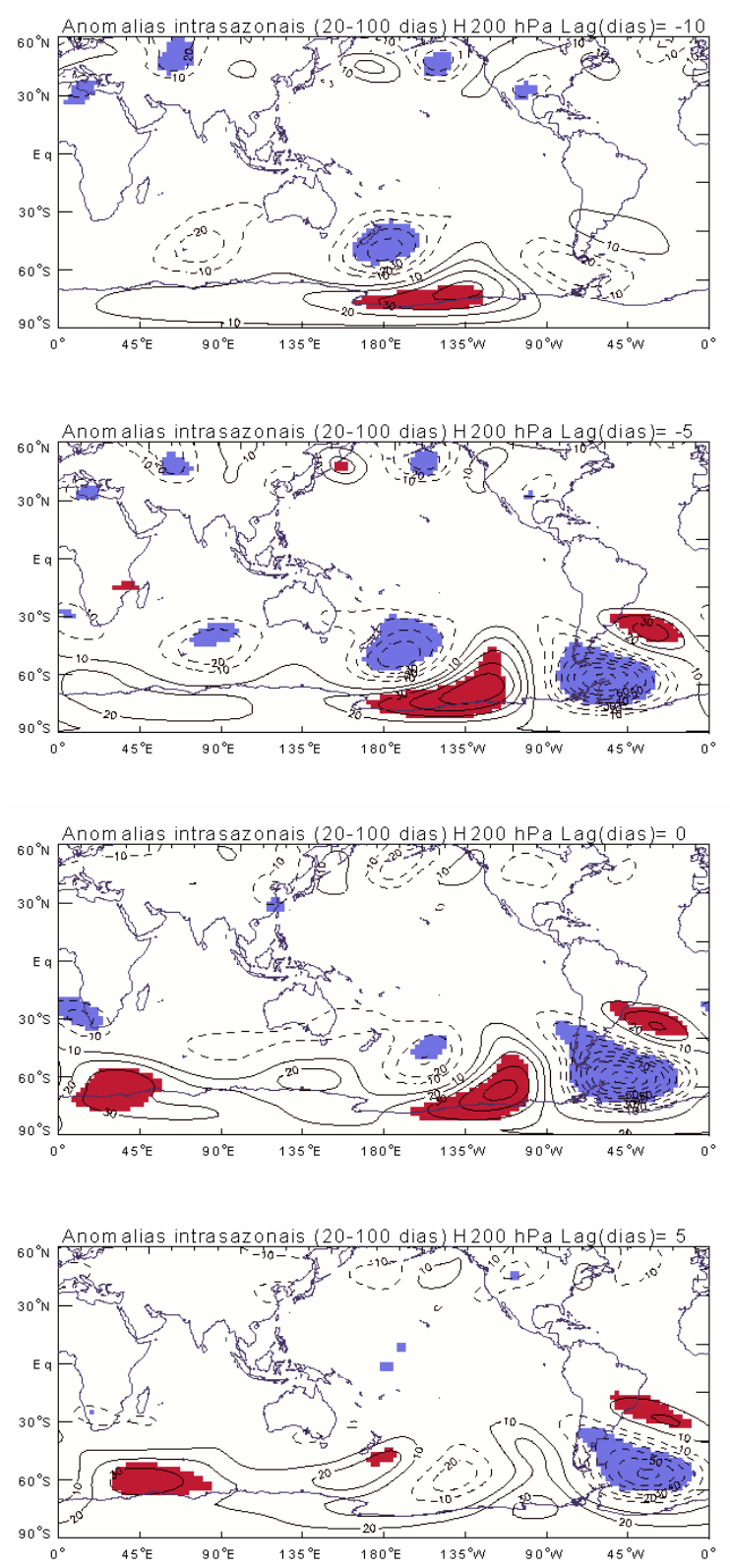

(b) EIQ
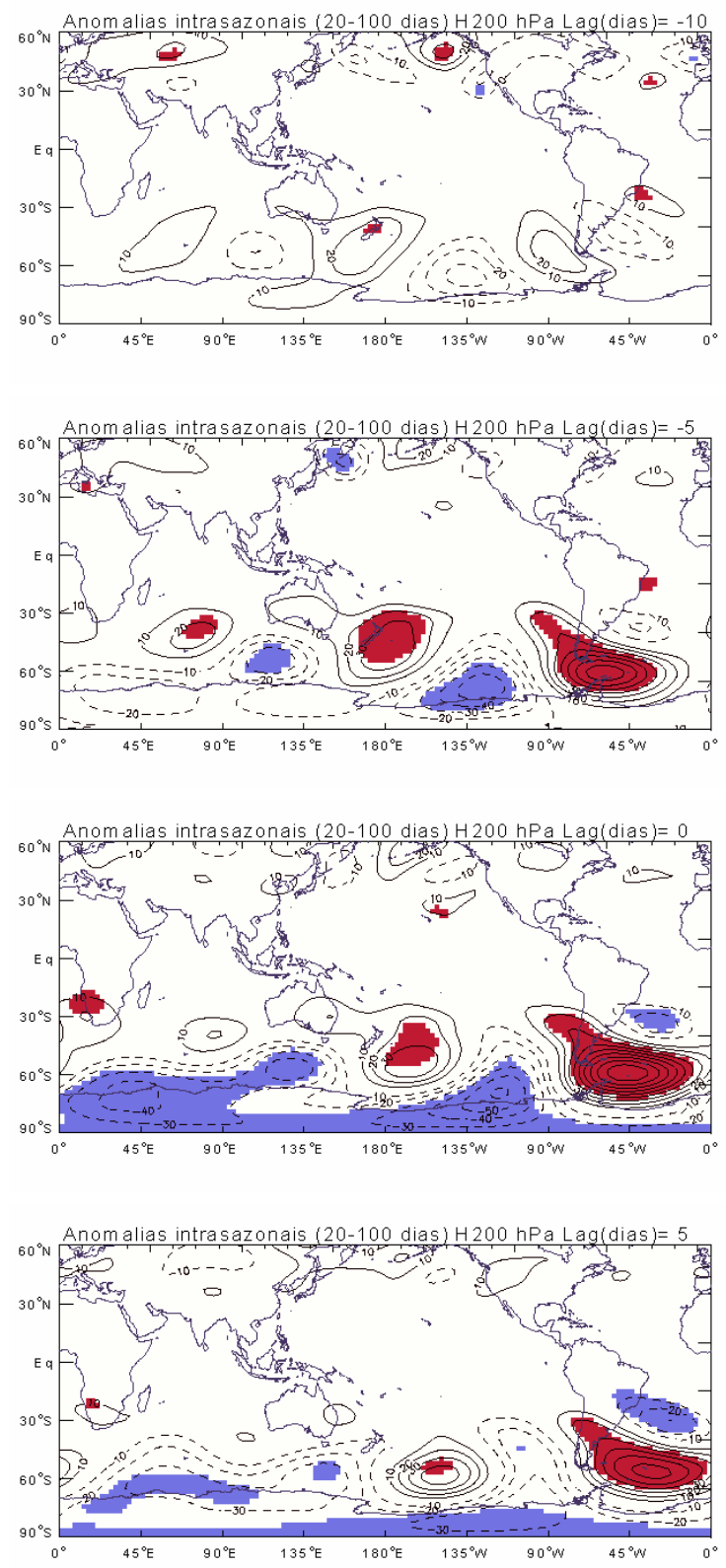

Figura 3. 12. Idem a Fig. 3.11, mas para Marambio (Península leste). 


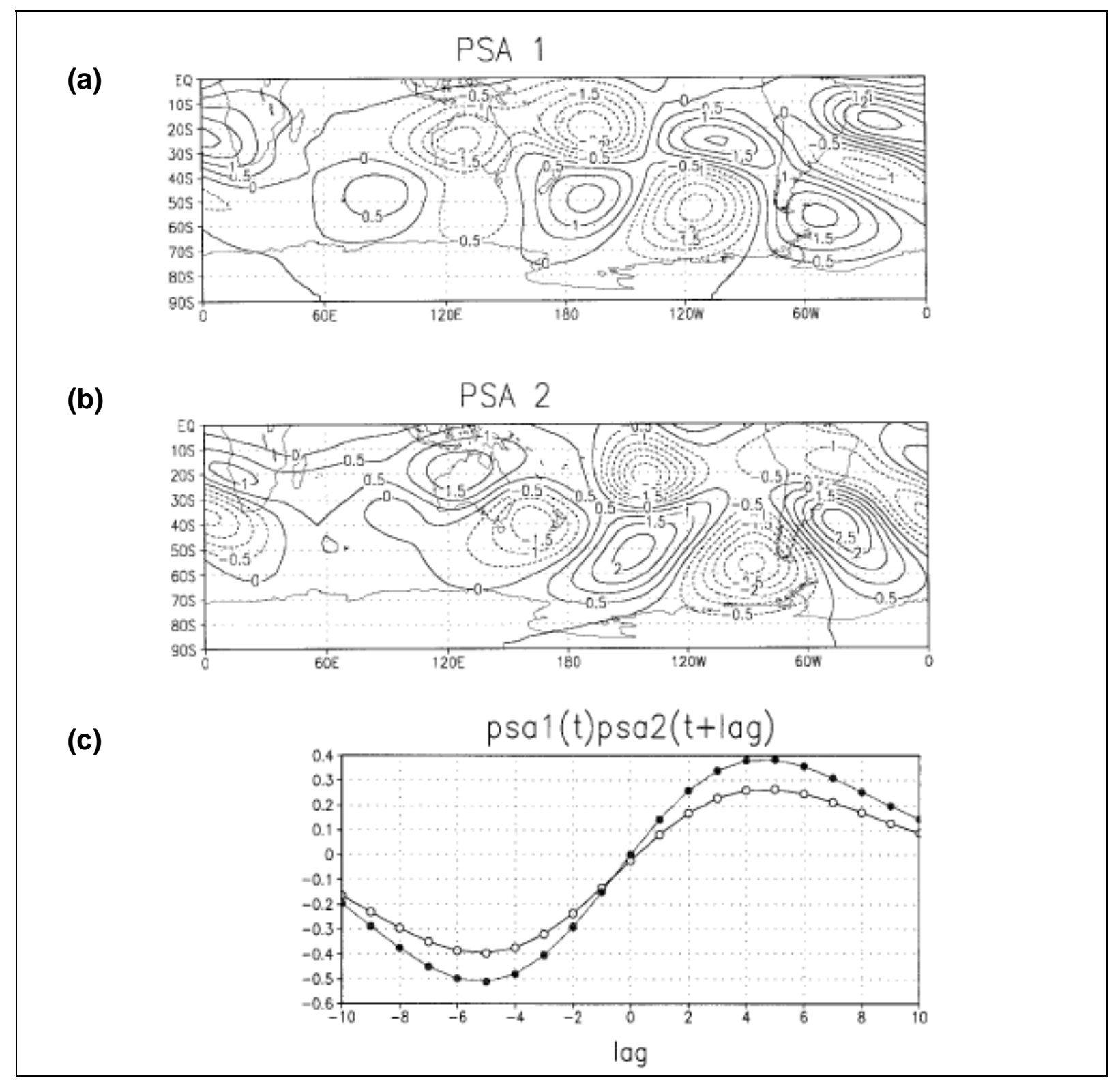

Figura 3. 13. (a) EOF1 e (b) EOF2 da função corrente turbulenta em $200 \mathrm{hPa}$ durante o inverno austral. (c) Correlações defasadas entre a PC1 e PC2 das anomalias totais (círculo em branco) e da série temporal filtrada na banda intra-sazonal (10-90 dias) (círculo em preto). Figura extraída de Mo e Higgins (1998). 


\section{PENÍNSULA OESTE}

(a) EIF
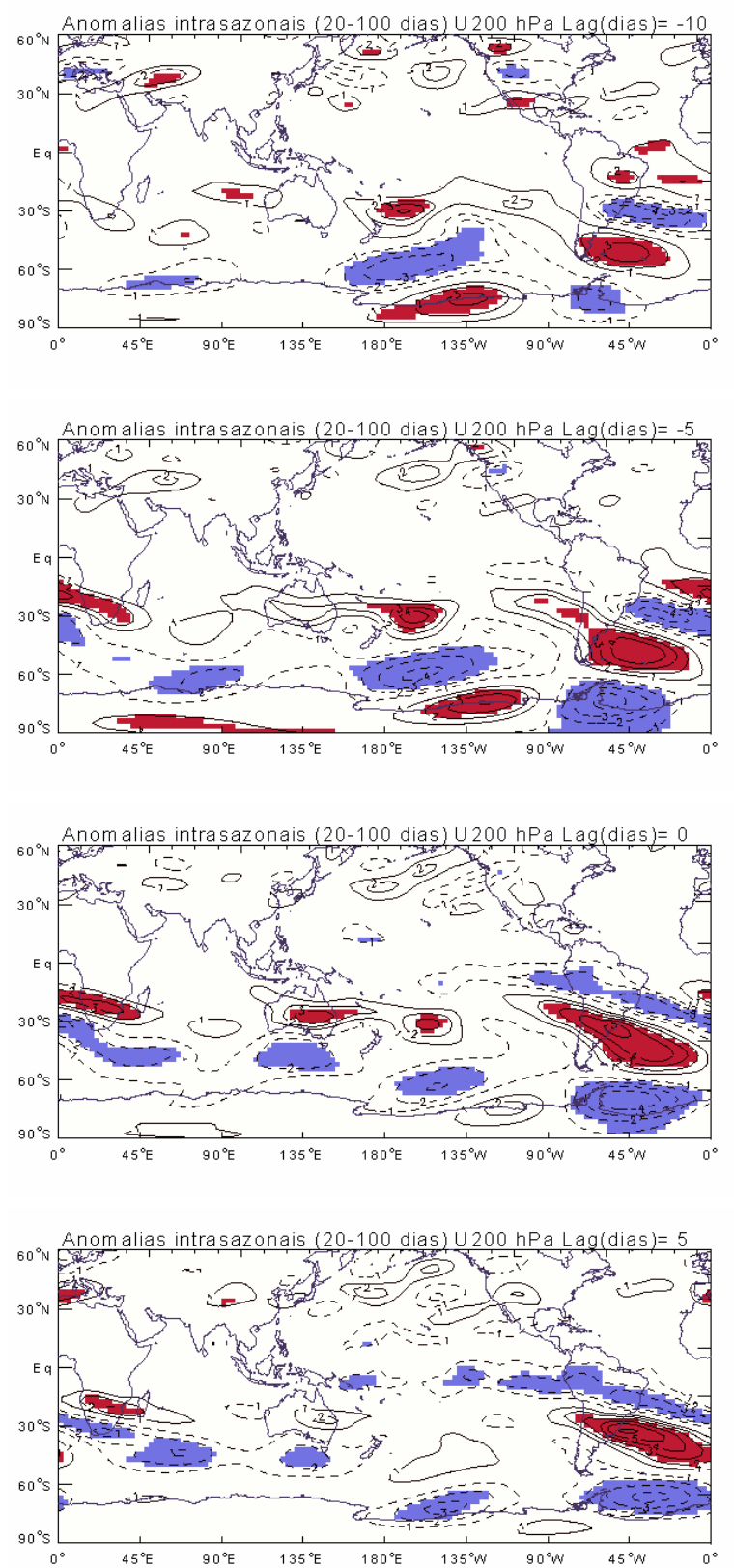

(b) EIQ
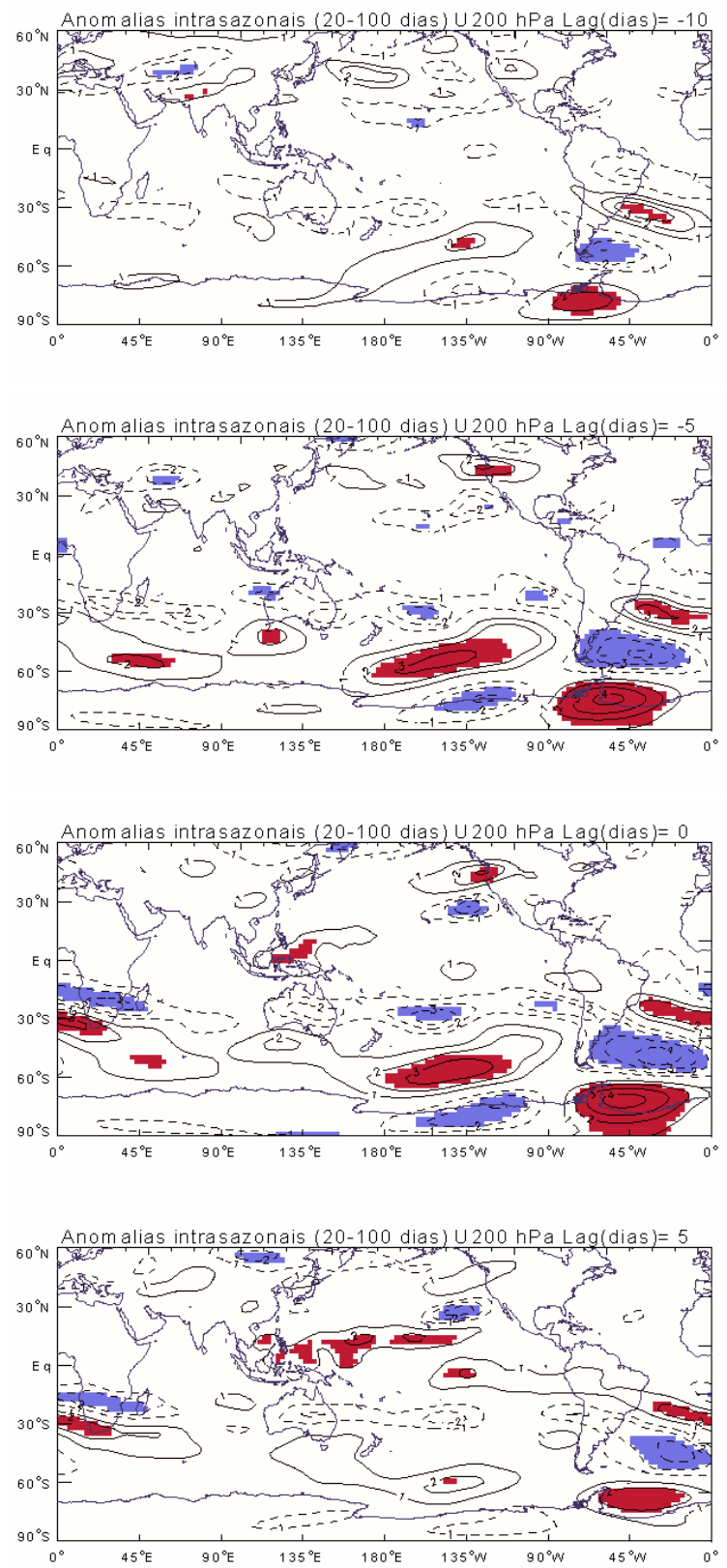

Figura 3. 14. Composições defasadas de anomalias intrasazonais do vento zonal $(\mathrm{m} / \mathrm{s}) \mathrm{em} 200 \mathrm{hPa}$ durante os eventos extremos intrasazonais: (a) frios (EIF) e (b) quentes (EIQ) no inverno em Arturo (Península oeste). As linhas contínuas (tracejadas) indicam valores positivos (negativos). As áreas destacadas em vermelho (azul) são para os valores positivos (negativos) estatisticamente significativos ao nível de $95 \%$, baseado no teste t-Student. O intervalo dos contornos é de $1 \mathrm{~m} / \mathrm{s}$. 


\section{PENÍNSULA LESTE \\ U200Is}

(a) EIF
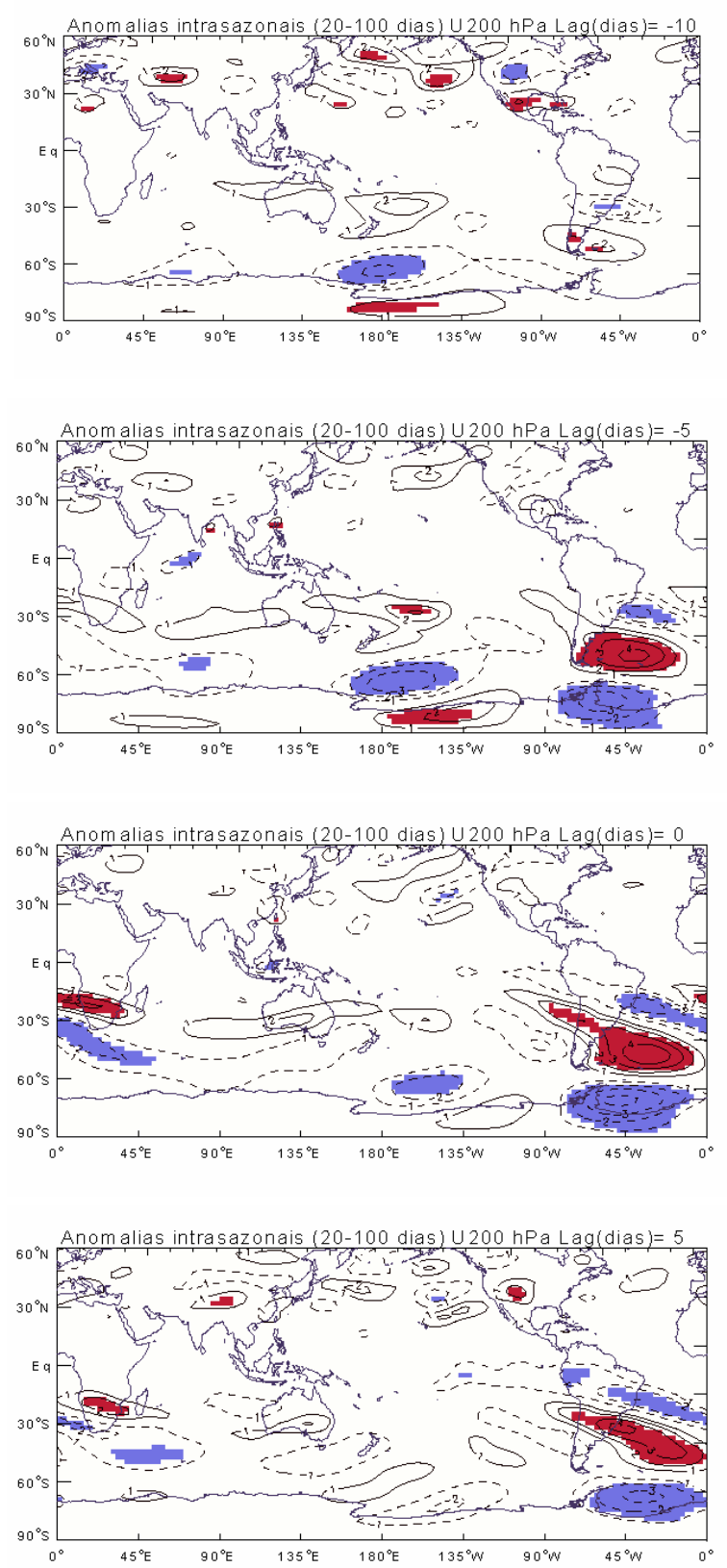

(b) EIQ
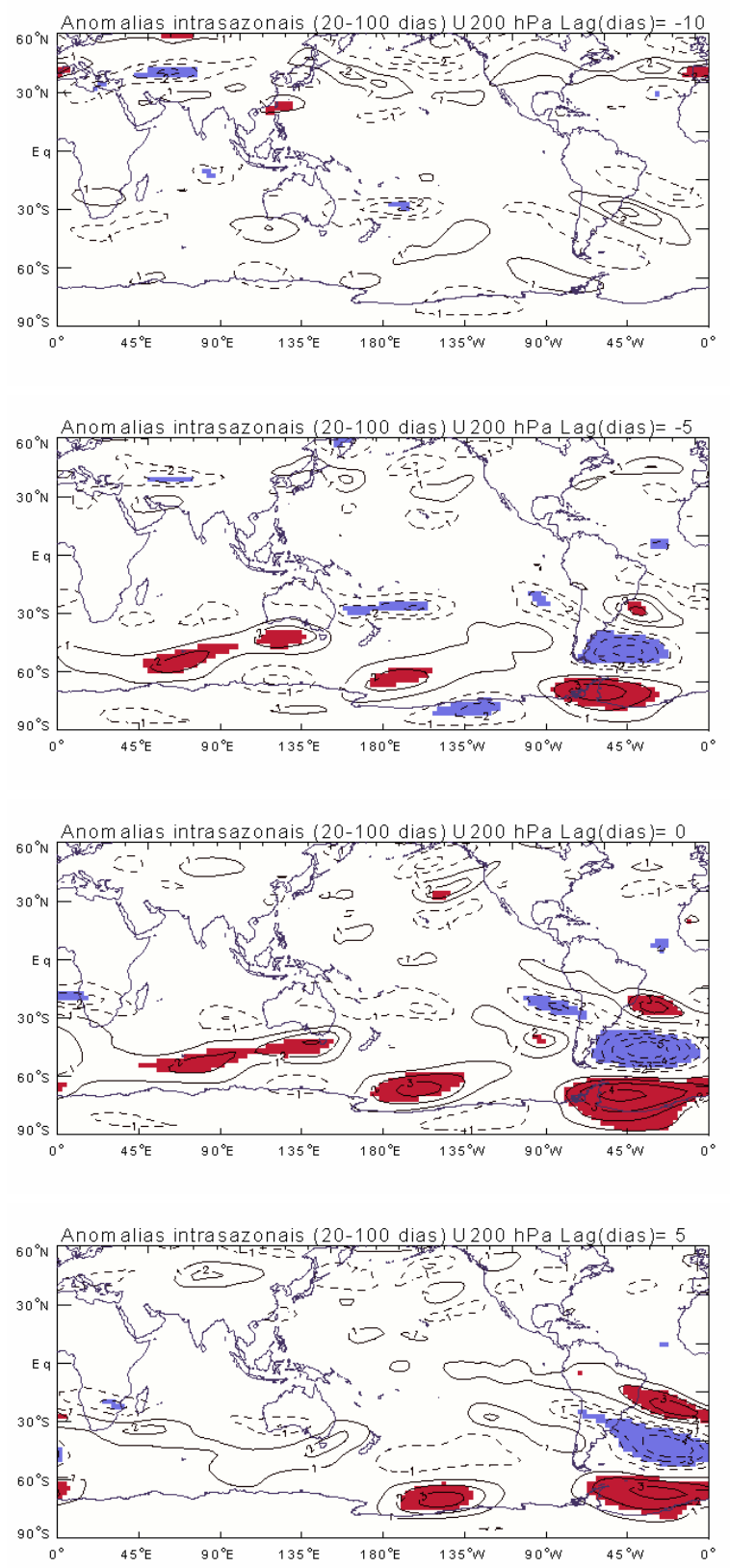

Figura 3. 15. Idem a Fig. 3.14, mas para Marambio (Península leste). 


\section{PENÍNSULA OESTE}

(a) EIF
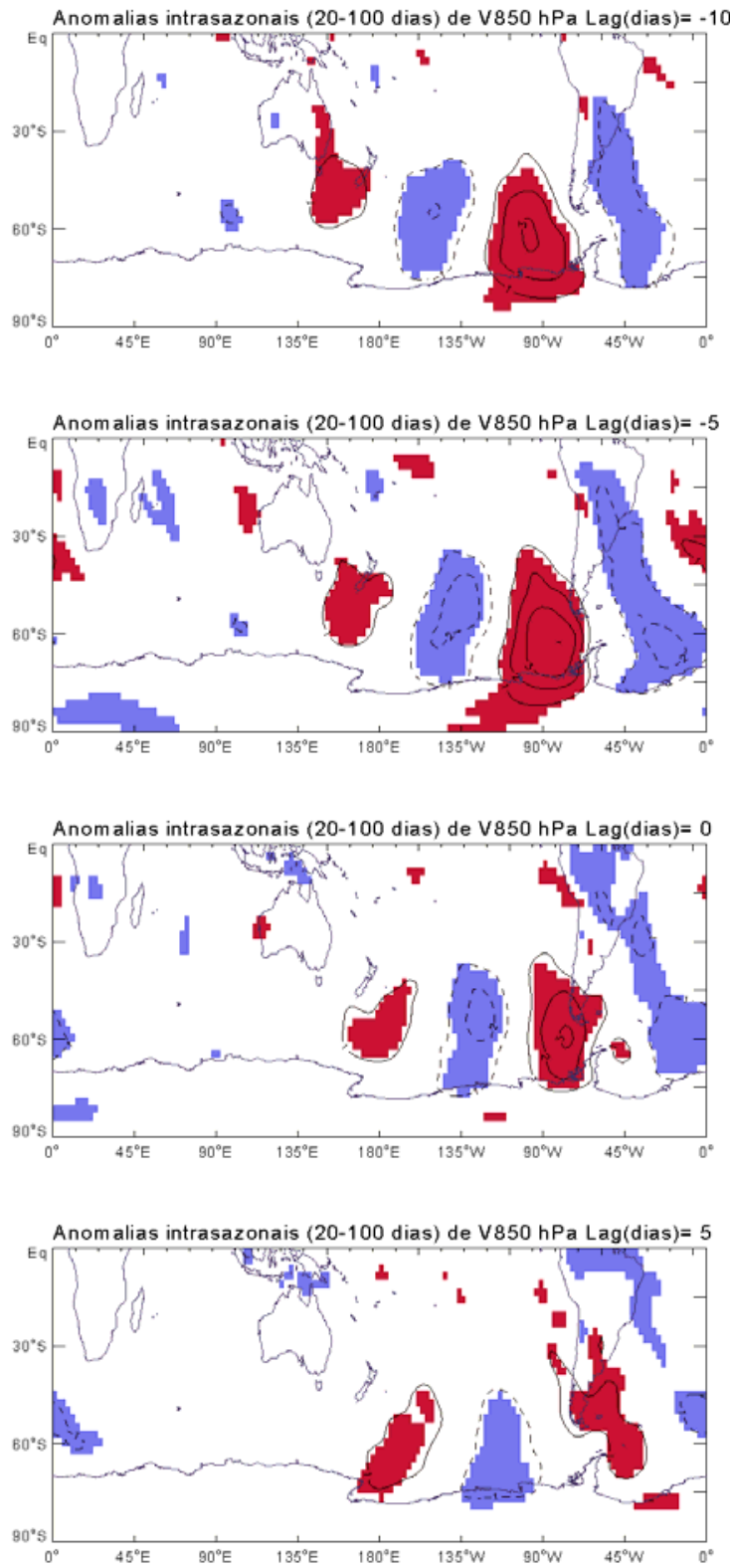

(b) EIQ
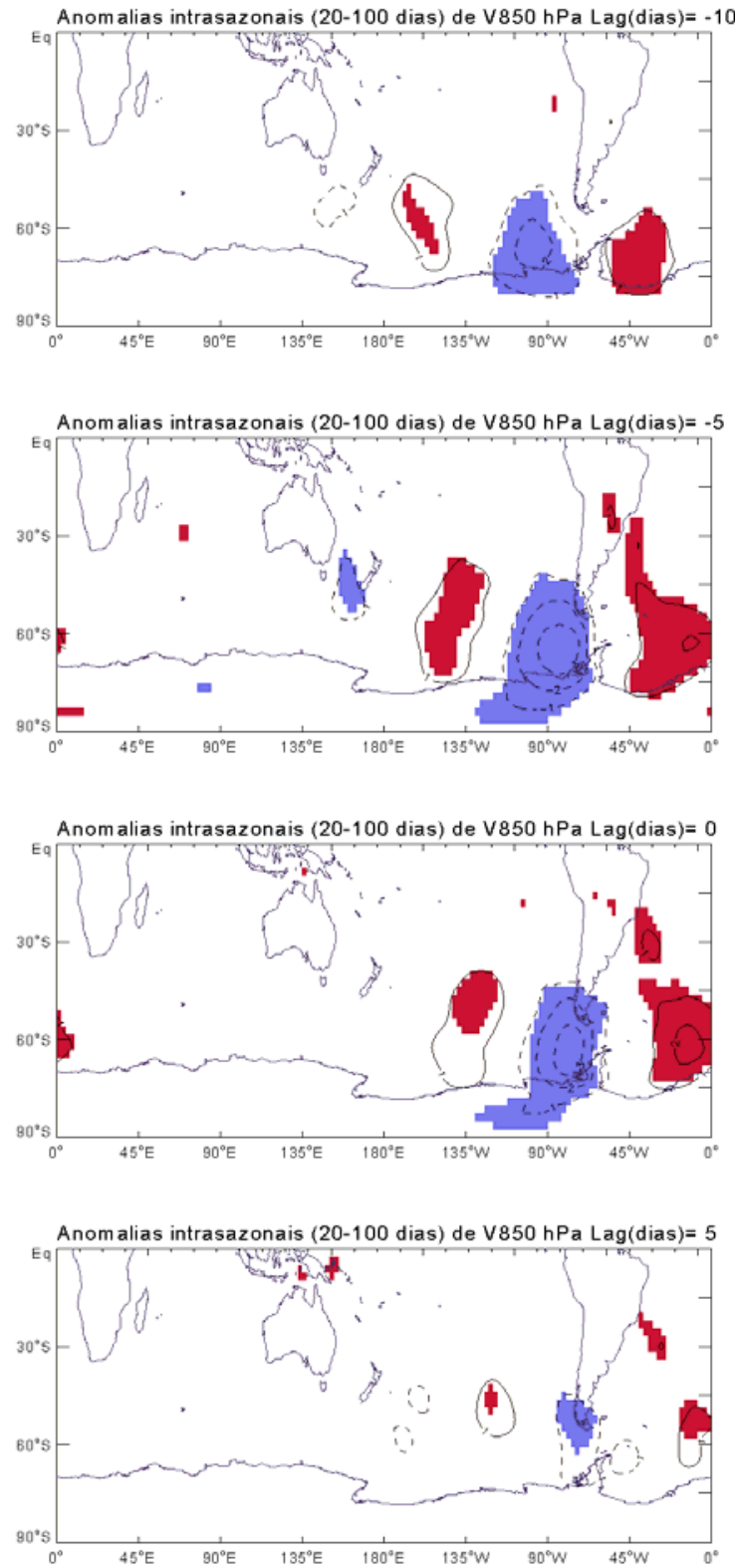

Figura 3. 16. Composições defasadas de anomalias intrasazonais do vento meridional $(\mathrm{m} / \mathrm{s})$ em $850 \mathrm{hPa}$ durante os eventos extremos intrasazonais: (a) frios (EIF) e (b) quentes (EIQ) no inverno em Arturo (Península oeste). As linhas contínuas (tracejadas) indicam valores positivos (negativos). As áreas destacadas em vermelho (azul) são para os valores positivos (negativos) estatisticamente significativos ao nível de $95 \%$, baseado no teste tStudent. O intervalo dos contornos é de $1 \mathrm{~m} / \mathrm{s}$. 


\section{PENÍNSULA LESTE}

(a) EIF
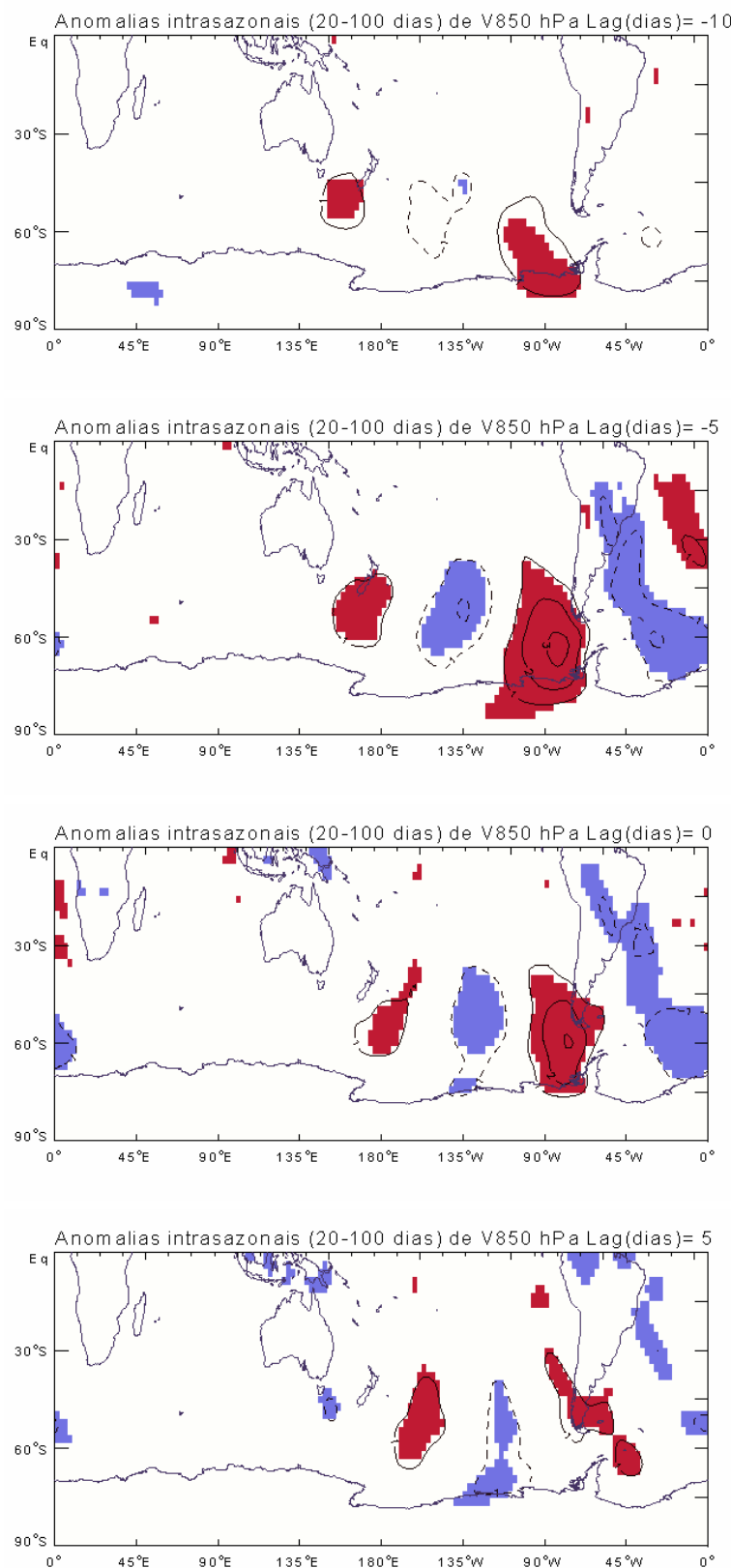

(b) EIQ
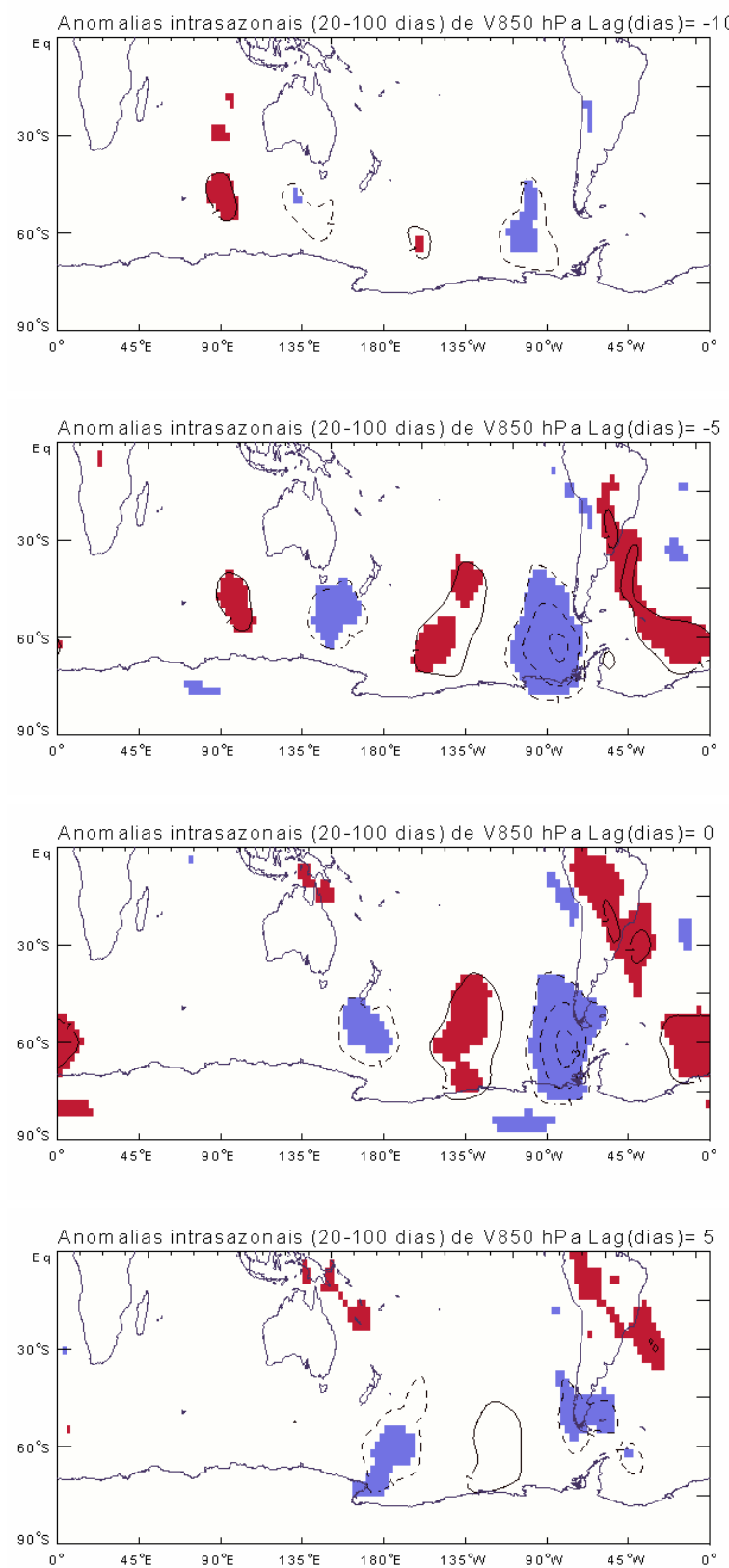

Figura 3. 17. Idem a Fig. 3.16, mas para Marambio (Península leste). 


\subsubsection{Primavera}

Um padrão semelhante ao detectado no inverno é observado na primavera. Os EIF na primavera estiveram associados com anomalias negativas (ciclônicas) de H200 IS sobre a Península Antártica (Figuras 3.18a e 3.19a). A anomalia ciclônica se propaga lentamente para leste, posicionando-se no Mar de Weddel no primeiro dia dos eventos frios (lag=0). Concomitantemente, uma anomalia anticiclônica se aproxima do Mar de Bellingshausen, o que propicia a advecção fria para as latitudes mais baixas. Comparando-se os EIQ (Figuras 3.18b e 3.19b) e os EIF (Figuras 3.18a e 3.19a) na região da Península Antártica, observa-se que estes estiveram associados a fases opostas do trem de ondas observado por meio de H200IS.

Observa-se, durante os EIF (Figuras 3.20a e 3.21a), a presença de anomalias negativas (de leste) de U200is sobre a Península Antártica, deslocando-se lentamente para leste, em direção ao Mar de Weddel no decorrer dos dias (lag=-10 a lag=5). Adicionalmente, anomalias de oeste no norte do Pacífico central norte e anomalias de leste ao sul desta região são observadas durante os EIF. Isto sugere uma possível resposta de Rossby aos distúrbios tropicais (ou subtropicais) como descrito por Grimm e Silva Dias (1995). A onda de Rossby, por sua vez, pode ser conduzida pelos jatos (Hoskins e Ambrizzi 1993; Ambrizzi et al. 1995), propagando-se para os extratrópicos em ambos os hemisférios. Outra característica de propagação de trem de ondas é observada próximo ao Oceano austral estendendo-se sobre a costa leste da África durante os EIF (lag=0 a lag=5, Figuras 3.20a e 3.21a). Este caminho de propagação foi observado por Ambrizzi et al. (1995) ao investigar os padrões de tele-conexão durante o inverno austral. De modo geral, para os EIQ (Figuras 3.20b e 3.21b), características opostas aos EIF foram observadas na circulação sobre a Península Antártica durante a primavera.

Os EIF (EIQ) na primavera estiveram associados com anomalias positivas (negativas) de V850Is, ou seja, anomalias de sul (de norte), persistentes até o lag=5 na Península Antártica (Figuras 3.22 e 3.23). 


\section{PENÍNSULA OESTE}

\section{H200Is}

(a) EIF
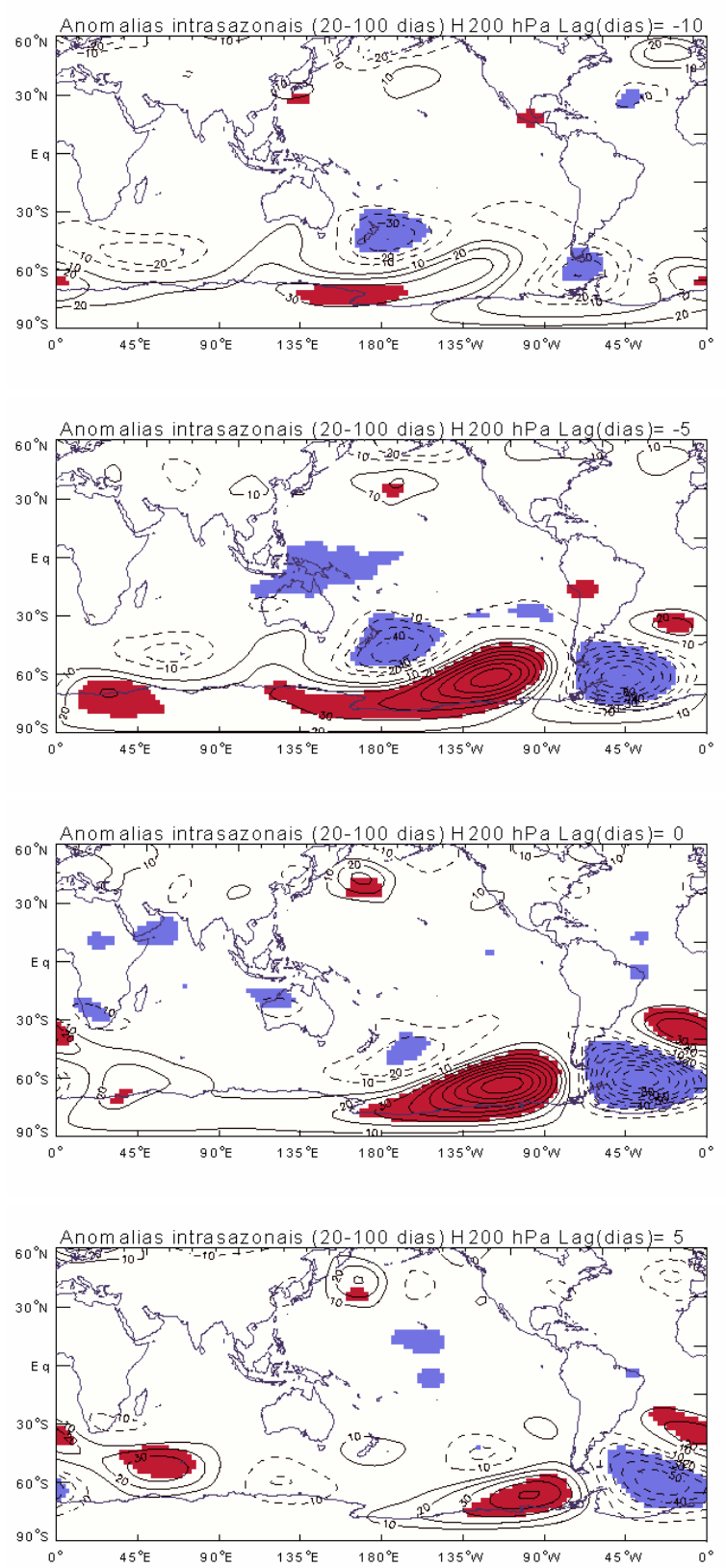

(b) EIQ
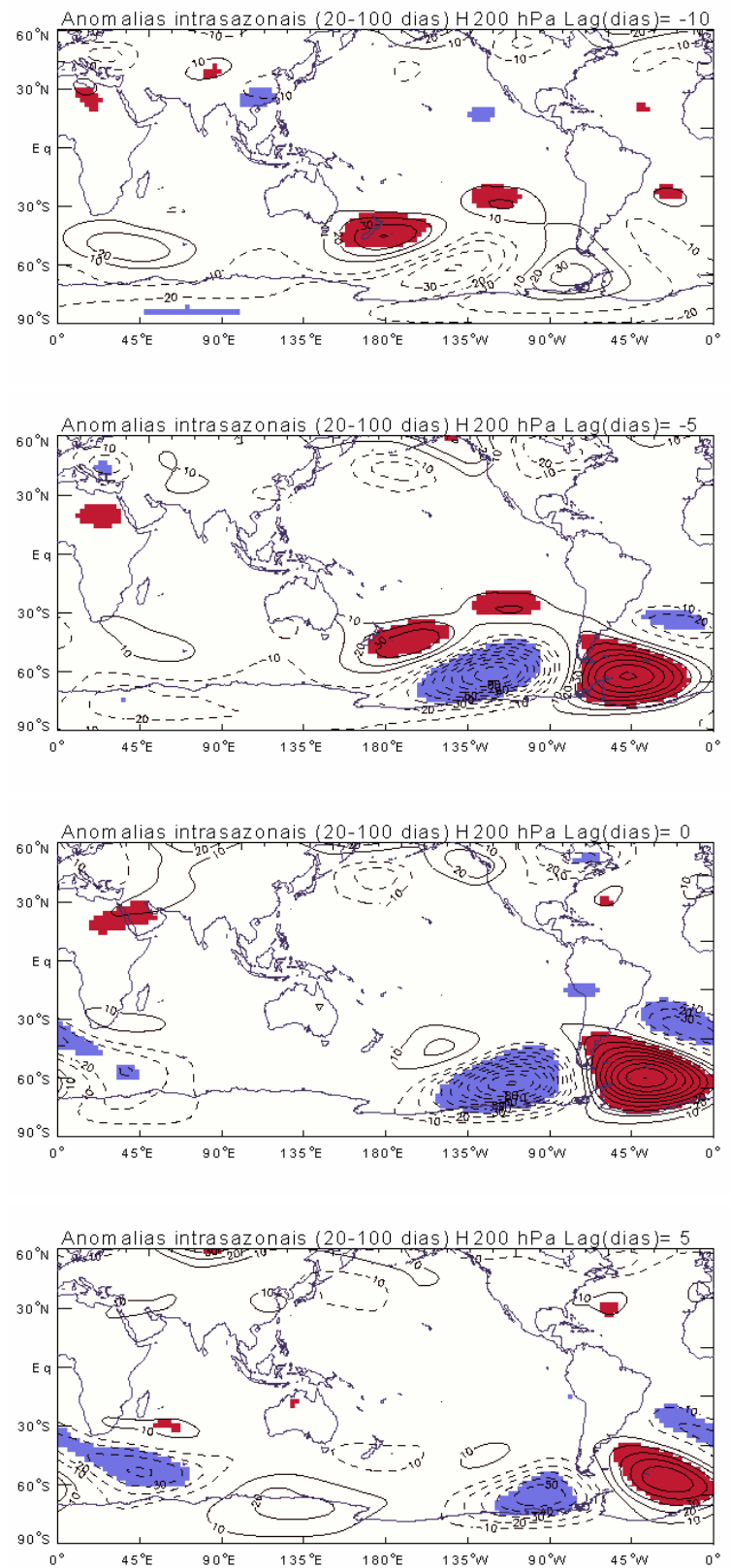

Figura 3. 18. Composições defasadas de anomalias intrasazonais do geopotencial (mgp) em $200 \mathrm{hPa}$ durante os eventos extremos intrasazonais: (a) frios (EIF) e (b) quentes (EIQ) na primavera em Arturo (Península oeste). As linhas contínuas (tracejadas) indicam valores positivos (negativos). As áreas destacadas em vermelho (azul) são para os valores positivos (negativos) estatisticamente significativos ao nível de $95 \%$, baseado no teste t-Student. O intervalo dos contornos é de 10 mgp. 


\section{PENÍNSULA LESTE}

(a) EIF
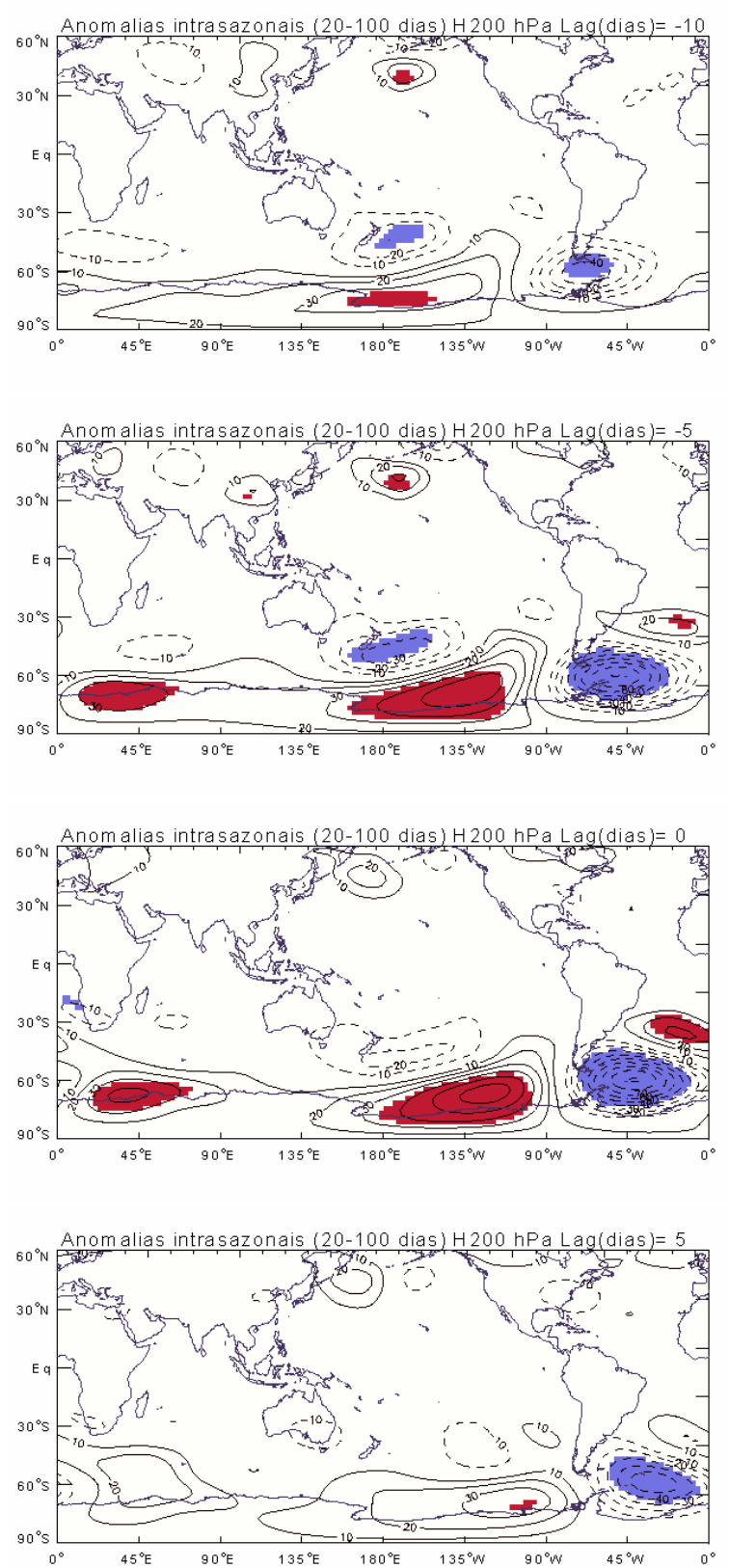

(b) EIQ
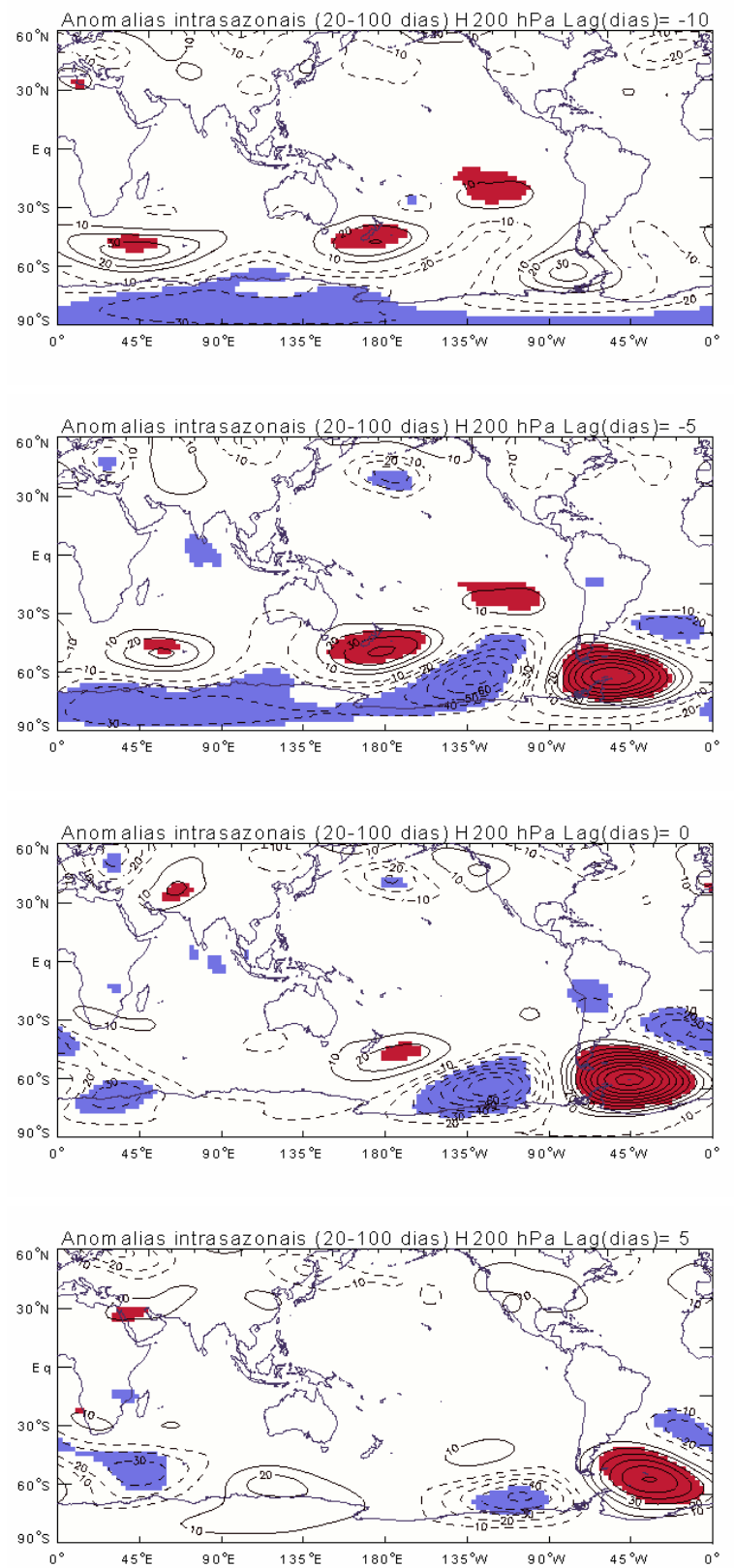

Figura 3. 19. Idem a Fig. 3.18, mas para Marambio (Península leste). 


\section{PENÍNSULA OESTE U200IS}

(a) EIF
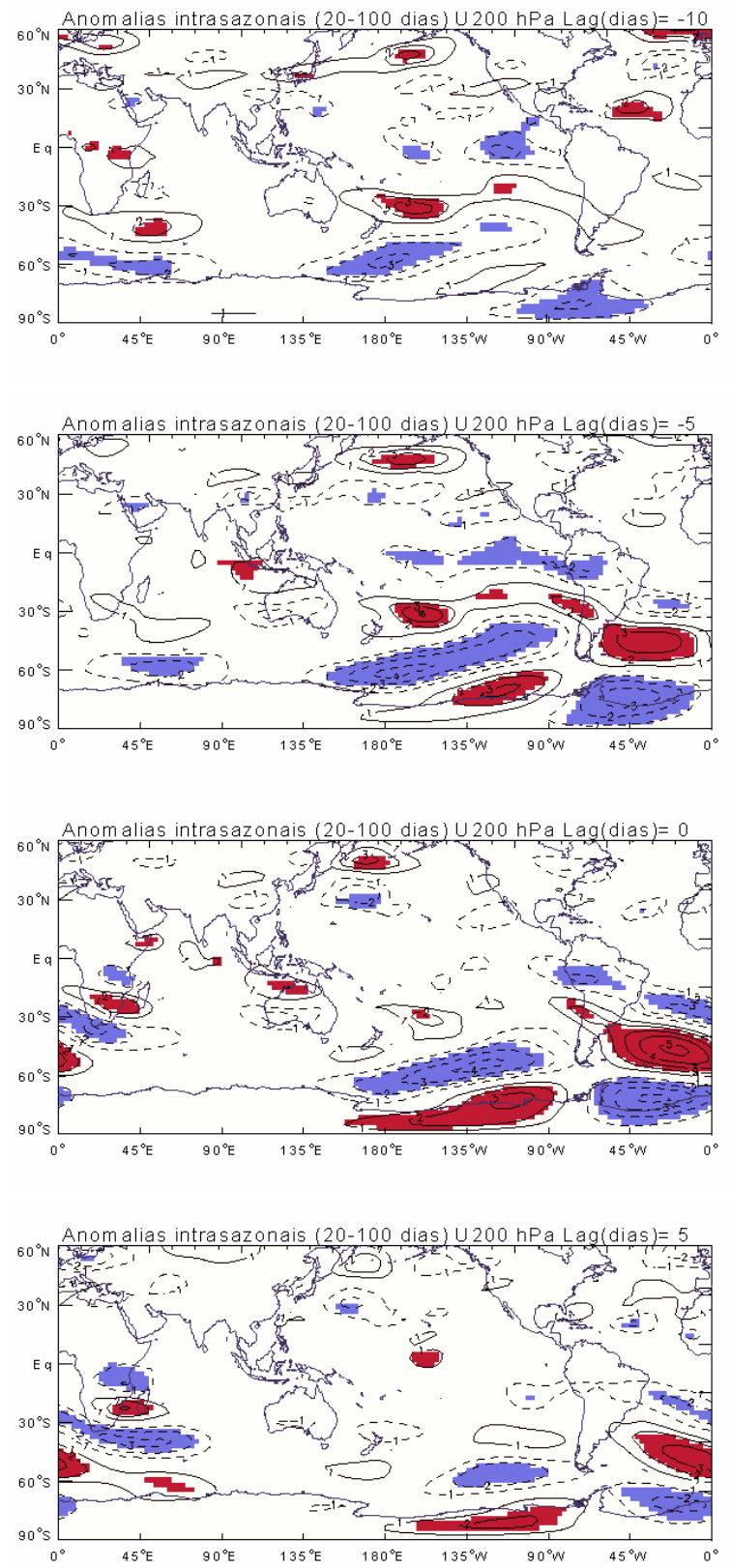

(b) EIQ
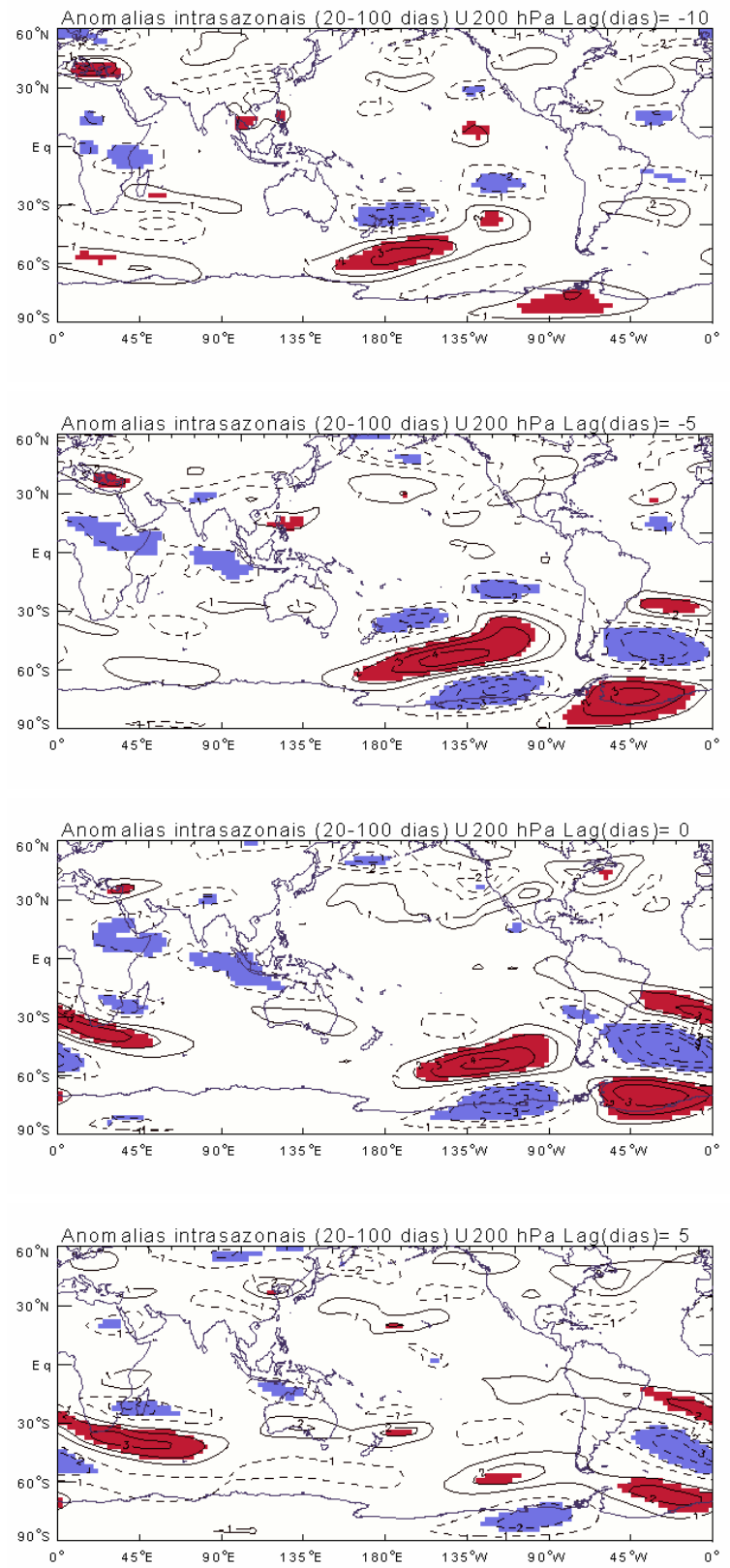

Figura 3. 20. Composições defasadas de anomalias intrasazonais do vento zonal $(\mathrm{m} / \mathrm{s})$ em $200 \mathrm{hPa}$ durante os eventos extremos intrasazonais: (a) frios (EIF) e (b) quentes (EIQ) na primavera em Arturo (Península oeste). As linhas contínuas (tracejadas) indicam valores positivos (negativos). As áreas destacadas em vermelho (azul) são para os valores positivos (negativos) estatisticamente significativos ao nível de $95 \%$, baseado no teste t-Student. O intervalo dos contornos é de $1 \mathrm{~m} / \mathrm{s}$. 


\section{PENÍNSULA LESTE}

\section{U200ıs}

(a) EIF
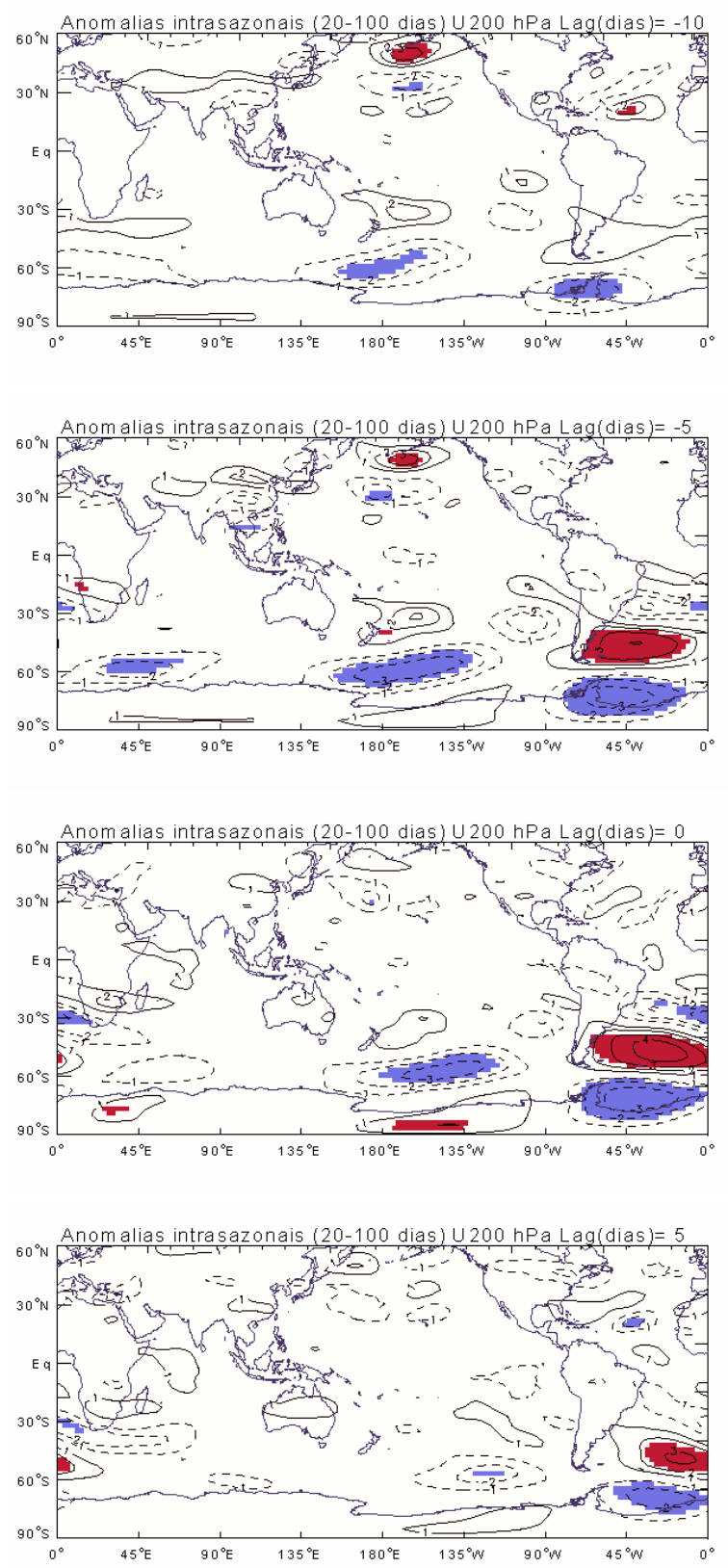

(b) EIQ
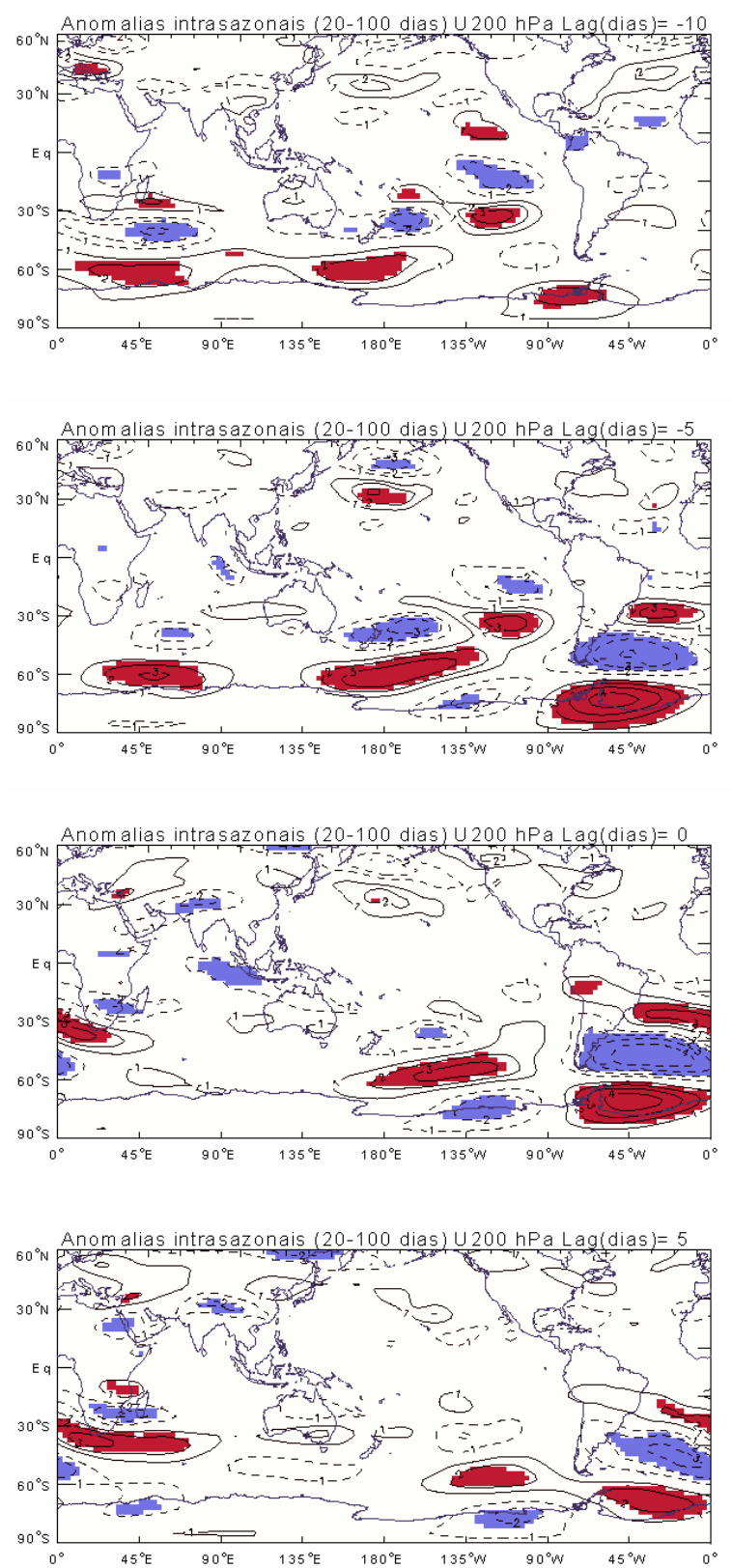

Figura 3. 21. Idem a Fig. 3.20, mas para Marambio (Península leste). 
PENÍNSULA OESTE

V850ıs

(a) EIF
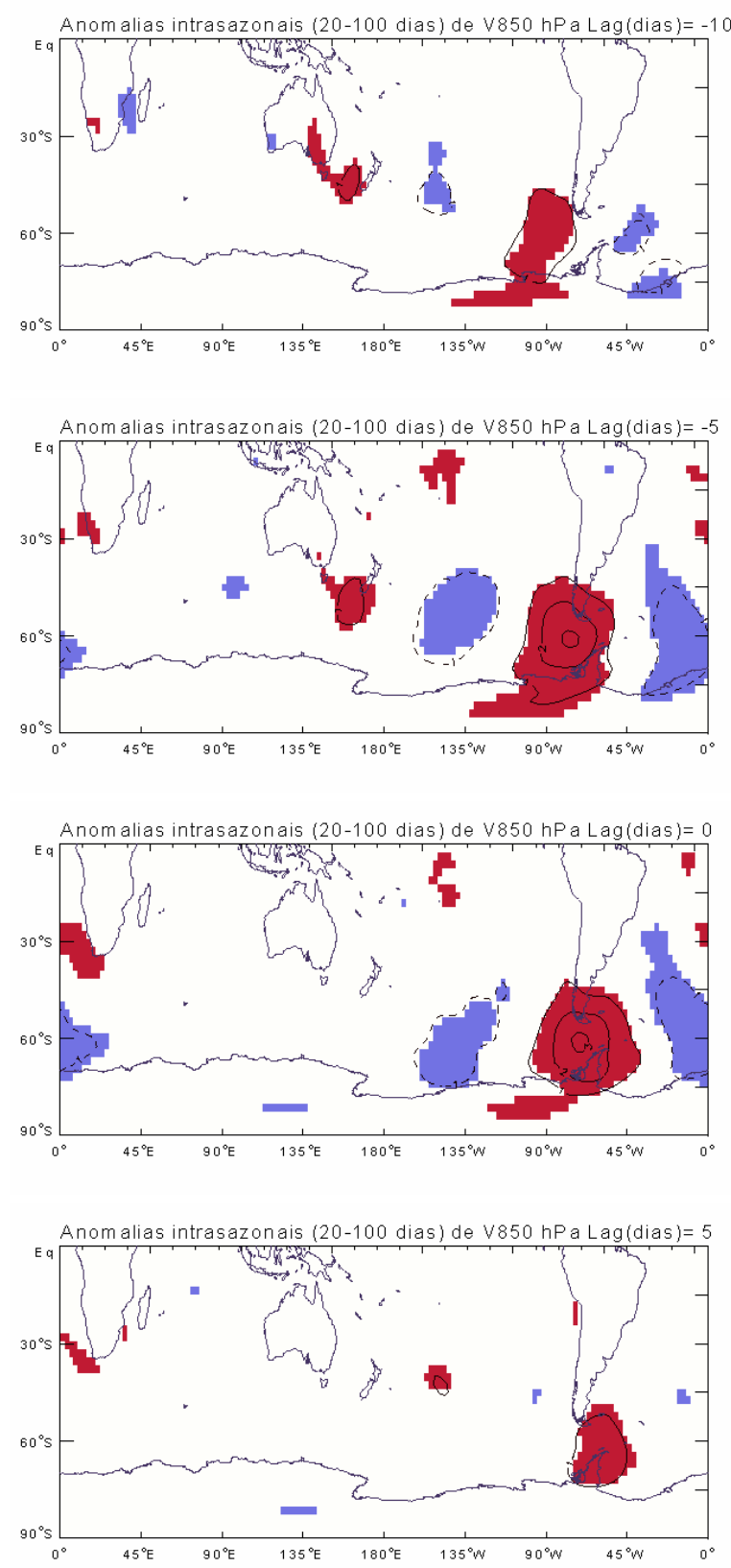

(b) EIQ
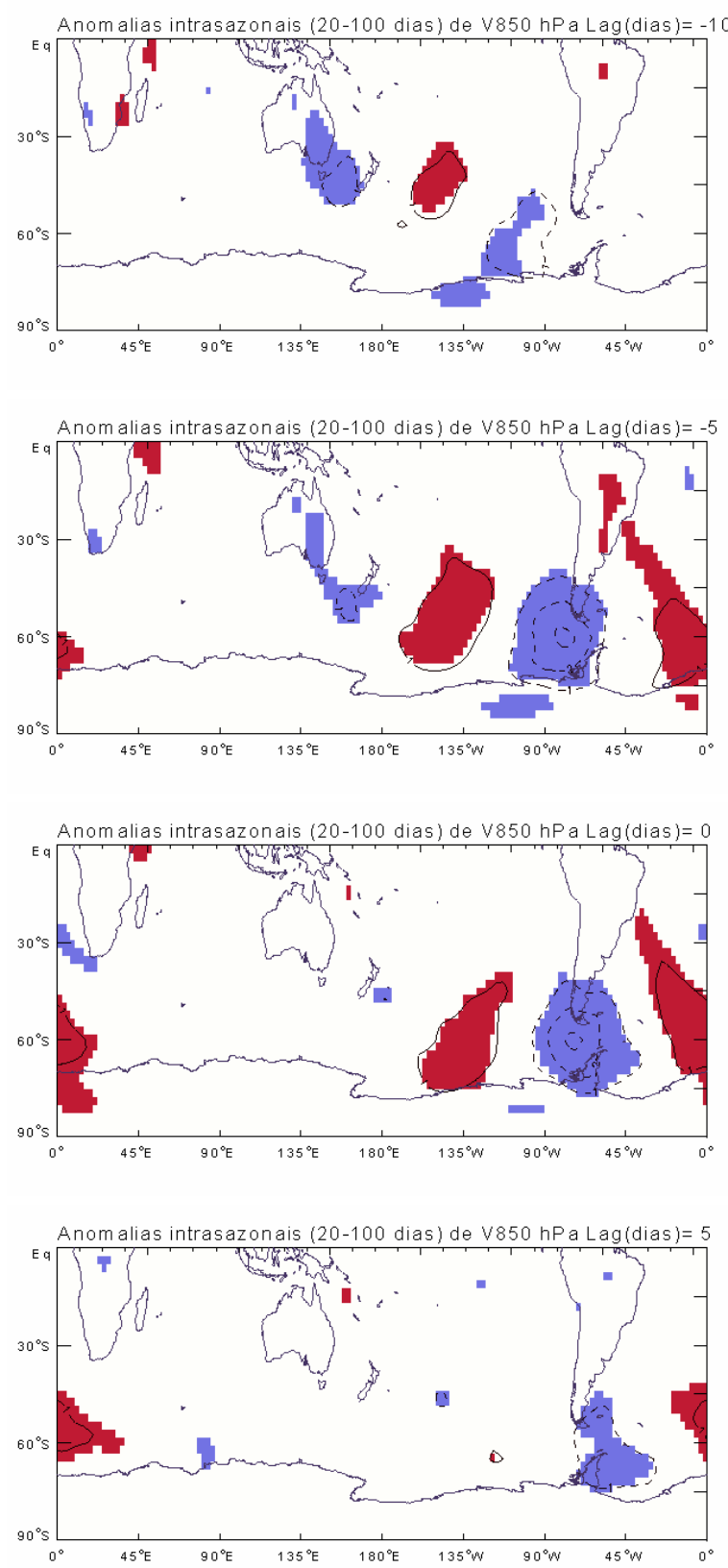

Figura 3. 22. Composições defasadas de anomalias intrasazonais do vento meridional (m/s) em $850 \mathrm{hPa}$ durante os eventos extremos intrasazonais: (a) frios (EIF) e (b) quentes (EIQ) na primavera em Arturo (Península oeste). As linhas contínuas (tracejadas) indicam valores positivos (negativos). As áreas destacadas em vermelho (azul) são para os valores positivos (negativos) estatisticamente significativos ao nível de $95 \%$, baseado no teste $\mathrm{t}$ Student. O intervalo dos contornos é de $1 \mathrm{~m} / \mathrm{s}$. 


\section{PENÍNSULA LESTE \\ V850Is}

(a) EIF

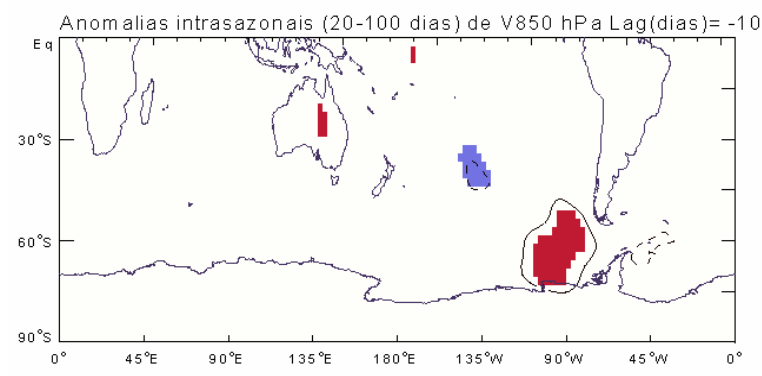

(b) EIQ
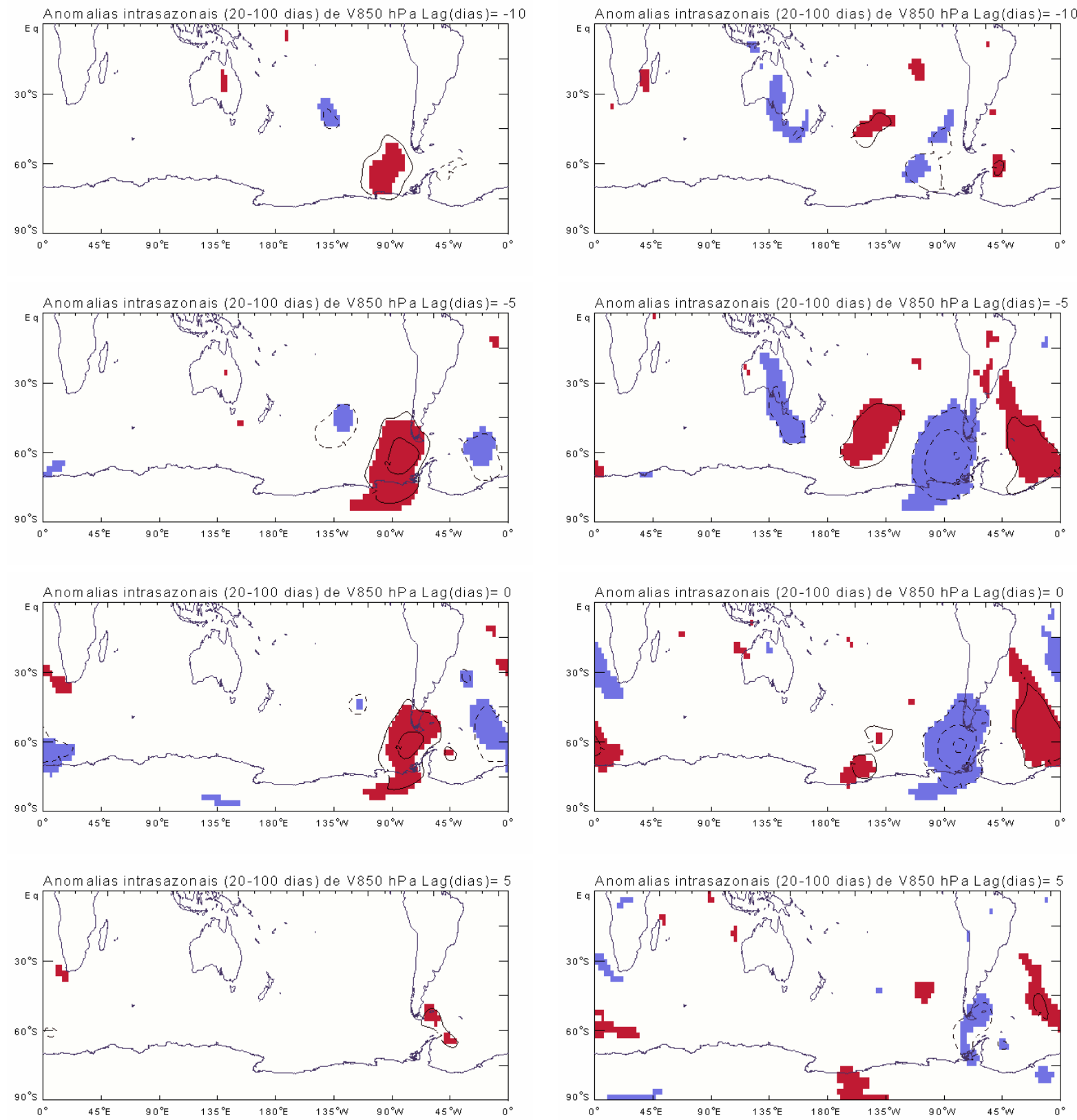

Figura 3. 23. Idem a Fig. 3.22, mas para Marambio (Península leste). 


\subsubsection{Verão}

Durante o verão, observa-se que a intensidade das anomalias associadas com o trem de ondas diminui (Figuras 3.24 e 3.25). Apenas próximo da ocorrência dos eventos (lag=-5 a lag $=0$ ), as anomalias indicam campos coerentes sobre a Península Antártica e oceanos adjacentes, sugerindo uma grande variabilidade caso a caso dos eventos.

As anomalias de leste observadas durante os EIF no verão sobre a Península Antártica (lag $=-5$ a lag=0, Figuras 3.26a e 3.27a), parecem ser precedidas de anomalias anticiclônicas persistentes (lag=-10) sobre o Oceano Pacífico Norte, associado a anomalias de oeste na porção mais ao norte do Pacífico Norte e a anomalias de leste na porção mais ao sul. Estas características foram observadas por Higgins e Mo (1997), ao investigar as anomalias persistentes na circulação no Pacífico Norte associada à oscilação intra-sazonal tropical. O padrão de anomalias observado na circulação nos dois hemisférios sugere a resposta extratropical da OMJ (Higgins e Mo 1997). Para os EIQ, observa-se uma característica oposta da circulação observada nos EIF, ou seja, com anomalias de oeste sobre a Península Antártica durante os eventos (lag=-5 a lag=0, Figuras $3.26 \mathrm{~b}$ e $3.27 \mathrm{~b}$ ). Além disso, as anomalias no Pacífico Norte são menos definidas durante estes eventos.

As anomalias de sul (de norte) associadas aos EIF (EIQ) persistiram até o primeiro dia dos eventos sobre a Península Antártica e oceanos adjacentes (Figuras 3.28 e 3.29). 
PENÍNSULA OESTE

H200IS

(a) EIF
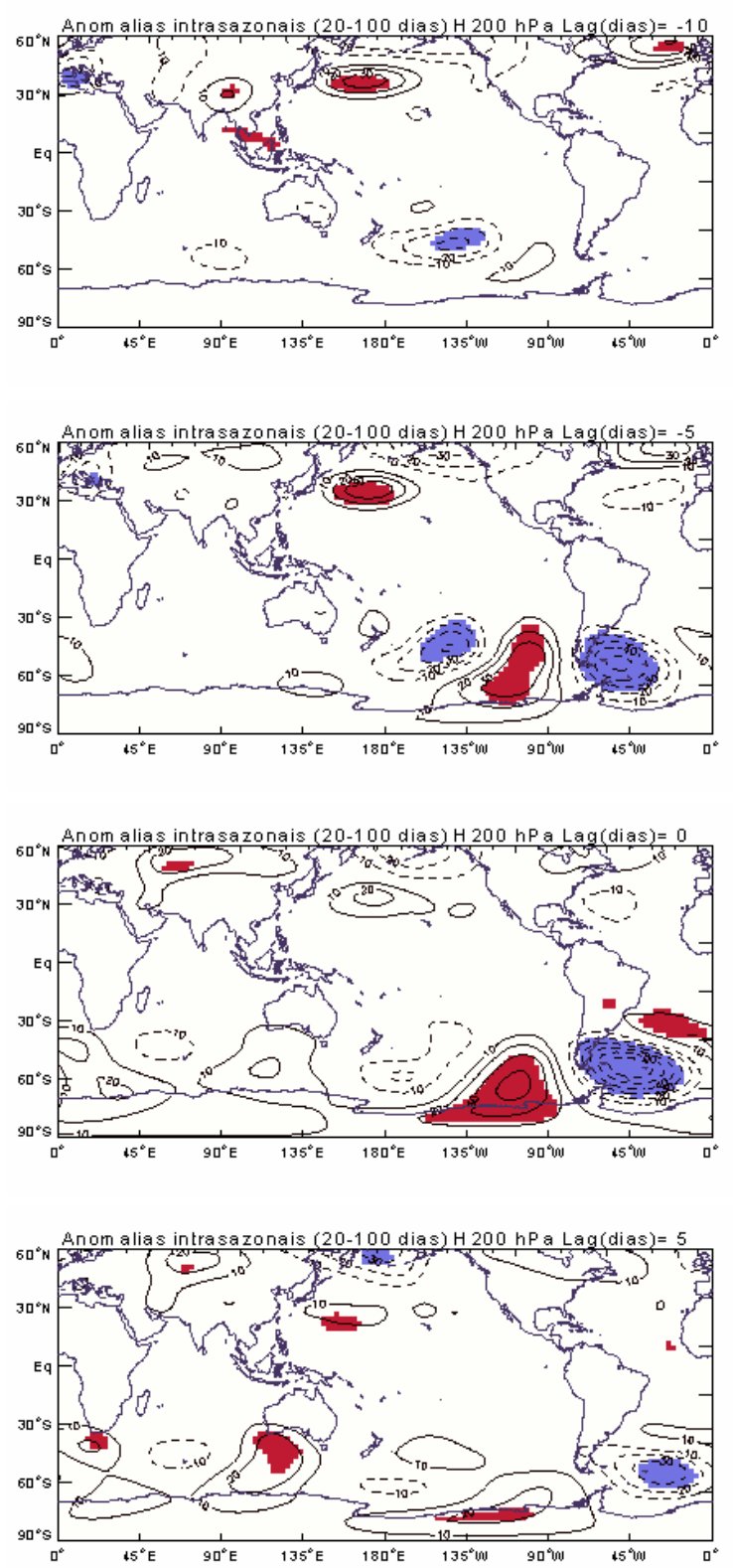

(b) EIQ
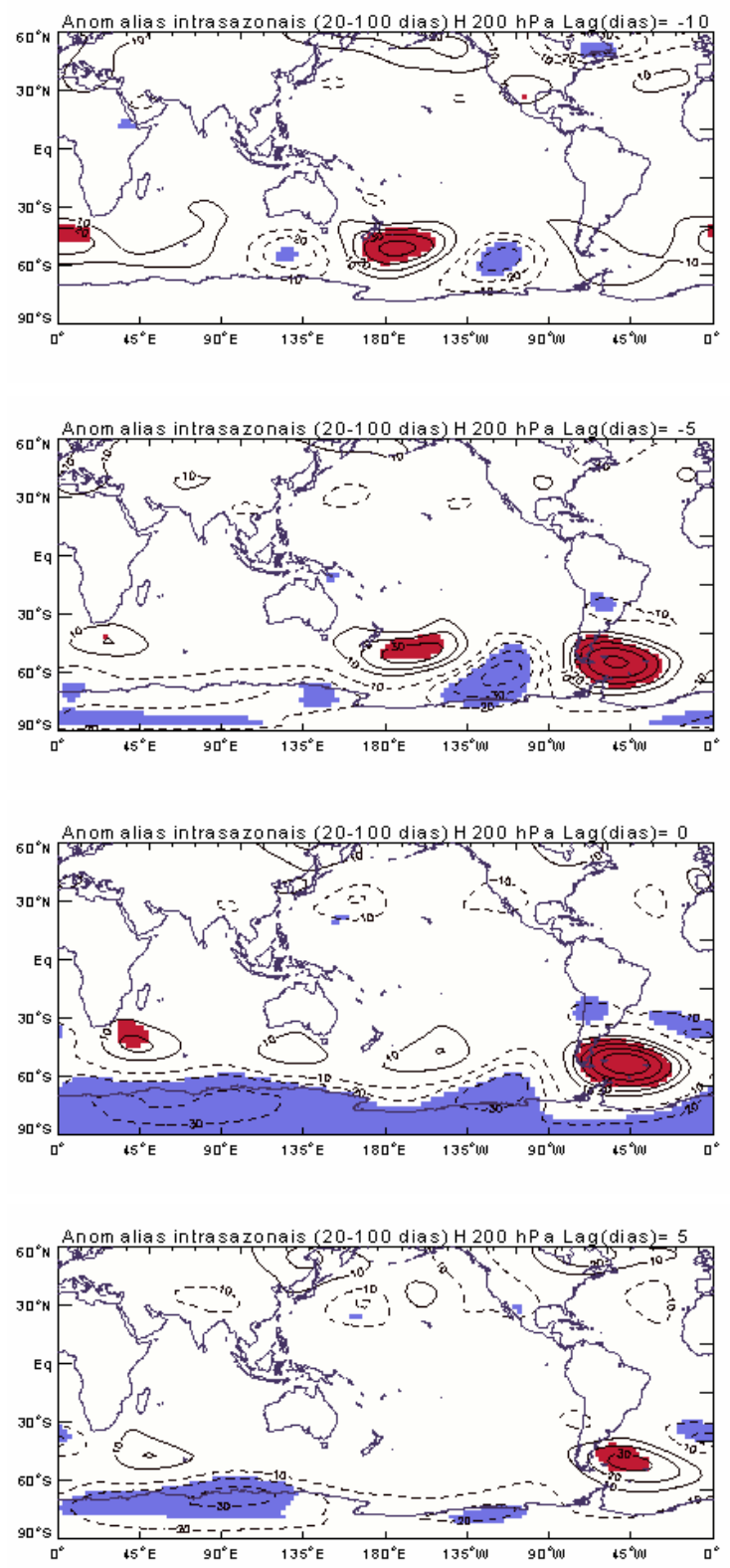

Figura 3. 24. Composições defasadas de anomalias intrasazonais do geopotencial (mgp) em $200 \mathrm{hPa}$ durante os eventos extremos intrasazonais: (a) frios (EIF) e (b) quentes (EIQ) no verão em Arturo (Península oeste). As linhas contínuas (tracejadas) indicam valores positivos (negativos). As áreas destacadas em vermelho (azul) são para os valores positivos (negativos) estatisticamente significativos ao nível de $95 \%$, baseado no teste t-Student. O intervalo dos contornos é de 10 mgp. 


\section{PENÍNSULA LESTE}

(a) EIF
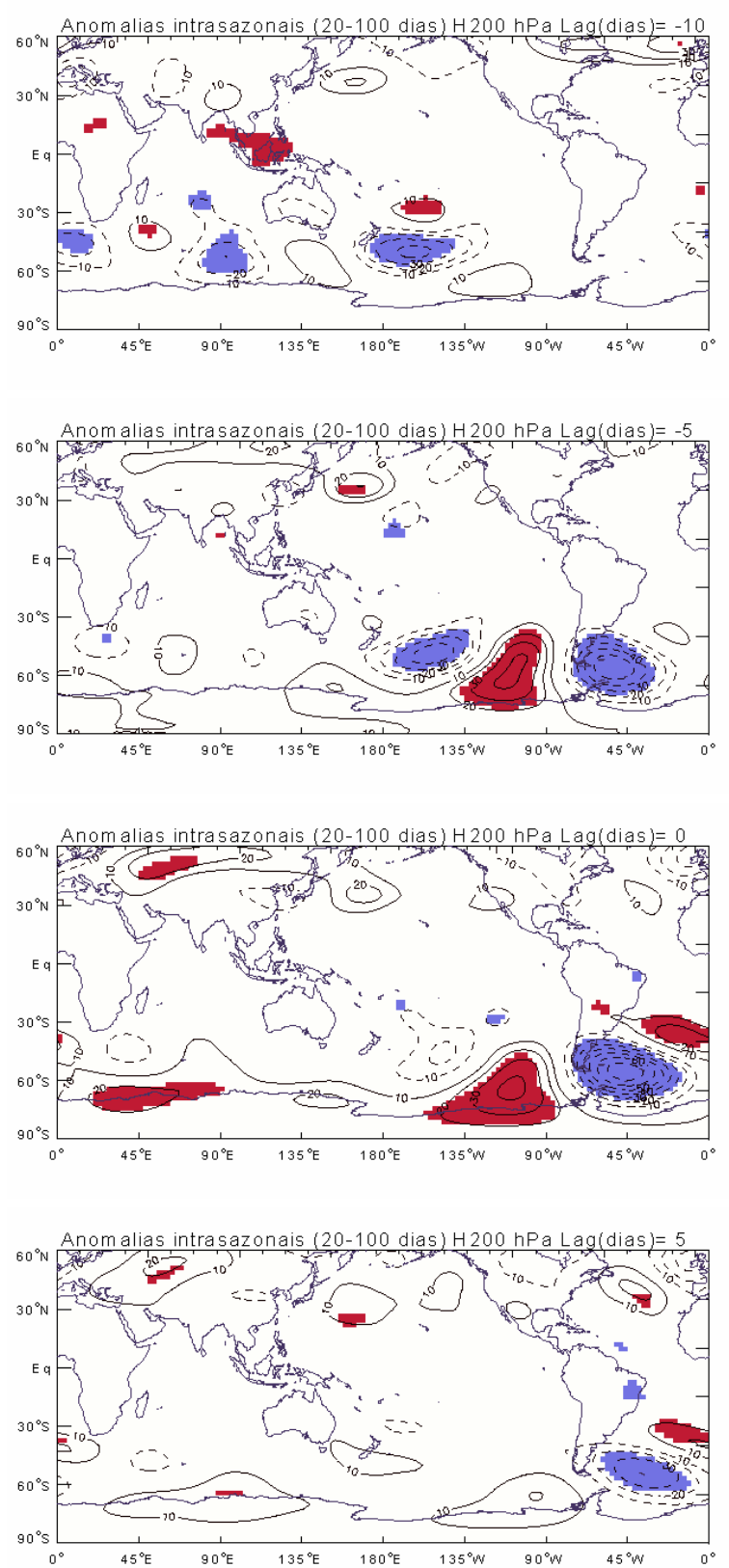

(b) EIQ
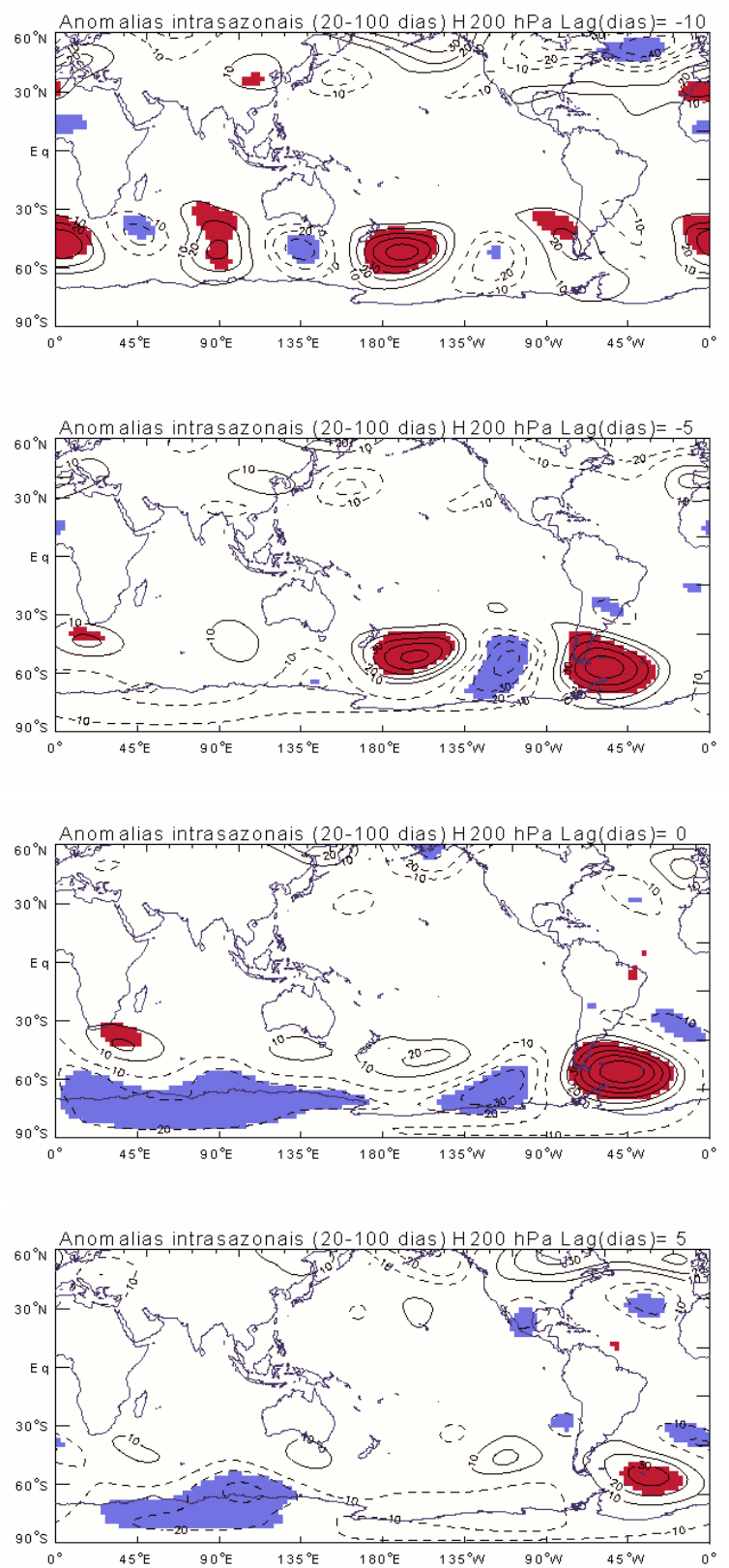

Figura 3. 25. Idem a Fig. 3.24, mas para Marambio (Península leste). 
PENÍNSULA OESTE

\section{U200is}

(a) EIF
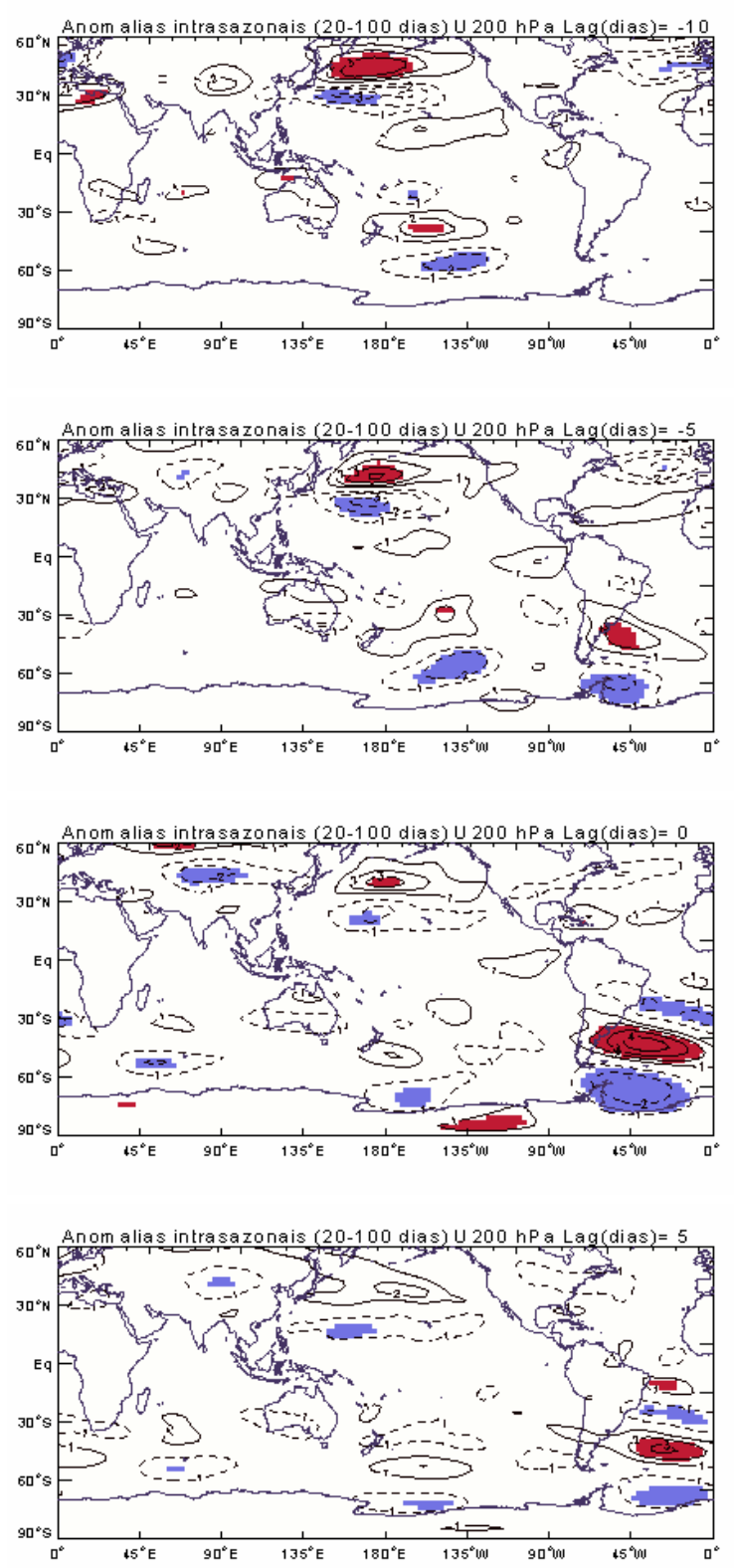

(b) EIQ
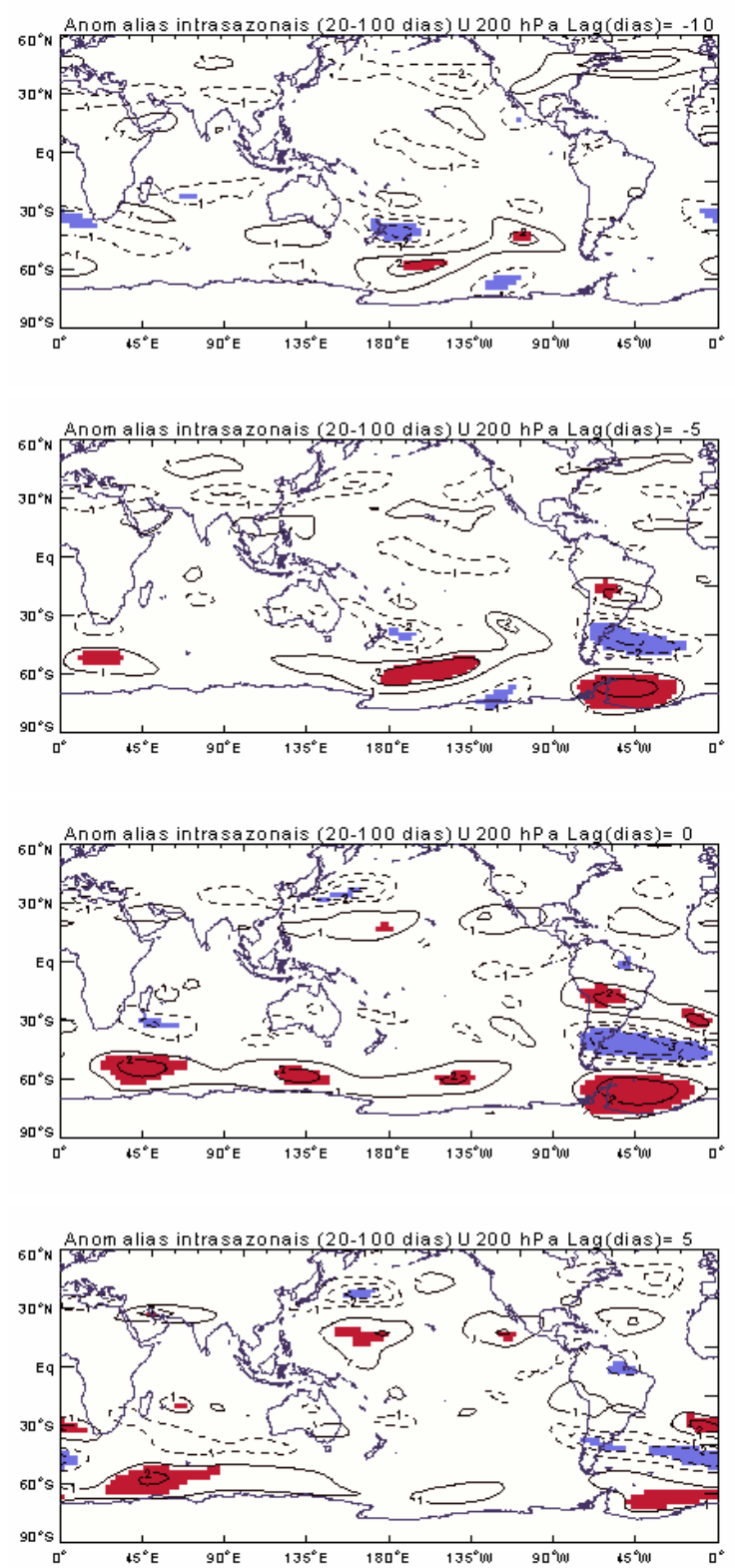

Figura 3. 26. Composições defasadas de anomalias intrasazonais do vento zonal (m/s) em 200 hPa durante os eventos extremos intrasazonais: (a) frios (EIF) e (b) quentes (EIQ) no verão em Arturo (Península oeste). As linhas contínuas (tracejadas) indicam valores positivos (negativos). As áreas destacadas em vermelho (azul) são para os valores positivos (negativos) estatisticamente significativos ao nível de $95 \%$, baseado no teste t-Student. $\mathrm{O}$ intervalo dos contornos é de $1 \mathrm{~m} / \mathrm{s}$. 


\section{PENÍNSULA LESTE}

(a) EIF
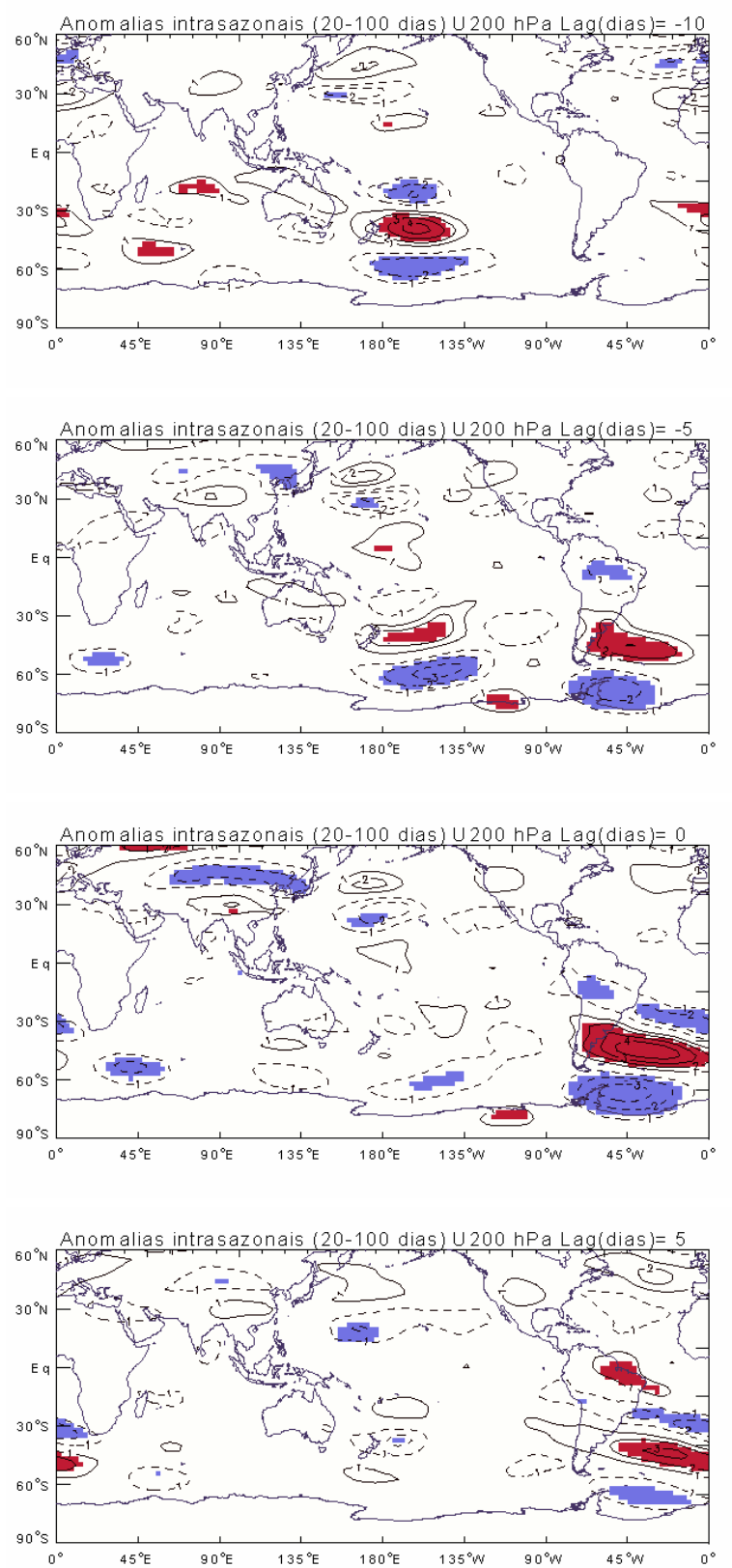

(b) EIQ
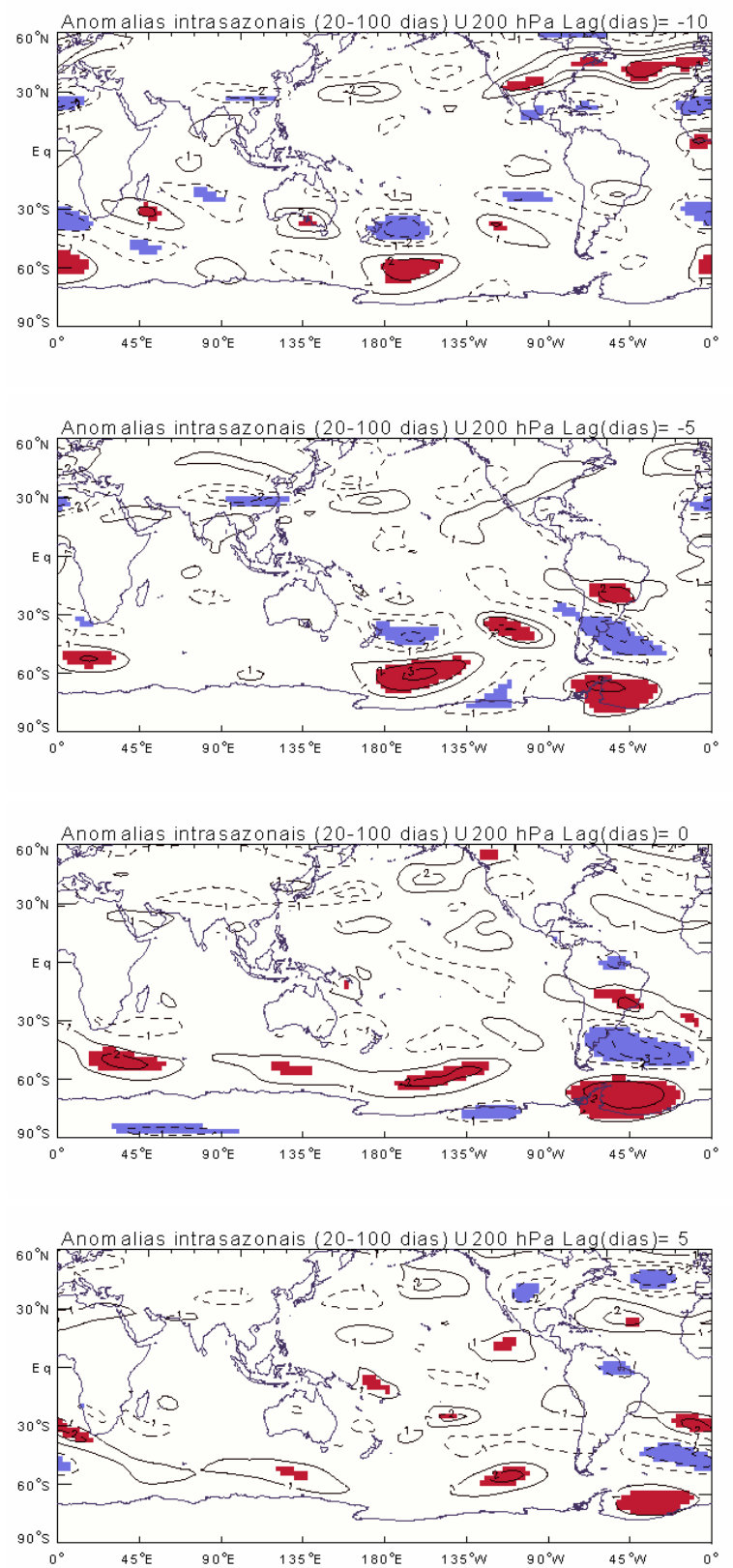

Figura 3. 27. Idem a Fig. 3.26, mas para Marambio (Península leste). 
PENÍNSULA OESTE

V850IS

(a) EIF
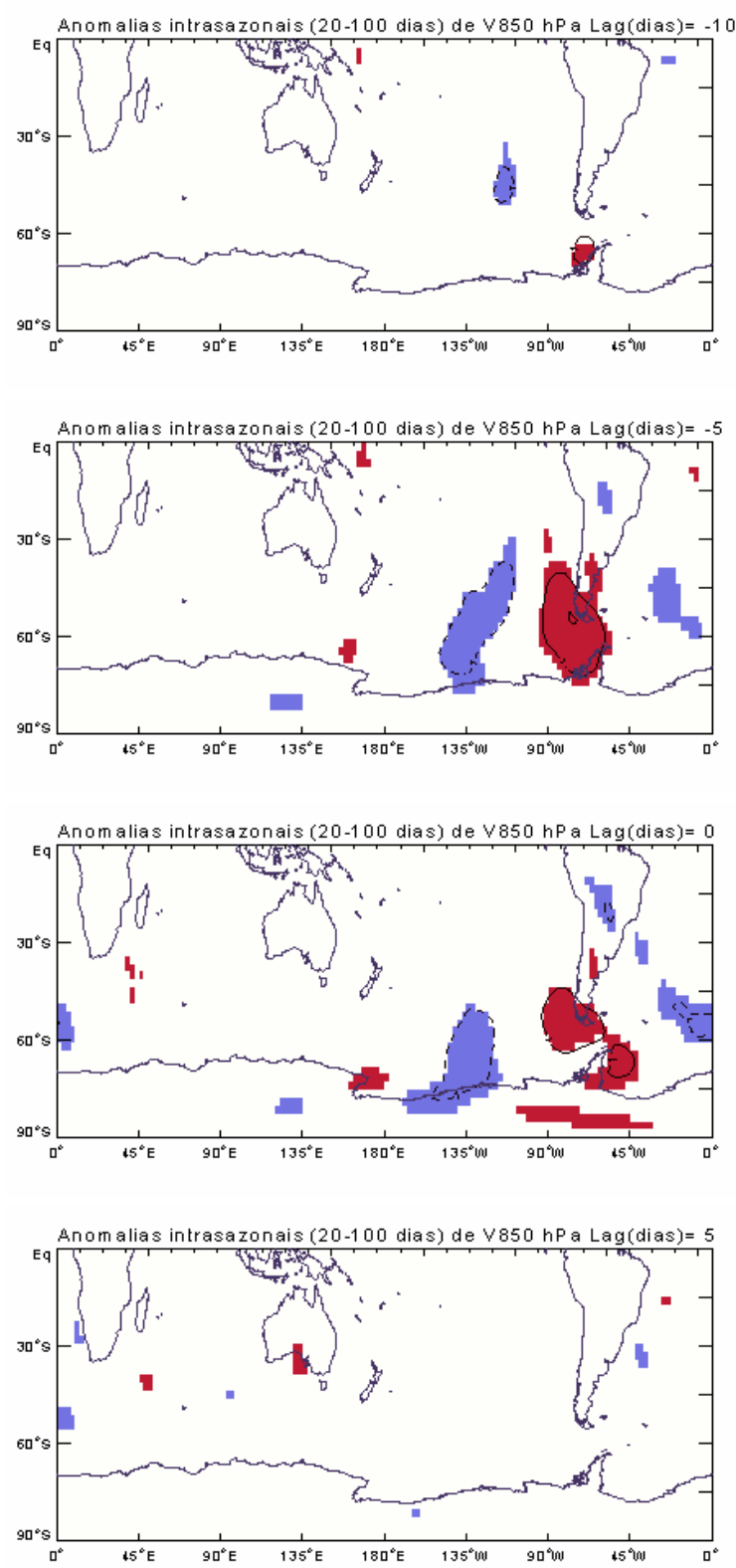

(b) EIQ
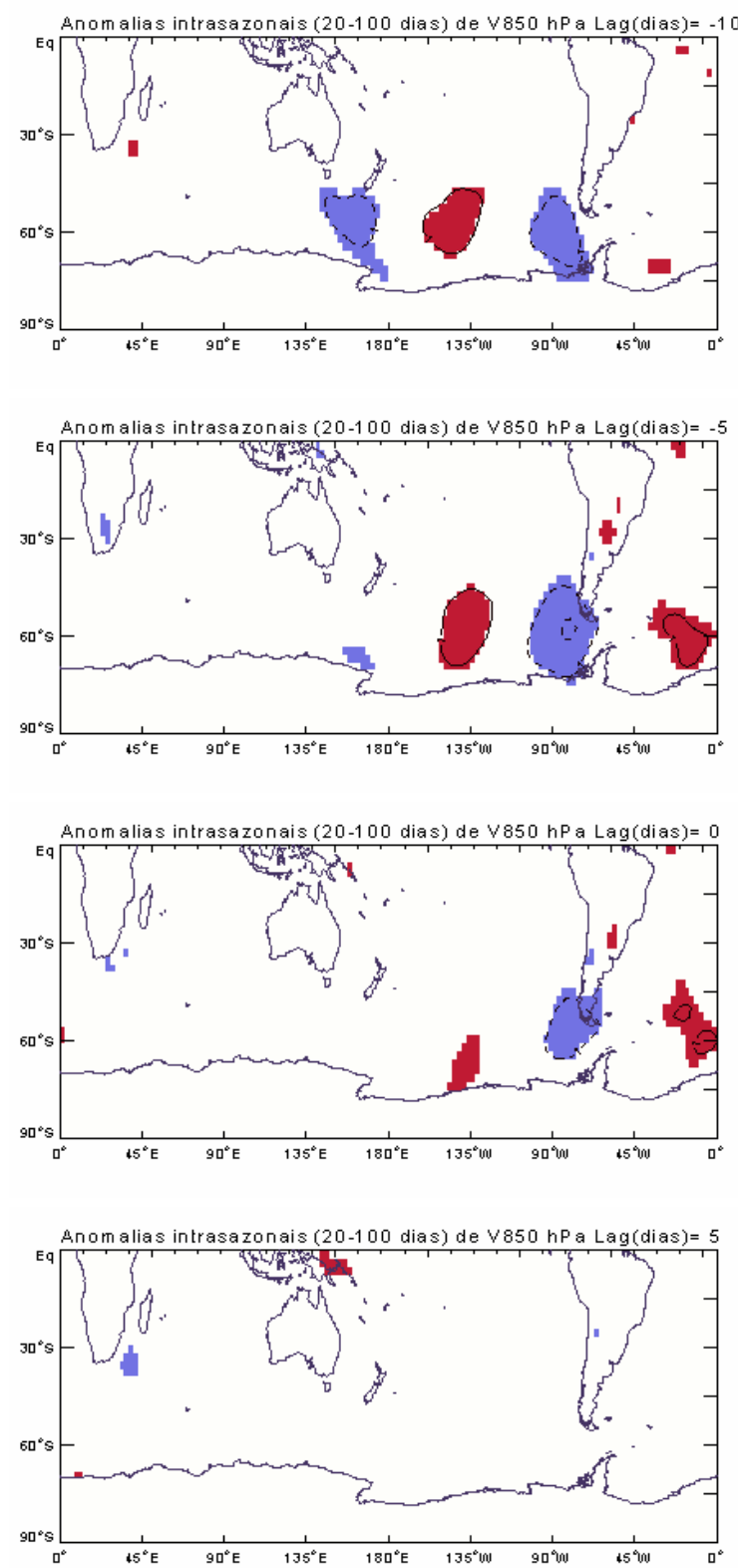

Figura 3. 28. Composições defasadas de anomalias intrasazonais do vento meridional (m/s) em $850 \mathrm{hPa}$ durante os eventos extremos intrasazonais: (a) frios (EIF) e (b) quentes (EIQ) no verão em Arturo (Península oeste). As linhas contínuas (tracejadas) indicam valores positivos (negativos). As áreas destacadas em vermelho (azul) são para os valores positivos (negativos) estatisticamente significativos ao nível de $95 \%$, baseado no teste t-Student. $\mathrm{O}$ intervalo dos contornos é de $1 \mathrm{~m} / \mathrm{s}$. 


\section{PENÍNSULA LESTE}

(a) EIF
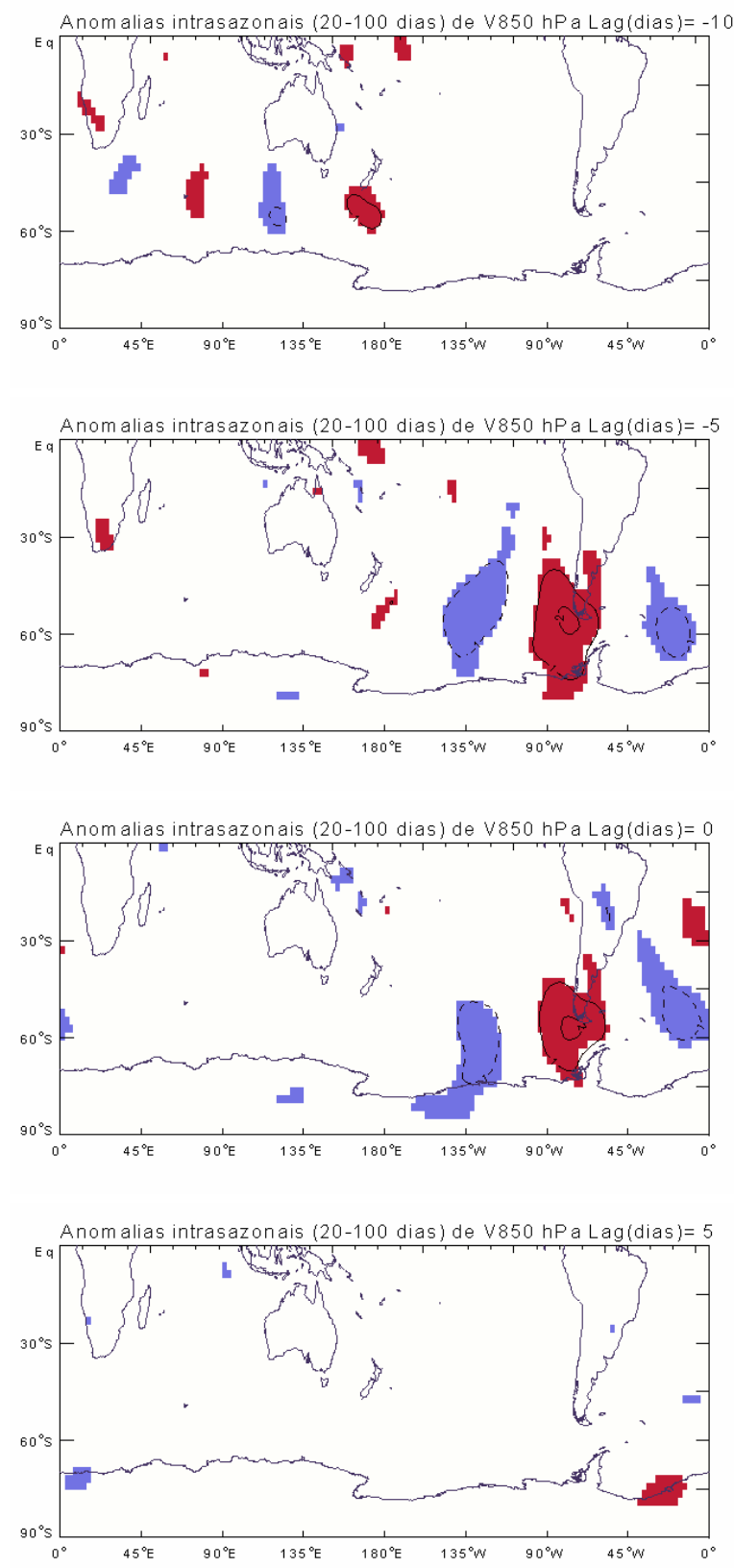

(b) EIQ
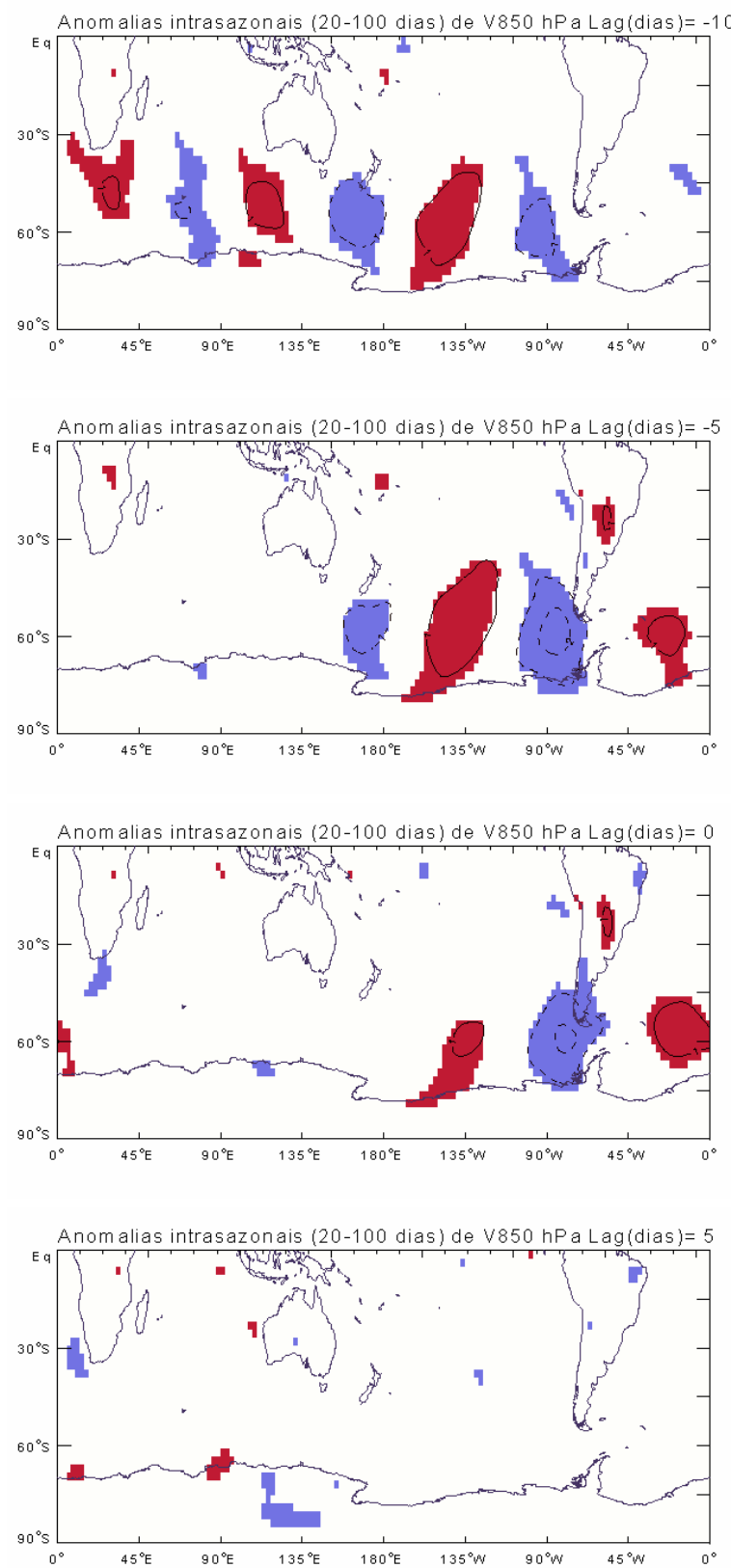

Figura 3. 29. Idem a Fig. 3.28, mas para Marambio (Península leste). 


\subsubsection{Comparação entre os casos com intensidades e persistências extremas e próximas da mediana}

Como descrito no item 3.2 os EIT foram definidos utilizando como critério o quartil inferior (q25) e superior (q75) das anomalias intra-sazonais de temperatura nas estações Arturo e Marambio, para o período de inverno, primavera e verão. Além disso, foram considerados todos os eventos independentes, sem nenhuma restrição quanto à persistência dos EIT. No entanto, algumas questões permanecem quanto à circulação atmosférica associada a intensidade e persistência dos EIT:

1) Qual a característica da circulação atmosférica associada a EIT mais intensos, ou seja, considerando o percentil de 10\% para os EIF e 90\% para os EIQ?

2) Há alguma alteração na circulação atmosférica observada anteriormente, se forem considerados os EIT com maior e menor persistência (acima do percentil de 75\% e abaixo do percentil de $25 \%$, respectivamente)? E quanto aos casos com persistência próxima da mediana (percentil de 50\%)?

Os padrões de circulação atmosférica em altos níveis, examinados por meio das composições de U200 IS, foram condicionados a estas variações nos limiares da intensidade e persistência dos EIT da estação Arturo (Península oeste) no período de inverno, primavera e verão (Figuras 3.30-3.32, respectivamente). A estação de Arturo foi selecionada por ter apresentado maior significância estatística nos picos espectrais correspondentes a escala intrasazonal (Fig. 2.12) e assim, buscar entender os mecanismos atmosféricos associados aos EIT observados nesta estação. Para as análises de persistência foram considerados somente os EIQ de Arturo, os quais apresentaram mais valores discrepantes e extremos na persistência do que os EIF na maioria das estações do ano (Fig. 3.5).

Observa-se que os casos com o percentil de $10 \%$ e $90 \%$ das anomalias intra-sazonais de temperatura no inverno em Arturo (Figuras 3.30a e 3.30b, respectivamente) apresentaram as mesmas características da circulação atmosférica observada durante os EIF e EIQ, considerando o percentil de $25 \%$ e $75 \%$, respectivamente (Figuras 3.14a e 3.14b). Para os EIQ no inverno em Arturo, ao considerar apenas os eventos de uma parte (1/4 e 1/2) da distribuição da persistência (Figuras 3.30c-3.30e), observa-se uma diminuição da 
significância estatística das anomalias na circulação, devido à diminuição do número de eventos independentes.

\section{INVERNO - PENÍNSULA OESTE}

\section{Intensidade}

(a) Casos p10

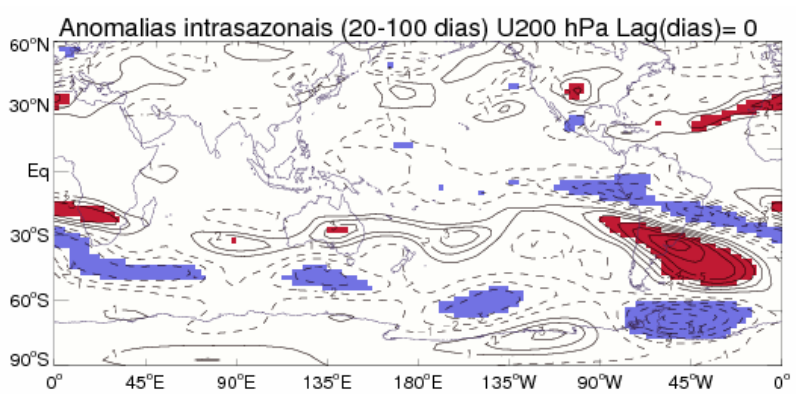

\section{(b) Casos p90}

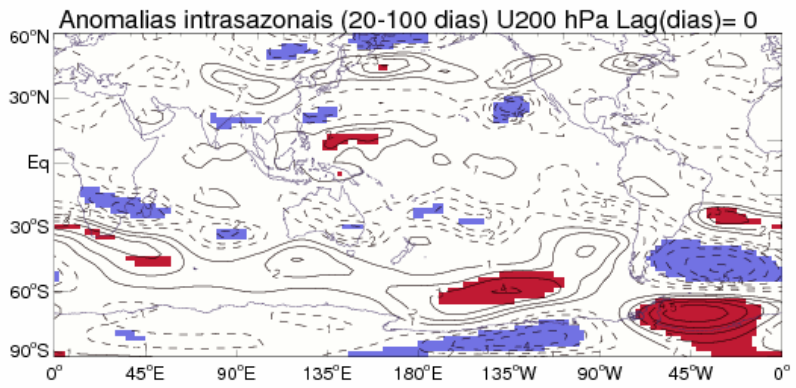

\section{Persistência}

(c) EIQ com persistência abaixo de p25 (8 dias)

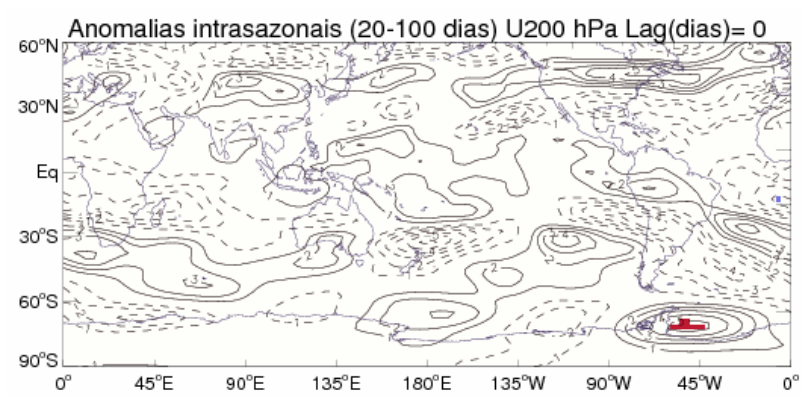

(d) EIQ com persistência igual a p50 (11-13 dias)

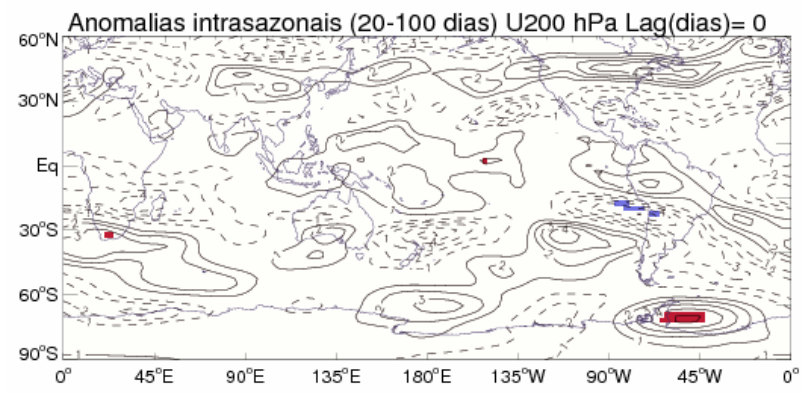

(e) EIQ com persistência acima de p75 (15 dias)

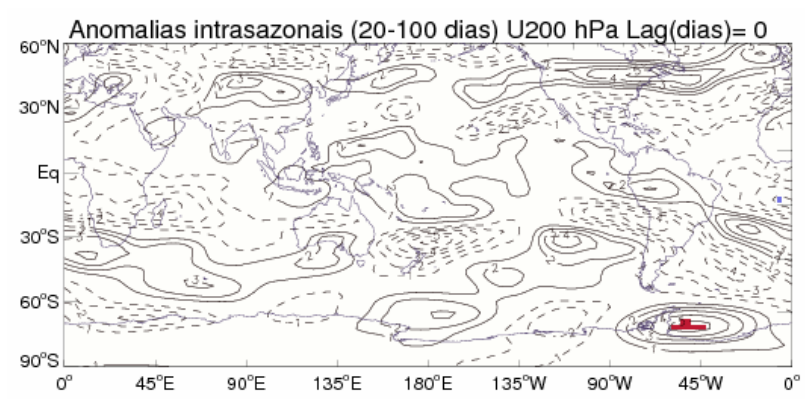

Figura 3. 30. Composições das anomalias intrasazonais do vento zonal (m/s) em $200 \mathrm{hPa}$ para os casos: (a) abaixo do percentil de $10 \%$ e (b) acima do percentil de $90 \%$ das anomalias intra-sazonais de temperatura no inverno em Arturo. As figuras (c-e) representam os EIQ em Arturo com persistência abaixo do percentil 25\%, igual ao percentil de 50\% e acima do percentil de 75\%, respectivamente. As linhas contínuas (tracejadas) indicam valores positivos (negativos). As áreas destacadas em vermelho (azul) são para os valores positivos (negativos) estatisticamente significativos ao nível de 95\%, baseado no teste t-Student. O intervalo dos contornos é de $1 \mathrm{~m} / \mathrm{s}$.

As composições da circulação atmosférica, através de U200 IS, associadas aos casos p10 e p90 das anomalias intra-sazonais de temperatura na primavera em Arturo (Figuras 3.31a e 3.31b) são semelhantes aos resultados obtidos pelos EIF e EIQ, representados pelo quartil de $25 \%$ e $75 \%$ (Fig. 3.20a e 3.20b, respectivamente). Os EIQ de baixa persistência na primavera em Arturo (Fig. 3.31c) não apresentaram anomalias significativas em U200 IS, por 
conta do baixo número de eventos independentes observados nestas condições. Já os EIQ com persistência próxima a mediana (Fig. 3.31d) e com persistência acima do percentil de 75\% (acima de 15 dias, Fig. 3.31e), apresentaram padrões de circulação semelhantes ao observado com todos os eventos independentes (Fig. 3.20b); porém, com menos significância estatística das composições de U200 IS quando comparado com a Figura 3.20b.

No verão em Arturo, os casos com o percentil de 10\% e 90\% das anomalias intrasazonais de temperatura (Figuras 3.32a e 3.32b, respectivamente) apresentaram padrões de circulação atmosférica semelhantes ao observado nos EIF e EIQ, considerando o percentil de 25\% e 75\%, respectivamente (Figuras 3.26a e 3.26b). Porém, durante os casos de EIQ mais intensos (p90, Fig. 3.32b), observa-se uma intensificação do par de anomalias significativas no Pacífico central norte quando comparado com os EIQ em q75 (Fig. 3.26b). Da mesma forma ocorre, quando se considera os EIQ mais persistentes em Arturo (acima de 14 dias, Fig. 3.32e). Durante os EIQ com persistência abaixo de p25 e igual a p50 (Figuras 3.32c e 3.32d), observa-se uma diminuição da significância estatística das anomalias na circulação, devido ao baixo número de eventos independentes. 


\section{PRIMAVERA - PENÍNSULA OESTE}

\section{Intensidade}

\section{(a) Casos p10}

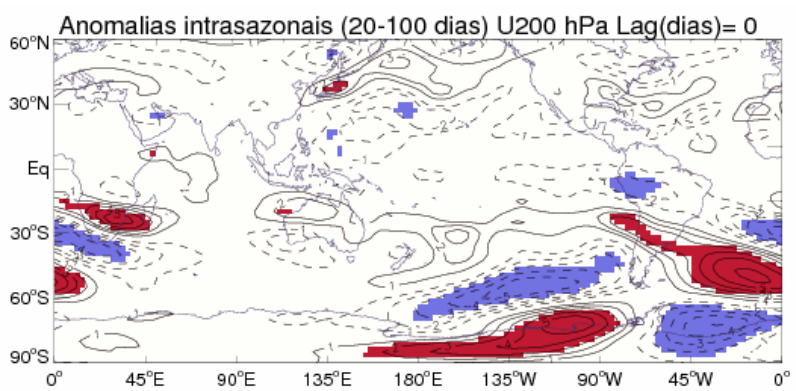

(b) Casos p90

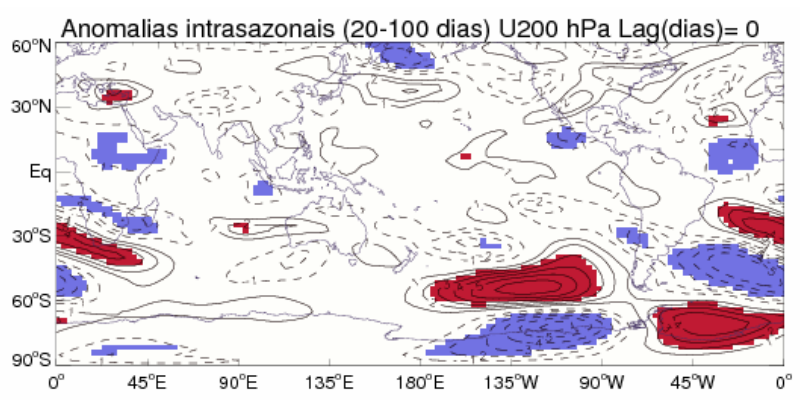

Figura 3. 31. Idem a Fig. 3.30, mas para a primavera.

\section{Persistência}

(c) EIQ com persistência abaixo de p25 (6 dias)

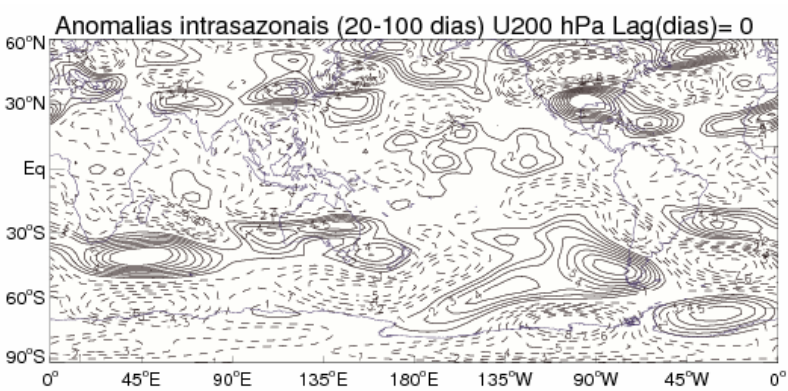

(d) EIQ com persistência igual a p50 (10-12 dias)

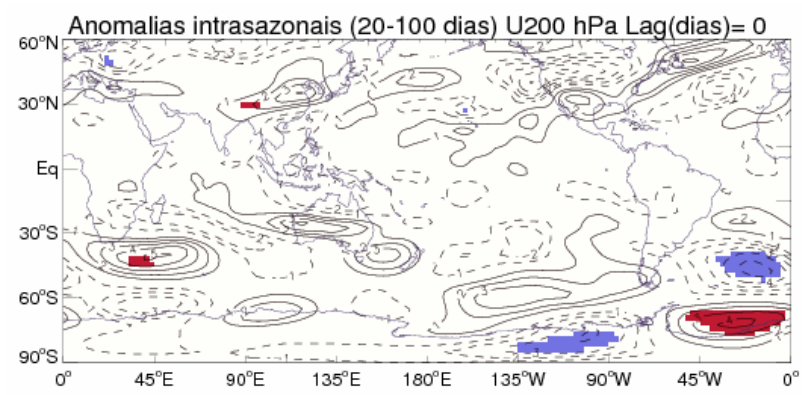

(e) EIQ com persistência acima de p75 (15 dias)

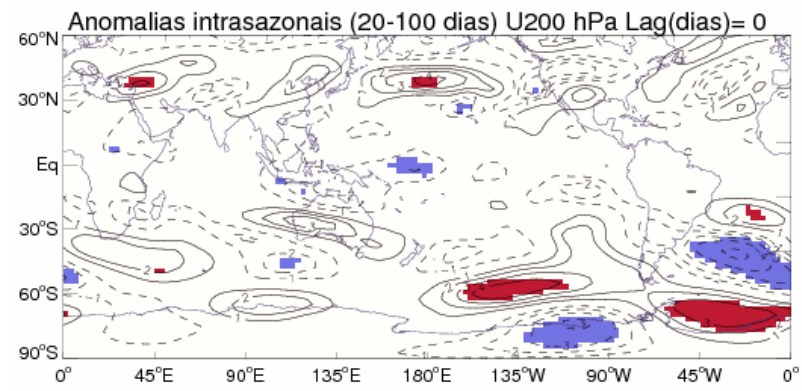




\section{VERÃO - PENÍNSULA OESTE}

\section{Intensidade}

\section{(a) Casos p10}

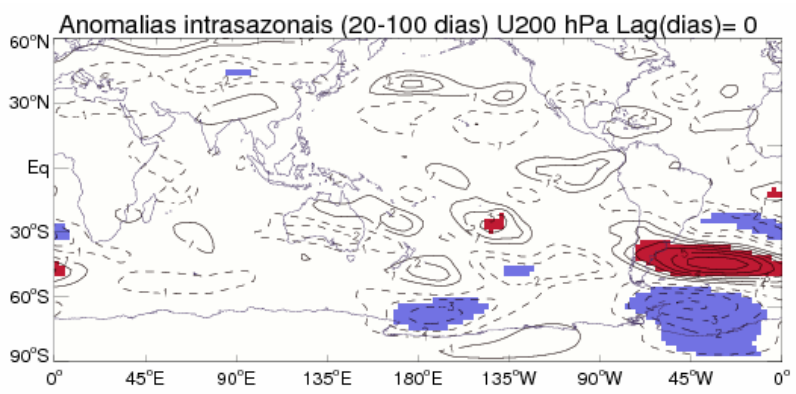

(b) Casos p90

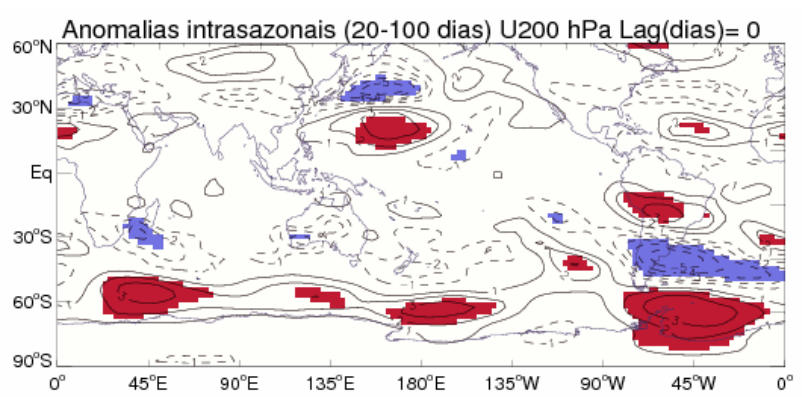

\section{Persistência}

(c) EIQ com persistência abaixo de p25 (8 dias)

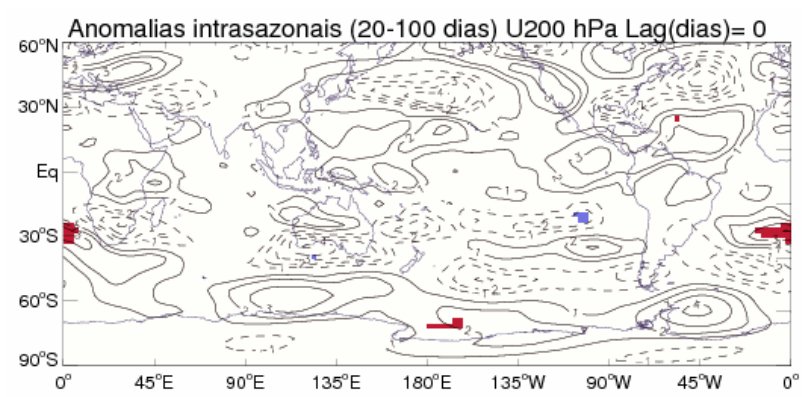

(d) EIQ com persistência igual a p50 (11-13 dias)

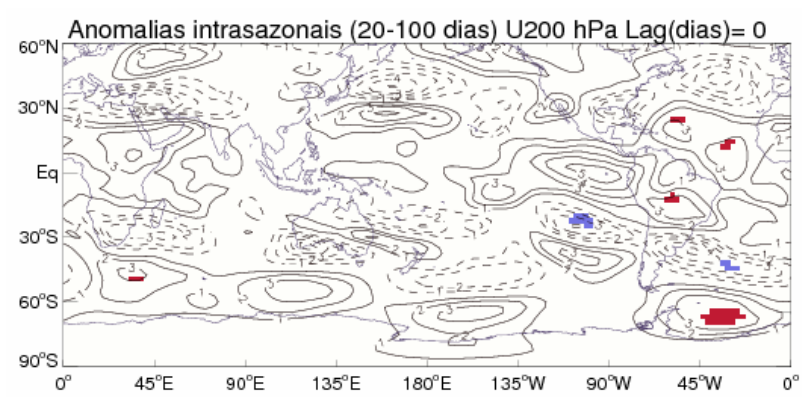

(e) EIQ com persistência acima de p75 (14 dias)

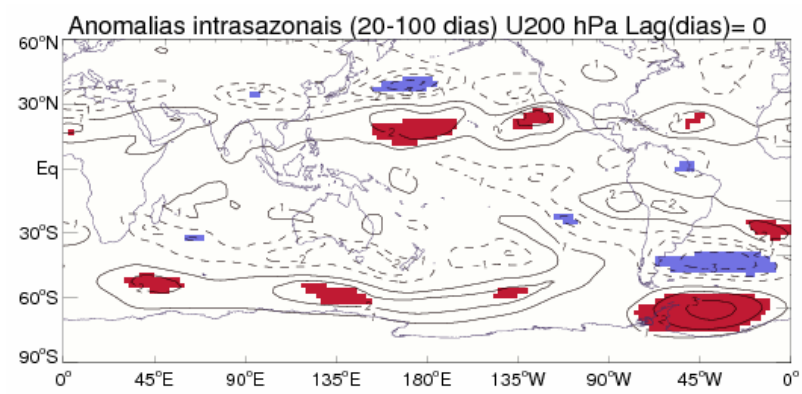

Figura 3. 32. Idem a Fig. 3.30, mas para o verão. 


\subsection{Variações intra-sazonais da atividade convectiva nos trópicos e os EIT}

Com o objetivo de verificar o papel da atividade tropical na propagação do trem de ondas observado nas análises anteriores, conforme sugerido em estudos prévios ( $p$. ex., Higgins e Mo 1997; Mo e Higgins 1998), as anomalias intra-sazonais de radiação de onda longa $\left(\mathrm{ROL}_{\mathrm{IS}}\right.$ ) foram obtidas da mesma forma como descrito no item 3.1. Os dados de ROL foram obtidos por reanálises $N C E P / N C A R$ (Kalnay et al, 1996) e estão setorizados no domínio de $60^{\circ} \mathrm{S}$ a $60^{\circ} \mathrm{N}$.

As composições defasadas de ROL $\mathrm{IS}_{\mathrm{S}}$ associadas aos EIF e EIQ da estação Marambio (Península leste) foram muito semelhantes às composições observadas em Arturo (Península oeste). Portanto, somente os resultados desta última estação serão apresentados (Figuras 3.33$3.35)$.

As composições indicam que há uma grande variabilidade caso a caso quando se considera a variável $\mathrm{ROL}_{\mathrm{IS}}$. Assim, o campo resultante não mostra coerência espacial, o qual é indicado pela baixa significância estatística das composições (Figuras 3.33-3.35). Se há influência da atividade convectiva nos trópicos em escala intra-sazonal sobre a variabilidade da circulação e os EIT sobre a Península Antártica, esta atividade não possui um caráter sistemático sob o ponto de vista de ROL $\mathrm{LIS}_{\text {. }}$

Estes resultados sugerem que, embora a resposta da onda de Rossby aos distúrbios tropicais é aparentemente evidente na circulação atmosférica entre latitudes médias e alta nos dois hemisférios (seção 3.3), não existe uma propagação coerente nas variações da atividade convectiva nos trópicos durante os EIT na Península Antártica. 


\section{INVERNO - PENÍNSULA OESTE ROLIS}

\section{(a) EIF}
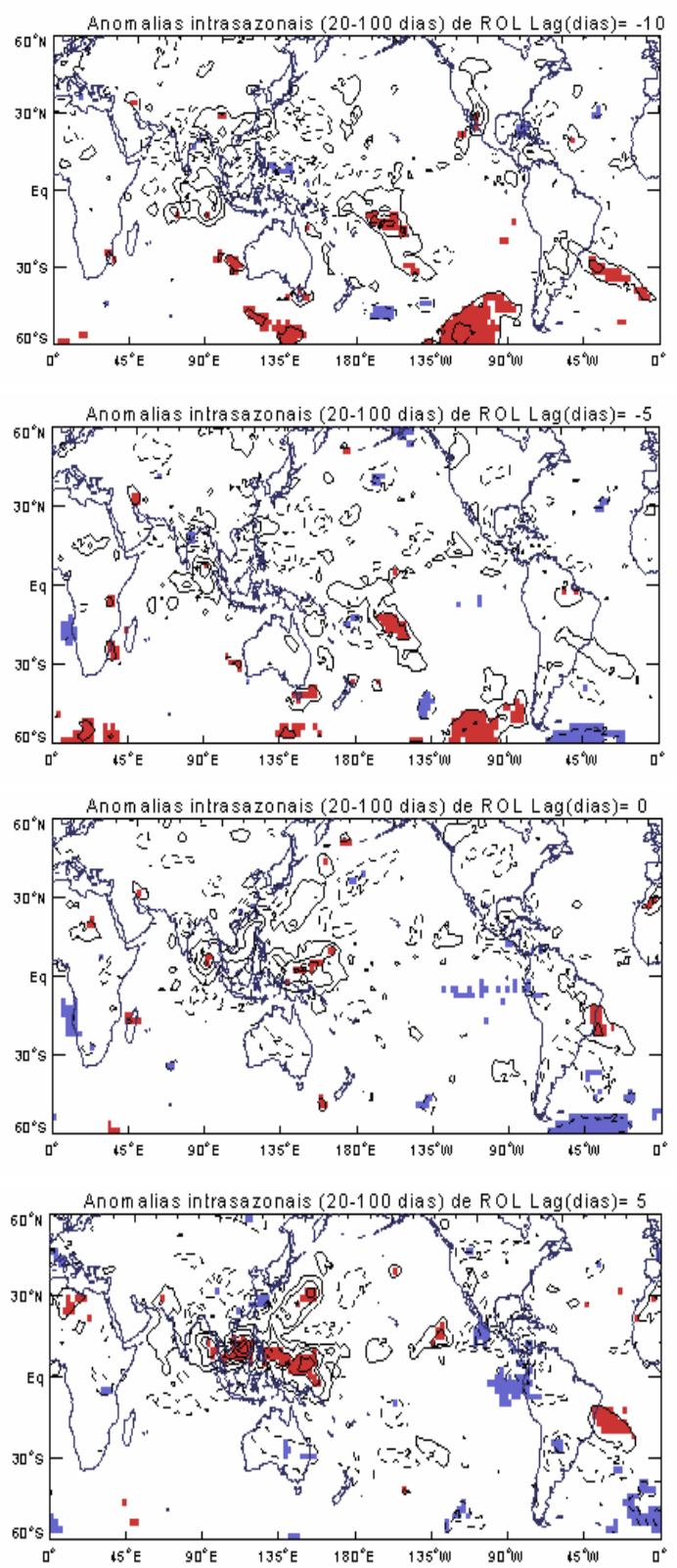

(b) EIQ
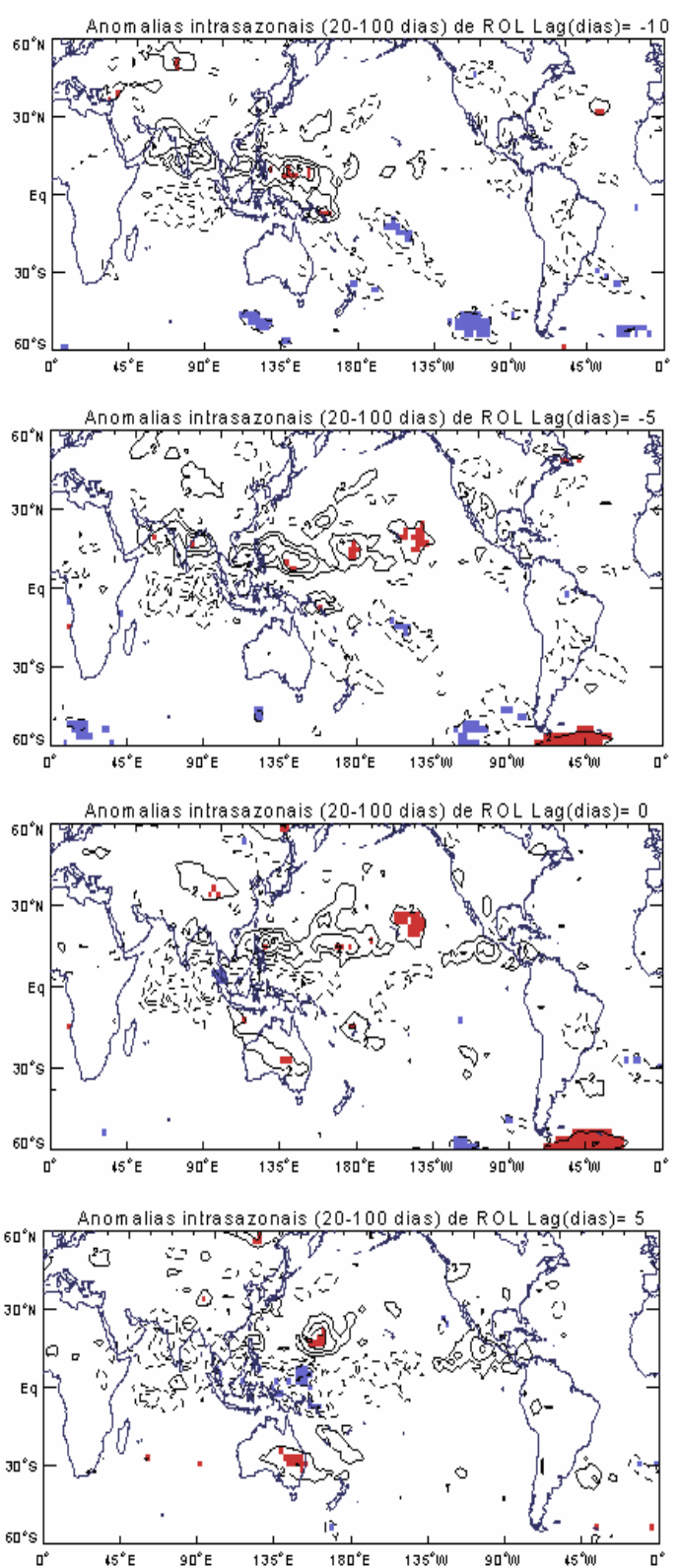

Figura 3. 33. Composições defasadas de anomalias intrasazonais de radiação de onda longa $\left(\mathrm{W} / \mathrm{m}^{2}\right)$ durante os eventos extremos intrasazonais: (a) frios (EIF) e (b) quentes (EIQ) no inverno em Arturo (Península oeste). As linhas contínuas (tracejadas) indicam valores positivos (negativos). As áreas destacadas em vermelho (azul) são para os valores positivos (negativos) estatisticamente significativos ao nível de $95 \%$, baseado no teste t-Student. O intervalo dos contornos é de $2 \mathrm{~W} / \mathrm{m}^{2}$. 
PRIMAVERA - PENÍNSULA OESTE

ROLIS

(a) EIF
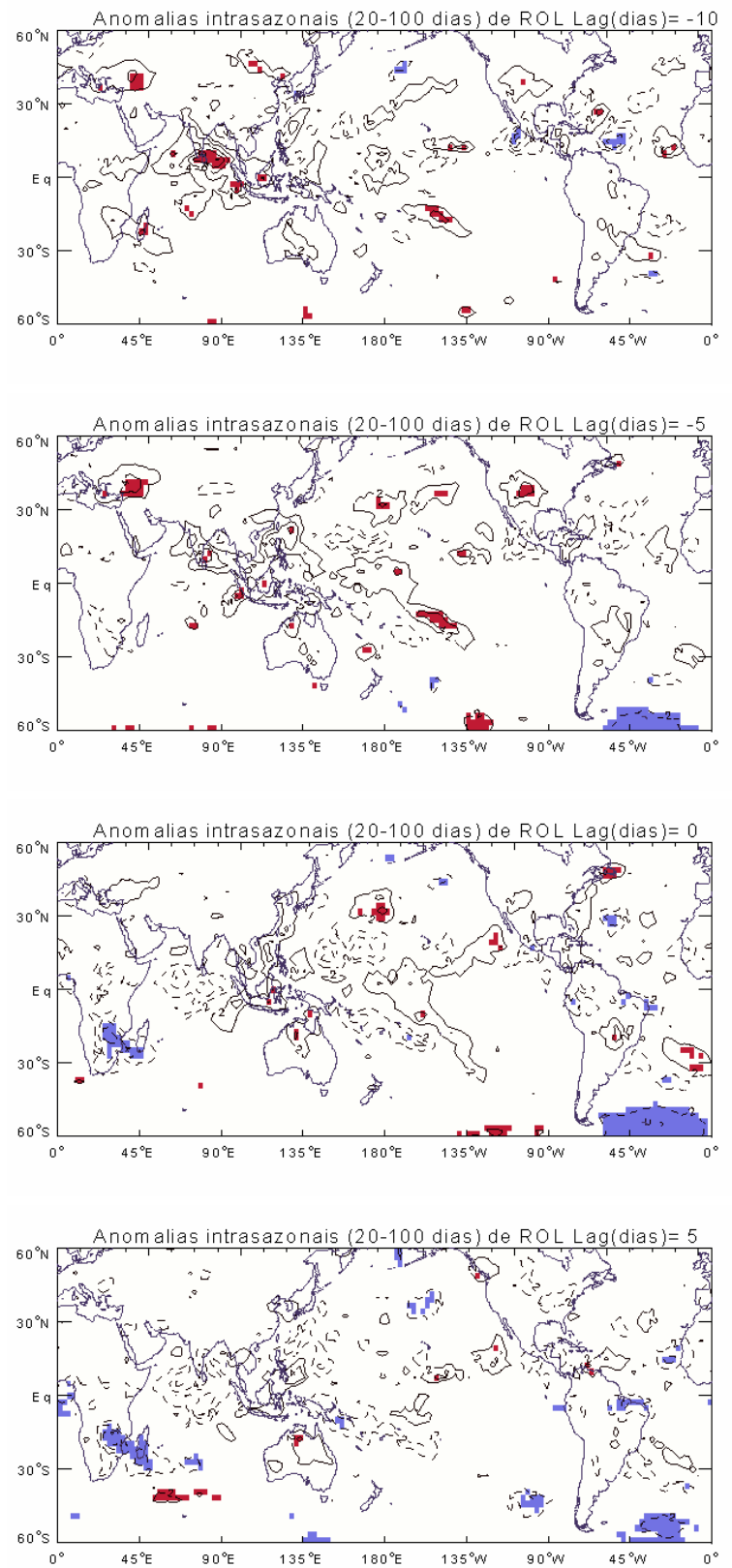

(b) EIQ
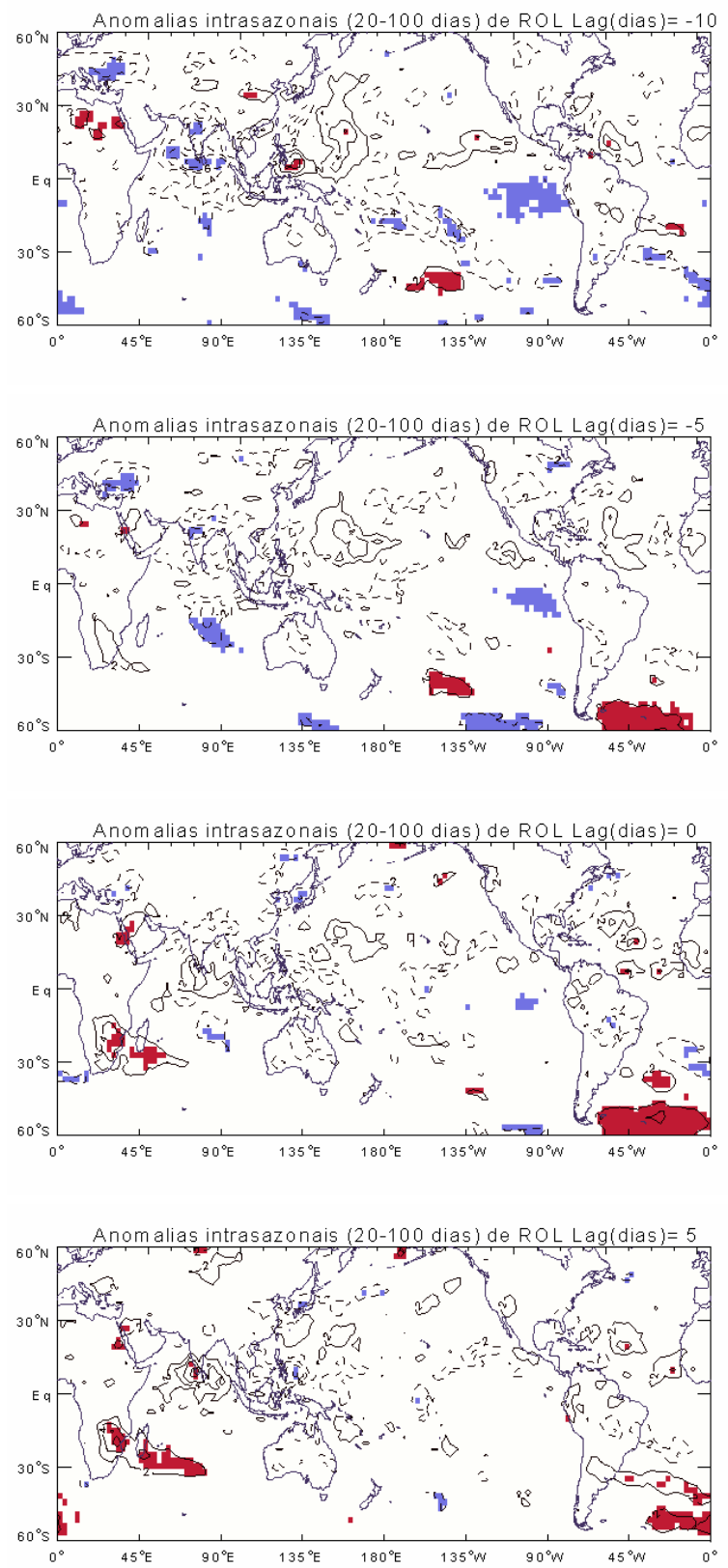

Figura 3. 34. Idem a Fig. 3.33, mas para a primavera. 
VERÃO - PENÍNSULA OESTE

\section{ROL IS}

(a) EIF
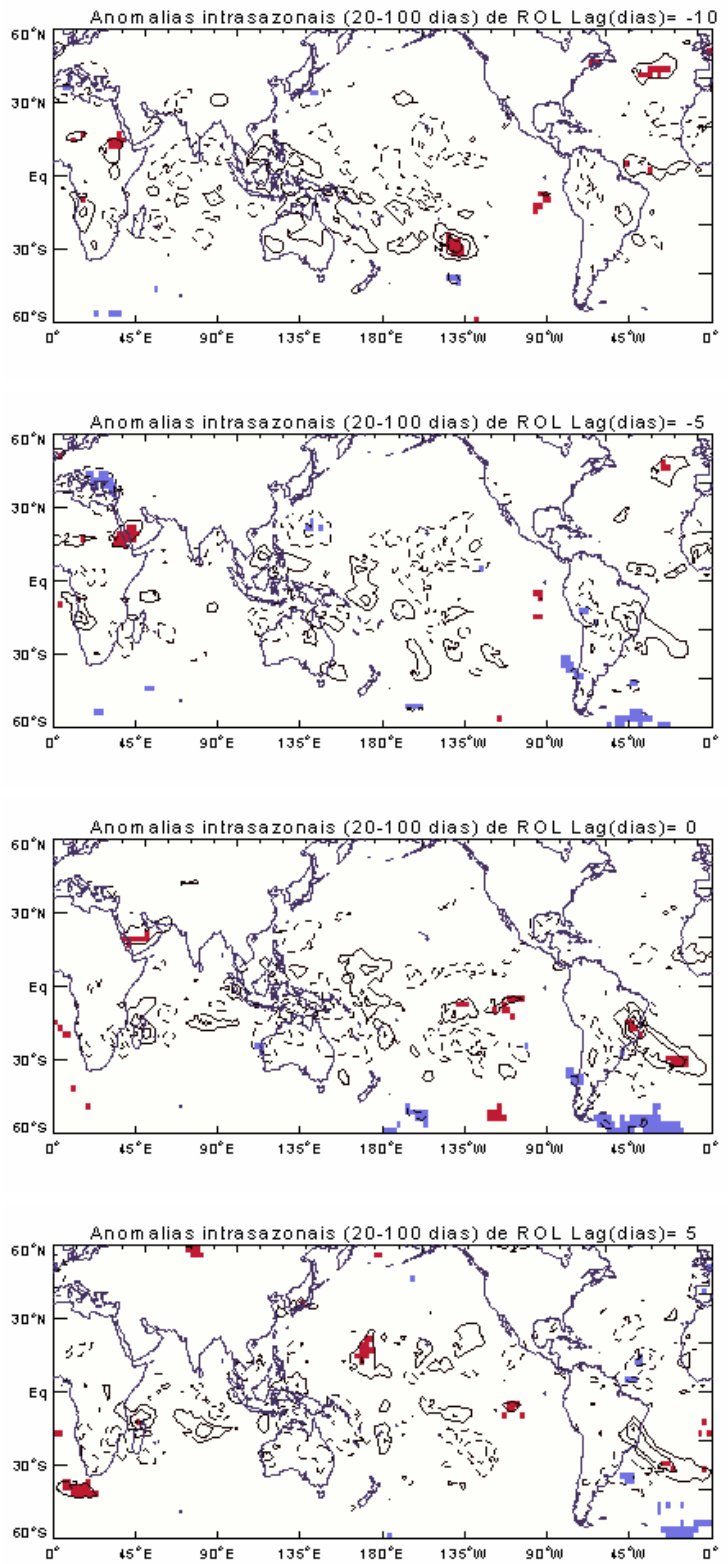

(b) EIQ
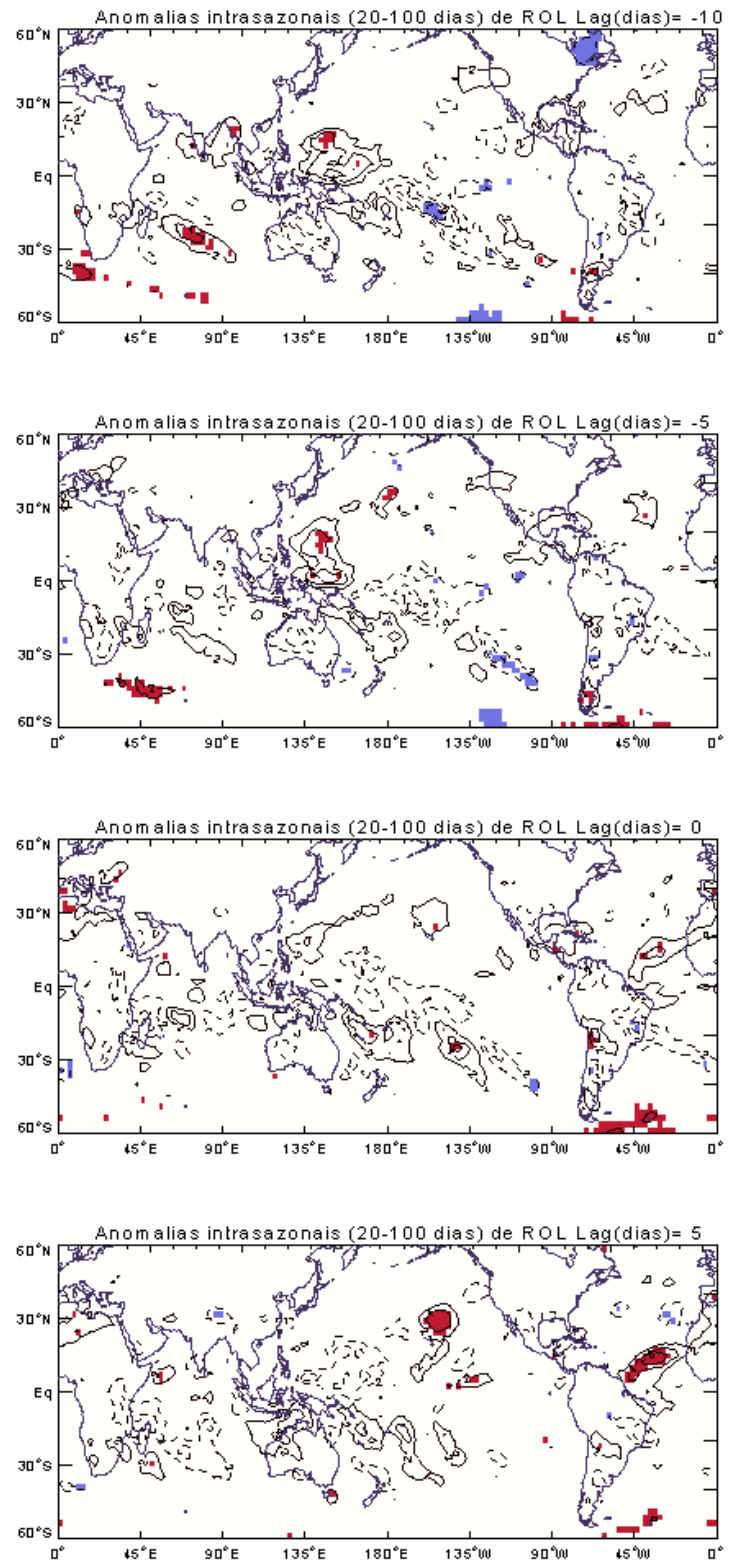

Figura 3. 35. Idem a Fig. 3.33, mas para o verão. 


\subsection{Variações intra-sazonais na estrutura da $A A O$ : relação com os EIT}

Como mencionado no Capítulo 1 (seção 1.2), a $A A O$ é um dos mais importantes modos de variabilidade dos extratrópicos no HS. Sua estrutura anular e simétrica implica na troca de momento e massa entre latitudes médias e altas (Fig. 3.36). A $A A O$ pode ser caracterizada através da análise de Funções Ortogonais Empíricas (Empirical Orthogonal Function - EOF) na anomalia da altura geopotencial em $700 \mathrm{hPa}$. A fase positiva da primeira componente principal (ou índice da $A A O$ ) consiste em anomalias negativas na altura geopotencial em $700 \mathrm{hPa}$ sobre a Antártica e próximo aos oceanos austrais em altas latitudes e anomalias positivas da altura geopotencial ao norte de $50^{\circ} \mathrm{S}$ (Carvalho et al. 2005; Figura 3.36). Nas fases negativas da $A A O$ uma situação oposta é observada. Isto implica no deslocamento do jato para o pólo (equador) de sua posição climatológica durante a fase positiva (negativa) da oscilação (Limpasuvan e Hartmann 2000; Carvalho et al. 2005). O vórtice polar expande e contrai em relação a estas variações na posição do jato. Carvalho et al. (2005) mostraram que os extremos das fases da AAO são modulados por variações nos trópicos em escalas intra-sazonais a interanuais. Estes autores mostraram ainda que o principal mecanismo de teleconexão está relacionado à intensidade e posição dos jatos subtropicais e polares.

O objetivo da presente análise é avaliar a relação entre o modo anular de altas latitudes do HS $(A A O)$ e os EIT observados nas estações Arturo e Marambio, através de análises de $E O F$ das anomalias intra-sazonais da altura geopotencial em $700 \mathrm{hPa}\left(\mathrm{H} 700_{\mathrm{IS}}\right)$ na área setorizada ao sul de $20^{\circ} \mathrm{S}$ e $180^{\circ} \mathrm{E}-180^{\circ} \mathrm{W}$. Os dados diários de $\mathrm{H} 700$ foram obtidos pelas reanálises do $N C E P / N C A R$ e filtrados na banda de 20-90 dias, semelhante ao procedimento descrito no item 3.1. As EOFs foram computadas espacialmente, obtendo-se os padrões de covariância, a intensidade e a posição espacial das anomalias de H700 IS para os EIT no inverno, primavera e verão separadamente, seguindo o procedimento proposto em Björnsson e Venegas (1997) e Hannachi (2004) (vide Apêndice B).

Os padrões espaciais, obtidos pela correlação entre as anomalias de $\mathrm{H} 700_{\mathrm{IS}}$ e a primeira EOF destas anomalias (EOF-1), associados aos EIT observados no inverno, primavera e verão, nas estações Arturo e Marambio, são apresentados nas Figuras 3.37-3.42. Comparando-se estes modos com o padrão espacial da $A A O$ obtido por Carvalho et al. (2005) (Figura 3.36), observa-se que tanto em Arturo quanto em Marambio, há uma característica de 
intensificação (enfraquecimento) do modo anular durante os EIF (EIQ) no inverno sobre a região da Península Antártica (Figuras 3.37 e 3.38, respectivamente). Na primavera, observase um enfraquecimento do modo anular no hemisfério oeste dos extratrópicos, principalmente sobre a Península Antártica, durante os EIF e EIQ nas estações Arturo e Marambio (Figuras 3.39 e 3.40, respectivamente). A presença de correlações de sinais opostos de H700 IS sobre o Pacífico subtropical e sudeste (próximo à costa sudoeste da América do Sul) durante os EIQ na primavera em ambas as estações (Figuras $3.39 \mathrm{~b}$ e $3.40 \mathrm{~b}$ ), sugere um possível papel do trem de ondas de latitudes médias, observado nas análises anteriores, no enfraquecimento do modo anular de altas latitudes do HS. No verão nas estações Arturo e Marambio, o modo anular intensifica sobre a região da Península Antártica durante os EIF (Figuras 3.41a e 3.42a, respectivamente), enquanto que nos EIQ (Figuras $3.41 \mathrm{~b}$ e $3.42 \mathrm{~b}$, respectivamente) observa-se uma configuração semelhante ao padrão obtido por Carvalho et al. 2005 (Fig. 3.36). É importante ressaltar que a inversão do sinal em $\mathrm{H} 700_{\mathrm{IS}}$ nos EIQ de verão, não é necessariamente indicativo de que na maior parte dos casos observou-se a fase positiva da $A A O$, pois se tratando de $E O F s$ o sinal é definido arbitrariamente.

Em suma, o primeiro modo dos extratrópicos do HS indicou mudanças dependendo da fase de propagação do trem de ondas. Os padrões de inverno, primavera e verão, associados aos EIT na Península Antártica, explicaram entre 24\% e 29\% da variância total dos dados.

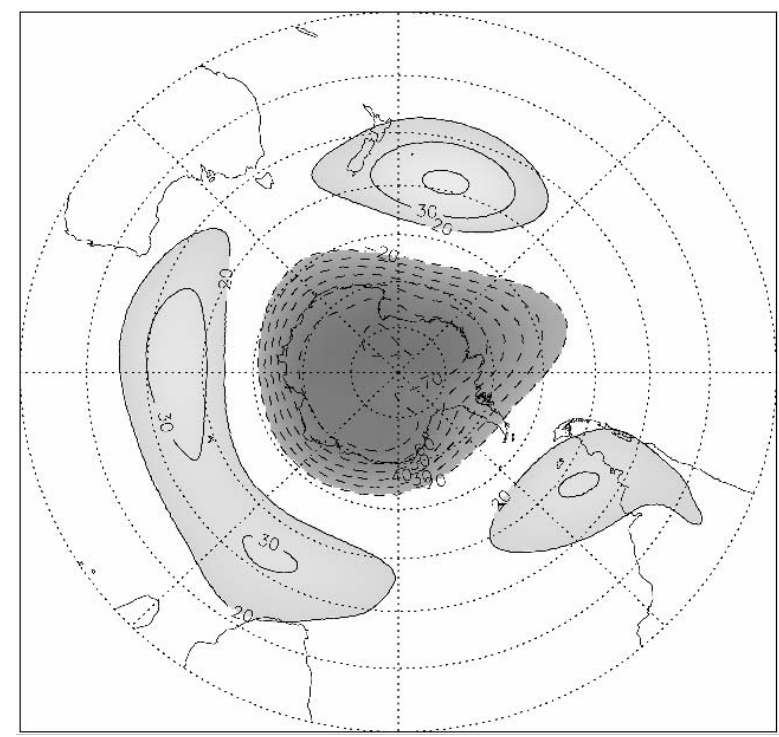

Figura 3. 36. Coeficiente de regressão das anomalias diárias da altura geopotencial em 700 hPa na EOF-1. Este modo explica cerca de $26 \%$ da variância total dos dados (Figura obtida em Carvalho et al. 2005). 


\section{INVERNO - PENÍNSULA OESTE}

(a) EIF (var=29\%)

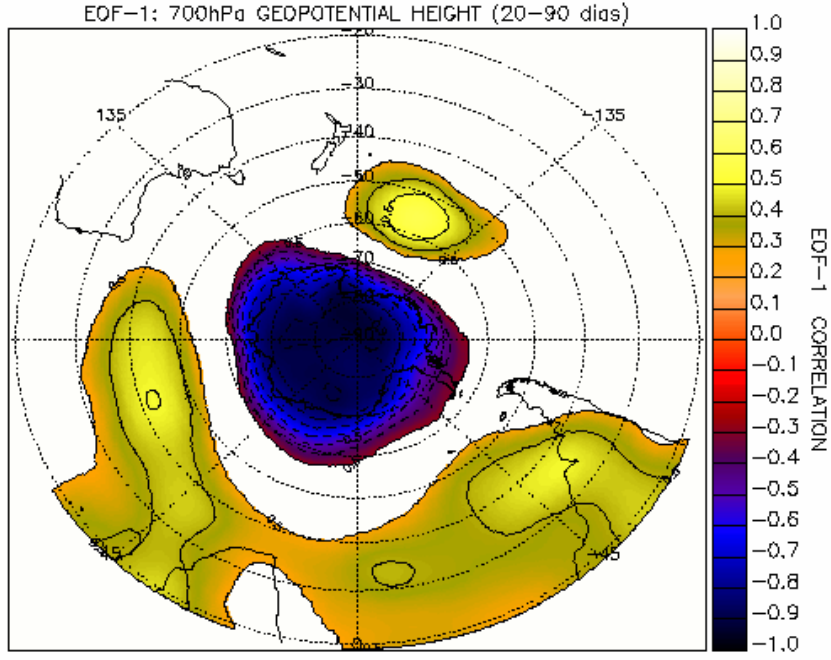

(b) EIQ (var=27\%)

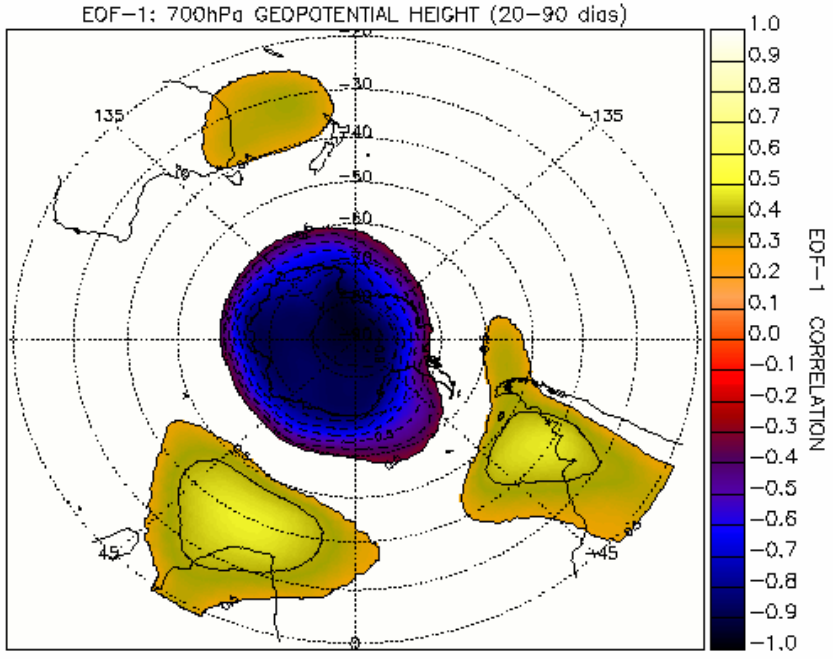

Figura 3. 37. Correlação entre as anomalias de H700 IS e a EOF-1 obtida para os EIF (a) e os EIQ (b), no inverno em Arturo. A variância explicada pela EOF-1 está indicada no topo de cada figura.

\section{INVERNO -PENÍNSULA LESTE}

(a) EIF (var=26\%)

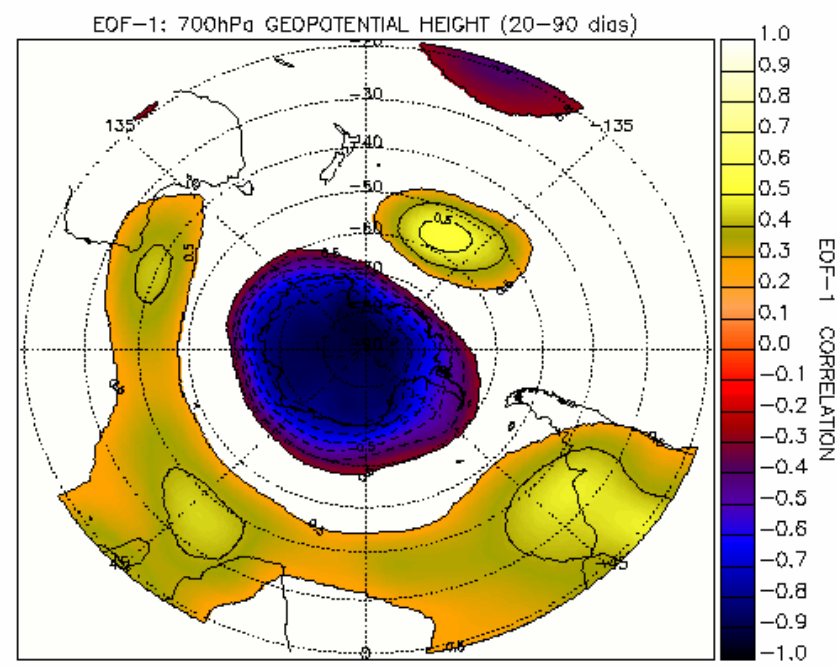

(b) EIQ (var=25\%)

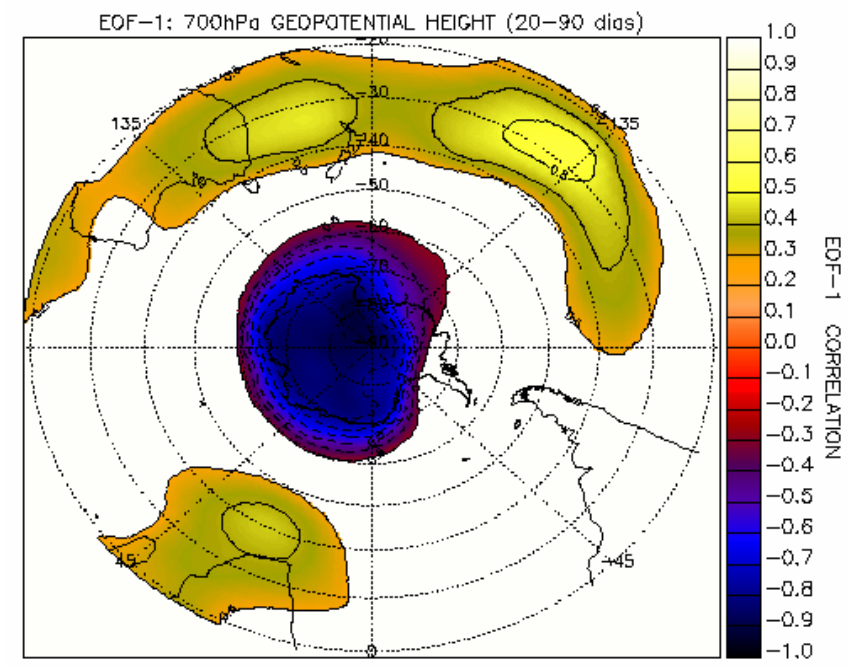

Figura 3. 38. Idem a Fig. 3.37, mas para Marambio. 


\section{PRIMAVERA - PENÍNSULA OESTE}

(a) EIF (var=26\%)

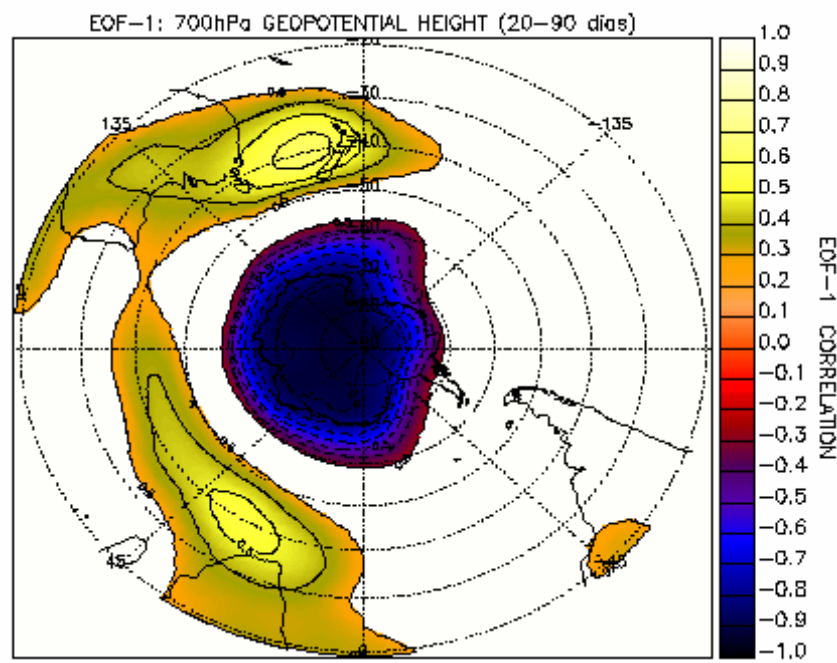

(b) EIQ (var=27\%)

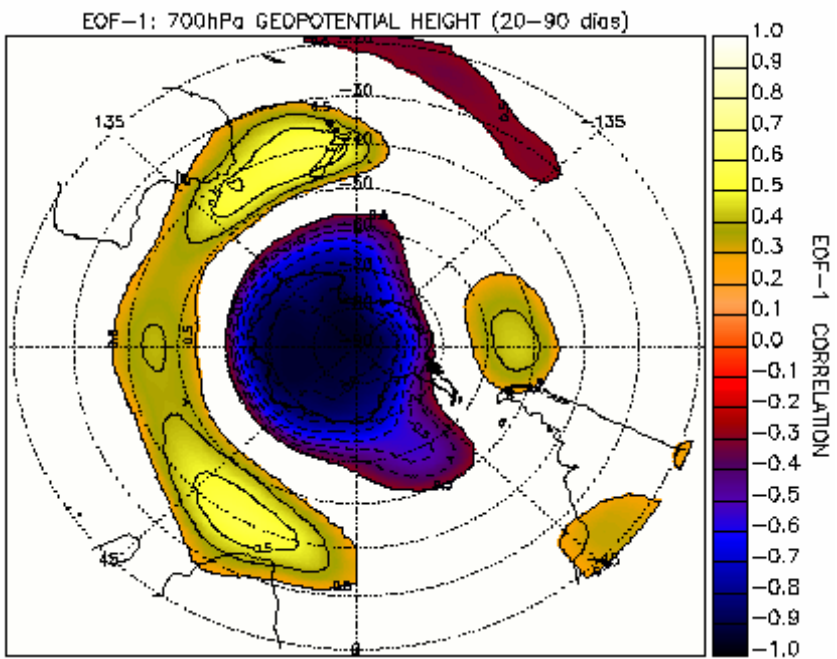

Figura 3. 39. Correlação entre as anomalias de H700 IS e a EOF-1 obtida para os EIF (a) e os EIQ (b), na primavera em Arturo. A variância explicada pela EOF-1 está indicada no topo de cada figura.

\section{PRIMAVERA - PENÍNSULA LESTE}

(a) EIF (var=28\%)

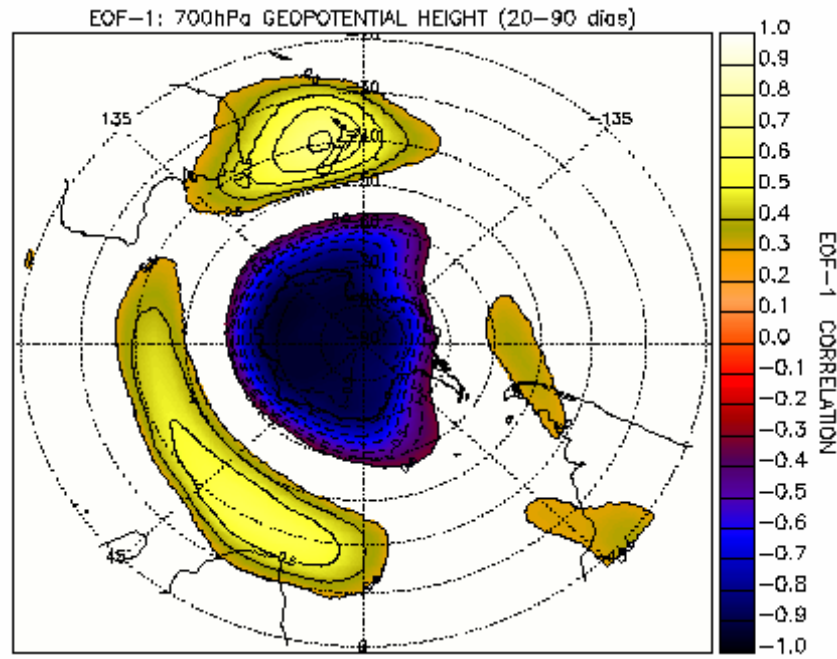

(b) EIQ (var=24\%)

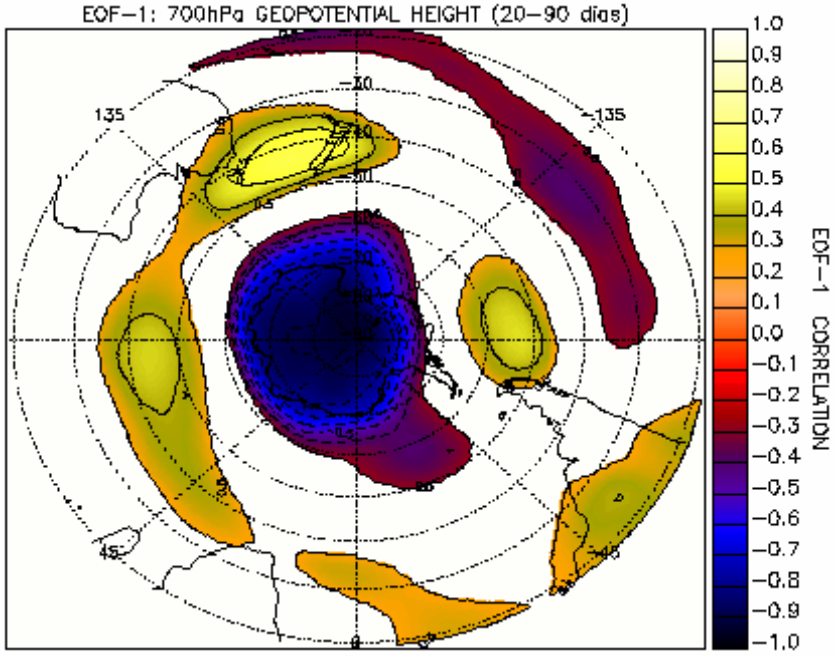

Figura 3. 40. Idem a Fig. 3.39, mas para Marambio. 


\section{VERÃO - PENÍNSULA OESTE}

(a) EIF (var=29\%)

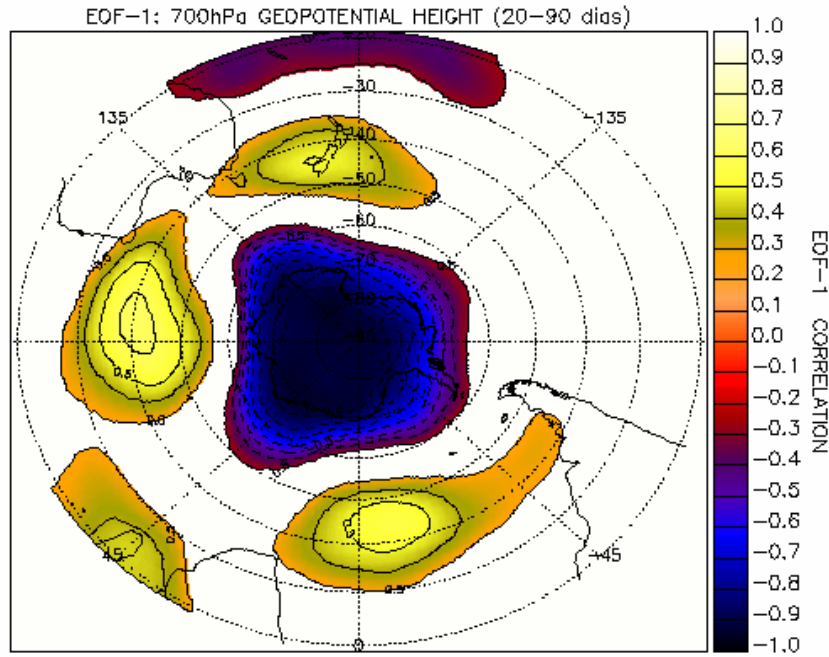

(b) EIQ (var=28\%)

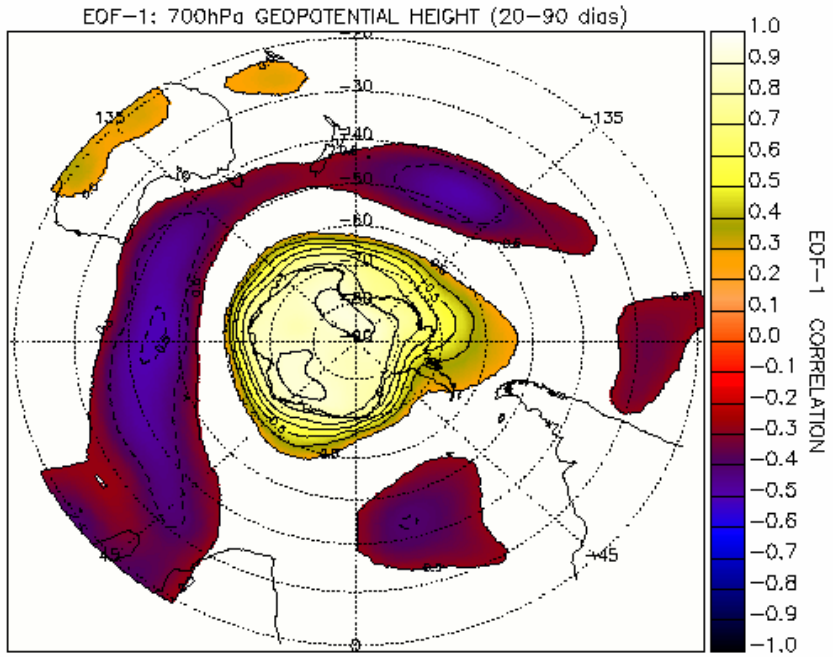

Figura 3. 41. Correlação entre as anomalias de H700 IS e a EOF-1 obtida para os EIF (a) e os EIQ (b), no verão em Arturo. A variância explicada pela EOF-1 está indicada no topo de cada figura.

\section{VERÃO - PENÍNSULA LESTE}

(a) EIF (var=29\%)

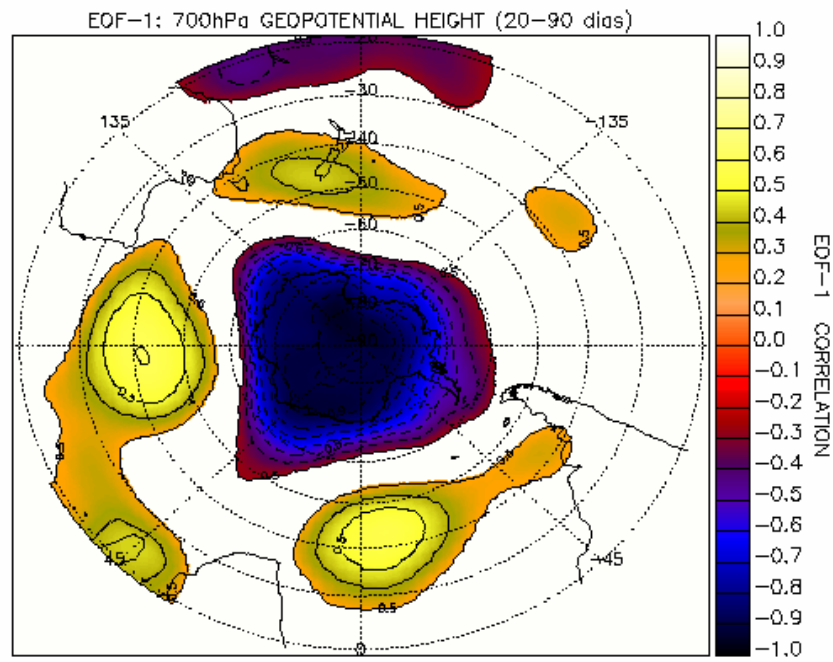

(b) EIQ (var=27\%)

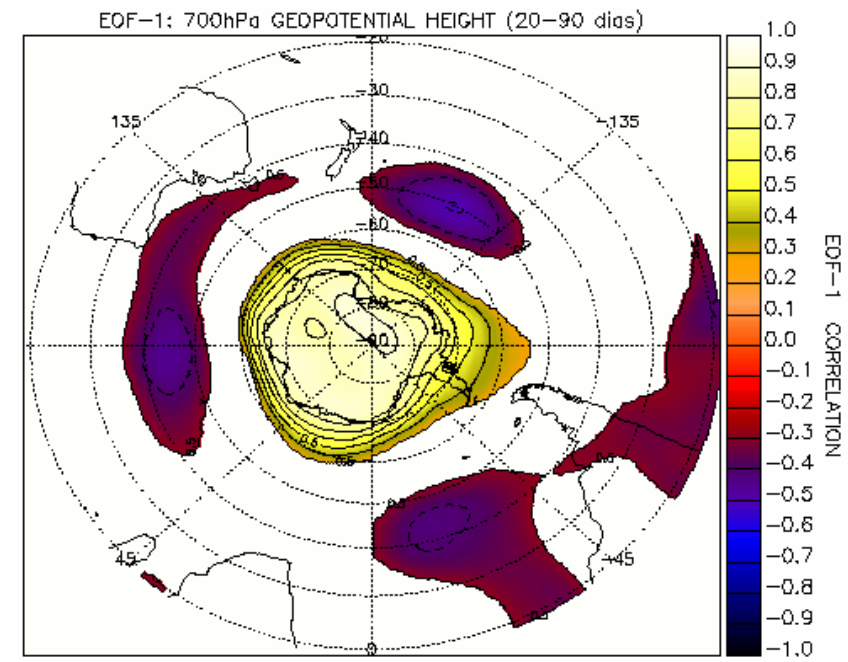

Figura 3. 42. Idem a Figura 3.41, mas para Marambio. 


\section{Capítulo 4: Interação troposfera-estratosfera e os EIT na Península Antártica}

Observações sugerem que a circulação estratosférica controla a temperatura em regiões polares. Thompson et al. (2002) mostraram evidências que anomalias de baixas (altas) temperaturas do ar em superfície durante o inverno e o aumento na freqüência de ocorrência de extremos frios (quentes) sobre algumas regiões continentais no $\mathrm{HN}$ estariam relacionadas ao enfraquecimento (intensificação) do vórtice polar estratosférico durante o inverno no HN.

Um acoplamento entre troposfera-estratosfera no HS foi encontrado por Hsu e Weng (2002). Os autores encontraram um padrão de circulação propagando-se para leste na estratosfera do HS, o qual denominaram de Oscilação Intra-sazonal Antártica Estratosférica, devido a periodicidade da oscilação em torno de 30 dias e aparecer em altas latitudes do HS. O resultado de uma análise da atividade de onda e da interação entre fluxo médio-onda durante a oscilação, mostrou um forte acoplamento entre a troposfera e estratosfera. A oscilação pode ser vista como uma manifestação da onda planetária, a qual é forçada pela topografia da Antártica e propaga para cima e para leste na estratosfera (Hsu e Weng 2002).

Motivado por estes trabalhos, neste capítulo será investigado o papel da interação alta troposfera-baixa estratosfera no controle dos EIT nas estações da Península Antártica, Arturo e Marambio, utilizando o diagnóstico da atividade de ondas e sua interação com o fluxo zonal médio, conhecido como o Fluxo Eliassen-Palm (EP) (e.g., Edmon et al. 1980). Após a descrição do fluxo EP, será abordada uma comparação entre a alta troposfera e a baixa estratosfera sob o ponto de vista climatológico da temperatura, circulação e a atividade de onda. Em seguida, serão apresentados os resultados referentes às anomalias intra-sazonais do fluxo EP associadas aos EIT na Península Antártica. 


\subsection{A atividade de onda e a interação com o fluxo zonal médio}

A variabilidade na circulação da estratosfera é caracterizada por escalas de tempo consideravelmente maiores que aquelas observadas na troposfera (Holton 1975). Estas escalas de tempo mais longas refletem em processos dinâmicos diferentes que perturbam a circulação em relação ao seu estado médio. Enquanto que a circulação troposférica extratropical é continuamente perturbada por rápidas ondas baroclínicas, as variações na circulação da estratosfera são conduzidas basicamente por interações mais lentas entre o fluxo zonal e ondas de escala planetária que dispersam para cima da troposfera (Holton 1975). Logo, as ondas planetárias desempenham um papel importante na circulação geral da estratosfera através de sua troca de momentum e energia com o fluxo zonal médio.

\subsubsection{O Fluxo Eliassen-Palm (EP)}

O Fluxo Eliassen-Palm (EP) tem sido utilizado para diagnosticar a propagação de onda e a interação entre o fluxo médio-onda (Andrews e McIntyre 1976, 1978; Edmon et al. 1980; Palmer 1981; Hartmann et al. 1984).

O formalismo matemático para o cálculo do vetor fluxo EP pode ser entendido pelo diagnóstico da transformada Euleriana das equações do momentum médio zonal e da termodinâmica (e.g., Hartmann et al. 1984), tal que:

$$
\begin{gathered}
\frac{\partial \bar{u}}{\partial t}-f \bar{v}^{*}-\overline{\mathfrak{I}}=\nabla \bullet F /\left(\rho_{0} a \cos \phi e^{-Z / H}\right) \equiv D F \\
\frac{\partial \bar{\theta}}{\partial t}+\bar{\theta}_{z} \bar{w}^{*}-\bar{Q}=0
\end{gathered}
$$

onde $\overline{\mathfrak{I}}$ representa as fontes de momento em escala sub-grade e Q é o efeito do aquecimento diabático; u e v são a componente zonal e meridional da velocidade do vento e $\theta$ é a temperatura potencial. DF é a forçante zonal induzida de onda por unidade de massa agindo no fluxo médio e $\theta_{z}$ mede a estabilidade estática. Barras e linhas (') denotam médias zonais e desvio das mesmas, respectivamente. F é o Fluxo Eliassen-Palm (EP). As médias residuais da circulação meridional $\left(0, \bar{v}^{*}, \bar{w}^{*}\right)$ são definidas por:

$$
\bar{v}^{*}=\bar{v}-\frac{1}{\rho_{o}} \frac{\partial}{\partial z}\left(\rho_{0} \overline{v^{\prime} \theta^{\prime}} / \bar{\theta}_{z}\right)
$$




$$
\bar{w}^{*}=\bar{w}+\frac{1}{a \cos \phi} \frac{\partial}{\partial \phi}\left(\cos \phi \overline{v^{\prime} \theta^{\prime}} / \bar{\theta}_{z}\right)
$$

O vetor fluxo EP é definido por:

$$
F \equiv\left(0, F_{y}, F_{z}\right) \equiv \rho_{o} a \cos \phi\left\{-\overline{u^{\prime} v^{\prime}}, f \overline{v^{\prime} \theta^{\prime}} / \bar{\theta}_{z}\right\}
$$

onde $\rho_{0}(z)=\rho_{s} \exp \{-z / H\}, \quad z=-H \ln \left(p / p_{s}\right), \quad H=7 \mathrm{~km} \quad$ e $\quad p_{s}=10^{5} \mathrm{~Pa}$

Assim, as secções transversais altura-latitude contendo os vetores de fluxo EP, representam a direção de propagação das ondas de Rossby. O vetor fluxo EP foi calculado utilizando os dados diários de reanálises do $N C E P / N C A R$ e multiplicado por $2 \pi$ acos $\varphi$ devido a geometria esférica da superfície da Terra, como em Palmer (1981) e Hartmann et al. (1984), onde $a$ é o raio da Terra e $\phi$ é a latitude.

\subsubsection{Comparação entre a climatologia da temperatura, da circulação e da atividade de onda entre a troposfera e estratosfera}

A climatologia sazonal da circulação zonal e da atividade de onda (fluxo EP; Fig. 4.1) foi calculada para o período de $1979-2005$, entre 150 e $10 \mathrm{hPa}$, para $80^{\circ} \mathrm{S}-80^{\circ} \mathrm{N}$. Neste mesmo período, foi obtida a climatologia sazonal da temperatura do ar na baixa estratosfera e alta troposfera (Figuras 4.2 e 4.3, respectivamente). Todas as climatologias foram obtidas com base nos dados de reanálises do $N C E P / N C A R$ para o inverno (JJA), primavera (SON), verão (DJF) e outono (MAM).

Durante o inverno, o vórtice polar no HS é intenso, associado a um aumento da atividade de onda da alta troposfera para a baixa estratosfera (Fig. 4.1a) e a temperatura na região polar é mais fria, tanto na baixa estratosfera (Fig. 4.2a), quanto na alta troposfera (Fig. 4.3a). Na primavera, a interação entre o fluxo médio e atividade de onda da alta troposfera para a baixa estratosfera ainda se encontra bastante ativa no HS (Fig. 4.1b) e as temperaturas na baixa estratosfera e alta troposfera sobre os extratrópicos do HS são mais quentes quando comparado com o inverno (Figuras $4.2 \mathrm{~b}$ e $4.3 \mathrm{~b}$ ). Thompson e Wallace (2000) relataram que o modo anular do HS é acoplado com a circulação estratosférica preferencialmente na primavera austral, o qual pode estar associado com episódios quentes na estratosfera. No verão, o vórtice polar enfraquece no HS (Fig. 4.1c) e a temperatura é mais alta na baixa 
estratosfera do que na alta troposfera nos extratrópicos do HS (Figuras 4.2c e 4.3c), associado à diminuição na atividade de onda da troposfera para a baixa estratosfera (Fig. 4.1c). No outono, o vórtice polar no HS começa a fortalecer-se novamente, aumentando a atividade de onda da alta troposfera para a baixa estratosfera (Fig. 4.1d) e a temperatura na região polar torna-se mais fria quando comparado com o verão, tanto na baixa estratosfera (Fig. 4.2d), quanto na alta troposfera (Fig. 4.3d). Da mesma forma, observa-se a variabilidade sazonal da atividade de onda em altas latitudes do $\mathrm{HN}$; porém, com menor intensidade do vento zonal de oeste na região polar quando comparado com os extratrópicos do HS. Por fim, observa-se a componente horizontal do vetor EP dirigida para o equador na camada entre 100-20 hPa em altas latitudes do HS, transportando momentum do pólo para o equador, o qual é mais evidente no inverno, primavera e outono austral.

Em suma, a circulação estratosférica é modulada por episódios de enfraquecimento e intensificação do vórtice polar e influenciada pela atividade de onda na baixa estratosfera, os quais controlam a temperatura na região polar no HS. 
(a) INVERNO

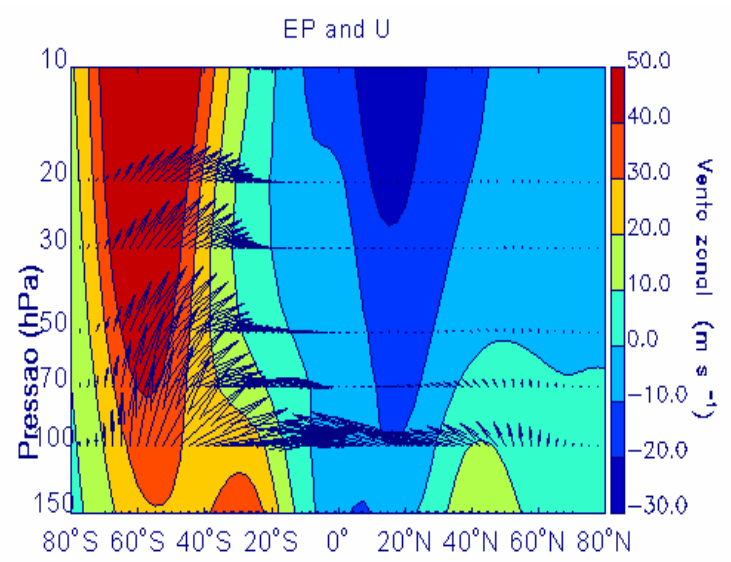

(c) VERÃO

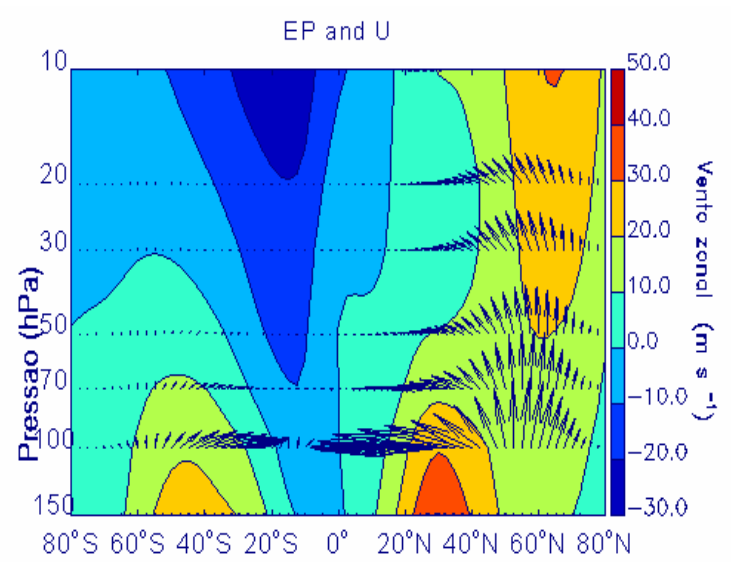

(b) PRIMAVERA

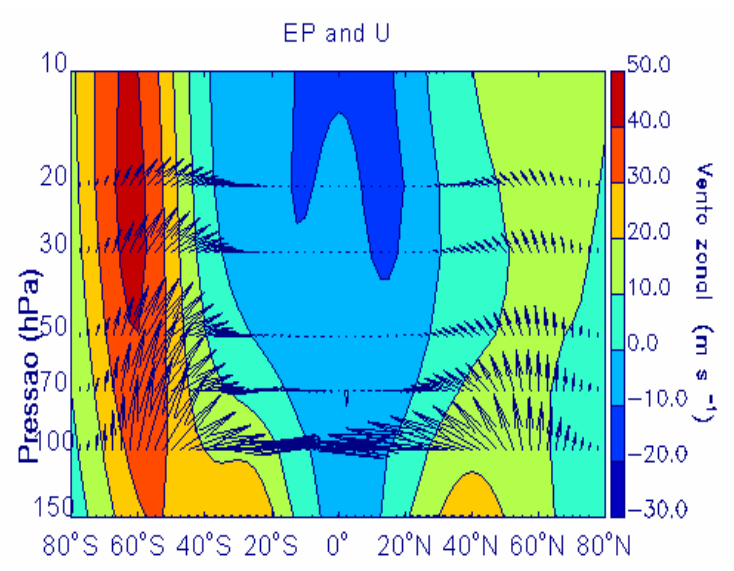

(d) OUTONO

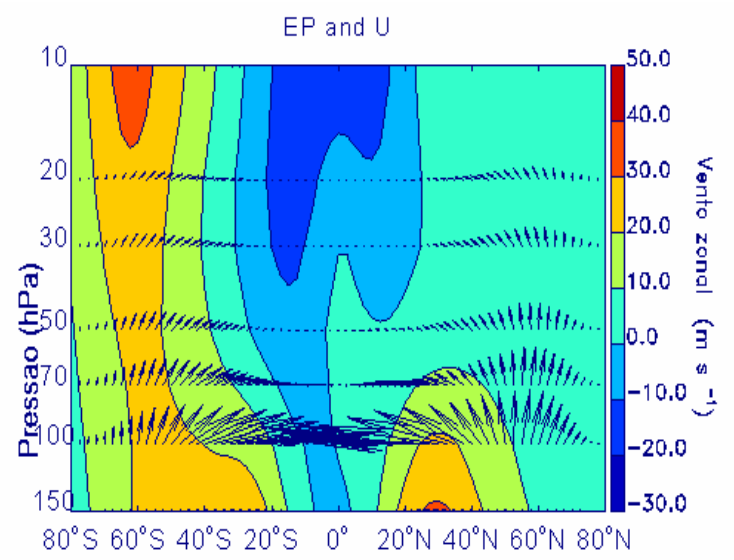

Figura 4. 1. Climatologia do vetor EP $\left(10^{11} \mathrm{~kg} \mathrm{~m} \mathrm{~s}^{-2}\right)$ e do vento zonal $(\mathrm{m} / \mathrm{s})$ na alta troposfera e baixa estratosfera para o inverno (a), primavera (b), verão (c) e outono (d), no período de 1979-2005. O vetor EP em $150 \mathrm{hPa}$ foi multiplicado por $10^{-1}$ devido as diferenças de magnitude entre a troposfera e estratosfera. Os vetores EP foram escalados tal que $F \mapsto\left(c F_{y}, F_{z}\right)$, onde c $=0,0091$, como descrito em Palmer (1981). 


\section{TEMPERATURA - BAIXA ESTRATOSFERA}

\section{(a) INVERNO}

NCEP/NCAR Rennalysis

$50 \mathrm{mb}$ air (C) Composite Mran

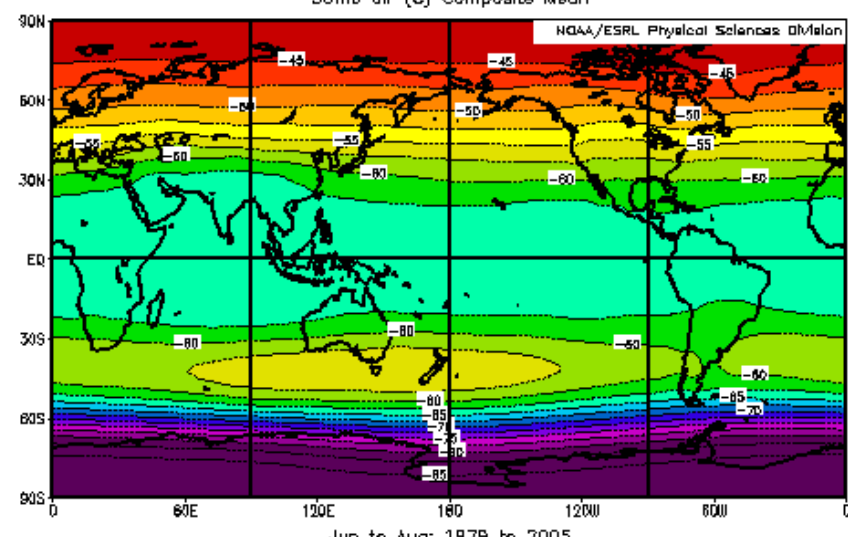

Jun to Alg: 1979 to 2005

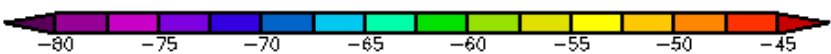

(c) VERÃO

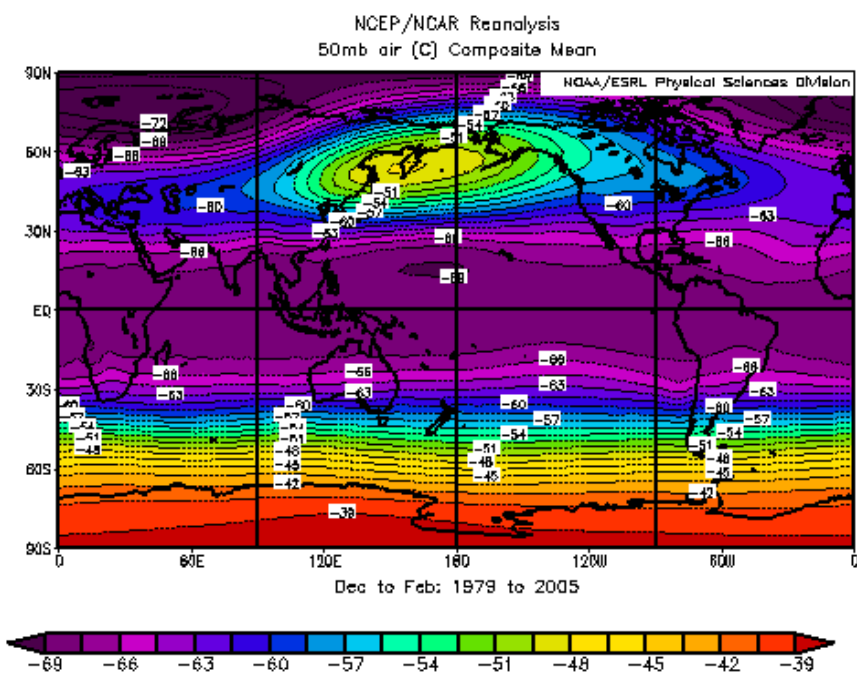

(b) PRIMAVERA

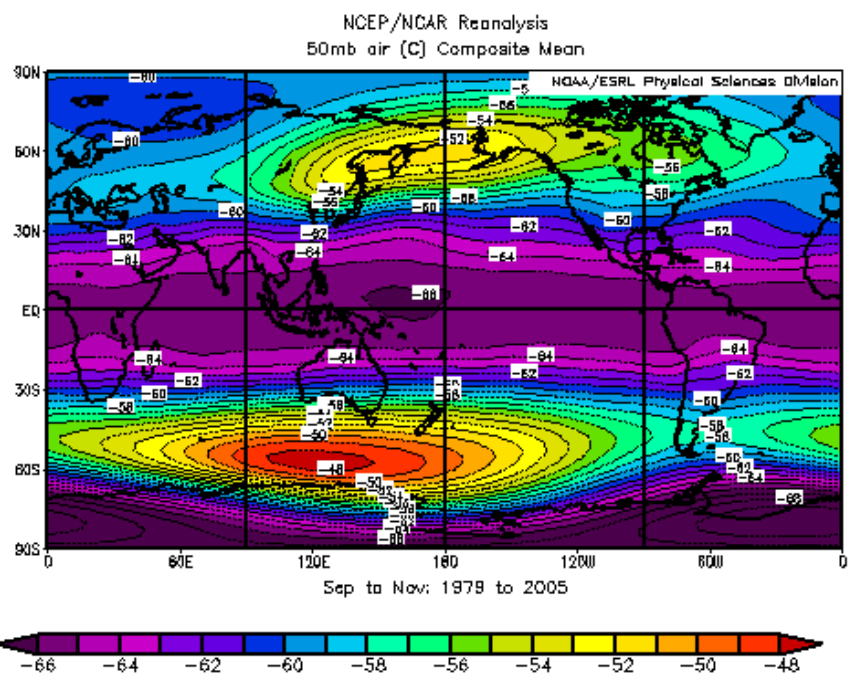

(d) OUTONO

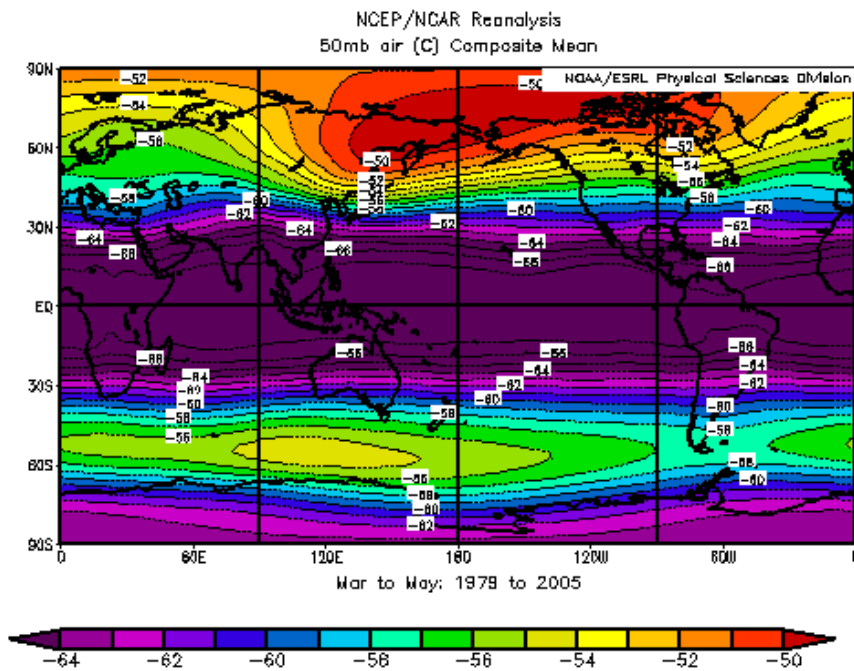

Figura 4. 2. Climatologia da temperatura do ar $\left({ }^{\circ} \mathrm{C}\right)$ na baixa estratosfera (em $50 \mathrm{hPa}$ ), durante o inverno (a), primavera (b), verão (c) e outono (d), obtida por reanálises do NCEP-NCAR no período de 1979-2005. 
TEMPERATURA - ALTA TROPOSFERA

(a) INVERNO

NCEP/NCAR Reanalysis

$200 \mathrm{mb}$ air (C) Composite Wran

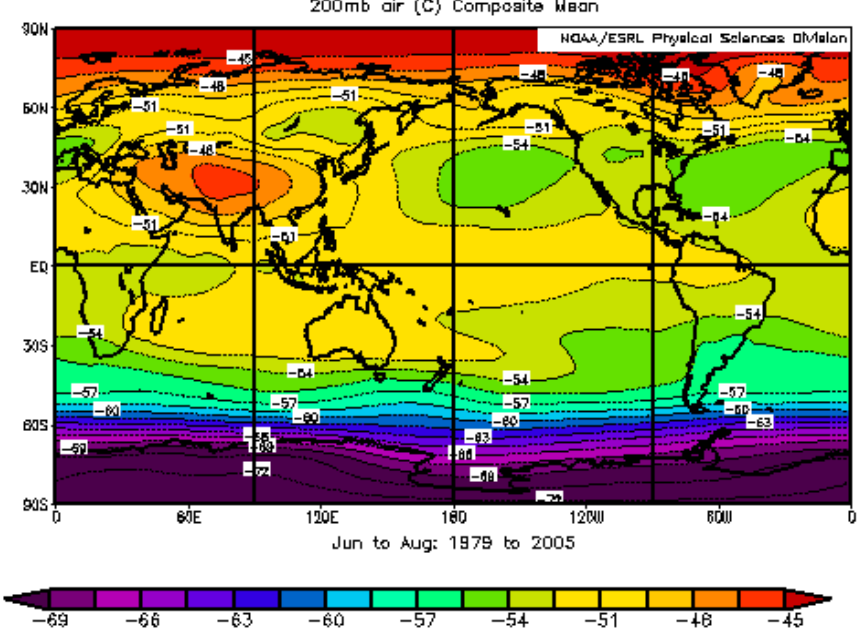

(c) VERÃO

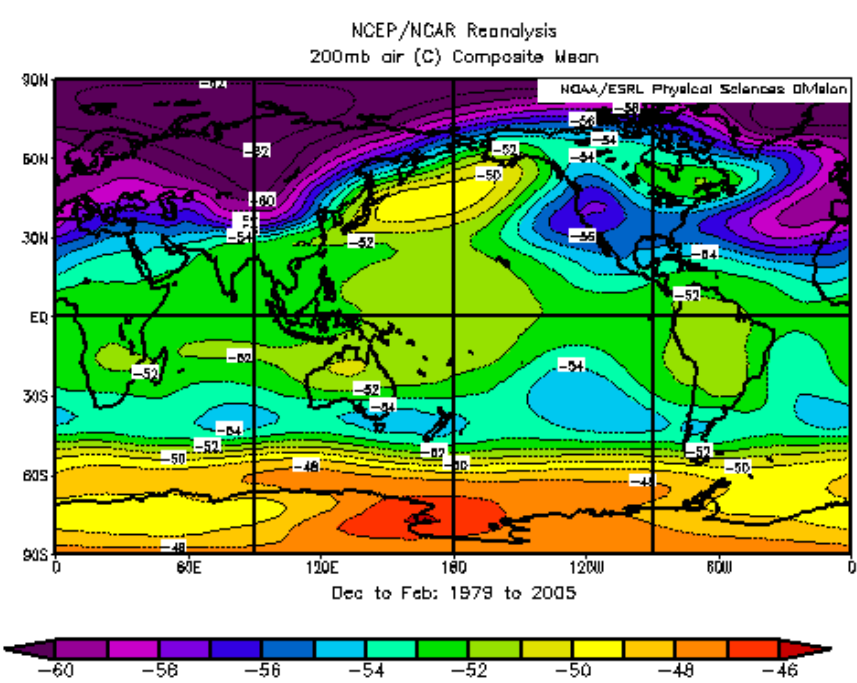

(b) PRIMAVERA

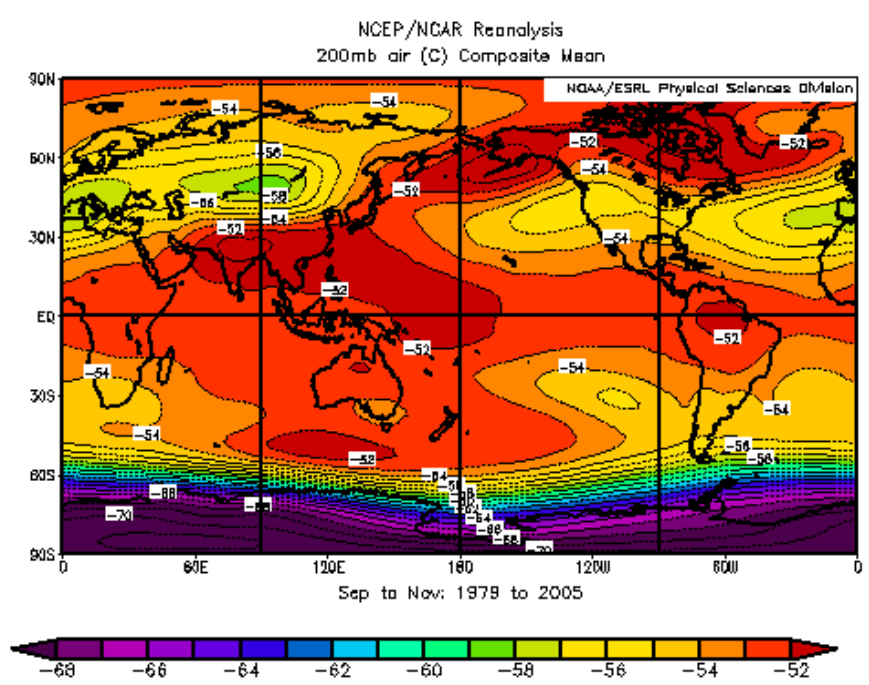

(d) OUTONO

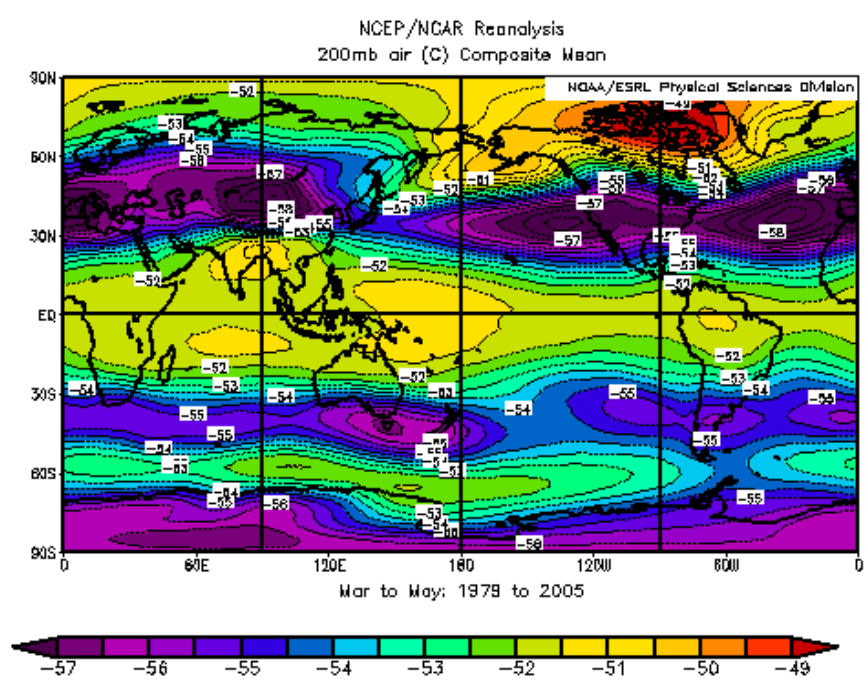

Figura 4. 3. Idem a Fig. 4.2, mas para alta troposfera (em $200 \mathrm{hPa})$.

\subsection{Anomalias intra-sazonais do Fluxo EP e os EIT}

As variações intra-sazonais do fluxo EP foram computadas utilizando a $F F T$, retendose os sinais no período entre 20-90 dias, semelhante ao procedimento descrito no item 3.1. Portanto, será investigada diretamente a contribuição das anomalias intra-sazonais da circulação zonal ( $\left.\mathrm{U}_{\mathrm{IS}}\right)$ nas anomalias intra-sazonais do fluxo EP (EPIS).

As composições defasadas de $\mathrm{U}_{\text {IS }}$ e $\mathrm{EP}_{\text {IS }}$ foram obtidas para os EIF e EIQ das estações Arturo e Marambio no período de inverno, primavera e verão (Figuras 4.4 - 4.9), com o 
objetivo de investigar a atividade de onda entre a alta troposfera e baixa estratosfera durante os EIT na Península Antártica.

\subsubsection{Inverno}

Observa-se que, durante os EIF no inverno em Arturo (Figura 4.4a), houve um aumento da atividade de onda da baixa estratosfera para a troposfera sobre a região da Península Antártica, o qual esteve associado à diminuição da intensidade do jato polar no HS (anomalias de leste de $\mathrm{U}_{\mathrm{IS}}$ ). Uma situação oposta é verificada para os EIQ (Figura 4.4b). A persistência destas anomalias $\left(\mathrm{EP}_{\mathrm{IS}}\right)$ superou 10 dias em ambos os eventos (EIF e EIQ) em Arturo, sugerindo uma intensa troca de energia entre troposfera-estratosfera durante estes EIT, devido à propagação das ondas de Rossby. Em Marambio, observam-se características semelhantes de $\mathrm{U}_{\mathrm{IS}}$ e $\mathrm{EP}_{\mathrm{IS}}$ durante os EIT (Figuras 4.5a e 4.5b). Somente durante e após os EIF (lag= 0 e lag= 5, Fig. 4.5a), ocorre uma diminuição da atividade de onda sobre a região Antártica e uma diminuição nas anomalias de leste de U IS. Observa-se também a presença de um trem de ondas meridional (lag=-5 a lag=0, Figuras 4.4 e 4.5), examinado através da composição de $U_{\text {IS }}$, entre o equador e pólo, o qual foi observado nas composições de U200 IS em Arturo e Marambio (Figuras 3.14 e 3.15, respectivamente). Adicionalmente, um trem de ondas entre trópicos e extratrópicos no HN é observado durante os EIT na Península Antártica; porém, mas evidente nos casos de Arturo (Fig. 4.4). 


\section{PENÍNSULA OESTE}

(a) EIF
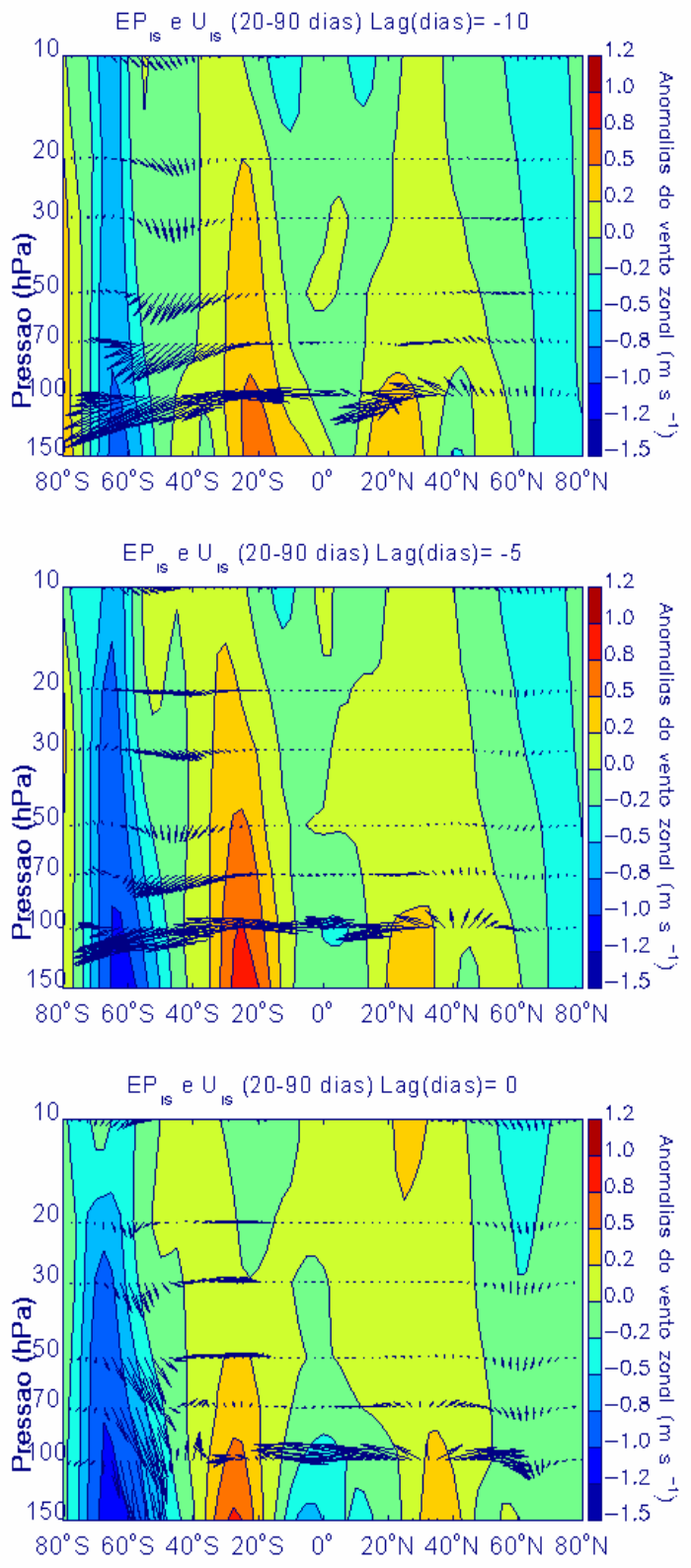

$E P_{\text {is }}$ e $U_{\text {is }}(20-90$ dias $) \operatorname{Lag}($ dias $)=5$

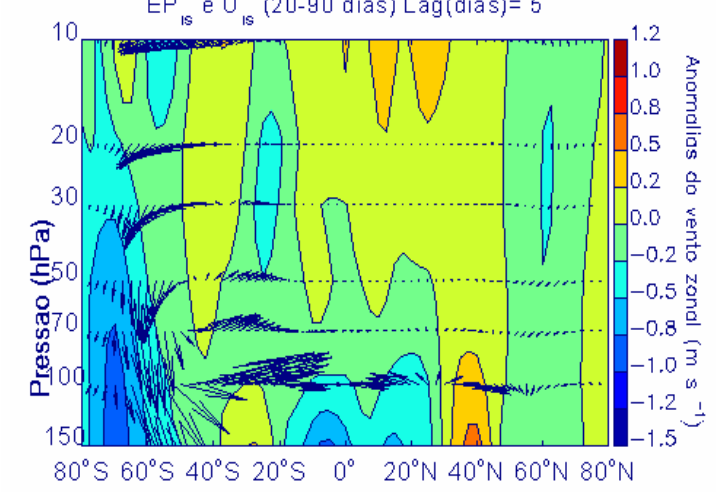

(b) EIQ
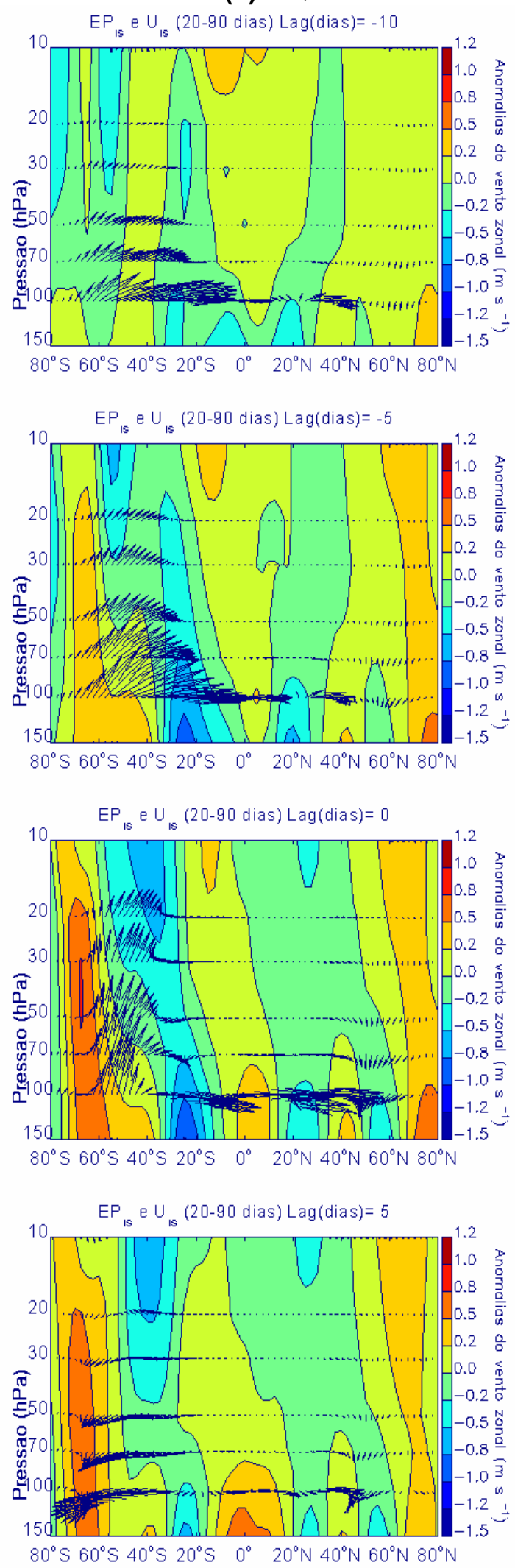

Figura 4. 4. Composições defasadas das anomalias intra-sazonais do vetor EP $\left(10^{11} \mathrm{~kg} \mathrm{~m} \mathrm{~s}^{-2}\right)$ e do vento zonal $(\mathrm{m} / \mathrm{s})$ na alta troposfera e baixa estratosfera para os EIF (a) e EIQ (b), durante o inverno em Arturo. O vetor EP em $150 \mathrm{hPa}$ foi multiplicado por $10^{-2}$ devido as diferenças de magnitude entre a troposfera e estratosfera. Os vetores EP foram escalados como na Fig 4.1. 


\section{PENÍNSULA LESTE}

(a) EIF

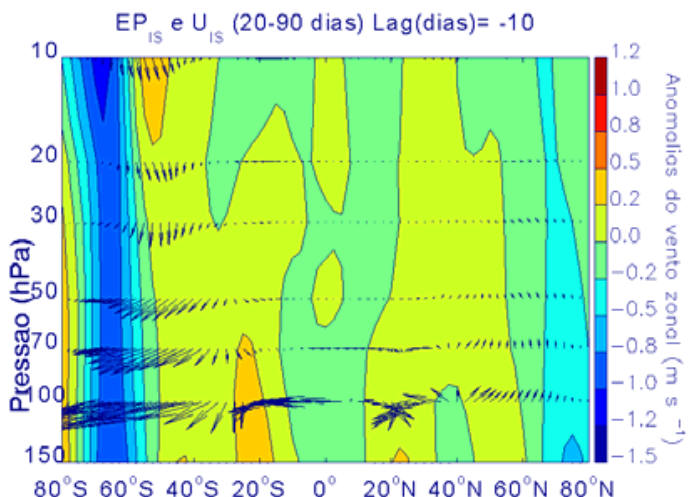

$E P_{1 S}$ e $U_{1 S}(20-90$ dias) $L$ ag(dias $)=-5$
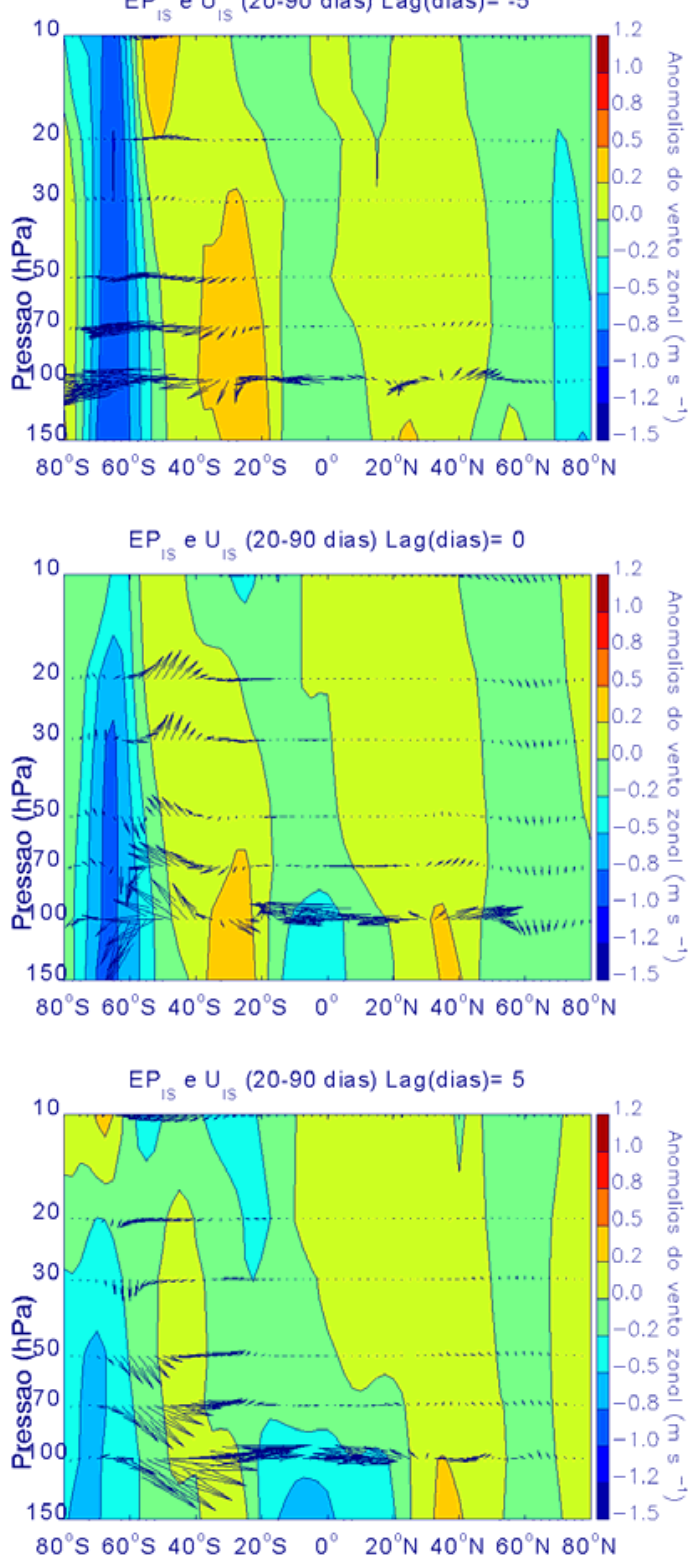

(b) EIQ

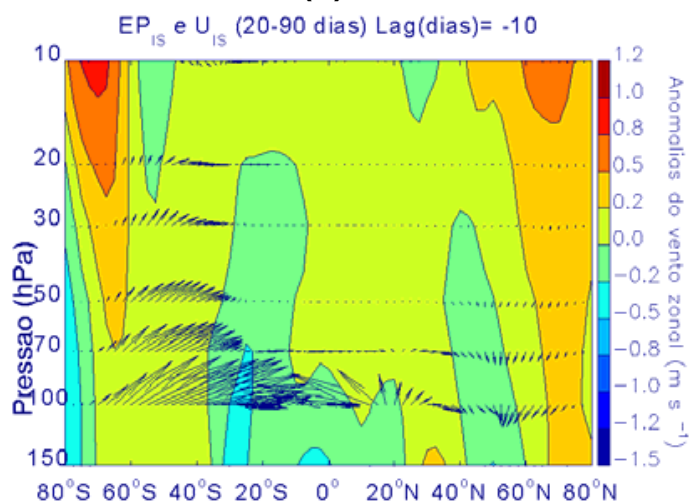

$E P_{\text {IS }}$ e $U_{\text {IS }}(20-90$ dias $) \operatorname{Lag}($ dias $)=-5$
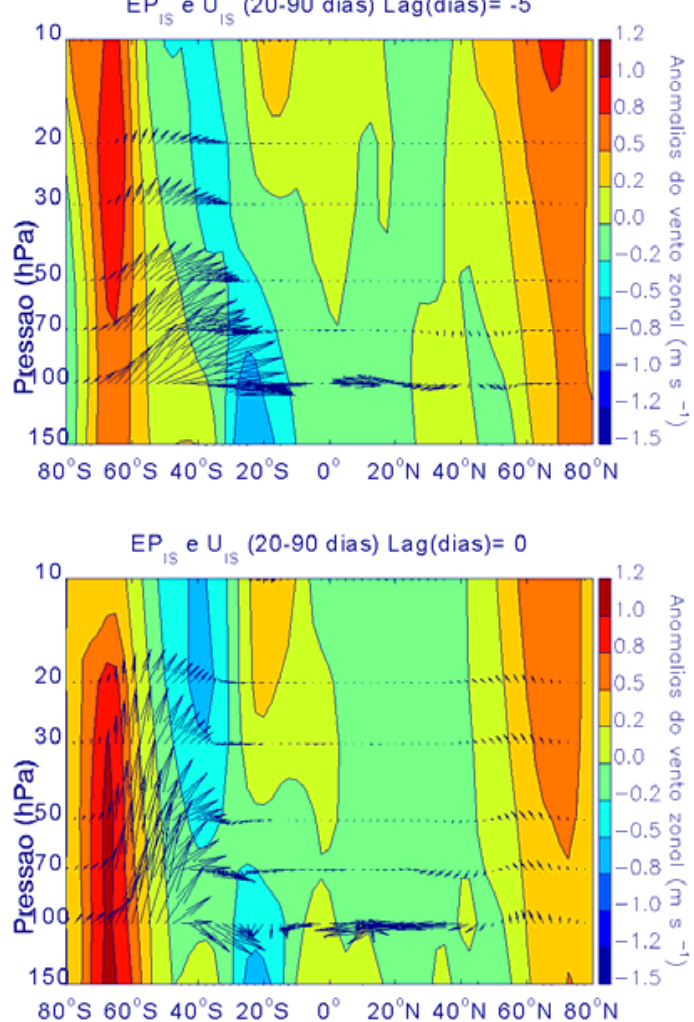

$E P_{\text {IS }}$ e U $U_{\text {IS }}(20-90$ dias) $\operatorname{Lag}($ dias $)=5$

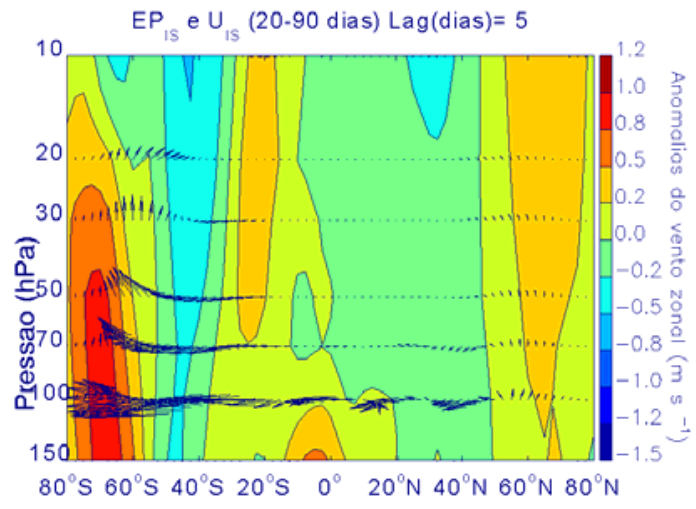

Figura 4. 5. Idem a Fig. 4.4, mas para a estação Marambio. 


\subsubsection{Primavera}

Na primavera em Arturo (Fig. 4.6), a atividade de onda apresentou maior intensidade e diferença na direção do fluxo $\mathrm{EP}_{\mathrm{IS}}$ durante os EIT quando comparado com o inverno (Fig. 4.4). Thompson e Wallace (2000) relataram que a primavera austral é a "estação ativa" da $A A O$, ou seja, o modo amplifica com a altura em direção à estratosfera nesta época do ano. Isto implica que a intensidade do fluxo zonal contribui para uma melhor interação entre fluxo médio-onda planetária.

Observam-se algumas alternâncias na direção do fluxo $\mathrm{EP}_{\mathrm{IS}}$ nos dias que precedem os eventos na primavera em Arturo (lag= -10, Figuras 4.6a e 4.6b). Em seguida (lag=-5 a lag=0, Fig. 4.6a), estabelece-se um aumento da atividade de onda da troposfera para a baixa estratosfera sobre a região Antártica, associado com o enfraquecimento do jato polar (anomalias de leste de $\mathrm{U}_{\mathrm{IS}}$ ). Para os EIQ em Arturo, observou-se uma situação oposta na direção do fluxo $\mathrm{EP}_{\mathrm{IS}}$, com o aumento da atividade de onda da baixa estratosfera para a alta troposfera (lag=-5 a lag=0, Fig. 4.6b), associado ao aumento da intensidade do jato polar (anomalias de oeste de UIS). Da mesma forma ocorre nos EIF e EIQ em Marambio, porém com anomalias de maior amplitude de $\mathrm{U}_{\mathrm{IS}}$ e $\mathrm{EP}_{\mathrm{IS}}$ (Figuras $4.7 \mathrm{a}$ e 4.7b). Ressalta-se também um aumento na intensidade das anomalias de $\mathrm{U}_{\mathrm{IS}}$ e $\mathrm{EP}_{\mathrm{IS}}$ nos extratrópicos do $\mathrm{HN}$ quando comparado com os EIT de inverno (Figuras 4.4-4.7). Estes resultados concordam com as anomalias estatisticamente significativas na circulação atmosférica sobre a região do Pacífico Norte, observadas nas composições da seção 3.3.2. 


\section{PENÍNSULA OESTE}

(a) EIF

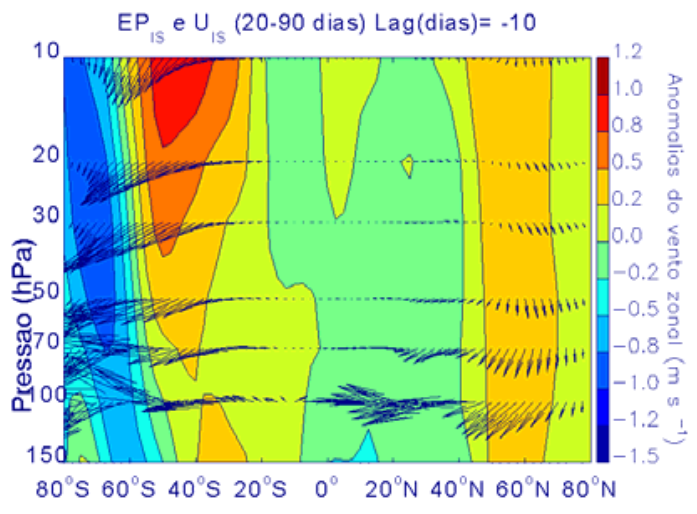

$E P_{1 S}$ e $U_{1 S}(20-90$ dias $) \operatorname{Lag}($ dias $)=-5$
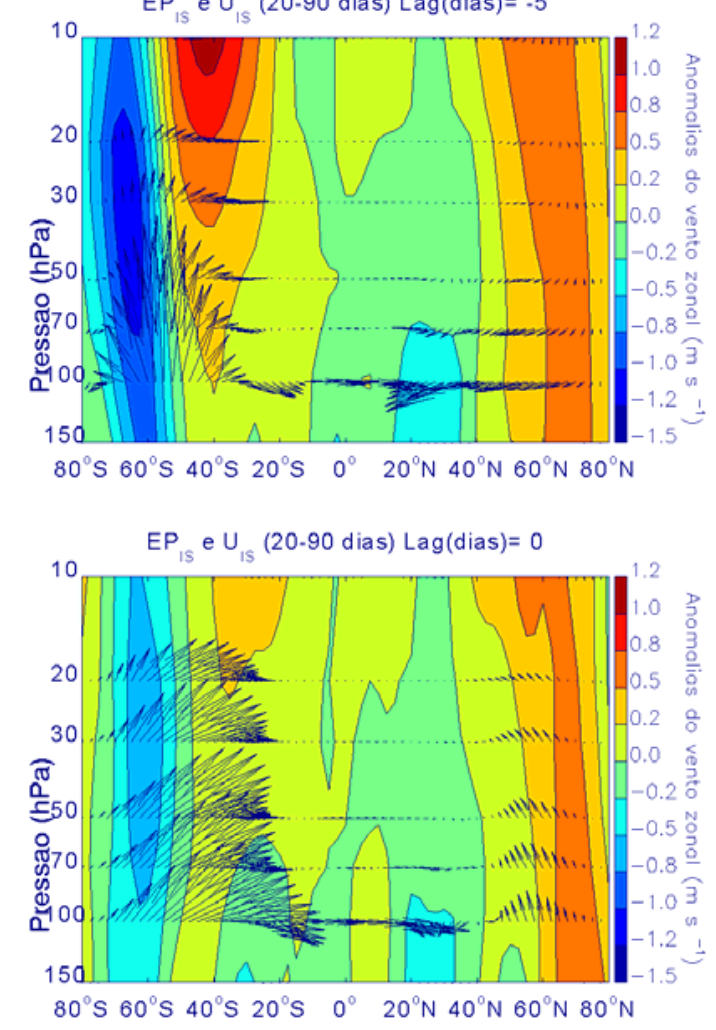

$E P_{\text {IS }}$ e $U_{\text {IS }}(20-90$ dias $)$ Lag(dias $)=5$

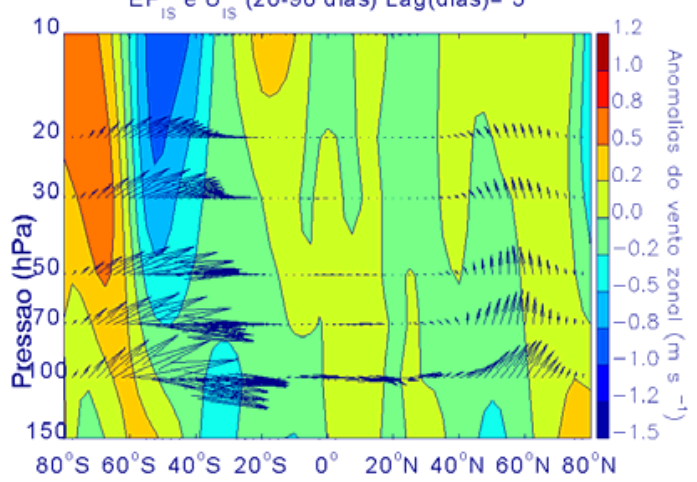

(b) EIQ
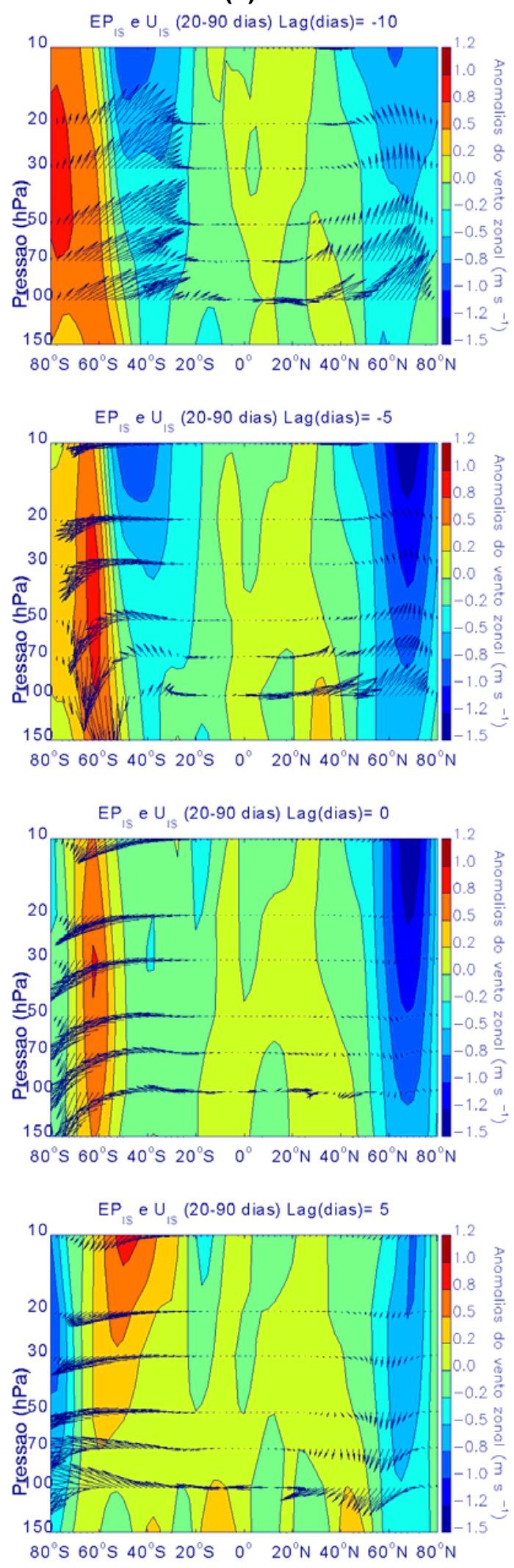

Figura 4. 6. Composições defasadas das anomalias intra-sazonais do vetor EP $\left(10^{11} \mathrm{~kg} \mathrm{~m} \mathrm{~s}^{-2}\right)$ e do vento zonal $(\mathrm{m} / \mathrm{s})$ na alta troposfera e baixa estratosfera para os EIF (a) e EIQ (b), durante a primavera em Arturo. O vetor EP em $150 \mathrm{hPa}$ foi multiplicado por $10^{-2}$ devido as diferenças de magnitude entre a troposfera e estratosfera. Os vetores EP foram escalados como na Fig 4.1. 
PENÍNSULA LESTE

(a) EIF

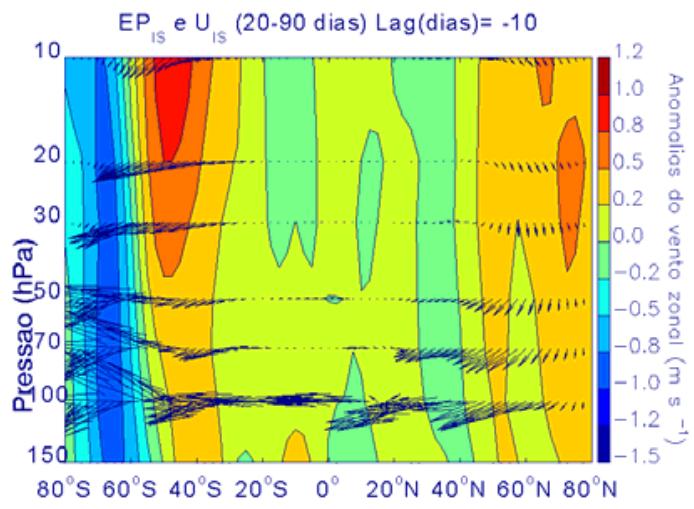

$E P_{1 S}$ e $U_{\text {IS }}(20-90$ dias $) \operatorname{Lag}($ dias $)=-5$
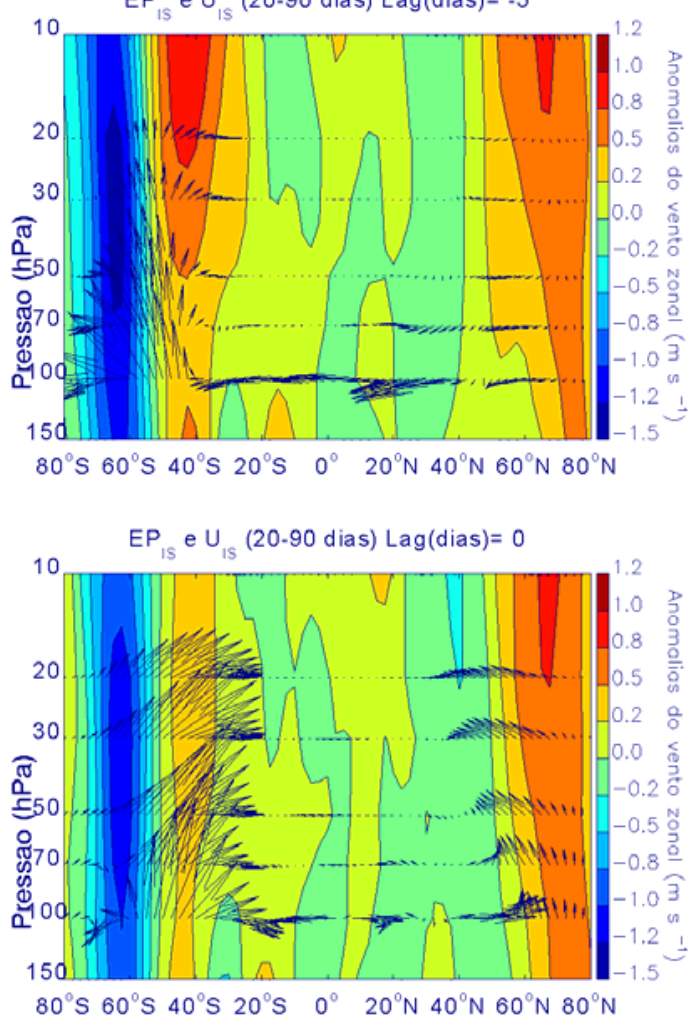

$E P_{\text {IS }}$ e $U_{\text {IS }}(20-90$ dias) $\mathrm{Lag}$ (dias) $=5$

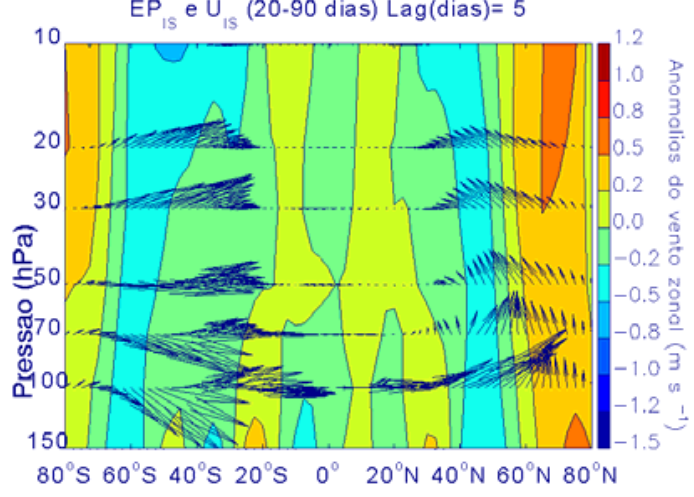

(b) EIQ

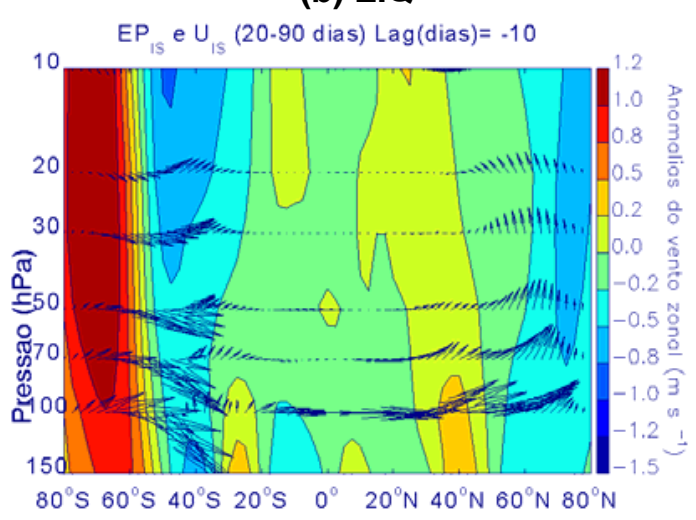

$E P_{\text {IS }}$ e U $U_{\text {IS }}(20-90$ dias) $\operatorname{Lag}$ (dias) $=-5$
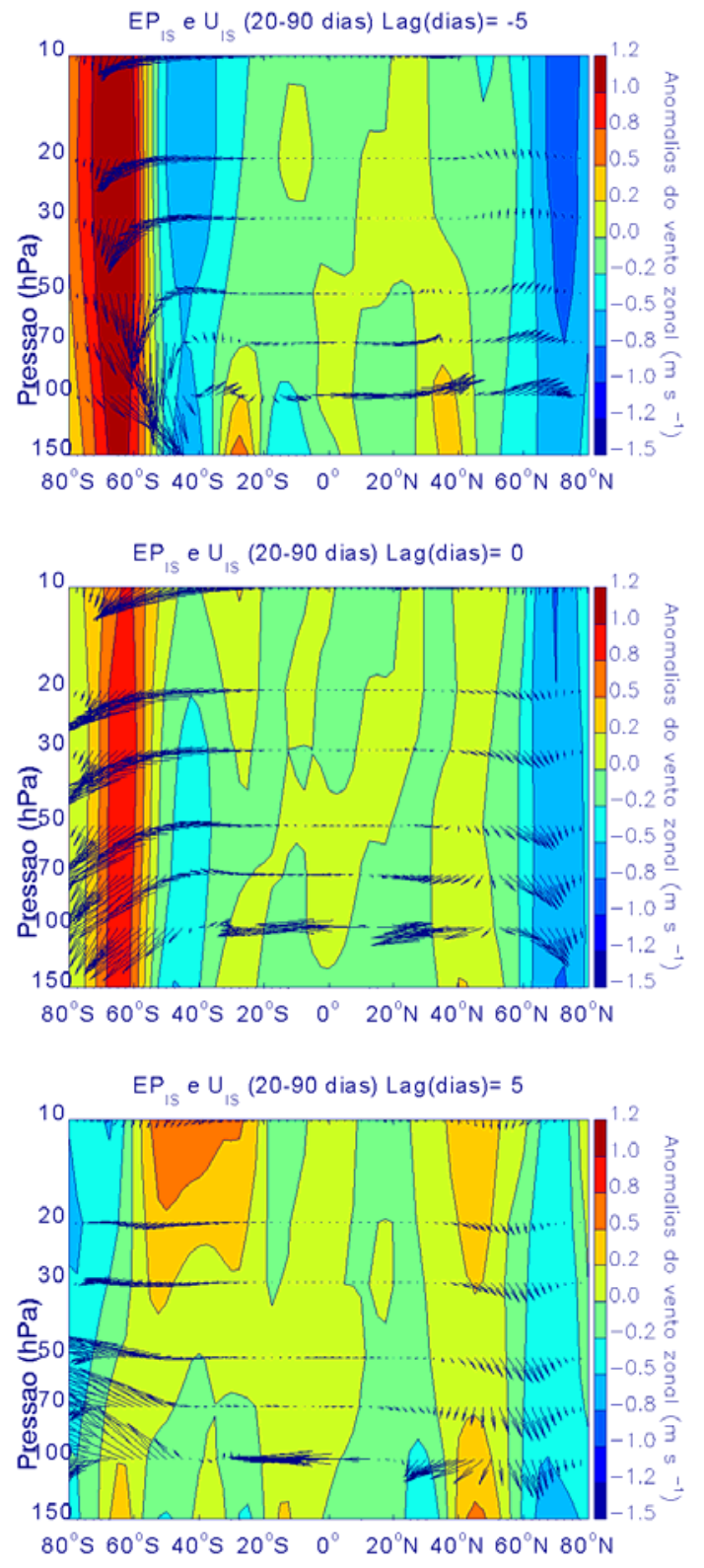

Figura 4. 7. Idem a Fig. 4.6, mas para Marambio. 


\subsubsection{Verão}

O fluxo $\mathrm{EP}_{\mathrm{IS}}$ torna-se mais fraco durante o verão austral na região Antártica, assim como UIS. No entanto, observa-se um pequeno aumento da atividade de onda da troposfera para a baixa estratosfera em ambos os eventos (EIF e EIQ) nas estações Arturo e Marambio (lag $=-5$ a $l a g=0$, Figuras 4.8 e 4.9), diferindo apenas na intensidade do $U_{I S}$ onde, para os EIF houve uma fraca anomalia de leste em Arturo e mais forte em Marambio (Figuras 4.8a e 4.9a, respectivamente); e para os EIQ, anomalias de oeste foram observadas em ambas as estações (Figuras $4.8 \mathrm{~b}$ e $4.9 \mathrm{~b}$ ). Concomitantemente aos EIF e EIQ em Arturo e Marambio (lag=0, Figuras 4.8 e 4.9, respectivamente), observa-se uma atividade de onda da baixa estratosfera para a alta troposfera na região polar no $\mathrm{HN}$, com a componente horizontal do vetor $\mathrm{EP}_{\mathrm{IS}}$ dirigida para o equador durante os EIF (lag=0, Figuras 4.8a e 4.9a). Além disso, observa-se a presença de um trem de ondas meridional na alta troposfera no HS e HN, examinado por meio de $U_{\text {IS }}$ o qual também foi observado nas composições de U200 Is para os EIT da Península Antártica (Figuras 3.26 e 3.27, respectivamente). Isto sugere uma conexão trópicosextratrópicos em ambos os hemisférios durante a ocorrência destes eventos, assim como discutido no Capítulo 3 (item 3.3.3). No entanto, nesta análise, o trem de ondas é mais evidente durante os EIQ (Figuras $4.8 \mathrm{~b}$ e $4.9 \mathrm{~b}$ ). 


\section{PENÍNSULA OESTE}

(a) EIF

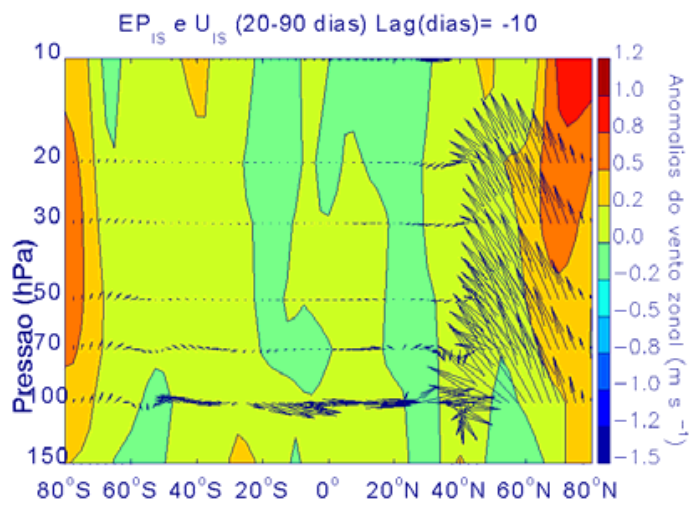

$E P_{1 S}$ e $U_{\text {IS }}(20-90$ dias) $L$ ag(dias $)=-5$
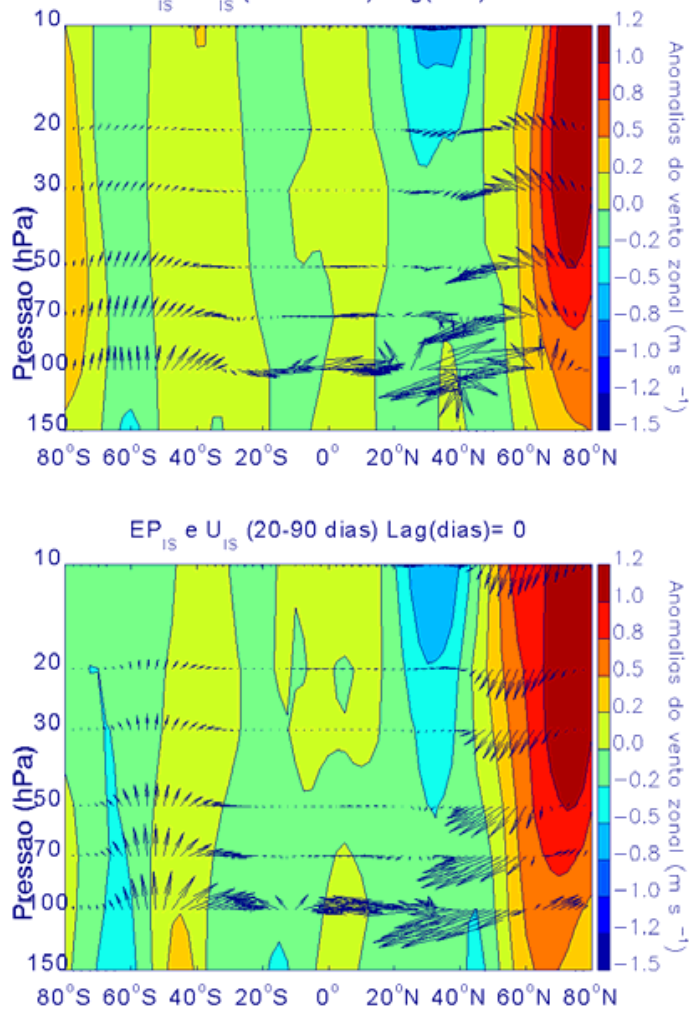

$E P_{\text {IS }}$ e $U_{\text {IS }}(20-90$ dias) $\operatorname{Lag}($ dias $)=5$

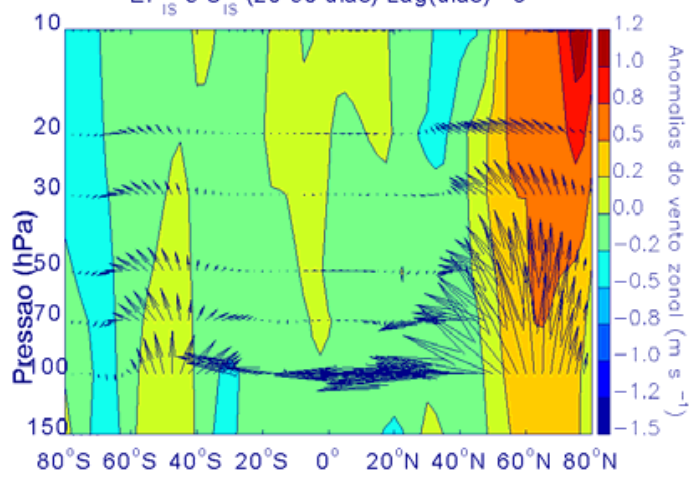

(b)EIQ

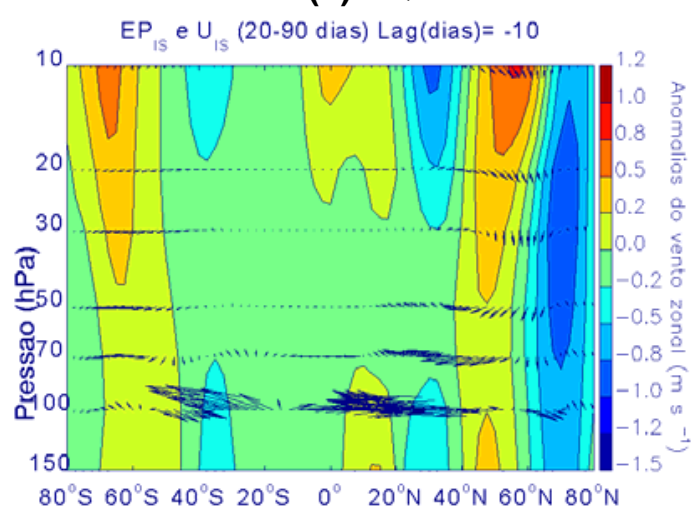

$E P_{\text {IS }}$ e U $U_{\text {IS }}(20-90$ dias) $\operatorname{Lag}$ (dias) $=-5$
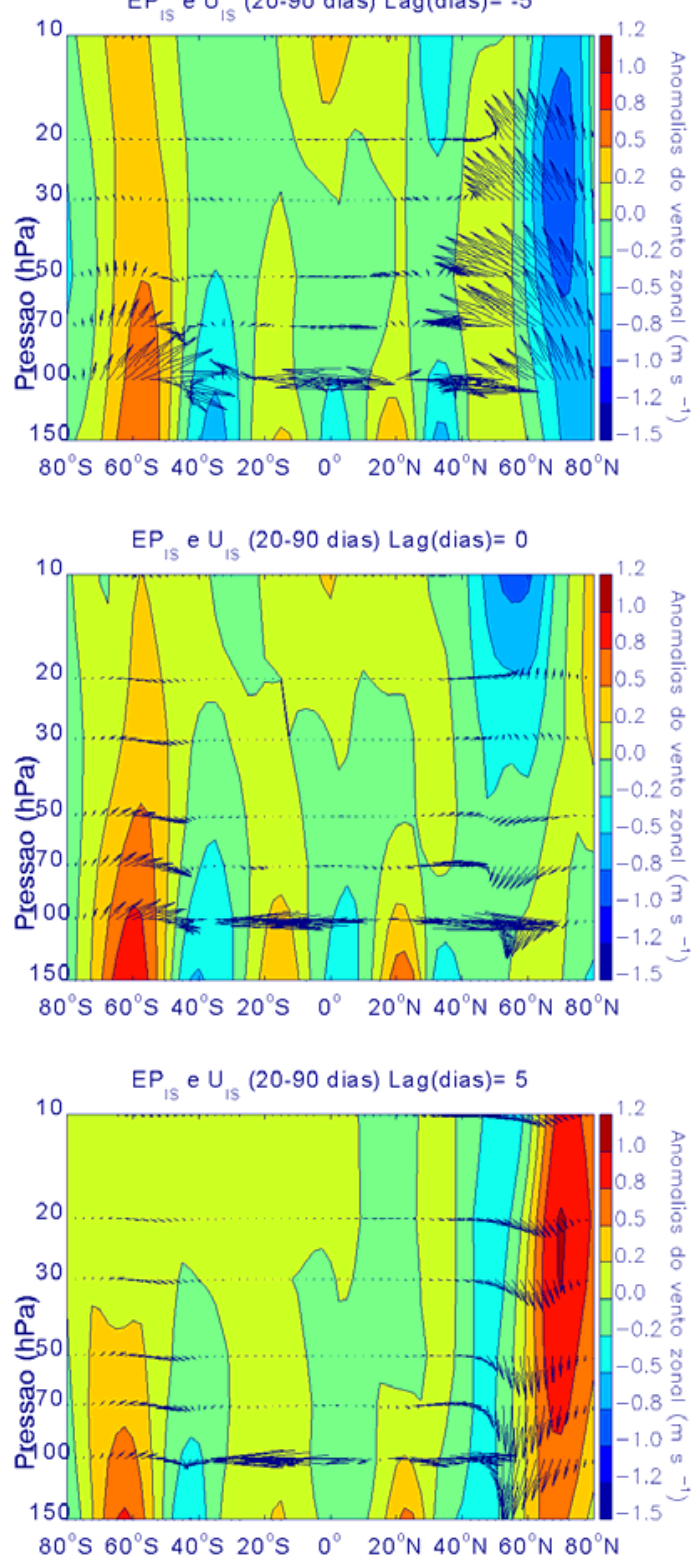

Figura 4. 8. Composições defasadas das anomalias intra-sazonais do vetor EP $\left(10^{11} \mathrm{~kg} \mathrm{~m} \mathrm{~s}^{-2}\right)$ e do vento zonal $(\mathrm{m} / \mathrm{s})$ na alta troposfera e baixa estratosfera para os EIF (a) e EIQ (b), durante o verão em Arturo. O vetor EP em $150 \mathrm{hPa}$ foi multiplicado por $10^{-2}$ devido as diferenças de magnitude entre a troposfera e estratosfera. Os vetores EP foram escalados como na Fig 4.1. 
PENÍNSULA LESTE

(a) EIF

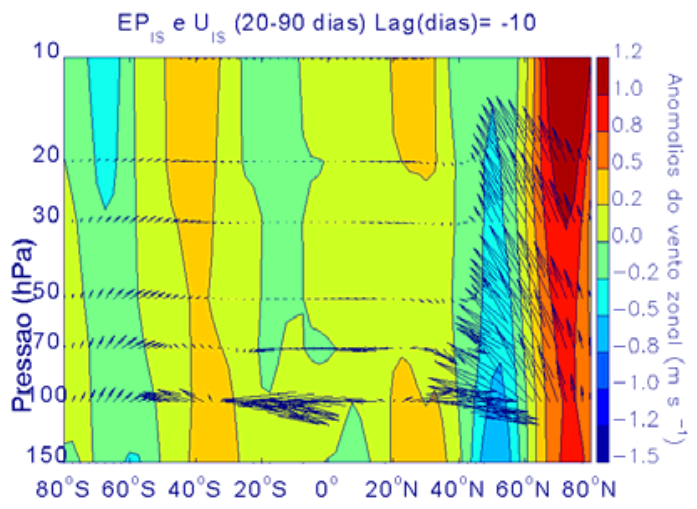

$E P_{1 S}$ e $U_{\text {IS }}(20-90$ dias $) \operatorname{Lag}($ dias $)=-5$
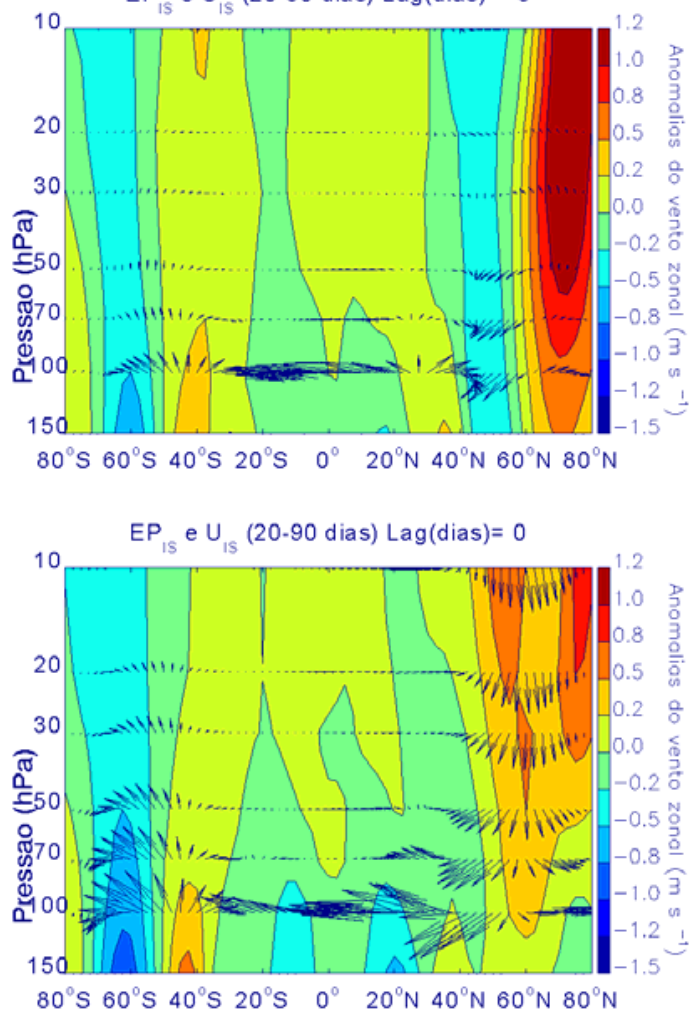

$E P_{\text {IS }}$ e $U_{\text {IS }}(20-90$ dias) $\mathrm{Lag}($ dias $)=5$

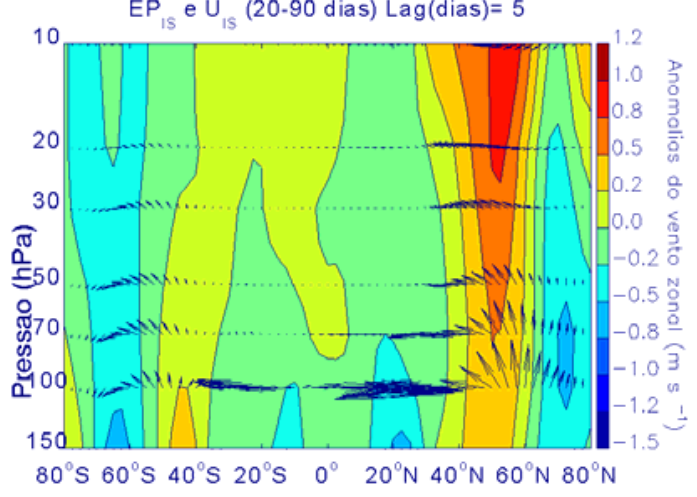

(b) EIQ

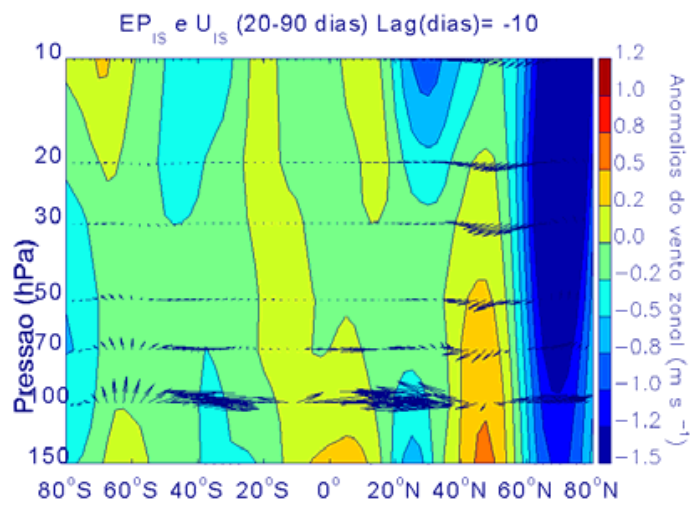

$E P_{\text {IS }}$ e $U_{\text {IS }}(20-90$ dias) $\operatorname{Lag}($ dias $)=-5$
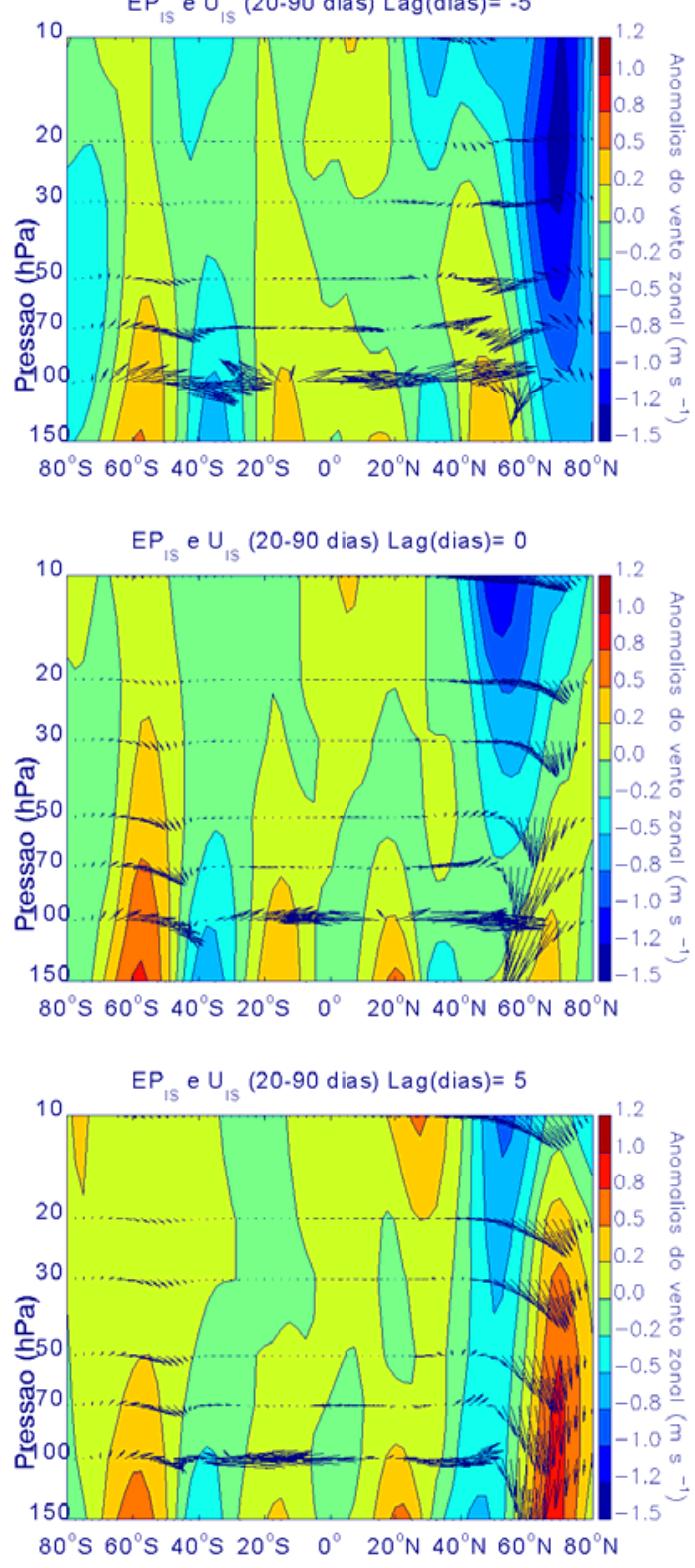

Figura 4. 9. Idem a Fig. 4.8, mas para Marambio. 


\subsection{Considerações gerais}

Estes resultados indicam que a propagação do trem de ondas de latitudes médias, observado durante os EIT nas três estações do ano na Península Antártica (seção 3.3), perturba a circulação da alta troposfera até a baixa estratosfera, tal como o jato polar.

O hemisfério de inverno apresenta o maior fluxo zonal, sofrendo perturbações devido à propagação do trem de ondas. No entanto, uma intensa atividade de onda também foi observada durante os EIT de primavera. Ressalta-se que tais perturbações também podem afetar a camada de ozônio, assim como mencionado por Thompson e Wallace (2000). Além disso, as anomalias intra-sazonais da atividade de onda e da circulação na troposfera e estratosfera foram observadas cerca de 10 dias antes da observação dos EIT de inverno na Península Antártica. Estes resultados concordam com o estudo de Thompson et al. (2002), quanto à relação entre as variações na circulação estratosférica e a ocorrência de eventos extremos de temperatura à superfície.

O presente trabalho é inédito em tentar explicar a relação entre a atividade intrasazonal extratropical e interações troposfera-estratosfera. Os padrões aqui obtidos, envolvendo esta relação nos EIT da Península Antártica, indicam a importância da compreensão dos mecanismos de teleconexão trópicos-extratrópicos. 


\section{Capítulo 5: Conclusões e sugestões para trabalhos futuros}

Neste estudo foram analisadas as variações da temperatura em estações de superfície nos lados leste e oeste da Península Antártica. Foram examinadas as similaridades entre as estações, distribuições de freqüência e tendências. Pela análise de agrupamentos entre os dados de temperatura das estações foi possível observar uma evidente distinção entre os setores oeste e leste da Península Antártica. Os menores valores e maior variabilidade da temperatura média anual foram observados na Península leste, os quais podem ser explicados pelo seu clima pseudo-continental (Aquino 1999). Já o setor oeste da Península Antártica apresentou as maiores temperaturas e menor variabilidade, possivelmente relacionados à influência marítima na região. Além disso, a Península oeste apresentou um pronunciado alongamento para as temperaturas frias na sua distribuição de freqüências ao longo dos meses, enquanto que a Península leste apresentou uma distribuição mais simétrica. Em relação às tendências, as estações da Península Antártica mostraram um aumento na temperatura ao longo dos anos, assim como observado em estudos prévios (p.ex. Turner et al. 2005; 2007). A Península oeste apresentou menor tendência na temperatura embora não estatisticamente significativa $\left(+0,68{ }^{\circ} \mathrm{C}\right.$ em 17 anos), enquanto que a estação do setor leste da Península Antártica apresentou maior aquecimento ao longo dos anos (aproximadamente $+2{ }^{\circ} \mathrm{C}$ em 17 anos, com significância estatística de 95\%).

A análise espectral dos dados de temperatura, efetuada sazonalmente, ressaltou a importância da escala intra-sazonal na temperatura no período de inverno, primavera e verão, particularmente sobre o setor oeste da Península Antártica. A escala intra-sazonal (banda de 20-100 dias) representou 50\% da variabilidade das anomalias totais de temperatura na região de estudo. Os EIT (frios e quentes) foram mais intensos durante o inverno, seguido pela primavera e mais fracos no verão. A freqüência e persistência dos EIF e EIQ apresentaram 
pouca variabilidade sazonal. A variabilidade interanual dos EIT indicou pouca relação com o ENOS, possivelmente devido à baixa amostragem de eventos El Niño e La Niña observados no período de estudo (1986-2002).

As composições da circulação atmosférica intra-sazonal associada aos EIF observados nas três estações do ano (inverno, primavera e verão) indicaram a persistência de anomalias ciclônicas em altos níveis, a diminuição da intensidade do jato polar e uma advecção de ar frio em baixos níveis sobre a região de estudo. Situação oposta foi verificada nos EIQ. Particularmente no inverno e primavera, observou-se um trem de ondas entre latitudes médias e altas no HS durante os EIT. Esta configuração mostrou-se semelhante ao padrão teleconexão conhecido como padrão Pacífico-Sul Americano (PSA), observado em diversos estudos prévios (p.ex., Mo e Ghil 1987; Ghil e Mo 1991; Ambrizzi et al. 1995; Mo e Higgins 1998). No verão, as anomalias associadas à propagação do trem de ondas no HS foram mais fracas e o campo de geopotencial $\left(\mathrm{H} 200_{\mathrm{IS}}\right)$ indicou estruturas mais zonais. No campo do vento zonal em 200hPa (U200 IS $)$ observou-se anomalias persistentes na circulação sobre o Pacífico Norte durante a ocorrência de EIT na Península Antártica. Este padrão de anomalias nos dois hemisférios sugere uma resposta extratropical da MJO (p.ex., Higgins e Mo 1997 e Mo e Higgins 1998). As composições defasadas de ROL $\mathrm{L}_{\mathrm{IS}}$ associadas aos EIF e EIQ de inverno, primavera e verão na região de estudo, evidenciaram uma grande variabilidade caso a caso quando se considera esta variável. Se há influência da atividade convectiva nos trópicos em escala intra-sazonal sobre a variabilidade da circulação e os EIT sobre a Península Antártica, esta atividade não possui um caráter sistemático sob o ponto de vista de ROL $\mathrm{L}_{\mathrm{IS}}$.

O primeiro modo dos extratrópicos do HS obtido por meio de EOF do geopotencial em $700 \mathrm{hPa}$ filtrado em escala intrasazonal indicou mudanças dependendo da fase de propagação do trem de ondas. Sua estrutura foi mais intensa (mais fraca) nos EIF (EIQ) de inverno sobre a região de estudo. Nos eventos das demais estações do ano, houve pouca influência da variabilidade intra-sazonal da estrutura deste modo nos extratrópicos.

As composições das anomalias intra-sazonais do fluxo $\mathrm{EP}_{\text {IS }}$ indicaram durante os EIF (EIQ) de inverno, um aumento da atividade de onda da baixa estratosfera (alta troposfera) para a alta troposfera (baixa estratosfera) em altas latitudes, associado à diminuição (aumento) da intensidade do jato polar. Na primavera, a atividade de onda foi mais intensa e verificou-se uma mudança na direção do fluxo $\mathrm{EP}_{\mathrm{IS}}$ quando comparado com os EIT de inverno. O fluxo $\mathrm{EP}_{\mathrm{IS}}$ e as anomalias intra-sazonais do vento zonal foram mais fracos no verão. No entanto, observou-se uma atividade de onda da baixa estratosfera para a alta troposfera na região polar no HN durante os EIT na Península Antártica. Estes resultados indicam que a propagação do 
trem de ondas de latitudes médias, observado durante os EIT nas três estações do ano na Península Antártica, perturba a circulação da alta troposfera até a baixa estratosfera, tal como o jato polar. Além disso, as anomalias intra-sazonais da atividade de onda e da circulação na troposfera e estratosfera foram observadas cerca de 10 dias antes da observação dos EIT de inverno na Península Antártica, concordando com os resultados de Thompson et al. (2002).

Os resultados encontrados sugerem que a variabilidade intra-sazonal nos extratrópicos pode modular a circulação da troposfera até a estratosfera e ter um papel no controle das anomalias de temperatura sobre os dois lados da Península Antártica. Há indícios de que a origem dos distúrbios intra-sazonais esteja relacionada a forçantes tropicais como a OMJ. Portanto, a atividade intra-sazonal nos extratrópicos e as interações troposfera-estratosfera aqui reportadas, evidenciaram a importância dos mecanismos de teleconexão trópicosextratrópicos sobre a variabilidade da temperatura na Península Antártica. Além disso, atentase à relevância da correta simulação dessas interações em modelos de circulação geral, a fim de diagnosticar-se e prever-se o clima e suas mudanças de modo acurado e realista.

\section{Sugestões para trabalhos futuros}

As análises observacionais dos EIT na Península Antártica podem ser ampliadas, de modo a compreender a origem dos distúrbios intra-sazonais e sua propagação em ambos hemisférios, através de uma análise de trajetórias de onda descrita em diversos estudos prévios (p.ex., Hoskins e Ambrizzi 1993; Kiladis 1998; Müller e Ambrizzi 2007). A relevância dos oceanos e possíveis feedbacks associados aos distúrbios intra-sazonais extratropicais também deve ser considerada. Por exemplo, identificar variações na temperatura da superfície do mar (TSM) decorrentes das alterações na circulação atmosférica, que possam ter efeito sobre a intensidade dos sistemas transientes (escala sinótica).

Duas questões relevantes poderiam ser consideradas através da modelagem numérica:

1) Qual a importância das forçantes remotas sobre a propagação dos distúrbios intrasazonais?

2) Quais os efeitos dos distúrbios intra-sazonais sobre a circulação de meso-escala na Península Antártica?

A primeira questão poderia ser abordada por meio de um modelo de circulação geral acoplado oceano-atmosfera, como por exemplo, o Ocean Land Atmosphere Model (OLAM), tendo como primeiro passo a escolha de uma parametrização apropriada e posteriormente, 
diagnosticar se e como os mecanismos de teleconexão trópicos-extratrópicos estão sendo representados. Para a segunda questão, por ter um enfoque mais regional, sugere-se a utilização de um modelo de área limitada (como o Regional Atmospheric Modeling Sistem $R A M S$ ). Neste caso, seriam realizadas simulações para as diferentes fases de propagação do trem de ondas (como aquelas identificadas nesta dissertação), o que permitiria estimar o impacto sobre as circulações locais na Península Antártica. 


\section{Referências Bibliográficas}

Ambrizzi, T. e B. J. Hoskins, H. H. Hsu, 1995: Rossby Wave Propagation and Teleconnection Patterns in the Austral Winter. J. Atmos. Sci., 52, 3661-3672.

Andrews, D. G. and M. E. McIntyre 1976, Planetary Waves in Horizontal and Vertical Shear: Asymptotic Theory for Equatorial Waves in Weak Shear, J. Atmos. Sci., 33, 2031-2048.

Andrews, D. G. and M. E. McIntyre 1978, Generalized Eliassen-Palm and Charney-Drazin theorems for waves on axisymmetric mean flows in compressible atmosphere. J. Atmos. Sci., 38, 819843.

Aquino, F.E. 1999. Sedimentação moderna associada à geleira de maré Lange. Dissertação de Mestrado, IG/UFRGS, 91p.

Björnsson H, Venegas SA. 1997. A manual for EOF and SVD analyses of climatic data. CCGCR Report, 97-1. McGill University, Québec. 52p.

Bloomfield, P.: 1976: Fourier analyses of time series: an introduction. New York.

Carrasco, J.; Bromwich, D.H.; Liu, Z. 1997. Mesoscale cyclone activity over Antarctica during 1991. Part 2: Near the Antarctic Peninsula. Journal of Geophysical Research, 102 (D12), p.1393913954.

Carvalho, L. M. V., C. Jones, e T. Ambrizzi, 2005: Opposite phases of the Antarctic Oscillation and relationships with intraseasonal to interannual activity in the Tropics during the austral summer. J. Climate. 18,702-718.

Carvalho, L. M. V., C. Jones e B. Liebmann, 2004. The South Atlantic convergence zone: intensity, form, persistence, relationships with intraseasonal to interannual activity and extreme rainfall. J. Climate, 17, 88-108.

Chapman, W. L., and J. E. Walsh, 2007: A Synthesis of Antarctic Temperatures. J. Clim., 20, 40964117. 
Chatfield C., 1996: The Analysis of Time Series: An introduction. Chapman \& Hall, fifth edition, NY. 283 pp

Chen B, Smith SR, Bromwich DH. 1996. Evolution of the tropospheric split jet over the South Pacific Ocean during the 1986-89 ENSO cycle. Monthly Weather Review 124: 1711-1731.

Edmon, H. J., B. J. Hoskins, M. E. McIntyre, 1980: Eliassen-Palm Cross Sections for the Troposphere. J. Atmos. Sci., 37, 2600-2616.

Ferron, F.A. 1999. Variações nas razões de isótopos estáveis na neve e no gelo da Ilha Rei George, Antártica. Dissertação de Mestrado, IG/UFRGS, 125p.

Ferron, F.A.; Simões, J.C.; Aquino, F.E.; Setzer, A.W. 2004. Air temperature time series for King George Island, Antarctica. Pesquisa Antártica Brasileira, 4, p.155-169.

Ghil, M. e K. Mo, 1991a: Intraseasonal oscillations in the global atmosphere. Part I: Northern Hemisphere and Tropics J. Atmos. Sci., 48, 752-779.

Ghil, M., e K. C. Mo, 1991b: Intraseasonal oscillations in the global atmosphere. Part II: Southern Hemisphere. J. Atmos. Sci., 48, 780-790.

Gong, D., e S. Wang, 1999: Definition of Antarctic oscillation. Geophys. Res. Lett., 26, 459-462.

Grimm, A. M. e P. L. Silva Dias, 1995: Use of Barotropic Models in the Study of the Extratropical Response to Tropical Heat Sources. J. Meteo. Soc. Japan, 73, 765-780.

Grimm, A. M. e P. L. Silva Dias, 1995: Analysis of Tropical-Extratropical Interactions with Influence Functions of a Barotropic Model. J. Atmos. Sci, 52, 3538-3555.

Hannachi A. 2004. A primer for EOF analysis of climate data. Department of Meteorology, University of Reading, U.K. 33p.

Harangozo SA. 2000. A search for ENSO teleconnections in the west Antarctic Peninsula climate in Austral winter. International Journal of Climatology 20: 663-679.

Hartmann, D. L , C.R. Mechoso, and K Yamazaki (1984), Observations of wave-mean flow interaction in the Southern Hemisphere. J. Atmos. Sci., 41, 351-362.

Hendon, H. H. e B. Liebmann, 1990: The intraseasonal (30-50 day) oscillation of the Australian Summer monsoon. J. Atmos. Sci., 47, 2909-2923.

Higgins, R. W., and K. C. Mo, 1997: Persistent North Pacific anomalies and the tropical intraseasonal oscillation. J. Climate, 10, 223-244.

Holton, J. R., 1975: The Dynamic Meteorology of the Stratosphere and Mesosphere. Meteor. Monogr., 137, Amer. Meteor. Soc., 218p.

Hoskins BJ, Karoly DJ. 1981. The steady linear response of a spherical atmosphere to thermal and orographic forcing. Journal of the Atmospheric Sciences 38: 1179-1196. 
Hoskins, B.J. e Ambrizzi, T., 1993: Rossby Wave propagation on a realistic longitudinally varying flow. Journal of the Atmospheric Sciences, 50:1661-1671.

Hsu, H. H., e S. Weng., 2002: Stratospheric Antarctic Intraseasonal Oscillation during the Austral Winter. J. Meteo. Soc. Japan, 80, 1029-1050.

IPCC, 2001: Climate Change: The Scientific Basis. Contribution of Working Group I to the Third Assessment Report of the Intergovernmental Panel on Climate Change. [Houghton, J. T., Y. Ding, D. J. Griggs, M. Nouguer, P. J. van der Linden, X. Dai, K. Maskell, and C. A. Johnson (eds)]. Cambridge United Kingdom and New York, NY, USA, 881 pp.

Jacobs, S.S.; Comiso, J.C. 1993. A recent sea ice retreat west of the Antarctic Peninsula. Geophysical Research Letters, 20 (12), p.1171-1174.

Jacobs, S.S.; Comiso, J.C. 1997. Climate variability in the Amundsen and Bellingshausen Seas. Journal of Climate, 10, p.697-709.

Jones, C., D. E. Waliser, and C. Gautier, 1998: The Influence of the Madden and Julian Oscillation on ocean surface heat fluxes and sea surface temperature. J. Clim., 11, 1057-1072.

Jones, C. 2000: Occurrence of extreme precipitation events in California and relationship with the Madden-Julian oscillation. J. Climate, 13, 3576-3587.

Jones, C. and L. M. V. Carvalho, 2002: Active and break phases in the South American monsoon system. J. Climate, 15, 905-914.

Jones, C., L. M. V. Carvalho, R. W. Higgins, D. E. Waliser, e J. K. E. Schemm, 2004: Climatology of tropical intraseasonal convective anomalies 1979-2004. J. Clim., 47, 523-539.

Jones, C. D. E. Waliser, K. M. Lau, and W. Stern, 2004: Global occurrences of extreme precipitation events and the Madden-Julian Oscillation: Observations and predictability. J. Clim., 17, 45754589.

Kalnay, E e colaboradores, 1996: The NCEP/NCAR Reanalysis 40-year Project. Bull. Amer. Meteor. Soc., 77, 437-471.

Karoly DJ. 1989. Southern Hemisphere circulation features associated with El Nĩno-southern oscillation events. Journal of Climate 2:1239-1252.

Kidson, J. W., 1988: Interannual Variations in the Southern Hemisphere Circulation. J. Clim., 1, 1177-1198.

Kiladis, G. N., e K. C. Mo, 1998: Interannual and intraseasonal variability in the Southern Hemisphere, in Meteorology of the Southern Hemisphere, D. J. Karoly e D. G. Vicent, Eds. Meteorological Monographs, 49, American Meteorological Society, Boston, MA, 1-46p.

King JC. 1994. Recent climate variability in the vicinity of the Antarctic Peninsula. International Journal of Climatology 14: 357-369. 
King, J.C.; Harangozo, S.A. 1998. Climate change in the western Antarctic Peninsula since 1945: observations and possible causes. Annals of Glaciology, 27, p. 571-575.

King, J.C.; Turner, J. 1997. Antarctic meteorology and climatology. Cambridge: Cambridge University Press, 409p.

Lau, K. M. e P. H. Chan, 1986: Aspects of the 40-50 days oscillation during the northern summer as inferred from outgoing longwave radiation. Mon. Wea. Rev., 114, 1354-1367.

Liebmann, B., G. N. Kiladis, C. S. Vera, A. C. Saulo, and L. M. V. Carvalho, 2004: Subseasonal variations of rainfall in the vicinity of the South American low-level jet stream and comparison to those in the South Atlantic Convergence Zone. J. Clim., 17, 3829-3842.

Limpasuvan, V. e D. L. Hartmann, 2000: Wave-Maintained Annular Modes of Climate Variability. J. Clim., 13, 4414-4429.

Madden, R. A. and P. R. Julian, 1971: Detection of the 40-50 day oscillation in the zonal wind in the Tropical Pacific. J. Atmos. Sci., 28, 702-708.

Madden, R. A., 1986: Seasonal variations of the 40-50 day oscillation in the Tropics. J. Atmos. Sci., $43,3138-3158$.

Madden, R. A., and P. R. Julian, 1994: Observation of the 40-50 day tropical oscillation- A review. Mon. Wea. Rev., 122, 814-837.

Marshall GJ, Lagun V, Lachlan-Cope TA. 2002. Changes in Antarctic Peninsula tropospheric temperatures from 1956-99: a synthesis of observations and reanalysis data. International Journal of Climatology 22: 291-310.

Mo, K. C., e G. H. White, 1985: Teleconnections in the Southern Hemisphere. J. Atmos. Sci., 44, 877-901.

Mo, K. C., e M. Ghil, 1987: Statistics and dynamics of persistent anomalies. Mon. Weat. Rev., 113, 22-37.

Mo, K. C., e R. W. Higgins, 1998: The Pacific-South American Modes and Tropical Convection during the Southern Hemisphere Winter. Mon. Wea. Rev., 126, 1581-1596.

Mo, K. C. e J. N. Paegle, 2001: The Pacific -South American Modes and their Downstream Effects. Inter.J. Clim., 21, 1211-1229.

Muza, M. N., 2005: Variabilidade intrasazonal e interanual dos eventos extremos de precipitação e seca no sul e sudeste do Brasil durante o verão austral. Dissertação de mestrado. Disponível no IAG/USP.

Palmer, T. N. (1981), Diagnostic Study of a Wavenumber-2 Stratospheric Sudden Warming in a Transformed Eulerian-Mean Formalism, J. Atmos. Sci., 38, 844-855. 
Schwerdtfeger, W. 1975. The effect of the Antarctic Peninsula on the temperature regime of the Weddell Sea. Monthly Weather Review, 103 (1), p.45-51.

Schwerdtfeger, W. 1976. Annual temperature and ice condition changes in the Antarctic Peninsula area. Antarctic Journal of the United States, 11 (5), p.152.

Schwerdtfeger, W. 1984. Weather and Climate of the Antarctic. Developments in Atmospheric Sciences, 15. Amsterdam: Elsevier, 261p.

Schwerdtfeger, W.; Amaturo, L.R. 1979. Wind and weather around the Antarctic Peninsula. Department of Meteorology. Madison: University of Wisconsin, 65p.

Setzer, A.W.; Hungria, C.S. 1994. Meteorologia na Península Antártica: alguns aspectos práticos. São José dos Campos: Instituto Nacional de Pesquisas Espaciais, 101p.

Smith, R.C.; Stammerjohn, S.E. 2001. Variations of surface air temperature and sea ice extent in the western Antarctic Peninsula region. Annals of Glaciology, 33, p.493-500.

Smith, R.C.; Stammerjohn, S.E.; Baker, K.S. 1996. Surface air temperature variations in the western Antarctic Peninsula region. Antarctic Research Series, 70, p.105-121.

Spiegel, M. R., e L. J. Stephens, 1998: Theory and Problems of Statistics. Third edition, Schaum's Outline Series, McGRAW-HILL.

Thompson D. W. J., and J. M. Wallace, 2000: Annular modes in the extratropical circulation. Part I: month-to-month variability. J. Climate, 13, 1000-1016.

Thompson D. W. J., J. M. Wallace, G. C. Hegerl, 2000: Annular modes in the extratropical circulation. Part II: trends. J. Climate, 13, 1018-1036.

Thompson, D. W. J e Solomon, S., 2002: Interpretation of the recent Southern Hemisphere climate change. Science, 296, 895-899.

Thompson D. W. J., M. P. Baldwin, J. M. Wallace, 2002: Stratospheric Connection Northern Hemisphere Wintertime Weather: Implications for Prediction. J. Climate, 15, 1421-1428.

Trenberth, K. E., P. D. Jones, P. Ambenie, R. Bojaru, D. Easterling, A. Klein, Tank, D. Parker, F. Rahimzadeh, J. A. Renwick, M. Rusticucci, B. Soden and P. Zhai, 2007: Observations Surface and Atmospheric Climate Change. In: Climate Change 2007: The Physical Science Basis. Contribution of Working Group I to the Fourth Assessment Report of the Intergovernmental Panel on Climate Change (Solomon, S., D. Qin, M. Manning, Z. Chen, M. Marquis, K. B. Averyt, M. Tignor and H. L. Miller (eds). Cambridge University Press, Cambridge, United Kingdom and New York, NY, USA.

Turner, J. Lachlan-Cope, T. A., Marshall, G. J., Morris, E. M., Mulyaney, R., Winter, W., 2002:Spatial variability of Antarctic Peninsula net surface mass balance. Journal of Geophysical Research, 107 (D 13), DOI: 10.1029/2001JD000755. 
Turner, J., 2004: The El Niño-Southern Oscillation and Antarctica-Review. Int. J. Climatol., 24, 1-31. Turner, J. e Pendlebury, S., 2004: The International Antarctic Weather Forecasting Handbook. British Antarctic Survey, 663p.

Turner, J., Colwell, S. R., Marshall, G. J., Lachlan-Cope T. A., Carleton, A. M., Jones, P. D., Lagun, V., Reid, P. A., Iagovkina, S., 2005: Antarctic Climate Change During the Last 50 Years. Int. J. Climatol., 25, 279-294.

Turner, J., T. A. Lanchlan-Cope, S. Colwell, G. J. Marshall, e W. M. Connolley, 2006: Significant warming of the Antarctic winter troposphere. Science, 311, 1914-1917.

Turner, J., J. E. Overland, J. E. Walsh, 2007: An Artic and Antarctic perspective on recent climate change. Inter. J. Clim., 27, 277-293.

Vaughan DG. 1993. Implications of the break-up of Wordie Ice Shelf, Antarctic for sea level. Antarctic Science 5: 403-408.

Vaughan DG, Marshall GJ, Connolley WM, King JC, Mulvaney R. 2001. Climate change — devil in the detail. Science 293:1777-1779.

Walker, G. T., 1928: World weather. Quart. J. Roy. Meteor. Soc., 54, 79-87.

Wallace, J., e D. S. Gutzler, 1981: Teleconnections in the geopotential height field during Northern Hemisphere winter. Mon. Wea. Rev., 109, 785-812.

Wallace, J., e Hobbs, P., 2006: Atmospheric Science - An Introduction Survey. Elsevier, 504p.

Zhang, C., and J. Gottschalck, 2002: SST anomalies of ENSO and the Madden-Julian Oscillation in the equatorial Pacific. J. Clim., 15, 2429-2445. 


\section{Apêndice A: Diferença entre duas proporções}

Com o objetivo de investigar a influência do ENOS nos EIT em cada estação do ano nas estações Arturo e Marambio, foram computadas as porcentagens dos dias com EIF e EIQ observados durante eventos El Niño, La Niña e neutros (Figuras 3.9 e 3.10, respectivamente). Deste modo, obteve-se as proporções tal que: $\mathrm{P}_{1}$ é a proporção dos EIF e EIQ observados nos eventos El Niño $\left(\mathrm{N}_{1}\right), \mathrm{P}_{2}$ é a proporção dos EIF e EIQ observados nos eventos La Niña $\left(\mathrm{N}_{2}\right)$ e $\mathrm{P}_{3}$ é a proporção dos EIF observados em eventos neutros $\left(\mathrm{N}_{3}\right)$. Os valores de $\mathrm{N}_{1}, \mathrm{~N}_{2}$ e $\mathrm{N}_{3}$ para cada estação do ano, são apresentados na Tabela 3.4. Para verificar se $\mathrm{P}_{1}$ difere estatisticamente da proporção $\mathrm{P}_{\mathrm{k}}$, onde $\mathrm{k}=2,3$, foi realizado um teste estatístico unilateral, considerando as hipóteses nula e alternativa $\left(H_{0}\right.$ e $H_{1}$, respectivamente):

$$
\begin{aligned}
& H_{0}: P_{1}=P_{k} \\
& H_{1}: P_{1}>P_{k}
\end{aligned}
$$

O teste estatístico empregado foi obtido em Spiegel e Stephens (1998) e é dado por:

$$
Z=\frac{P_{1}-P_{k}}{\sigma}
$$

onde:

$$
\begin{gathered}
\sigma=\sqrt{P Q\left(\frac{1}{N_{1}}+\frac{1}{N_{k}}\right)} \\
P=\frac{N_{1} P_{1}+N_{k} P_{k}}{N_{1}+N_{k}}
\end{gathered}
$$




$$
Q=1-P
$$

Assim, calculou-se o Z para os EIF e EIQ observados em cada estação do ano de acordo com as fases do ENOS e comparou-se este valor com o valor obtido pela tabela da distribuição normal $\left(Z_{c}\right)$ com o nível de significância adotado (neste caso, para 95 e $90 \%, Z_{c}=$ 1.64 e 1.28 , respectivamente). No entanto, $H_{0}$ não foi rejeitado em nenhum dos casos, pois nenhum valor de $\mathrm{Z}$ ficou acima de $Z_{\mathrm{c}}$. Ou seja, as proporções dos EIT observados na fase El Niño do ENOS não foram estatisticamente diferentes das proporções dos eventos observados nas demais fases do ENOS. 


\section{Apêndice B: Funções Ortogonais Empíricas (EOF)}

Também denominada Análise de Componentes Principais, a análise por Funções Ortogonais Empíricas (Empirical Orthogonal Function - EOF) visa extrair da evolução temporal dos campos de uma determinada variável os padrões espaciais de variabilidade e a sua variação no tempo, fornecendo a magnitude da "importância" de cada padrão (ou modo). Esta magnitude é dada pelo percentual da variância explicada do modo (Björnsson e Venegas, 1997). Esta técnica tornou-se bastante popular em ciências atmosféricas, pois reduz de forma eficiente um grande conjunto de dados para poucas combinações lineares que contenham a maior parte da variância presente nos dados originais.

Primeiramente, as anomalias intra-sazonais altura geopotencial em $700 \mathrm{hPa}\left(\mathrm{H} 700_{\mathrm{IS}}\right)$ foram transpostas para uma matriz $t x p$, onde cada linha representa o tempo $t$ e cada coluna um ponto de grade $p$. A partir desta matriz calculou-se a matriz de covariância, dada por:

$$
R=\frac{1}{n-1} X^{\prime T} X^{\prime}
$$

onde $X^{\prime}$ é a matriz $t x p$ das anomalias de $\mathrm{H} 700_{\mathrm{IS}}, X^{, T}$ é a matriz transposta de $X^{\prime}$, e $R$ é uma matriz $p x p$ cujos elementos diagonais são as variâncias dos $p$ pontos e os outros elementos são as covariâncias entre os $p$ pontos.

A meta principal desta técnica consiste em encontrar a combinação linear entre todas as variáveis, isto é, pontos de grade, que explica a variância máxima (Hannachi, 2004). Isto significa encontrar uma direção $\mathbf{c}=\left(c 1, \ldots, c_{p}\right)^{T}$ tal que $X^{\prime} c$ tenha a máxima variabilidade. A variância da série temporal $X$ 'c é dada por:

$$
\operatorname{var}\left(X^{\prime} \mathbf{c}\right)=\frac{1}{n-1}\left\|X^{\prime} \mathbf{c}\right\|^{2}=\frac{1}{n-1}\left(X^{\prime} \mathbf{c}\right)^{T}\left(X^{\prime} \mathbf{c}\right)=\mathbf{c}^{\mathrm{T}} R \mathbf{c}
$$


O problema em questão é, portanto, maximizar $\mathbf{c}^{\mathrm{T}} \mathrm{R} \mathbf{c}$ ao limite tal que $\mathbf{c}^{T} \mathbf{c}=\mathrm{I}$ (i.e. que o vetor $\mathbf{c}$ seja unitário; I é a matriz-identidade). A solução para isto é simplesmente resolver o problema de autovalor:

$$
\mathrm{Rc}=\lambda \mathbf{c}
$$

onde $\lambda$ é a matriz diagonal contendo os autovalores $\lambda_{i}$ de $R$ (a matriz de covariância, por definição, é simétrica e portanto diagonalizável), e os vetores-coluna ci de c são os autovetores de $R$ correspondentes aos autovalores $\lambda_{i}$. Tanto $\lambda$ quanto $\mathbf{c}$ têm dimensões $p x p$. O $i$ ésimo vetor-coluna c $i$ vem a ser a $i$-ésima $E O F$, $\log$ o as $E O F s$ estão ordenadas de acordo com o tamanho dos autovalores associados $\left(\lambda_{1} \geq \lambda_{2} \geq \ldots \geq \lambda p\right)$. Assim, a $1^{\text {a }} E O F$ é o autovetor associado ao maior autovalor, aquele associado ao segundo maior autovalor é a $2^{\text {a }} E O F$, etc (Björnsson e Venegas, 1997; Hannachi, 2004).

Conforme foi definido para a resolução do problema de autovalor, a matriz c de autovetores, tem a propriedade $\mathbf{c}^{T} \mathbf{c}=$ I. Isto implica que os auto-vetores sejam ortogonais entre si, por isso o nome Funções Ortogonais Empíricas , ou seja, são linearmente independentes.

O significado físico desta propriedade é que as EOFs não estão correlacionadas no espaço.

Cada autovetor pode ser entendido como um mapa (i.e., a distribuição espacial do modo), se re-posicionados os pontos $p$ na grade original. O padrão aí obtido representa uma oscilação permanente, estacionária. A evolução temporal de uma EOF demonstra como esse padrão oscila no tempo. Esta evolução é dada pelo coeficiente de expansão da $E O F$, ou a componente principal, que vem a ser a projeção dos $t$ campos de anomalias (os dados originais) na $E O F$, ou seja:

$$
\mathrm{a} i=X^{\prime} \mathrm{c}_{i}
$$

sendo a $i$ um vetor com $t$ componentes. Assim como as EOFs não são correlacionadas no espaço, os seus coeficientes de expansão não são correlacionados no tempo.

Decorrente do fato da matriz de dados $X^{\prime}$ ser real, a matriz de covariância $R$ é definida positiva. Logo, todos os autovalores são positivos, sendo que cada um deles dá a medida da variância explicada pelo modo (i.e. pela $E O F$ ) a ele associado, dada por:

$$
\operatorname{var}_{\exp l i c a d a}=\frac{\lambda_{i}}{\sum_{i=1}^{p} \lambda_{i}} 100 \%
$$


Se $R$ é simétrica, segue que os autovalores $\lambda_{i}$ e os autovetores $\mathrm{c}_{i}$ (as EOFs) decompõem $R$ de acordo com:

$$
R=\lambda_{1} c_{1} c_{1}^{T}+\lambda_{2} c_{2} c_{2}^{T}+\ldots+\lambda_{p} c_{p} c_{p}^{T}
$$

É nesta decomposição que se baseiam constatações como "a $1^{\text {a }}$ EOF explica y\% da variância dos dados" (neste caso, $\lambda_{I} / \Sigma_{i} \lambda_{i}=\mathrm{y} / 100$ ). Geralmente os primeiros poucos autovalores dominam os demais, significando que a maior parte do comportamento da matriz de dados pode ser explicada por alguns poucos vetores (Björnsson e Venegas, 1997). É exatamente isto que se espera da análise por EOFs - reduzir os dados em alguns (poucos) modos de variabilidade.

Os padrões espaciais correspondentes aos diferentes modos da EOF podem ser apresentados por diversas formas. Uma possibilidade é calcular o mapa de correlação entre os coeficientes de expansão associados com o autovetor, e os dados $X^{\prime}$. Desta forma, o $i$-ésimo mapa de correlação é definido como o vetor dos valores de correlação entre o coeficiente de expansão do $i$-ésimo modo de um campo e os valores do mesmo campo em cada ponto de grade (Björnsson e Venegas, 1997). Desta forma, os mapas de correlação são bons indicadores da localização espacial da co-variância entre o campo e seu $i$-ésimo modo. 